Im Auftrag der Wahrheit 
Maria Dätwyler - 978-3-96975-231-9

Downloaded from mentis.de@4/26/2023 04:20:01AM via free access 
Maria Dätwyler

\section{Im Auftrag der Wahrheit}

Selbstpositionierungsstrategien der Philosophie im 20. Jahrhundert

BRILL | mentis 


\section{Publiziert mit Unterstützung des Schweizerischen Nationalfonds zur Förderung der wissenschaftlichen Forschung.}

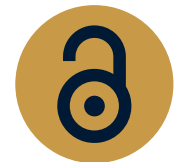

Dies ist ein Open-Access-Titel, der unter den Bedingungen der CC BY-NC-ND 4.o-Lizenz veröffentlicht wird. Diese erlaubt die nicht kommerzielle Nutzung, Verbreitung und Vervielfältigung in allen Medien, sofern keine Veränderungen vorgenommen werden und der/die ursprüngliche(n) Autor(en) und die Originalpublikation angegeben werden.

Weitere Informationen und den vollständigen Lizenztext finden Sie unter https://creativecommons.org/licenses/by-nc-nd/4.o/

Die Bedingungen der CC-Lizenz gelten nur für das Originalmaterial. Die Verwendung von Material aus anderen Quellen (gekennzeichnet durch eine Quellenangabe) wie Schaubilder, Abbildungen, Fotos und Textauszüge erfordert ggf. weitere Nutzungsgenehmigungen durch den jeweiligen Rechteinhaber.

DOI: https://doi.org/10.30965/9783969752319

Bibliografische Information der Deutschen Nationalbibliothek

Die Deutsche Nationalbibliothek verzeichnet diese Publikation in der Deutschen Nationalbibliografie; detaillierte bibliografische Daten sind im Internet über http://dnb.d-nb.de abrufbar.

(c) 2021 bei der Autorin. Verlegt durch Brill mentis, Wollmarktstraße 115, D-33098 Paderborn, ein Imprint der Brill-Gruppe

(Koninklijke Brill NV, Leiden, Niederlande; Brill USA Inc., Boston MA, USA; Brill Asia Pte Ltd, Singapore;

Brill Deutschland GmbH, Paderborn, Deutschland; Brill Österreich GmbH, Wien, Österreich)

Koninklijke Brill NV umfasst die Imprints Brill, Brill Nijhoff, Brill Hotei, Brill Schöningh, Brill Fink, Brill mentis, Vandenhoeck \& Ruprecht, Böhlau, Verlag Antike und V\&R unipress.

www.mentis.de

Der Verlag Brill mentis behält sich das Recht vor, die Veröffentlichung vor unbefugter Nutzung zu schützen und die Verbreitung durch Sonderdrucke, anerkannte Fotokopien, Mikroformausgaben, Nachdrucke, Übersetzungen und sekundäre Informationsquellen, wie z.B. Abstraktions- und Indexierungsdienste einschließlich Datenbanken, zu genehmigen.

Anträge auf kommerzielle Verwertung, Verwendung von Teilen der Veröffentlichung und/oder Übersetzungen sind an Brill mentis zu richten.

Einbandabbildung: Marco Baumgartner, Zürich Einbandgestaltung: Anna Braungart, Tübingen Herstellung: Brill Deutschland GmbH, Paderborn

ISBN 978-3-95743-231-5 (hardback)

ISBN 978-3-96975-231-9 (e-book) 
Nur der Philosoph hat sich vor aller Welt hören zu lassen, denn er ist nicht nur eine rara avis und als solche eine merkwürdige Erscheinung, sondern er wirkt auch dort, wo er lückenhaft erscheint, wie Balsam, da er sich am Wege zur Wahrheit befindet. Deshalb muss er auch Wort halten, um einst billigerweise die Erlösung herbeizuführen.

Helene von Druskowitz (1905) 
Maria Dätwyler - 978-3-96975-231-9

Downloaded from mentis.de@4/26/2023 04:20:01AM via free access 


\section{Inhalt}

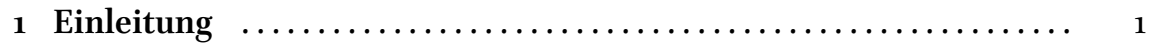

1.1 Philosophie und/oder Wissenschaftsforschung? .......... 3

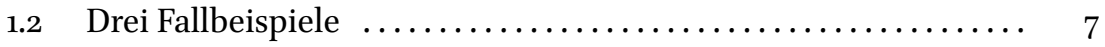

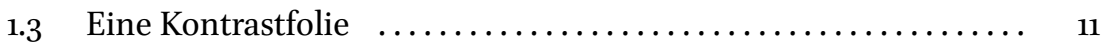

1.4 In Reaktion auf die Einzelwissenschaften: Unterschiedliche Strategien der Selbstbehauptung $\ldots \ldots \ldots \ldots \ldots \ldots \ldots \ldots . \ldots \ldots$

1.5 Unausweichliche Agonalität der Philosophie ............ 19

2 Bewusstsein als Verhängnis: Philosophieinterne Krisen ......... 25

Unheilvolle Apologie auf die Wissenschaft: Alfred Seidels

Circulus vitiosus .......................... 28

Rezeption: Manifestation einer Krise ............. 30

Verlust disziplinärer Standpunkte .............. 37

Das Weltganze zum Gegenstand machen ........... 40

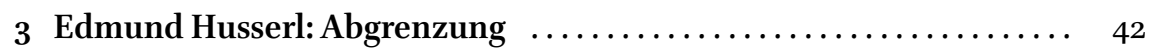

3.1 Herausforderung: Psychologisierung des Geistes .......... 42

Ein konstruktives Problem für die Philosophie:

Psychologismus ........................... 43

»Der Geist als Sublimierung des hypertrophierten

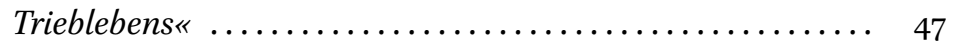

Ein $»$ ausgesprochener Denkertyp « ............... 48

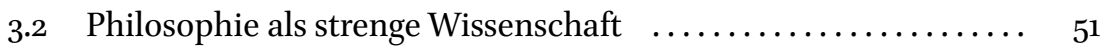

Die $»$ Wissenschaftlichkeit» kritisieren .............. 53

Kritik am Naturalismus: Psychologiekritik ........... 55

Auf die Angriffe aus der Psychologie reagieren .......... 57

Wissenschaftliche Entscheidungen tragen den

Stempel der Ewigkeit $\ldots \ldots \ldots \ldots \ldots \ldots \ldots \ldots \ldots \ldots \ldots \ldots$

Aus der Philosophie resultiert Wissenschaftlichkeit-

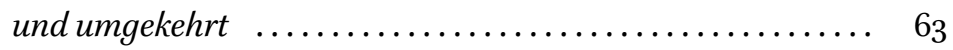

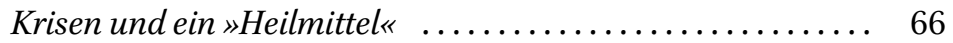

3.3 Fundierung durch Abgrenzung $\ldots \ldots \ldots \ldots \ldots \ldots \ldots \ldots . \ldots 6$

Husserls Denken setzt dort ein, wo Seidels Denken

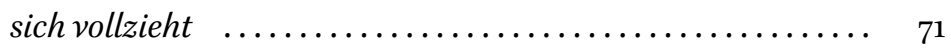

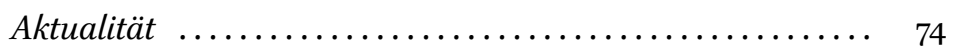


4 Wiener Kreis: Identifikation $\ldots \ldots \ldots \ldots \ldots \ldots \ldots \ldots \ldots \ldots \ldots \ldots \ldots \ldots \ldots$

4.1 Herausforderung: Verlust wissenschaftlicher Objektivität $\ldots . . . \quad 77$

4.2 Eine eigene Zeitschrift, Kongresse und eine Werbebroschüre ... 80

Die erste Ausgabe der »Erkenntnis« ................ 82

Ein Manifest ............................... 85

Die Berliner Gruppe und der Wiener Kreis . ............ 87

Identifikation mit den Naturwissenschaften, Abgrenzung

von der Philosophie .......................... 89

4.3 Philosophie als logische Analyse $\ldots \ldots \ldots \ldots \ldots \ldots \ldots \ldots \ldots . \ldots 2$

Eine grundsätzliche Wende der Philosophie $\ldots . \ldots \ldots \ldots . .692$

Die Genese der Logik aus der Mathematik .............. 95

Philosophische Altlasten aus dem Weg räumen:

Metaphysikkritik ........................... 100

Die Philosophie als Methode bzw. Tätigkeit ............ 105

Kein eigenes Fach, aber Königin aller Fächer! .......... 110

Allgemeingültigkeit ......................... 112

4.4 Zwischenfazit: Fundierung durch Identifikation $\ldots \ldots \ldots \ldots \ldots \quad 114$

4.5 Eine politisch und wissenschaftlich neutrale Instanz $\ldots \ldots \ldots \ldots$

5 Kritische Theorie: Kooperation $\ldots \ldots \ldots \ldots \ldots \ldots \ldots \ldots \ldots \ldots \ldots \ldots \ldots$

$\begin{array}{llll}5.1 & \text { Herausforderung: Verlust gesellschaftlicher Legitimität } \ldots \ldots \ldots & 127\end{array}$

Weder Adorno noch Mannheim $\ldots . \ldots \ldots \ldots \ldots \ldots \ldots . .128$

Erstarren vor der Kompliziertheit, Ekel vor der Banalität,

Versinken im Relativismus ....................... 133

Selbstreflexiver Kollaps $\ldots \ldots \ldots \ldots \ldots \ldots \ldots \ldots \ldots \ldots, 137$

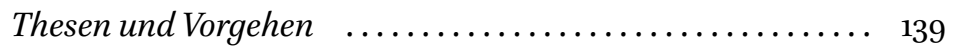

5.2 Die Philosophie als Problem der Gesellschaft

(Lukács und Korsch) .......................... 142

Ausgangslage: Materialistische Dialektik ............. 143

Argumentativer Rückgriff auf die Soziologie ............ 146

Das Problem: Verdinglichte Gesellschaft als Totalität ...... 148

Die Lösung:Klassenrevolution $\ldots . \ldots \ldots \ldots \ldots \ldots \ldots . . \ldots 150$

Aufhebung der Philosophie: Durchdringung von Theorie

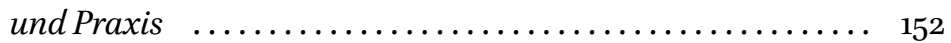

5.3 Die Gesellschaft als Problem der Philosophie (Adorno und

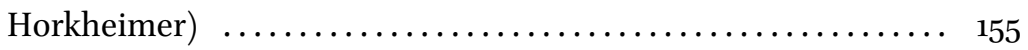

Positionierung in der philosophischen Tradition ........ 157

Zusammenschluss der Philosophie mit den empirischen

Sozialwissenschaften ........................... 159 
Abgrenzung gegenüber der Wissenssoziologie $\ldots \ldots \ldots \ldots .162$ Neubestimmung: Die Philosophie als Instrument der Kritik ................................... 167

Ein Paradox produktiv machen: Philosophie trotz ihrer Unmöglichkeit! ................................ 169

Die Genese der Kritik aus der Philosophie selbst ......... 174 »Kein dritter Standpunkt « - eine Methode ............ 177

Wahrheit statt Opferung des Geistes ................. 179

5.4 Selbstreflexion als philosophisches Programm $\ldots \ldots \ldots \ldots \ldots$..... 180

Exkurs: Wahrheit und Macht .................... 183

6 Philosophische Selbstpositionierungen - Fazit ................. 189

Sich am eigenen Schopf aus dem Sumpf ziehen ......... 198

Ein Dilemma, das bleibt ....................... 202

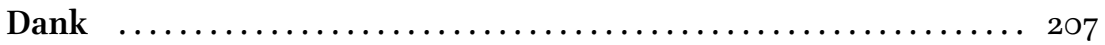

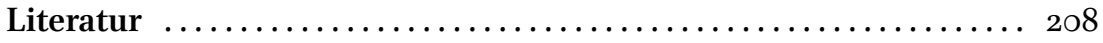


Maria Dätwyler - 978-3-96975-231-9

Downloaded from mentis.de@4/26/2023 04:20:01AM via free access 


\section{Einleitung}

»Noch immer ergeht sich unsere Zeit trotz aller auftauchenden Resignation in der Verherrlichung der Bewußtheit und des Wissens. Fast in jeder Einleitung eines naturwissenschaftlichen, soziologischen oder psychologischen Buches findet man diese Apologie auf die Wirkungen der Wissenschaft« (Seidel 1927: 71). Mit diesen Sätzen beginnt Alfred Seidel sein 1924 verfasstes Manuskript Bewußtsein als Verhängnis. Fragmente über die Beziehungen von Weltanschauung und Charakter oder über Wesen und Wandel der Ideologien, das 1927 aus seinem Nachlass erscheint. Seidel selbst erlebt die Veröffentlichung nicht mehr: Er begeht 29-jährig, unmittelbar nach der Abfassung seiner Schrift, Suizid. Vorher bittet er seinen Bekannten, den Psychiater und Kunsthistoriker Hans Prinzhorn, in einem Brief, die Herausgabe seines Textes zu veranlassen:

Wenn Sie diesen Brief erhalten, lebe ich nicht mehr. Das Buch ist vollständig fertig, mein Lebenssinn, für den ich seit Jahren unter größten Qualen lebe, ist erfüllt. [...] Nicht ich, sondern der Weltgeist, das Schicksal dachten in mir. Ich weiß, welche teuflische Aufgabe ich zu erfüllen hatte. Aber dies alles mußte gesagt werden in dieser Zeit [...]. Ist es Verrat, mein Werk so zu verlassen? Aber wer es gelesen hat, wird selbst sagen, dass damit kein Mensch mehr leben kann. [...] Sorgen Sie für die Herausgabe des Werks. Ich lege es Ihnen ans Herz. (Prinzhorn 1927:45)

Prinzhorn kommt Seidels Ersuchen drei Jahre später nach. Die Bitte Seidels, nämlich das Buch »stilistisch zu verbessern und einige allzu deutliche Züge des Wahnsinns und der Groteskerie« auszubessern (ebd.: 46), erfüllt Prinzhorn insofern, als dass er Bewußtsein als Verhängnis ein ausgiebiges Vorwort beifügt, das Seidels »tragisch zerbrochene Persönlichkeit« als Grund anführt, diesen »wenig einladenden Gedankenrohbau«, der sich »von ähnlichen Unternehmungen deutlich abhebt«, zu veröffentlichen. »Die Drucklegung dieses Buches erfolgt nicht wegen der Reife oder der formalen Vollendungsstufe, die es in wissenschaftlicher oder bekenntnishaft-philosophischer Hinsicht etwa besäße [...] « (ebd.: 3). Sie sei vielmehr motiviert durch den »überwältigende[n] menschliche[n] Reiz einer im vitalen oder im erkennerischen Sinne ganz tiefen und tragisch zerbrechenden Persönlichkeit, die erst nach ihrem Tode die ihr gebührende Führerrolle, nunmehr mittels des nachgelassenen Werkes, ausüben sollte« (ebd.). Die »Führerrolle«, die Prinzhorn - und wie weiter unten deutlich wird, auch andere Rezipienten und Rezipientinnen - Seidel einräumt, ist eine radikal negative: Dieser mache mit seinem Text und seiner Selbsttötung

(C) MARIA DÄTWYLER, 2021 | DOI:10.30965/9783969752319_002

This is an open access chapter distributed under the terms of the CC BY-NC-NPa 4 1 license 
auf ungleich dringlichere Art als andere zeitgenössische Intellektuelle auf die unheilvolle Situation seiner Zeit aufmerksam. In der Tat: In Seidels Schreibstil und Gedankengängen ist eine Verzweiflung spürbar, die den wissenschaftlichen Inhalt und die Aussagen des Textes im Ausmaß weit überschreitet. In seinem Buch wird in aller Vehemenz greifbar, dass die zunehmende Deutungsmacht anderer Wissenschaften grundlegende philosophische Krisen auslöst: Ist das Denken der Menschen noch frei - und falls ja, was ist darunter zu verstehen? -, wenn das Bewusstsein mit experimentellen Methoden der Psychologie erklärt werden kann? Was ist wissenschaftliche Objektivität, wenn Erkenntnisse lediglich zeit- und ortsgebundene Wahrheiten enthalten so wie es die Kulturwissenschaften behaupten? Und wie steht es generell um die menschliche Vernunft, wenn sie Kriege nicht aufzuhalten weiß oder diese gar befürwortet?

In Nachfolge Prinzhorns wird Seidel rezeptionsgeschichtlich zu einer Person stilisiert, deren Arbeit in extremer Form verdeutliche, dass die damalige Welt in eine Krise geraten sei. Insbesondere Seidels »Unzufriedenheit mit der [sic!] herrschenden Wissenschaftsübungen « habe diesen - so Siegfried Kracauer - zur Absage an die »vernunftmäßige Bewußtheit« geführt (Kracauer 2011 [1927]: 523-524). Kurz: An Seidels theoretischer und auch existenzieller Dramatisierung des Bewusstseins als eines grundlegenden Verhängnisses wird in radikaler Weise deutlich, dass naturwissenschaftliche und empirische Wissenschaften philosophische Grundannahmen und Wahrheitsansprüche insbesondere die Annahme eines reinen, von anderen Faktoren unabhängigen Geistes - in fundamentaler Weise herausfordern. Seidel beendet sein Manuskript denn auch mit den resignierten Worten: »Mögen die Waffen gegen das allein herrliche analytische Bewußtsein immer schärfer gespitzt werden und es an seinem eigenen Geiste zugrunde gehen - und wäre dieser sogar: die Wahrheit selbst « (Seidel 1927: 205). ${ }^{2}$

Hundert Jahre später kann festgestellt werden, dass weder das »analytische Bewußtsein« noch »die Wahrheit« in den 192oer-Jahren »zugrunde

1 »Was soll Philosophie, wenn sie nichts dazu beiträgt oder dazu beitragen kann, diese menschheitlichen Katastrophen [die Barbarei, die ihre Chiffre im Namen Auschwitz gefunden hat] zu verhindern? « (Gamm 2009: 19).

2 Diese dramatische Zuspitzung ist möglicherweise der editorischen Arbeit Prinzhorns geschuldet (siehe dazu Kapitel 2). Prinzhorn vermerkt in einer Fußnote: »Von hier ab ist das Manuskript sehr schwer leserlich. Ohne deutliche Zeilenführung sind die Worte in flüchtigen Schriftzeichen hingeworfen, wobei doch die Formen und die zahlreichen Durchstreichungen für einen tief erregten Zustand sprechen, aus dem die überraschende und erschütternde Schlußwendung hervorbricht « (Seidel 1927: 205). Diese Schlusswendung lautet: »Und wenn einer sagte, Christus wäre Gegner der Wahrheit, so würde ich doch mit Christus ziehen - und gegen die Wahrheit« (ebd.). 
gingen «. Im Verlaufe des 20. Jahrhunderts wird im Gegenteil erkennbar, dass der Anspruch auf Wahrheit - auch auf eine letzte - für die Wissenschaften konstitutiv ist. Wahrheitsansprüche und wissenschaftliche Deutungsmacht sind untrennbar verknüpft. Zugleich ist die Rhetorik der Krise, wie sie an Seidel, seinem Buch und auch an dessen Rezeptionsgeschichte erkennbar wird, ein bis heute wiederkehrendes Moment. Die zentrale Stoßrichtung des vorliegenden Buches ist, dass diese Krisen nicht nur etwas sind, was die Wissenschaften gewissermaßen von außen und unmittelbar befällt, sondern dass wissenschaftliche Disziplinen fundamentale Krisen zugleich für ihre Legitimation und Erneuerung nutzen können. Dies möchte ich am Beispiel der Philosophie zeigen. Die leitende These ist, dass die Philosophie nicht nur auf Krisen reagiert, sondern diese im Zuge ihrer disziplinären Selbsterhaltung auch aktiv erzeugt: Das Aufgreifen von Krisen und die dazugehörige Suche nach Auswegen und Alternativen ist für die Philosophie ein zentraler Modus, wie sie sich ihre disziplinäre Unabhängigkeit über die Zeit hinweg bewahren kann.

Insofern sind die >Angriffe $<$, die die Philosophie durch die Weiterentwicklungen anderer Wissenschaften im 20. Jahrhundert erfährt - etwa, wenn die Psychologie das Bewusstsein auf biologische bzw. neurophysiologische Prozesse zurückführt -, höchst produktiv. Durch die fundierte Auseinandersetzung mit Herausforderungen, die das philosophische Selbstverständnis im Kern treffen, gelingt es Philosophen und Philosophinnen immer wieder, die Daseinsberechtigung ihrer Disziplin als eigenständige Wissenschaft neu zu begründen und zu aktualisieren.

\subsection{Philosophie und/oder Wissenschaftsforschung?}

Im Zentrum steht die Frage, mit welchen argumentativen Strategien Philosophen am Anfang des 20. Jahrhunderts ihre Disziplin erneuern und legitimieren. Mit dieser Frage, die nicht eigentlich eine philosophische, sondern eine metaphilosophische Perspektive verlangt, verortet sich die vorliegende Untersuchung auf der Schnittstelle zwischen Philosophie und Wissenschaftsforschung. Ludwik Fleck stellt Anfang des 20. Jahrhunderts mit seinen Begriffen des Denkkollektivs bzw. Denkstils die bis heute wohl instruktivsten Mittel zur Verfügung, wissenschaftliche Disziplinen zu historisieren und deren Entstehungsbedingungen zu thematisieren. ${ }^{3} »$ Jedem

3 Nachdem Thomas S. Kuhn in The Structure of Scientific Revolutions von 1962 bekundet, dass Flecks »fast unbekannte Monographie« Entstehung und Entwicklung einer wissenschaftlichen 
Erkennen, jedem Erkenntnissysteme, jedem sozialen Beziehungseingehen entspricht eine eigene Wirklichkeit. Dies ist der einzig gerechte Standpunkt « (Fleck 1983: 48). Fleck argumentiert dezidiert für die historische und soziale Verfasstheit der Erkenntnis: Jedes Wissen habe einen »eigenen Gedankenstil mit seiner Tradition und Erziehung « (ebd.), Wissen und Soziales stehen also in einer Wechselbeziehung zueinander. »Erkenntnisse werden von Menschen gebildet, aber auch umgekehrt: sie bilden Menschen. Es wäre einfach töricht, zu fragen, was hier >Ursache< und was >Wirkung ist« (ebd.: 49). Denn: »Wie könnte ich sonst begreifen, dass z.B. der humanistisch Gebildete die Wissenschaft des Naturforschers nie vollständig versteht? Oder gar der Theologe? Soll ich, wie es leider so oft geschieht, jene für Narren halten?« (ebd.). Dass »jede Erkenntnistheorie ohne geschichtliche und vergleichende Untersuchungen ein leeres Wortspiel, eine Epistemologia imaginabilis« bleibe (Fleck 1980 [1935]: 31), gehört zu den Überzeugungen, die mit und seit Fleck die Wissenschaftsforschung und -geschichte prägen. Die Historisierung wissenschaftlicher Erkenntnis ist in der Wissenschaftsforschung denn auch ein »epistemischer Standard«, der »zwar stets verbesserungsfähig ist, hinter den es jedoch kein Zurück gibt« (Hagner 2001: 30). Die Wissenschaftsforschung verfügt mit den Werken von Ludwig Fleck, Gaston Bachelard, Georges Canguilhem, Thomas S. Kuhn, Michel Foucault, Lorraine Daston oder Bruno Latour ${ }^{4}$ inzwischen über einen Kanon, der unter dem Begriff der Historischen Epistemologie gefasst wird (Rheinberger 2007). Im Verlaufe des 20. Jahrhunderts, so Hans-Jörg Rheinberger, »entwickelte sich eine breit gefächerte neue Reflexion über Wissenschaft [...], die in vielgestaltiger Weise begann, die

Tatsache viele seiner Gedanken vorwegnehmen würde (Kuhn 1976 [1962]: 8), beginnt Flecks Wiederentdeckung. Fleck - der Immunologe - wird vermittelt durch Kuhn aus der Unbekanntheit geholt, um im Nachhinein zu einem der Gründerväter der Wissenschaftsgeschichte, Wissenschaftstheorie und Wissenschaftsforschung stilisiert zu werden. The Structure of Scientific Revolutions wiederum wird innerhalb der Wissenschaftstheorie als eine Art historische Zäsur behandelt. Kuhns Konzept der Scientific Revolutions wird als theoretischer Meilenstein rezipiert und kritisiert; der Terminus der Kuhn'schen Wende hat sich inzwischen etabliert. (Wahlweise wird diese Wende auch die konstruktivistische oder die antipositivistische Wende der Wissenschaftsforschung genannt (vgl. Hofmann/ Hirschauer 2012: 86; Paulitz 2012: 41).) Dass eine Vielzahl an Ansätzen und Methoden der aktuellen Wissenschaftsforschung und -geschichte bereits vor der Kuhn'schen Wende entwickelt worden war, merkt Wolf Lepenies an: »Heute [1979, MD] sehen wir uns der eigentlichen Situation gegenüber, daß die Nach-Kuhnsche Wissenschaftsforschung auf Konzepte, Methoden und Theorie-Ansätze zurückgreift, die der Struktur wissenschaftlicher Revolutionen um Jahrzehnte vorausgingen « (Lepenies 1979: I).

4 Es handelt sich hier um eine exemplarische, nicht um eine vollständige Auflistung. 
Epistemologie zu historisieren « (ebd.: 9). Diese Zugangsweise, in der die Art und Weise, wie Epistemologien hervorgebracht werden, selbst zum wissenschaftlichen Gegenstand wird, ist die Ausgangslage des vorliegenden Buches.

Aus dem Anspruch, die Philosophie mit Mitteln derWissenschaftsforschung zu untersuchen, hat sich jedoch ein folgenreiches Problem ergeben: Die Wissenschaftsforschung widmet sich vor allem der Entwicklung von naturwissenschaftlichem, nicht aber geistes- oder sozialwissenschaftlichem Wissen. Flecks berühmte Studie zur Entstehung und Entwicklung einer wissenschaftlichen Tatsache etwa ist im Bereich der Mikrobiologie angelegt (Fleck 2011 [1935]), Steve Woolgars und Bruno Latours Studie zum Laboratory Life ist im Bereich der Biochemie (Latour/Woolgar 1979) und Lorraine Dastons bzw. Peter Galisons Objectivity ist - im weitesten Sinne - im Bereich der Naturwissenschaften angesiedelt (Daston/Galison 2007). Die Produktionsbedingungen von geistes- und sozialwissenschaftlichem Wissen jedoch werden innerhalb dieses Kanons nur am Rande betrachtet, implizit mitgedacht oder gar aktiv ausgeklammert bzw. ignoriert. Diese Situation wiederum bedeutet nicht, dass es keine Studien gäbe, die den Blick tatsächlich auf die Produktionsbedingungen spezifischen geistes- und sozialwissenschaftlichen Wissens richteten (z.B. Kusch 1995/200o; Bollenbeck/Knobloch 2004; Kleeberg/Suter 2014; Amslinger 2017; Morgenthaler 2020). Allerdings verweist das wiederholt vorgetragene Desiderat, die Geisteswissenschaften aus der Perspektive der Wissenschaftsforschung zu untersuchen (z.B. Hamann 2015), darauf, dass diese Studien kaum Eingang in den genannten Kanon finden, sondern tendenziell der jeweils untersuchten Disziplin zugeordnet und nur von dieser rezipiert werden.

Im Fall der Philosophie wird die Situation besonders komplex, da die Grenze zwischen Wissenschaftsforschung und Philosophie weder methodisch noch inhaltlich klar gezogen werden kann. Exemplarisch steht hierfür Bruno Latour, der sich nach einer langen Karriere als Wissenschaftsforscher nun als Philosoph verstanden wissen will (Dätwyler 2018). Die Philosophie, so macht es den Anschein, besitzt auch in der Wissenschaftsforschung eine Art Sonderstatus als Leitwissenschaft. Sie ist zweierlei: eine Disziplin unter Disziplinen und zugleich ein Analyseinstrument, um andere wissenschaftliche Disziplinen zu untersuchen. Mit welchen analytischen Instrumenten aber kann die Philosophie selbst konfrontiert werden? Lässt sich dieser Diszplin, von ihrem Selbstverständnis her der selbstkritischsten und metawissenschaftlichsten unter allen Disziplinen, überhaupt ein Spiegel vorhalten? Oder verliert man, wie es das Schicksal Alfred Seidels befürchten lässt, den Verstand, wenn man dies tut? Kann es diese zur Analyse notwendigen Instrumente gar nicht geben, 
weil ein Vorhaben, das sich ihrer Anwendung verdankt, zwingend zur Absage an wissenschaftliche Wahrheitsbehauptungen führen muss - so auch das vorliegende?

Wie keine andere Disziplin ist die Philosophie mit dem Begriff der Wahrheit verbunden. ${ }^{5}$ Ohne Wahrheitsansprüche verliert sie und mit ihr die Wissenschaft generell ihre wichtigste Fragestellung. Die zentrale Herausforderung, die sich für diese Untersuchung gestellt hat, lag also darin, Instrumente zu finden, mit denen sich die Philosophie zwar spiegeln lässt, ohne jedoch in die so unsinnige wie unhaltbare Lage zu geraten, den untersuchten philosophischen Positionen ihren Wahrheitsgehalt absprechen zu wollen. Es galt, eine Perspektive zu finden, die die Philosophie nicht >von außen< betrachtet und beurteilt, sondern die es vermag, philosophische Argumentationsstrategien >von innen< nachzuzeichnen und zu verstehen. Die Leistung dieser Perspektive musste die sein, die Wege und Aushandlungsprozesse nachzuzeichnen, mit denen Philosophen ihre Argumente erhärten und legitimieren, statt philosophische Argumente als gegeben hinzunehmen. Der Blick musste darauf gerichtet sein, wie Philosophen durch spezifische Argumente ihre Disziplin stabilisieren, statt direkt inhaltliche Aussagen oder Argumente von Philosophen zu fokussieren. Diese Perspektive verlangt auf den ersten Blick etwas Widersprüchliches: Sie erfordert gleichzeitig eine radikale Distanzierungsbewegung gegenüber der Philosophie und ein radikales Eintauchen in die jeweilige philosophische Argumentation.

Das analytische Intrument, das ich entwickelt habe, um diesen Ansprüchen gerecht zu werden, fasse ich mit dem Begriff der Selbstpositionierungsstrategie. Der Begriff der Positionierung verweist darauf, dass jedes Argument in spezifischen Kontexten vorgebracht wird und dass diese Kontexte für die Geltungskraft von Argumenten konstitutiv sind. Die Betonung als Selbstpositionierung hingegen verweist darauf, dass es hier, wie gesagt, um die Perspektive der Philosophie selbst geht. So werden die Einzelwissenschaften, mit denen sich Philosophen auseinandersetzen, um ihre genuin philosophischen Argumente hervorzubringen, nicht eigenständig dargestellt, sondern aus der Perspektive der jeweiligen Philosophen selbst. ${ }^{6}$

5 Bernhard Kleeberg und Robert Suter haben in Form einer »ersten Hermeneutik « das Forschungsprogramm einer Praxeologie der Wahrheit vorgeschlagen (Kleeberg/Suter 2014). In diesem an Michel Foucault angelehnten Operationalisierungsentwurf geisteswissenschaftlicher Wissensproduktion nehmen die Autoren die Herstellung von >Wahrheit< als solcher in den Blick.

6 Analog dazu geht es in dieser Untersuchung um die Frage, wie Philosophen andere Wissenszugänge für ihre eigene Positionierung bzw. Neubegründung in Anspruch nehmen, und nicht 
Ein klassischer Ansatz der Wissenschaftsforschung ist es, im Labor die konkret stattfindenden Vorgänge der Wissensproduktion zu beobachten und zu analysieren. Woraus aber besteht das Labor von Philosophen und Philosophinnen? Ich habe mich entschieden, philosophische Texte als Labor zu verstehen und zu behandeln. Das heißt, dass ich die behandelten Texte (auf die Kriterien der Auswahl gehe ich weiter unten ein) als Orte verstehe, wo philosophisches Wissen produziert wird. Mein Bestreben war es, in diesen Texten zentrale Strategien ausfindig zu machen, wie die Philosophen ihre Argumente schärfen. Nicht die Argumente auf der Oberfläche haben mich interessiert, sondern die darunter liegenden Strategien, wie diese Argumente Sichtbarkeit und Gültigkeit erlangen. Wie begründen Philosophen ihren Erneuerungsanspruch? Welche argumentativen Strategien kommen dabei zum Vorschein? Und welches disziplinäre Selbstverständnis spiegelt sich darin wider? Die Entstehungsbedingungen der Texte selbst habe ich nicht in die Untersuchung miteinbezogen. Dies hätte einer wissenschaftshistorischen Untersuchung entsprochen. Das Augenmerk des vorliegenden Buches liegt dadurch weder auf wissenschaftshistorischen noch auf fachphilosophischen Details. Ich widme mich hingegen den Selbstpositionierungsstrategien, die ich in kanonischen Texten der deutschsprachigen Philosophie des 20. Jahrhunderts identifizieren konnte.

Die Resultate, die hier präsentiert werden, sind somit für beide Disziplinen von Relevanz: für die Philosophie, weil durch den analytischen Zugang Einsichten in das Selbstverständnis der kanonischen Philosophie des 20. Jahrhunderts gewährt werden. Und für die Wissenschaftsforschung, weil hier an einer Disziplin Methoden und Zugangsweisen erprobt werden, die - in modifizierter Form - auch für die Untersuchung anderer geisteswissenschaftlicher Disziplinen von Bedeutung sein könnten.

In Bezug auf die Beschreibung philosophischer Epochen schlägt der Philosoph Herbert Schnädelbach vor, das 19. und 20. Jahrhundert durch die symbolische Jahreszahl 1918 voneinander zu trennen. Durch die Kriegsniederlage würden in Deutschland Umbruchstendenzen außerordentlich verstärkt. »In der Zeit der Weimarer Republik geht manches zu Ende, und es werden die Weichen des Neuen gestellt, was man auch in der Philosophie daran erkennen kann, dass

um die Frage, wie diese Positionierungen wiederum in anderen disziplinären Kontexten rezipiert werden. 
die großen Kontroversen, die unsere Gegenwartsdiskussionen bestimmen, sämtlich auf jene Jahre zurückgehen" (Schnädelbach 1983: 15-16). In der Philosophie, so pointiert Schnädelbach, »beginnt das 20. Jahrhundert erst in den 1920er Jahren « (Schnädelbach 1992: 309). Demnach werden die 1920erJahre häufig als ein Wiederaufstieg oder als eine Blütezeit der Philosophie beschrieben. In dieser Zeit entstehen einflussreiche, die philosophische Diskussion bis heute prägende Strömungen wie die Phänomenologie, die Kritische Theorie, die analytische Sprachphilosophie sowie die Kulturphilosophie oder die Philosophische Anthropologie.

Angesichts der Vielzahl und Heterogenität philosophischer Neupositionierungen zu Beginn des 20. Jahrhunderts bin ich auf drei verschiedenen Ebenen selektiv vorgegangen. Erstens habe ich mich in Anlehnung an Schnädelbach, der die Sprache, die Gesellschaft und das Sein als die neuen Horizonte für das 20. Jahrhundert beschreibt (Schnädelbach 1992: 309), für drei philosophische Paradigmen entschieden: für die analytische Sprachphilosophie, die Kritische Theorie und die Phänomenologie. Zweitens verläuft die Art und Weise, wie ich mir Zugang zu den Selbstpositionierungen dieser Traditionen verschafft habe, über wenige einzelne Philosophen. Ich habe Philosophen ausgewählt, die diese Paradigmen gewissermaßen als Galionsfiguren verkörpern. Schnädelbach spricht von der Philosophie als einer »personengebundenen Deutungsdisziplin, in der man sich wesentlich durch die Nennung von Eigennamen orientiert«(Schnädelbach 1983:120). Es gebe sicherlich auch in anderen Disziplinen »Parteienstreit und Schuloberhäupter, aber nirgends ist dies so ausgeprägt wie in der Philosophie« (ebd.). Ich habe mich für jene »Schuloberhäupter« entschieden, die je als Begründer eines dieser Paradigmen gelten: Edmund Husserl als Begründer der Phänomenologie, ${ }^{7}$

7 Dass für die vorliegende Arbeit Husserl und nicht Heidegger ausgewählt worden ist, ist der Tatsache zuzurechnen, dass Heideggers Denken zwar Husserls Phänomenologie »sprengt« (Schnädelbach 1992: 310), aber dennoch der phänomenologischen Tradition verhaftet bleibt, als deren Begründer Husserl gilt. Es wäre allerdings ein verlockendes Unterfangen, die Erneuerungsstrategien, die mit Sein und Zeit evoziert wurden, zu untersuchen. Wie Dieter Thomä betont, sind in dieser Schrift Krisen und Umbrüche deutlich greifbar: »Die aktuell übliche Fokussierung der Debatte auf das Verhältnis zwischen Sein und Zeit einerseits sowie Heideggers NS-Engagement andererseits lenkt die Aufmerksamkeit ungünstigerweise von der heftigen Verschiebung, Verunsicherung, Verschärfung oder, kurz gesagt, Krise, die an Heideggers Schriften zwischen 1927 und 1933 ablesbar ist, ab« (Thomä 2018: 100). Von Schnädelbach übernommen wurde die Vermutung, dass den drei Traditionen eine gemeinsame Wurzel zugrunde liegt, die »Verheißung nämlich, ohne Rückfall in vorkritische Metaphysik endlich in den Rücken des akademisch zu Tode analysierten transzendentalen Bewußtseins zu gelangen « (Schnädelbach 1992: 310). In allen drei Beispielen wird der Anspruch auf eine Überwindung der Metaphysik deutlich. Dieser Aspekt wird vor allem im 
die Vertreter des Wiener Kreises als Begründer des Logischen Positivismus bzw. der analytischen Sprachphilosophie sowie Max Horkheimer und Theodor W. Adorno (unter Einbezug von Georg Lukács und Karl Korsch) als Begründer der Kritischen Theorie. Gerade weil die Arbeiten der ausgewählten Philosophen ein fixer Bestandteil des philosophischen Kanons sind, bedeutet das Aufspüren ihrer Argumentationsstrategien gleichzeitig eine Auseinandersetzung mit den Anfängen von Traditionen, die den philosophischen Diskurs des 20. und 21. Jahrhunderts maßgeblich prägen. ${ }^{8}$

Drittens schließlich bin ich auch bezüglich der Textauswahl in folgender Weise selektiv vorgegangen: Es stehen bekannte Texte aus dem westlichen philosophischen Kanon im Zentrum, in denen Husserl, die Vertreter des Wiener Kreises sowie Horkheimer und Adorno ihr Programm paradigmatisch ausdrücken. Nicht die sogenannten Hauptwerke werden analysiert, sondern Texte, in denen die Autoren ihre spezifische philosophische Erneuerung gegenüber der Wissenschaftsgemeinde vertreten: programmatische Aufsätze (vor allem bei Husserl), Ankündigungen einer neuen Zeitschrift (vor allem beim Wiener Kreis) und Antrittsreden (vor allem bei Horkheimer und Adorno). Wie diese Texte einzuordnen sind, ist jeweils Thema der Teilkapitel. An dieser Stelle möchte ich lediglich auf die Heterogenität des Materials eingehen, die eine Folge der Unterschiedlichkeit der drei Denktraditionen selbst ist: So wird etwa die Phänomenologie - anders als der Logische Positivismus und die Kritische Theorie - auf Husserl als alleinigen Begründer zurückgeführt. Deswegen steht im Kapitel zu Husserl dessen Aufsatz Philosophie als strenge Wissenschaft (1910/11) im Zentrum. Dieser Text ist für die spätere Begründung und Ausformulierung der Husserl'schen Phänomenologie maßgeblich. Der Wiener Kreis hingegen hat u.a. mit Rudolf Carnap, Moritz Schlick, Hans Hahn und Otto Neurath gleich mehrere Exponenten. Die Protagonisten des Wiener Kreises widersetzen sich explizit dem Geniekult innerhalb der Philosophie, d.h., sie verstehen Philosophie nach dem naturwissenschaftlichen Modell als ein gemeinschaftliches, interdisziplinäres und personenunabhängiges Arbeitsprojekt. Aus diesem Grund steht im Kapitel zum Wiener Kreis nicht ein einzelner Text eines einzelnen Autors im Vordergrund, sondern zwei Dokumente, in denen verschiedene Autoren zu Wort kommen: die erste und zweite Ausgabe der Zeitschrift »Erkenntnis« (inklusive Vorwörtern und

Unterkapitel »Philosophische Altlasten aus dem Weg räumen« (S. 100-105) und im Fazit (S. 193-194) thematisiert.

8 Das Schisma zwischen analytischer und kontinentaler Philosophie etwa, das die Philosophie des 20. und 21. Jahrhunderts bis heute prägt, wird an den Auseinandersetzungen zwischen Carnap (als Mitbegründer der analytischen Philosophie) und Heidegger (hier verstanden als Husserls Nachfolger) ersichtlich (Friedman 2000). 
Tagungsberichten) sowie der als Manifest bekannt gewordene Text Wissenschaftliche Weltauffassung. Der Wiener Kreis (Neurath/Hahn/Carnap 1929). Mit diesen Publikationen wenden sich die Protagonisten des Wiener Kreises erstmals an eine breitere Öffentlichkeit. Obwohl sich auch die Frankfurter Schule der Interdisziplinarität verschreibt, wird sie weit stärker als der Wiener Kreis mit den Namen der Protagonisten in Verbindung gesetzt. Die Namen Horkheimer und Adorno stehen beinahe synonym für die Kritische Theorie. In diesem Kapitel werden folglich sowohl Horkheimers Antrittsrede »Die gegenwärtige Lage der Sozialphilosophie und die Aufgaben des Instituts für Sozialforschung « (1931) als auch Adornos Antrittsrede »Zur Aktualität der Philosophie « (1931) sowie Aufsätze, in denen Horkheimer und Adorno explizit die Funktion der Philosophie thematisieren, untersucht. Die Argumentationsstrategien von Horkheimer und Adorno können jedoch kaum ohne Rückbezug auf jene marxistischen Theorien analysiert werden, die in den 192oer-Jahren die verstärkte Einbeziehung der Philosophie in marxistische Diskussionen gefordert haben. Deswegen werden in diesem Teil auch Auszüge aus Georg Lukács' Aufsatzsammlung Geschichte und Klassenbewußtsein (1923) und aus Karl Korschs Aufsatz Marxismus und Philosophie (1923) eine wichtige Rolle spielen.

Die Heterogenität der untersuchten Texte widerspiegelt eine wichtige Einsicht der Wissenschaftsforschung, nämlich dass Erkenntnisse und Denktraditionen immer auch materiell bedingt sind bzw. im Material selbst zum Vorschein kommen. Das heißt, die epistemologischen Besonderheiten der drei Traditionen sind eine direkte Folge der ganz konkreten Arbeitsweisen, des intellektuellen Milieus, der ökonomischen Bedingungen etc. der jeweiligen Autoren. Wie angesprochen handelt es sich hier jedoch nicht um eine im engeren Sinne wissenschaftshistorische Untersuchung, d.h., die Analysen verbleiben auf der Ebene der philosophischen Argumentationen. Dadurch werden letztlich Quervergleiche zwischen den in inhaltlicher Hinsicht höchst unterschiedlichen Traditionen ermöglicht: An welchen Schnittstellen wenden Philosophen, die sich teilweise äußerst scharf voneinander abgrenzen, ähnliche oder sogar analoge Strategien an, um ihre spezifische Erneuerung als genuin philosophische zu verteidigen? Wie deutlich werden wird, zeichnen sich diese Schnittstellen dort ab, wo die verschiedenen Philosophen sich in je unterschiedlicher Weise auf etwas anderes, d.h. auf andere Wissenschaften, beziehen, um ihrer Position Gültigkeit und Geltungskraft zu verleihen.

Es sind jene Punkte, die in der Selbstbeschreibung und im Selbstverständnis der Philosophie, die sich selbst als autonom und unabhängig versteht, häufig unterschlagen werden, jedoch dann offensichtlich zutage treten, wenn man den Blick verschiebt und - anstatt direkt die Argumente zu untersuchen - die 
Strategien aufspürt, mit denen Philosophinnen und Philosophen diese Argumente vorbringen.

\subsection{Eine Kontrastfolie}

Wie zu Beginn angesprochen, spielen eine weitere Person und ein weiterer Text in diesem Buch eine wichtige Rolle: der wenig bekannte Autor Alfred Seidel und sein fragmentarischer Text Bewußtsein als Verhängnis, der 1927 erscheint. In der vorliegenden Untersuchung nimmt Seidel die Funktion einer Kontrastfolie ein, da sein Text Dynamiken zeigt, die in kanonisierten philosophischen Texten unausgesprochen bleiben.

Seidel bezeichnet sich selbst weder als Philosoph, noch verortet er seine Untersuchung innerhalb der Philosophie. Er verwehrt sich gegen einen »metaphysischen « Standpunkt: »Die metaphysische Grundlage dieser Arbeit ist hier, wo es sich um eine psychologische und soziologische Problemstellung handelt, nicht entwickelt - das würde in einen größeren Rahmen gehören -, sie ist bewußt herausgezogen worden « (Seidel 1927: 71). Seidel möchte das Bewusstsein - das philosophische Thema per se - also nicht philosophisch, sondern ausgehend von anderen Perspektiven beleuchten. Er stellt sich die Frage, »ob die Erkenntnis der sozialen und psychischen Vorgänge nicht gerade ihre Beeinflussung unmöglich macht, zumindest hemmt - die Frage nach dem Bewußtsein als Verhängnis« (ebd.: 74).

Seidels wissenschaftliche Arbeit über das Verhängnisvolle des Bewusstseins ist untrennbar mit seiner eigenen Existenz verknüpft. Sein Ringen mit den Möglichkeiten und Unmöglichkeiten wissenschaftlicher Erkenntnis ist im Text permanent spürbar. Er möchte das Phänomen des Bewusstseins resp. die »Ideologien der Gegenwart $\aleph^{9}$ mit den wissenschaftlichen Mitteln seiner Zeit, d.h. mit naturwissenschaftlichen, soziologischen, psychologischen und historischen Theorien, untersuchen, zerbricht aber - so seine Selbstdarstellung - an diesem Vorhaben. Seine Einsicht, dass auch er selbst als Wissenschaftler den zeitgenössischen Ideologien ausgeliefert ist, er also nicht sicher sein kann, dass nicht auch er sich von den vorherrschenden wissenschaftlichen, kulturellen und philosophischen Wahrheitsansprüchen blenden lassen könnte, scheint Seidel in eine analytisch und existenziell ausweglose

9 Seidel diskutiert in diesem Zusammenhang den »Marxismus-Sozialismus«, die »Neuromantik« (Gemeinschaft, Religion, das Kulturgewollte, die Natürlichkeit, das Erlebnis und die Frauenbewegung), den »Nationalismus«, den »Pazifismus« und die »Untergangsidee« im Sinne Oswald Spenglers (Seidel 1927: 166-202). 
Situation zu bringen. Denn selbst eine »Analyse der Analyse « werde den Analytiker lediglich »erläutern, soweit er ehrlich ist«, sie werde dann aber »möglicherweise negativ auf ihn wirken, d.h. ihm seinen Glauben an die Wirkungen des Bewußtseins erschüttern« (ebd.: 205). Und das, fügt Seidel lapidar an, »wäre der schönste Erfolg « (ebd.). Selbst der Zynismus, der üblicherweise aus Gedankengängen wie diesem einen Ausweg bietet, ist aus dieser Perspektive letztlich nur eine verzweifelte Möglichkeit, den Glauben an das Bewusstsein aufrechtzuerhalten.

Seidel räumt der finalen Erkenntnis und der absoluten Wahrheit kein Refugium mehr ein. Man erhält während der Lektüre den Eindruck, dass er eine Position sucht, von der aus das menschliche Bewusstsein als Gegenstand zu erfassen wäre - doch dies scheint weder mit psychologischen, soziologischen, naturwissenschaftlichen noch mit historischen Zugriffen möglich zu sein. Jede dieser Perspektiven mündet für Seidel letztlich in eine Ideologie und die komplette Desillusionierung der wissenschaftlichen - auch der kulturund geisteswissenschaftlichen - Erkenntnis. Nach der Lektüre des Textes bleibt Resignation: Naturwissenschaftliche, soziologische, psychologische und historische Erkenntnisse scheinen den reinen philosophischen Geist derart herauszufordern, dass selbst die Wahrheit (und damit die Philosophie als deren Verwalterin) zerstört werden wird. Lösungsansätze, wie die Wahrheit und - im Besonderen die wissenschaftliche Wahrheit - in dieser Situation noch zu retten wäre, gibt es nicht.

Seidels Schrift gibt davon Zeugnis, wie prekär und existenziell philosophisches Denken werden kann, wenn es in aller Konsequenz ausgeübt wird. Bewußtsein als Verhängnis ist also keinesfalls ein kulturpessimistisches Pamphlet, in dem Intellektualismus, die Wissenschaft oder kurz: der menschliche Geist als Verhängnis angegriffen werden. Der Text ist im Gegenteil von der Einsicht bestimmt, dass die Annahme eines freien, von anderen Faktoren unabhängigen menschlichen Geistes tatsächlich in die Bredouille geraten ist und dass Erkenntnisse aus anderen Wissenschaften den reinen Geist bzw. philosophische Standpunkte in fundamentaler Weise infrage stellen. An seiner Selbstdarstellung wird deutlich, dass eine Objektivierung des Geistes mit wissenschaftlich-analytischen Mitteln für ihn undurchführbar ist. Er macht durch seine Arbeit in exemplarischer Weise die Verluste genuin philosophischer Standpunkte infolge der Erkenntnisse aus anderen Wissenschaften deutlich.

Wo Seidel die von anderen Wissenschaften ausgelösten Herausforderungen für die Philosophie klar zur Sprache bringt, werden diese von Philosophen zugunsten ihrer eigenen Disziplin objektiviert, in unterschiedlichen Weisen operationalisiert und dadurch in spezifischer Weise unsichtbar gemacht. 
Bewußtsein als Verhängnis stellt in der vorliegenden Untersuchung somit eine Art Kontrastfolie dar. Im direkten Gegensatz zu den Texten in den drei Fallbeispielen zu Husserl, zum Wiener Kreis und zur Kritischen Theorie ist Seidels Bewußtsein als Verhängnis ein Text, der aufgrund seiner unklaren Gattungszugehörigkeit philosophisch nicht kanonisiert werden kann: In Seidels Gedankengängen ist keine Orientierung an einer philosophischen Lösung der traktierten Problematik zu entdecken, d.h., die Analysen sind bar jeder argumentativen Strategie formuliert. Auf den ersten 130 Seiten entwickelt er zwar seine Thesen über das Bewusstsein als Verhängnis (Seidel 1927: 71-205), in inhaltlicher Hinsicht fransen seine Analysen jedoch immer wieder aus. Letztlich werden in diesem Text keine systematischen Begründungen sichtbar, warum das Bewusstsein verhängnisvoll ist, sondern es werden ex negativo die Konsequenzen nachgezeichnet, die diese Diagnose auf das Denken und die Philosophie selbst hat. Auf den letzten 14 Seiten des Buches (»Anhang«) hat Prinzhorn, der es posthum herausgegeben hat, zusätzlich »Bruchstücke aus anderen Schriften« in Form von Fragmenten aufgelistet (ebd.: 207-221). Es werden auch Auszüge aus diesen Fragmenten zitiert.

Dieser textsortenspezifische Unterschied zwischen Seidel und den anderen Autoren ist für die Konzeption des vorliegenden Buches zentral. Seidel behandelt keine »Krisen«; er denkt - jedenfalls in diesem Text ${ }^{10}$ - nicht in Mustern möglicher akademisch-philosophischer Profilierung. Gerade deswegen zeichnet sich in Bewußtsein als Verhängnis - als unterschwelliger Kontrast - die illusio von überwiegend akademisch ausgerichteten Philosophen und Philosophinnen punktuell ab. »Die illusio«, so schreibt Pierre Bourdieu, »gehört nicht zu den expliziten Prinzipien, den Thesen, die man aufstellt und die verteidigt werden, sondern zum Handeln, zur Routine, zu den Dingen, die man halt tut und die man tut, weil es sich gehört und weil man sie immer getan hat « (Bourdieu 2001 [1997]: 129). Seidel denkt gewissermaßen über die Denkroutinen hinaus, die Philosophinnen und Philosophen qua ihrer Disziplinierung einüben und anwenden. ${ }^{11}$ Aus diesem Text können Muster philosophischer Denkbewegungen extrapoliert werden, die ausgehend

10 Im Gegensatz zu Bewußtsein als Verhängnis ist seine Dissertation klar strukturiert (siehe S. 128).

11 »Das Erlernen einer wissenschaftlichen Disziplin«, schreibt Patricia Purtschert in ihrem Buch Grenzfiguren, »gestaltet sich immer auch als Prozess der Disziplinierung. In der Philosophie gehört dazu das Erwerben der Fertigkeiten, Textstellen zu übersehen und zu überlesen, die für eine philosophische Interpretation >zu historisch<, >zu exemplarisch<, >zu anekdotischく oder schlicht >zu unbedeutendく sind. Das Einüben dieses selektiven Blicks wird dabei kaum je zum Thema; er wird vielmehr stillschweigend vermittelt und erlernt« (Purtschert 2006: 13). 
von der üblichen fachinternen Logik nicht erfasst werden können. Seidel und sein Text fungieren hier als eine Möglichkeit, die Philosophie und ihre Wahrheitsansprüche zu spiegeln. Diese Möglichkeit ergibt sich vor allem aus seinem Anspruch, das Bewusstsein explizit nicht aus einer philosophischen Perspektive, sondern ausgehend von anderen Disziplinen zu beleuchten. Er macht dadurch nicht nur das Verhängnis sichtbar, in das eine solche Auffassung von Bewusstsein führen kann, sondern verdeutlicht zudem die Bedrängnis, in die die Philosophie gerät, wenn ihre Kernthemen von anderen Disziplinen aufgegriffen und bearbeitet werden.

\subsection{In Reaktion auf die Einzelwissenschaften: Unterschiedliche Strategien der Selbstbehauptung}

Was an Seidels Text beispielhaft deutlich wird - die Selbstwahrnehmung der Philosophie als einer Disziplin in der Krise - widerspiegelt auch die philosophische und historische Fachliteratur. »Die Hoheit über das Wissen von den Menschen wird von der Psychologie und Soziologie, aber auch der Medizin reklamiert, das Wissen um die Gesetzmäßigkeiten der materiellen Welt fällt an die Physik, die Chemie und an die Biologie - was also bleibt für die Philosophie?« (Gamm 2009: 17). Dass die herausgehobene Stellung der Philosophie um 1900 gegenüber den Einzelwissenschaften zusammenbricht und die Philosophie nun als eine Fachwissenschaft neben anderen steht, wird laut dem Wissenschaftshistoriker Paul Ziche von Philosophen als Bedrohung oder gar Katastrophe beurteilt, auf die die Philosophie zur Sicherung ihrer eigenen Existenzberechtigung zu reagieren habe (Ziche 2008: $31-41$ ). ${ }^{12}$ Die Ausgliederung der einzelnen Wissenschaften aus der Philosophie, die um 1900 weitgehend abgeschlossen sei und das heutige System der Einzelwissenschaften bilde (ebd.: 25), eröffne für die Philosophie paradoxerweise neue Möglichkeitsräume für ihre Selbstdefinition. Wie der Philosoph Gerhard Gamm betont, trat die Philosophie, wie man im Rückblick sagen kann, zu dieser Zeit in einen Prozess ununterbrochener Selbstverständigung über sich und die Welt ein (Gamm 20og: 12).

Philosophische Kontroversen werden vor allem dann ausgelöst - das betont auch der Soziologe und Philosoph Martin Kusch -, wenn sich die philosophische Gemeinschaft oder Teile davon vom Erfolg anderer Disziplinen

12 »Eine Bibliographie der Schriften, in denen das Ende der Philosophie verkündet wurde, wäre ein lohnenswertes Unternehmen; es ließe sich zeigen, daß ihre Autoren fast sämtlich Philosophen waren« (Schnädelbach 1983: 282, Fn. 8). 
bedroht fühlen. »Controversies in philosophical community feel endangered by the success and appeal of one or several antidisciplines. In such cases, philosophers then start to search for hidden tendencies in each other's work, tendencies that allegedly provide an insufficient defence against usurpation « (Kusch 1995: 277). Im Unterschied zu Ziches wissenschaftshistorischem und Gamms philosophiehistorischem Zugriff ist Kuschs Ansatz einer Sociology of Philosophical Knowledge (Kusch 1995; 2000) der Wissenschaftssoziologie verpflichtet. ${ }^{13}$ Trotz ihrer unterschiedlichen disziplinären Zugänge vertreten jedoch alle diese Autoren die Auffassung, dass Krisen für die Neubestimmung der Philosophie produktiv genutzt werden. »Gerade die Krisensituation eröffnet optimale Bedingungen für eine Neubestimmung der Philosophie; vor dem Hintergrund der Katastrophe bleibt die Wiedergeburtsforderung zunächst allerdings programmatisch $[\ldots] \ll^{14}$ (Ziche 2008: 35 ). Nicht Krisen

13 Speziell im Bereich der Philosophie hat vor allem Martin Kusch mit seinem Ansatz einer >Sociology of Philosophical Knowledge< (SPK) versucht, eine entsprechende Forschungsrichtung zu lancieren (Kusch 1995: 2000). In Anlehnung an marxistische und feministische wissenssoziologische Perspektiven verortet sich SPK explizit im Strong Programme der Wissenschaftssoziologie. Das Strong Programme wurde ausgehend von Kuhns The Structure of Scientific Revolutions in den 197oer-Jahren entwickelt und verfolgt den Anspruch, jedes Wissen zur Untersuchung freizugeben, und zwar ohne Vorannahme darüber, ob dieses Wissen `wahr $<$ oder `falsch $<$ ist. Diese Gleichbehandlung jedes Wissens impliziert, dass die Wahrheit oder Falschheit von Wissenschaft neutral bzw. symmetrisch betrachtet wird. Mit dem Strong Programme der Wissenschaftsforschung geht eine radikale >Soziologisierung< der Erkenntnistheorien einher. Kusch adaptiert also die für die Untersuchung der Naturwissenschaften konzipierten und an ebendiesen erprobten soziologischen Forschungsprogramme für die Anwendung auf die Philosophie. Wie vor allem im ersten Kapitel deutlich werden wird, sind seine Analysen zum »Psychologismus « für die vorliegenden Untersuchungen zentral. Methodisch wird hier jedoch eine andere Richtung eingeschlagen. Kusch extrahiert Merkmale philosophischer Wissensproduktion, wie sie in philosophischen Kontroversen anzutreffen sind. »The key concept of the approach employed in this study is the notion of controversy « (Kusch 1995). Im Gegensatz zu diesem Vorgehen werden hier keine philosophischen Kontroversen, sondern Argumentationsstrategien ausgewählter Philosophen innerhalb dieser Kontroversen in den Blick genommen. Nebst Kuschs Ansatz ist Allan Janiks und Stephen Toulmins Buch Wittgenstein's Vienna diesbezüglich von Bedeutung. Janik und Toulmin verorten Wittgensteins Philosophie explizit in ihrem kulturellen, historischen und sozialen Kontext (Janik/Toulmin 1973). Weiter einschlägig ist Martina Plümachers Buch Philosophie nach 1945 in Deutschland, in dem die Rolle der Philosophie im Zusammenhang mit anderen Disziplinen, vor allem mit den empirischen Wissenschaften, mit Blick auf das philosophische Selbstverständnis untersucht wird (Plümacher 1996).

14 Ziche verweist an dieser Stelle auf Fritz K. Ringer, der in seiner detailreichen Studie Die Gelehrten. Der Niedergang der deutschen Mandarins 1890-1933 erarbeitet, inwiefern sich die deutschen Gelehrten seit 189o in einer Kulturkrise sahen und wie diese >Krisenwahrnehmung mit einer zunehmend nationalistischen Orientierung der akademischen 
an sich, sondern die explizite Auseinandersetzung mit Krisen, so die zentrale Implikation, ist ein produktives Element in der neuen Verhältnisbestimmung zwischen Einzelwissenschaften und Philosophie um 1900. ${ }^{15}$

Von Schnädelbach stammt der bislang umfassendste Versuch, die Geschichte der Philosophie als »eine Geschichte philosophischer Reaktionen auf das, was in der Wissenschaft und mit der Wissenschaft in einer veränderten Kultur geschieht « (Schnädelbach 1983: 118), aufzufassen (vgl. Ziche 2008). Dieser betrachtet die Philosophiegeschichte seit Hegel als eine Art Krisenbewältigungsgeschichte und unterscheidet diesbezüglich vier Typen: Im ersten Typus - Philosophie als Wissenschaft - versuche die Philosophie, »es der Wissenschaft gleichzutun und einen Platz im Spektrum anerkannter Forschungswissenschaften zu finden: sie konzentriert sich auf historischhermeneutische Forschung und bestimmt sich als Geisteswissenschaft « (ebd.: 119). Hier suche die Philosophie einen Ausweg durch die »Verwissenschaftlichung der Philosophie mit geisteswissenschaftlichen Mitteln« (ebd.: 121). Im zweiten Typus - Wissenschaft als Philosophie - werden die Wissenschaften selbst als Philosophie bestimmt. Das »Resultat ist der Szientismus in verschiedener Gestalt« (ebd.: 119). Diesen Typus beschreibt Schnädelbach als eine »Identifikation mit dem Angreifer«. »Die Philosophie läuft zu derjenigen Instanz über, die sie bedroht - zur Wissenschaft« (ebd.: 123). Ein dritter Typus Philosophie als Kritik - sei »die Abwendung von dem traditionellen Philosophiemodell und die Neubestimmung der Philosophie als Kritik, die dann eine fundamentale Philosophiekritik durchaus einschließt« (ebd.: 119). Hier werde die Kritik an der Philosophie überhaupt zum Topos:

Die Philosophen machen damit die philosophie-externen Zweifel an der Existenzberechtigung ihres Faches zu ihrer eigenen Sache, und dies mit der Konsequenz, dass die internalisierte Kritik der Philosophie zu einer Neubestimmung der Philosophie als Kritik führt. Man respektiert das allgemeine Todesurteil über die Philosophie als eigenständiges Erkenntnisgebiet und glaubt, nur noch im Gestus der Kritik am philosophischen Geist festhalten zu können. (ebd.: 128)

Oberschicht in der Weimarer Republik und einer Anfälligkeit für den Nationalsozialismus in den Jahren nach 1933 korreliert (Ringer 1983 [1969]).

15 Der Zusammenschluss zwischen Philosophie und Krise kann als ein Topos verstanden werden. Sowohl inner- als auch außerakademisch ist die Rede von der Krise der Philosophie bzw. die Philosophie der Krise häufig anzutreffen. Insbesondere Reinhart Koselleck hat den Begriff der Krise geprägt (Koselleck 1979 [1954]; 2004; 2006). Zur Krisenrhetorik siehe etwa Goeze/Strobl 2011; Grunwald/Pfister (Hrsg.) 2007. Weitere Literatur: Oexle (Hrsg.) 2007; Scholten (Hrsg.) 2007; Weiss 2012; Blum 2015. 
Im vierten Typus schließlich - Rehabilitierung der Philosophie - versuche sich »die Philosophie durch Neubegründung ihrer Aufgaben und Methoden zu rehabilitieren « (ebd.: 119). Er zeige sich darin, dass man der Philosophie »in einem wissenschaftlichen Zeitalter einen von den Einzelwissenschaften unabhängigen Bereich von Aufgaben zuweist, durch deren Bearbeitung sie selbst als Wissenschaft auftreten kann « (ebd.: 131). Schnädelbach betont, dass alle »vier Weisen, mit der Identitätskrise der Philosophie nach Hegel fertig zu werden, bis in die Gegenwart [1983, MD] das kontroverse Selbstverständnis der Philosophen [bestimmen] (ebd.: 119).

Ziche kritisiert Schnädelbachs Typologisierung dahingehend, dass dessen Darstellung »zu stark auf eine möglichst eindeutige Abgrenzung unterschiedlicher Richtungen « ziele (Ziche 2008: 327). Den entscheidenden Einwand sieht Ziche darin, »dass diese Reaktionsweisen nicht, wie Schnädelbach suggeriert, wechselseitig exklusiv sind. In mehreren Punkten wird man in ihnen eine Rückprojektion einer erst in der Folge entstandenen, durch bestimmte Schulbildungen fixierten Philosophieeinteilung sehen müssen « (ebd.). Diese Kritik wird hier geteilt: Auf der einen Seite wendet sich Schnädelbach explizit gegen die Tendenz, die Philosophien des 19. Jahrhunderts als Repräsentationen der »großen Denker« oder »Schulen« darzustellen (Schnädelbach 1983: 16), um philosophisches Wissen gewissermaßen neu zu ordnen. Auf der anderen Seite liegt die Crux seiner "problemgeschichtlichen Untersuchung «, wie Schnädelbach selbst einräumt, in der Gefahr eines »Übergewichts der Systematisierung « (ebd.). Wo Ziche und Kusch konkrete Debatten und Kontroversen untersuchen, um damit das neue Verhältnis zwischen Philosophie und Einzelwissenschaften zu bestimmen, schlägt Schnädelbach eine neue Typologie philosophischer Reaktionsweisen vor.

Ungeachtet der Differenzen in den referierten Ansätzen nehmen alle Autoren eine Perspektive auf die Philosophie ein, die auch hier von entscheidender Bedeutung ist: Sie beleuchten die Reaktionen der Philosophie auf die Entwicklungen in den Wissenschaften und beurteilen diese Reaktionen als wesentlich für die Disziplinbildung der Philosophie. Genau diese Dynamik soll hier an drei ausgewählten Philosophen des frühen 20. Jahrhunderts idealtypisch nachgezeichnet werden: Indem sich Husserl, die Vertreter des Wiener Kreises sowie Horkheimer und Adorno mit den Herausforderungen aus anderen Wissenschaften auseinandersetzen, schwächen sie nicht nur die Infragestellung ihrer eigenen Disziplin ab, sondern entwickeln und erhärten zugleich je neue philosophische Positionen. Theoretisch gewendet bedeutet das: Um ihre Standpunkte hervorzubringen, sind diese Philosophen auf ein »konstitutives Außen« (z.B. Derrida 2004) - im hier eingenommenen 
Blickwinkel in Form der Erkenntnisse aus anderen Wissenschaften angewiesen. Husserl begründet die Phänomenologie durch eine Abgrenzung von der experimentellen Psychologie, um sie dadurch als »Erste Wissenschaft« zu etablieren (Abgrenzungsstrategie). Die Vertreter des Wiener Kreises begründen den Logischen Positivismus durch eine Identifikation naturwissenschaftlicher Modelle mit der Philosophie, um dadurch den Objektivitätsanspruch der Philosophie zu rehabilitieren (Identifikationsstrategie). Horkheimer und Adorno schließlich begründen die Kritische Theorie durch eine Kooperation mit den empirischen Sozialwissenschaften, um eine Zurückführung der Philosophie auf die Praxis zu rechtfertigen (Kooperationsstrategie).

Dieses heuristische Modell - bzw. die Sondierung dreier unterschiedlicher Strategien - dient im vorliegenden Buch als Rahmen, um danach zu fragen, wie Philosophen ihre Erneuerungsansprüche im Kontext anderer Disziplinen begründen. Es liegt auf der Hand, dass in jedem der drei Beispiele jede der drei Strategien auffindbar ist - und mit Sicherheit auch noch andere. Das Modell ist der Organisiation und Struktur des Buches geschuldet und dient dazu, die Gemengelage, die aus der Thematik und Fragestellung resultiert, zu systematisieren. Inwiefern sich dieses Muster philosophischer Selbstpositionierung, wonach sich die Philosophie in spezifischer Weise an einer anderen Wissenschaft zu orientieren habe, auch in den Strategien anderer kanonisierter Philosophen wiederfindet, müsste untersucht werden. Carl Schmitts Auseinandersetzungen mit den Politikwissenschaften, Ernst Cassirers Auseinandersetzungen mit den Kulturwissenschaften oder Max Schelers Auseinandersetzungen mit der Anthropologie etwa sind Indizien, dass sich das hier herausgearbeitete Muster philosophischer Aktualisierung auch auf andere Philosophen und Philosophinnen des 20. Jahrhunderts übertragen lassen könnte.

Die Fragen, die in diesem Buch gestellt werden, sind dem Desiderat geschuldet, zu verstehen, welche Strategien Philosophinnen und Philosophen im 20. Jahrhundert wählen, um ihre eigene Disziplin durch die Rezeption anderer Wissenszusammenhänge zu erneuern, damit aufrechtzuerhalten und als eigenständig zu behaupten. Es versteht sich von selbst, dass diese Fragestellung keine umfassende Diskussion der einzelnen Philosophen bzw. von deren Theoriegebäuden zulässt. Es geht hier nicht darum, den einzelnen Philosophen in ihrer Bandbreite gerecht zu werden, sondern punktuell Strategien zu identifizieren, die Philosophen anwenden, um die Philosophie als Wissenschaft zu verteidigen. Insofern interessiert hier auch weniger, ob philosophische Argumente gut oder schlecht sind, ob sie für eine bessere Gesellschaft >nützlich sind oder nicht, sondern philosophische Argumente werden selbst problematisiert und kontextualisiert. 


\subsection{Unausweichliche Agonalität der Philosophie}

Im Unterschied zu den oben referierten Ansätzen von Schnädelbach, Ziche und Kusch geht es hier weder um eine ideengeschichtliche noch um eine vergleichende wissenschaftshistorische oder wissenschaftssoziologische Untersuchung. Vielmehr wird untersucht, wie philosophische Selbstverständnisse in einem bestimmten Kontext jeweils konstruiert werden. Die zugrunde liegende Annahme ist, dass mit philosophischen Aktualisierungen immer auch eine Klärung der Rolle einhergeht, welche die Philosophie für die Wissenschaften spielt oder spielen möchte. »Für die akademische Philosophie ist vor allem die Klärung ihrer Stellung im Rahmen der >Arbeitsteilung` der Disziplinen des >Kosmos der Wissenschaften< von hervorragender Bedeutung « (Plümacher 1996: 7). Es wird sich zeigen, dass in allen drei Fällen eine herkömmliche Vorstellung von Philosophie als Leitwissenschaft mobilisiert und neu begründet wird. Die seit der Antike transponierte Vorstellung der Philosophie als >Königin der Wissenschaften< ist in allen drei Beispielen in je unterschiedlicher Weise anzutreffen.

In ihren Versuchen, die Philosophie auf neue wissenschaftliche Grundlagen zu stellen, klären Philosophen immer auch disziplinäre Machtverhältnisse. Sie tarieren das Verhältnis zwischen der Philosophie und anderen Wissenschaften so aus, dass sich die Philosophie in ihrem Selbstverständnis nicht nur gegenüber anderen Wissenschaften behaupten, sondern sich in spezifischer Weise über diese erheben kann. So etabliert Husserl - vorwegnehmend gesagt - die Philosophie in traditioneller Manier als Methode, die über einen privilegierteren Zugang zur Wahrheit verfügt als andere Wissenschaften. Der Wiener Kreis vermittelt die fundamentale Bedeutung der Philosophie durch die Vorstellung, mit der Klärung der Logik und ihrer sprachlichen Bedingungen würden die Grundlagen der Wissenschaften bestimmt. Und durch die Betonung der herausragenden Bedeutung von Kritik möchte die Kritische Theorie zeigen, dass die Philosophie ein notwendiges Korrektiv für andere Wissenschaften darstellt.

Philosophische Selbstbehauptungsstrategien sind mit der Stabilisierung von disziplinären Machtverhältnissen eng verknüpft. Diese Stoßrichtung verfolgt Jürg Berthold in seiner Studie Kampfplatz endloser Streitigkeiten. Studien zur Geschichtlichkeit der Philosophie (2011). Philosophische Texte werden von ihm als »Interventionen « verstanden, die sich im »Kampfplatz endloser Streitigkeiten $\ll^{16} \mathrm{zu}$ behaupten haben: als behauptendes Sich-Behaupten.

16 Die Kampfplatzmetaphorik ist an Immanuel Kant angelehnt, wie dieser sie in der Vorrede in seiner Kritik der reinen Vernunft verwendet. Berthold wendet sich gegen die Vorstellung von Kant, wonach sich diese endlosen Streitigkeiten schlichten ließen (Berthold 2011: 30-31). 
Was ein »philosophischer Text « ist, wird unter dieser Perspektive weit gefasst: Es handelt sich dabei nicht im engen Sinne um einen geschriebenen Text, sondern vielmehr um $\gg$ Performances [...], deren >Pointe $<$ darin besteht, $>$ Wahrheit « zu produzieren « (Berthold 2011: 45). Bertholds Zugang gleicht der hier eingenommenen Perspektive, wonach Texte als Labor verstanden werden, als Ort, an dem Wahrheiten produziert werden. Eine radikale Historisierung der Philosophie und das Herausstellen der grundsätzlichen Agonalität innerhalb der Philosophie sind die zentralen Stränge in seinen Überlegungen. So seien in philosophischen »Interventionen « immer auch Aushandlungen darüber enthalten, was Philosophie ist und sein soll. »Das Anliegen ist nicht der Entwurf einer Metaphilosophie; dennoch ist darauf zu insistieren, dass jedes Philosophieren auch eine Darstellung ist, was Philosophie ist. Die Arbeit redet nicht einem Relativismus das Wort; dennoch erscheint die Pluralität der Stimmen, die Wahres sagen, in ihrer Unausweichlichkeit « (ebd.: 20). Er verfolge keineswegs den Anspruch, ein philosophisches Spezialproblem zu behandeln, vielmehr ziele seine Frage letztlich auf die »Fortschrittsfähigkeit der Philosophie und damit in den Kern ihres Selbstverständnisses, wenn nicht auf die Frage ihrer Legitimität« (ebd.: 39). In Bezug auf die Frage, was sich ändern würde, wenn man den von ihm proponierten Weg einschlagen würde, schreibt Berthold: »Man würde genauer lesen, mit mehr Aufmerksamkeit auf das, was die philosophische Rede konstituiert, mit einer Neugier für die Strategien, mit denen die Narrationen zu einem Mittel ihrer Selbstbehauptung werden. Man würde über die Formen nachdenken wollen, in denen sich Akte der Selbstbehauptung vollziehen« (ebd.: 46). Eine Rede, so fährt Berthold fort,

impliziert und inthronisiert immer eine Instanz, der sie ihre Legitimität abbettelt. Aber noch in dieser Kritik hätte man ein Bewusstsein davon, dass auch die eigene Rede immer all dem unterworfen ist, was sie behauptet. Man würde sich für Grenzziehungen interessieren, weil sie unerlässlich sind. Aber die Demarkationslinien erschienen einem in ihrerWillkürlichkeit nicht als Ausdruck der Sache selbst, sondern als Effekte jener Strategien, die das Philosophieren erst ermöglichen. (ebd.: 46-47, Herv. MD)

Das »behauptende Sich-Behaupten« in der Philosophie geht laut Berthold also immer mit Grenzziehungen einher und spielt sich immer in spezifischen Kontexten ab. Der Begriff der Selbstbehauptung und der der Grenzziehung nehmen in seiner Studie Schlüsselrollen ein.

Er schlägt einen Zugang vor, der philosophische Texte in Beziehung setzt, um dadurch die grundsätzliche Historizität, Perspektivität, Agonalität 
und Pluralität philosophischen Denkens sicht- und greifbar zu machen. Er fokussiert zudem die Rhetorizität ${ }^{17}$ philosophischer Texte:

Polemische Diskussionen gehörten immer wieder zur Philosophie, sie wurden aber meist als eigenartig sekundär wahrgenommen. Das Bild, das Philosophen in diesen Situationen abgeben, scheint der Philosophie unwürdig zu sein; es ist, als würde der polemische Ton den Wohlklang philosophischer Rede stören. Ihre Sache ist, respektive scheint zu sein: der kühle Kopf, das kluge Argument, der weite Horizont. Ihr Duktus scheint sich am Ideal eines zwanglosen Zwanges in Rede und Gegenrede zu orientieren. (ebd.: 31)

Vielleicht, so Berthold, verhält es sich aber gerade umgekehrt: »Was, wenn sich in den polemischen Debatten und Interventionen etwas zeigte von der Philosophie, was sich in den gemessen [sic!] Vorstellungen von Weisheitsliebe und Rationalität gewöhnlich verbirgt? « (ebd.). Er nimmt für seine Analysen Begriffe aus der aktuellen Theoriebildung auf (Performance, Narration, Intervention, Akt, Imitation, Parodie etc.); er untersucht philosophische Texte also ausgehend von einem poststrukturalistisch verstandenen Textbegriff. ${ }^{18}$

17 Judith Butler beschreibt in ihrem Aufsatz »Kann das >Andere die Bedeutung der Rhetorizität für philosophische Argumente wie folgt: »Ein Großteil der philosophischen Arbeit, die außerhalb der Philosophie vor sich geht, ist frei, auf die rhetorischen und literarischen Aspekte philosophischer Texte einzugehen und speziell danach zu fragen, welchen besonderen philosophischen Wert diese rhetorischen und linguistischen Merkmale transportieren oder inszenieren. Die rhetorischen Aspekte eines philosophischen Textes umfassen seine Gattung, die variieren kann, die Form, in der die Argumente vorgetragen werden, und die Art, wie die Darstellungsweise das Argument selbst prägt, indem sie das Argument manchmal implizit inszeniert oder gelegentlich ein Argument inszeniert, das völlig im Gegensatz zu dem steht, was der philosophische Text ausdrücklich erklärt« (Butler 2009 [2004]: 370). Um disziplininterne Dynamiken aufzuspüren, so folgt aus Butlers Darstellung, ist die Überschreitung dieser Disziplin notwendig.

18 Wie Ziche verweist ebenfalls Berthold kritisch auf Schnädelbach, wenn auch in einem anderen Kontext: Mit Schnädelbach sei »auf einem Philosophieren in der ersten Person und auf einem pluralen Verständnis von Philosophie zu bestehen « (Berthold 2011: 26). Gleichzeitig sei gegen Schnädelbach eine zweifache Verharmlosung zu vermeiden: Erstens sei die Textgebundenheit des Philosophierens, d.h. »das Angewiesensein auf Hermeneutik im weitesten Sinne«, nicht zu trivialisieren. Und zweitens sei ein »plurales Verständnis der Philosophie nicht zu verkürzen auf ein harmloses Nebeneinander unterschiedlicher Praxen und als ein Zustand, der sich gewissermaßen von selbst klärt - sei es über die Mechanismen des Wettbewerbs, sei es durch den Streit der Argumente oder sei es durch evolutionistisch zu verstehende Gesten der Macht, die die anderen Stimmen zum Verstummen bringen« (ebd.). 
Bertholds Studie ist für die hier eingenommene Perspektive instruktiv, unterscheidet sich aber in einem wesentlichen Punkt: er zielt - so wird der Anschein erweckt und ähnlich wie Schnädelbach - darauf ab, zu verstehen, was Philosophie insgesamt ist und wie Philosophieren heute möglich ist. Er stellt fest, dass Philosophie wesentlich durch Selbstbehauptungen bestimmt ist, und erläutert dies an konkreten philosophischen Texten und deren Beziehungen zueinander. Hier hingegen soll an drei konkreten Beispielen aufgezeigt werden, wie Philosophen ihre Selbstbehauptungen - nämlich im Kontext anderer Disziplinen - begründen. PhilosophischeSelbstbehauptungen ereignen sich innerhalb des Kontextes der Gesamtwissenschaften, d.h., Philosophen schreiben sich mit ihren Erneuerungsansprüchen in die Dynamiken der Wissenschaftslandschaft allgemein ein. ${ }^{19}$

Obwohl auch das vorliegende Buch aus einer vom Poststrukuralismus geprägten Denkweise entstanden ist, wird hier weitgehend auf diese Begrifflichkeiten verzichtet. Wie weiter oben erwähnt, ist für mich der Begriff der Selbstpositionierungsstrategie (und synonym dazu der der Argumentationsstrategie) zentral. Der Begriff der Strategie ist keineswegs intentional zu verstehen, d.h., es geht nicht darum, herauszufinden, was die betreffenden Philosophen >eigentlich $<\mathrm{zu}$ sagen beabsichtigten, sondern es interessieren Taktiken und Arrangements, die im Material der Texte selbst manifest werden. ${ }^{20}$ Philosophische Argumente werden also nicht hinsichtlich ihrer kognitiven Überzeugungskraft untersucht, sondern mit Blick auf ihre soziale Funktion: Wie wird Plausibilität für die jeweilige Neubegründung erzielt? Wie stützen und legitimieren die vorgebrachten Argumente das Weiterbestehen der Disziplin? Da nicht der inhaltliche Gehalt der Texte im Analysefokus steht, sondern die darin enthaltenen Argumentationsstrategien, wird ein neuer Blick auf sie möglich: Durch die Untersuchung der je geglückten Erneuerungsansprüche werden implizit Einsichten in die Frage gewährt, warum diese Texte kanonisch geworden sind.

Durch den gewählten analytischen Zugang wird erkennbar, dass Disziplinierungsvorgänge mit der Aushandlung von Machtverhältnissen eng zusammenspielen. Das Zusammenspiel von Disziplinierung, Wissen und Machtverhältnissen hat in jüngerer Zeit insbesondere Michel Foucault an verschiedenen Untersuchungsfeldern erarbeitet. Foucault hat in seinen Büchern eine Denkweise und eine Perspektive etabliert, die den analytischen Zugang und den Aufbau dieser Untersuchung mitgeformt haben. So ist

\footnotetext{
19 Siehe dazu Fn. 201.

20 Vgl. Foucault 1977: 95-102. Für einen Überblick zum Strategiebegriff im Kontext diskurstheoretischer und -analytischer Überlegungen vgl. Wrana et al. (Hrsg.) 2014: 387-388.
} 
seine Setzung, »dass es keine Machtbeziehung gibt, ohne dass sich ein entsprechendes Wissensfeld konstituiert, und kein Wissen, das nicht gleichzeitig Machtbeziehungen voraussetzt und konstituiert« (Foucault 1976 [1975]: 39), ein permanent mitgedachter Subtext der nachfolgenden Analysen. Die Überzeugung, dass das Ausgeschlossene und Marginalisierte für das Sichtbare und Hegemoniale konstitutiv sind - und umgekehrt - und es sich lohnt, von den $>$ Rändern $<$ her zu denken, wird in den nachfolgenden Analysen gewissermaßen durchgängig leitend sein. Bei Foucault findet sich folgende, für die Konzeption des vorliegenden Buches treffende Formulierung:»Es handelt sich [bei der Geschichte des Denkens, MD] um eine kritische Analysebewegung, über die versucht wird herauszufinden, wie die verschiedenen Lösungen für ein Problem erstellt werden konnten, aber auch, wie diese verschiedenen Lösungen zu einer spezifischen Problematisierungsform gehören« (Foucault 2005 [1984]: 733). Die Philosophen, die in dieser Arbeit behandelt werden, haben je Lösungen für bestimmte Probleme gefunden, wobei das Gewicht und das Existenzielle dieser Probleme in ihren Texten nicht mehr oder nur noch als Spuren erkennbar sind. Damit jedoch die Strategien sichtbar werden, mit denen Philosophen diesen Lösungen argumentativ Geltungskraft verliehen haben, müssen auch die Probleme nachgezeichnet werden, die die Philosophen umgetrieben haben. Im Text Seidels werden sie direkt und offenkundig ausgebreitet. Daraus ergibt sich folgender Aufbau: Aus Seidels Text werden philosophieinterne >Krisen< (Problematisierungen) extrapoliert (Kapitel 2), um je an einem Beispiel herauszuarbeiten, welche $>$ Lösungen $<$ Philosophen für diese Probleme gefunden haben (Kapitel 3-5). Die Argumente von Husserl, den Vertretern des Wiener Kreises sowie Horkheimer und Adorno werden gemäß dem hier gewählten Ansatz als >Lösungen< für ein grundsätzliches Problem verstanden, nämlich dass die Daseinsberechtigung einer wissenschaftlichen Disziplin - hier der Philosophie - von anderen Disziplinen immer abhängig ist. Neue Erkenntnisse aus den Naturwissenschaften, der Psychologie und der Soziologie - so kann man aus Seidels Schrift ableiten - setzen die Philosophie unter Druck. Diese Situation der Bedrängnis wird - so machen die darauffolgenden Kapitel deutlich - von Philosophen aufgenommen und für die Neupositionierung der eigenen Disziplin produktiv gewendet. In jedem der drei Fallbeispiele wird zu Beginn mit Rückbezug auf Seidel auf eine spezifische Krise fokussiert: So steht bei Husserl die Psychologisierung des Geistes, beim Wiener Kreis der Verlust philosophischer Objektivität und bei der Kritischen Theorie der Verlust der Legitimität der Philosophie generell im Zentrum.

Wer sich in die akademische Philosophie und Wissenschaft einschreibt so eine Überzeugung, die ich in den Analysen bestätigt gefunden habe und am Schluss wieder aufnehmen werde -, verfolgt immer auch bestimmte 
Interessen. Der philosophische Blick ist nie >rein<, oder wie Donna Haraway sagt: Er ist nie unschuldig (z.B. Haraway 1988: 582 ). ${ }^{21}$ Die in dieser Arbeit geführten Auseinandersetzungen sind demnach zwingend und konstitutiv mit der Frage nach meiner eigenen Positionierung verknüpft. Diese Frage zieht sich gewissermaßen als Subtext entlang der Figur Seidel wie ein roter Faden durch den Text. Die Problematik, mit der in Bewußtsein als Verhängnis mit Vehemenz gerungen wird, nämlich die notorische Unmöglichkeit, die eigenen Wahrheitsansprüche reflexiv zu erfassen, betrifft auch das vorliegende Buch.

21 In diesem Zusammenhang ist Haraways Auseinandersetzung mit feministischen Standpunkttheorien, etwa von Nancy Hartsock und Sandra Harding, zu verstehen (z.B. Haraway

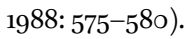




\section{Bewusstsein als Verhängnis: Philosophieinterne Krisen}

Seine Arbeit sei »aus den geistigen und politischen Kämpfen dieser Zeit entstanden « (Seidel 1927: 72). Alfred Seidel hat mit seinem Text Bewußtsein als Verhängnis einen Text verfasst, der Krisen - und in der hier eingenommenen Interpretation insbesondere philosophieinterne Krisen - am Anfang des 2o. Jahrhunderts in markanter Form nachzeichnet. Seidel, so Hugo Velarde, trage nicht nur zur Zeitdiagnose bei, sondern »ist selbst der untergehende Beweis für eine Zeit, die Verhängisvolles bereithält« (Velarde 2008: 176). Im Kontrast zu den drei folgenden Fallbeispielen (Husserl, Wiener Kreis, Kritische Theorie) verkörpern Seidel und sein Text im vorliegenden Buch jene Krisen, die Philosophen erkenntnistheoretisch zu bewältigen versuchen.

Nebst Velarde hat sich in jüngerer Zeit der Kulturhistoriker Christian Voller in Form zweier Aufsätze intensiv mit Seidel beschäftigt. Für die hier geführten Auseinandersetzungen sind Vollers wissenschaftshistorische Aufarbeitungen instruktiv, d.h., die biografischen und wissenschaftshistorischen Angaben über Seidel sowie das Bild, das rezeptionsgeschichtlich von ihm gezeichnet wurde, sind vor allem seinen Aufsätzen entnommen. Eine Besonderheit an Seidels Text ist dessen Edition: Wie erwähnt ist es der Psychiater und Kunstwissenschaftler Hans Prinzhorn, der Seidels Buch nach dessen Suizid posthum herausgibt. Es bleibt unklar, »welchen Anteil Prinzhorn bei der Edition der Arbeit hatte«, d.h., es bleibt auch unklar, ob wir es »überhaupt mit einem >authentischen<Seidel zu tun haben «(Voller 2017:84). Das Originalmanuskript gilt als verschollen; es ist demnach »unmöglich, nachzuvollziehen, wie tiefgreifend Prinzhorns Überarbeitung des Manuskripts ausgefallen ist « (ebd.: 70)..${ }^{22}$ Bereits der Sozialphilosoph Jürgen Frese, der Bewußtsein als Verhängnis 1975 für seine Antrittsvorlesung bearbeitet hat, ${ }^{23}$ spricht in Bezug auf Seidels

22 Prinzhorn schreibt im Vorwort, dass man sich »der Einsicht nicht verschließen [konnte], daß für eine Veröffentlichung die vorliegende Fassung keineswegs ohne weiteres verwendbar sei, wenn man dem Wertgehalt des Werkes zur Auswirkung verhelfen wollte. Von der urspünglichen Absicht, das Ganze oder Bruchstücke daraus mit allen Unvollkommenheiten einfach als >document humain $<$ zu veröffentlichen, mußte daher Abstand genommen werden « (Prinzhorn 1927: 8).

23 Frese ließ sein Manuskript später »trotz offenkundig erheblicher Mängel« drucken. Er betont in diesem Zusammenhang, dass weitere Publikationen zu Seidel und ein SeidelSammelband gescheitert seien (Frese 2001/o2: 61, Fn. 1). Wie Voller ausführt, fehlt Seidels 
Biografie von einer »dunklen Quellen-Sachlage« (Frese 2001/o2: 62, Fn. 5). Es sei »gut möglich, daß das im Text kondensierte Seidel-Bild hochgradig durchsetzt ist mit historisch fragwürdigen Konfabulationen Sohn-Rethels (mythisch verstärkt durch meine sicher selektiven Erinnerungen)« (ebd.). ${ }^{24}$ Ich werde Seidel im Folgenden trotz dieser Umstände selbst sprechen lassen. Da es mir analog zu den anderen Kapiteln dieser Arbeit - weder um die Intentionen des Autors noch um historische Vollständigkeit, sondern um die diskursiven Denkbewegungen jener Zeit geht, scheint mir dieses Vorgehen zulässig.

Seidels Text macht weniger den Eindruck, als ob darin Krisen diagnostiziert oder objektiviert, sondern als ob sie erfahren und durchlebt worden wären. Er legt am Anfang der Studie seine Skepsis offen, dass er möglicherweise keine letztgültigen >Lösungen< finden werde: Er gebe »keine fertigen Lösungen, sondern nur Lösungsversuche oder Andeutungen zu solchen, sowie neue Problemstellungen [...], soweit diese Arbeit überhaupt Wissenschaft sein will und nicht nur Anklage und Kritik« (Seidel 1927: 72). Ludwig Klages beginnt eine zeitgenössische Rezension von Bewußtsein als Verhängnis mit den Sätzen: »Bedeutung und Grenze des eigentümlichen Buches lässt sich mit dem einen Satze kennzeichnen: Es übt Kritik, scharfsinnig absprechende und oftmals treffende Kritik, ohne uns etwas Bejahenswürdiges nennen zu können« (Klages 1928: 629). Dass Seidels Buch kein Programm bereitstellt, wird auch von Voller betont: »Im Unterschied zu anderen Krisendiagnosen unterschiedlicher Couleur bietet Bewußtsein als Verhängnis kein Programm, dem es sich zu verschreiben lohnte, keine Rettung des im Untergang befindlichen Abendlandes, keine letzte Schlacht, die auf welchem Weg auch immer zu gewinnen sei, kein Versprechen einer kommenden Gemeinschaft« (Voller 2012: 323-324). Diese Alternativlosigkeit ist - laut Voller - einer der Gründe, weshalb Bewußtsein als Verhängnis Beachtung verdiene: Es reihe sich in die lange Reihe »alarmierender Krisendiagnosen « ein, ${ }^{25}$ um sich durch seinen

Name fast ausnahmslos »in den Biographien jener Denker, mit denen er in Kontakt stand, in den Kompendien, Überblickswerken und Einzelstudien zur (Heidelberger) Soziologie der Zwischenkriegszeit, zur frühen Kritischen Theorie und zur Geistes- und Intellektuellengeschichte der Weimarer Republik« (Voller 2012: 315). Einzige Ausnahmen sind Bernd Wirkus' Deutsche Sozialphilosophie in der ersten Hälfte des 20. Jahrhunderts (Wirkus 1996: 231-235) und Reinhard Laubes Karl Mannheim und die Krise des Historismus (Laube 2004: 418-422).

24 Gemäß Frese ist die einzige authentische Quelle von Seidels Biografie die Darstellung seines Lebenslaufes am Ende seiner Dissertation. Weiter gibt er als Quellen Prinzhorns Vorwort von Bewußtsein als Verhängnis und die mündlich überlieferten Erinnerungen Alfred Sohn-Rethels - eines Jugendfreundes Seidels - an (Frese 2001/o2: 62, Fn. 5).

25 Gemäß Christian Voller gehört Bewußtsein als Verhängnis in die lange Reihe »alarmierender Krisendiagnosen«, wie sie in den 1920er-Jahren erscheinen: Georg Lukács' 
»kompromisslosen Pessimismus « gleichzeitig von diesen zu unterscheiden: »Das Buch ist Ausdruck reiner Verzweiflung, der ohne Appell - und gewissermaßen folgerichtig in der lautlosen Selbststrangulation - verhallt; ein Aspekt, der vor allem ideen-, intellektuellen- und mentalitätsgeschichtliches Interesse verdiente« (ebd.: 323-324). Ein Text, der weder Alternativen noch »Identifikationsperspektiven « (Frese 2001/o2: 61) bereitstellt, sich aber dennoch intensiv mit den wissenschaftlichen Herausforderungen seiner Zeit auseinandersetzt, ist so selten wie aufschlussreich.

Ein weiterer Grund, weshalb Bewußtsein als Verhängnis gemäß Voller Beachtung verdient, liegt darin, dass Seidels Notizen »auf eigentümliche Weise den damals noch gültigen Zwischenstand einer geistesgeschichtlichen Entwicklung [konservieren], die von der gemeinsamen Erfahrung des Aufbruchs in der Jugendbewegung und einem geteilten Kanon literarischer und wissenschaftlicher Quellen zur Ausdifferenzierung und Aufspaltung in theoretisch wie politisch unversöhnliche Lager führte (Voller 2012: 324). Eine Gegenüberstellung von Seidels Text mit philosophiehistorisch epochemachenden Texten und Autoren erbringt den Befund, dass zeitbedingte Krisen und Herausforderungen für die Erneuerung der akademisch etablierten philosophischen Tradition einen zentralen Impetus darstellen. Ausgehend von einer Lektüre von Bewußtsein als Verhängnis lässt sich also in exemplarischer Weise aufzeigen, was in Texten, die sich primär mit Lösungen und Alternativen auseinandersetzen, meistens nur implizit vorhanden ist: die Problemkonstellationen, aus denen die Suche nach Alternativen erfolgt ist. Gleichzeitig kann deutlich gemacht werden, dass die von mir ausgewählten Philosophen ein bei Seidel auffindbares Dilemma (ich nenne es den Seidel'schen Circulus vitiosus) gar nicht erst aufkommen lassen: die Frage nach der Legitimität des eigenen Standpunkts. ${ }^{26}$

Im ersten Teil dieses Kapitels werden in knapper Form Einsichten in Seidels Schrift gewährt. Im zweiten Teil wird gezeigt, wie die zwar marginale, aber seit dem Erscheinen von Bewußtsein als Verhängnis sich kontinuierlich fortsetzende Rezeptionsgeschichte nahelegt, Seidels Text als ein extremes Beispiel für die gesellschaftliche und politische Krise der Weimarer Zeit zu verstehen. In einem dritten Teil schließlich versuche ich zu zeigen, dass Bewußtsein als Verhängnis als ein Beispiel für die Verschiebung philosophischer Themen in

Geschichte und Klassenbewußtsein (1923), Martin Heideggers Sein und Zeit (1927), Walter Benjamins Einbahnstraße (1928), Ludwig Klages' Der Geist als Widersacher der Seele (1929), Karl Jaspers Geistige Situation der Zeit (1931), Ernst Jüngers Arbeiter (1932) oder Max Horkheimers Wissenschaft und Krise (1932) (Voller 2012: 315).

26 Dieser Aspekt wird insbesondere im Kapitel zur Kritischen Theorie fokussiert. Im Fazit wird das Dilemma auf die Positionierung vorliegender Arbeit bezogen (siehe S. 198-206). 
andere Disziplinen angesehen werden kann: Der Text macht deutlich, dass sich die Philosophie am Anfang des 2o. Jahrhunderts einer Herausforderung ihrer Grundlagen gegenübersieht, indem er darlegt, dass die Inanspruchnahmen philosophischer Themen durch andere Disziplinen die Daseinsberechtigung der Philosophie im Allgemeinen infrage stellen.

\section{Unheilvolle Apologie auf die Wissenschaft: Alfred Seidels Circulus vitiosus}

»Wie kindlich optimistisch sind die Zeiten des Rationalismus in dem überschwenglichen Glauben an die Wirkungen des Erkennens; trotz aller Kritik ist noch heute das Pathos der Wissenschaft vielfach von diesem Glauben getragen « (Seidel 1927: 75). Seidel möchte in seinem Buch aufzeigen, inwiefern die zunehmende Bewusstwerdung wissenschaftlicher Zusammenhänge sowohl auf persönlich-individueller als auch auf gesellschaftlich-politischer Ebene zersetzend und zerstörend wirkt. »Wohlgemerkt greifen wir nicht den Wahrheitsgehalt der wissenschaftlichen Erkenntnisse an, sondern die Behauptung, dass sie ausschließlich die proklamierten Wirkungen auslösen « (ebd.). Angesichts der aus seiner Sicht problematischen Glorifizierung des wissenschaftlichen Fortschritts und des »Bewußtseins « stellt sich Seidel in seinem Buch wie bereits weiter oben erwähnt die Frage, »ob die Erkenntnis der sozialen und psychischen Vorgänge nicht gerade ihre Beeinflussung [der Erkenntnis, MD] unmöglich macht, zumindest hemmt - die Frage nach dem Bewußtsein als Verhängnis« (ebd.: 74).

Seidel zeigt in seinen Analysen, dass und inwiefern die zunehmende Bewusstwerdung naturwissenschaftlicher, psychologischer und soziologischer Zusammenhänge sowohl für das Individuum als auch für die Gesellschaft einen - mit Max Weber gesprochen - >entzaubernden< Effekt hat. Die »zunehmende Intellektualisierung und Rationalisierung «, so Seidel, steigere nicht die »echte allgemeine Erkenntnis der Lebensbedingungen, unter denen man steht « (ebd.: 8o). Sie bedeute im Gegenteil, »dass man alle Dinge - im Prinzip - durch Berechnen beherrschen könne« (ebd.). Unter dieser Voraussetzung untersucht Seidel die Bildung und Wirkung von Ideologien. Die Auswahl, die er diesbezüglich trifft, widerspiegelt zentrale Schlagworte der Zeit. Diskutiert werden der »Marxismus-Sozialismus«, die »Neuromantik« (unterteilt in: Gemeinschaft, Religion, das Kulturgewollte, die Natürlichkeit, das Erlebnis und die Frauenbewegung), der »Nationalismus«, der »Pazifismus« und schließlich auch die »Untergangsidee« im Sinne Oswald Spenglers (ebd. 166-202). Seidel könnte, so Jürgen Frese, problemlos als »Ahnherr« der Kritischen Theorie figurieren (Frese 2001/o2: 47). Voller nimmt diesen Aspekt 
auf und stellt Seidel explizit in den Kontext einer Vorgeschichte der Kritischen Theorie (Voller 2017). ${ }^{27}$

Dass Seidel jedoch auch die Wissenschaften, die Philosophie und vor allem seinen eigenen Standpunkt als Ideologien begreift, scheint ihn - im Unterschied zu Horkheimer und Adorno - in ein unerträgliches Dilemma zu treiben: Insbesondere im »Schluss « und im »Anhang « (»Bruchstücke aus anderen Schriften«) gleichen seine Gedankengänge einem Circulus vitiosus. »Da der Lebensfähige nur Illusionen als Weltbild haben kann, so ist dagegen der, der diese Illusionen zerstört, also der Wahrheitssadist, ein an sich lebensunfähiger, ein Selbstmördertypus, ein Instinktloser, ein Psychopath im üblichen Sinne« (ebd.: 220). Der Teufelskreis nimmt im Text immer dann seine Form an, wenn Seidel seine Analysen auf die Wissenschaft selbst bzw. auf seine eigene Stellung als Wissenschaftler rückbindet.

Seidels Dilemma korrespondiert mit dem Verlust einer >Außenperspektiveく. Denn da er sich selbst zum »Typus « des analytischen Wissenschaftlers, d.h. zu den »Wahrheitssadisten« zählt (ebd.: 31), arbeitet er ja auch selbst aktiv am individuellen und kulturellen Zerfallsprozess mit. Wie, so fragt sich Seidel, »kann man an dem eigenen Schopfe sich selbst aus dem Sumpfe ziehen" (ebd.: 212). ${ }^{28}$ Er sieht keine Möglichkeit, dem Dilemma zu entkommen: Es gebe »nichts Negativeres als das Gerede von der Positivität: der wahrhaft Positive redet nicht von ihr, braucht es auch nicht. Für den aber, der unter keinem festen Glauben steht, der also in diesem analytischen Geiste gefangen ist, was bleibt für ihn übrig, sofern er ein geistig aktiver Mensch ist? (ebd.: 203). Seidel demonstriert, dass ein solcher Mensch tatsächlich in die Bredouille gerät, denn: »Bewusster Nihilismus um des Nihilismus willen ist schon psychologisch nicht möglich, mit jedem Atemzuge verneint er diesen Nihilismus« (ebd.). Es bleibe also nur übrig, »den Nihilismus zu nihilisieren, all den Bewegungen, die unter einem Gerede von Posivität [sic!] de facto nur nihilistisch wirken, die Maske vom Gesicht zu reißen, sie zu entlarven « (ebd.). Man müsse »den Gegner in sich selbst auflösen, indem man seine eigene Theorie auf ihn anwendet« (ebd.). Seidel transponiert denselben Gedankengang auf den Bereich der Kultur. Es gälte, »den Kampf zu führen gegen die schamlose Selbstbejahung unserer Zeit um der Reinheit des Geistes und der wahren Kultur willen, sei sie auch in dieser Kultur nicht mehr möglich « (ebd.). Da für Seidel die »Reinheit des Geistes« in dieser Kultur nicht mehr zurückzuerlangen ist, besteht

$27 \quad$ Siehe Kapitel 5.1.

28 Diese Metapher wird im Fazit wieder aufgenommen. 
seine `Lösung« schließlich in einer »Nihilisierung des Nihilismus« (ebd.: 202). Man müsse »aus innerer Notwendigkeit negativ sein, aber gegen die Negativität, nihilistisch gegen den Nihilismus« (ebd.: 204). Der »Kampf« müsse somit »gegen den eigenen Typus « - gegen den »Wahrheitssadisten « - gerichtet sein, indem man »die Analyse gegen die Analyse treibt« (ebd.). Die »Sublimierung des Selbstmords«, schreibt Seidel, sei die »einzig mögliche psychische Grundlage richtiger Erkenntnisse« (ebd.: 214).

Seidel, so macht es den Anschein, reflektiert nicht nur andere wissenschaftliche Positionen, sondern versucht zugleich, seinen eigenen Standpunkt reflexiv zu erfassen. Er sucht nach Möglichkeiten, seine eigenen Gedanken und Überzeugungen zu legitimieren - und findet sie nicht. Seine Überlegungen fallen erkenntnistheoretisch gewissermaßen ins Bodenlose: Das Bewusstsein als eigenständige analytische Kategorie scheint aufgrund der Einsicht in andere Wissensformen immer wieder zu kollabieren. Mit anderen Worten: Seidels Text demonstriert die Unmöglichkeit, das Bewusstsein jenseits psychologischer und soziologischer Wirkungszusammenhänge zu denken oder zu behaupten. Folgendes Zitat verdeutlicht diesen Aspekt prägnant: »Die Entthronung der absoluten Ideen durch die Bejahung der Realitäten - heißen diese nun Leben, Macht, Sexualität einerseits oder Nation und Klasse andererseits - ist Zeichen der Auflösung der Kultur. Die Spannung zwischen Idee und Realität wird aufgehoben, die Realität selbst zur Idee erhoben [...] «(ebd.: 202). ${ }^{29}$ Das heißt, die Realitäten (im weitesten Sinne psychologische und soziologische Wirkungszusammenhänge) sind an die Stelle der absoluten Ideen (im weitesten Sinne des Bewusstseins bzw. der Philosophie) getreten. Realität (Psychologie/Soziologie) und Idee (Philosophie) fallen zusammen.

\section{Rezeption: Manifestation einer Krise}

Seidel, 1895 in Schlesien geboren, hat (nach einem Semester Medizin in Leipzig) in Freiburg, Berlin, Göttingen und Heidelberg Philosophie und Geschichte, später zusätzlich Nationalökonomie und Soziologie studiert. Vorlesungen besucht hat er u.a. bei Heinrich Rickert, Edmund Husserl, Ernst Troeltsch, Werner Sombart, Alfred und Max Weber, Karl Mannheim, Karl Jaspers und Ernst Bloch. Am Anfang der 1920er-Jahre lernte er Walter Benjamin, Siegfried Kracauer und Theodor W. Adorno kennen. ${ }^{30}$ In Freiburg war Seidel eine Zeit lang Mitglied einer Gruppe der freistudentischen Jugendbewegung. In Berlin schloss er sich dem Kreis rund um die als linksradikal,

29 Dieses Zitat wird zusätzlich auf S. 73 im Zusammenhang mit Husserls Selbstpositionierungen besprochen. 
pazifistisch und antibürgerlich geltende Zeitschrift »Der Aufbruch $\aleph^{31}$ an, und in Heidelberg (1919-1922) bildete sich rund um den Ökonomen und Soziologen Emil Lederer im Anschluss an dessen Vorlesung über die Sozialtheorie des Marxismus eine zeitweise enge Arbeits- und Lebensgemeinschaft. In Heidelberg wurde Seidel in den Vorstand und zum Leiter der wissenschaftlichen Abteilung des Sozialistischen Studentenbundes gewählt. ${ }^{32}$ Seine von Alfred Weber betreute Dissertation Produktivkräfte und Klassenkampf ${ }^{33}$ kann laut Voller durchaus als eine Schrift begriffen werden, die mit Lukács' Geschichte und Klassenbewußtsein und Karl Korschs Marxismus und Philosophie die Entwicklung und Etablierung der Kritischen Theorie prägten (Voller 2017: 84).

Seidel bewegte sich in illustren intellektuellen Kreisen. Ohne jedoch ein autorisiertes Zeugnis seines Denkens hinterlassen zu haben (Voller 1912: 313), nimmt er sich 1924 das Leben. Wie erwähnt kommt der Psychiater und Kunsthistoriker Hans Prinzhorn Seidels Ersuchen, die Herausgabe seines Buches zu veranlassen, nach. In einer Mischung aus Paternalismus und Fürsorglichkeit zeichnet Prinzhorn das Bild eines Menschen, der in akademischer Hinsicht zwar scheitert, durch seine Redlichkeit aber »moralisch siegte« (Prinzhorn 1927: 20). Bezeichnend ist die Schilderung eines Vortragsabends im Kreise Karl Mannheims, der für Seidel »denkbar ungünstig« verlief; man habe eine »zerfahrene monologisierende Sprechweise« vernommen, »ein dürres Argumentieren « und ein »Zerreden von Tatsachen«, ohne »daß der einheitliche Sinn klar geworden wäre« (ebd.). »Immerhin haben einige Teilnehmer gespürt, daß sie hier einem ehrenvollen Unterliegen beiwohnten und daß ein Unzulänglicher, aber von einem reinen Müssen Getriebener moralisch siegte - beinahe noch wo er faktisch Unrecht hatte - nur dadurch, dass er ohne praktische Interessen seine Brust darbot und sein Wort aussprach" (ebd.). In Prinzhorns Vorwort wird Seidel als eine Person beschrieben, die sich mit absoluter Ehrlichkeit, ohne Berechnung und Kalkül einer vom Schicksal auferlegten Bestimmung hingibt und sich dem akademischen Kontext schutzlos

31 Nach vier Nummern wurde die Zeitschrift 1915 durch die Zensurbehörde verboten. »Anlass für das Verbot war ein Artikel [Ernst] Joëls >Von deutschen Hochschulen<, in welchem er den geist- und gehaltlosen Patriotismus der Studierenden und akademischen Soldaten anprangerte und sich für einen aristokratischen Bildungsbegriff Fichtes, Arndts und Kleists stark machte « (Bruns 2008: 217).

32 Dazu Seidel in einem Brief (1920): »Man presste mich als einziges Renommier-Goy in den Vorstand des sozialistischen Studentenbundes, und ich bin eingetreten, und zwar als formeller Leiter der wissenschaftlichen Abteilung, gerade wo meine Wissenschaft und mein Sozialismus, also besonders mein wissenschaftlicher Sozialismus zusammenbrechen« (Seidel 1927: 32).

33 Seidels Dissertation wurde erstmals 2008 unter dem veränderten Titel Produktivität und Klassenkampf gedruckt und mit einem Vorwort von Hugo Velardes versehen. 
ausliefert. So sei der Text Bewußtsein als Verhängnis »getragen von dem durchaus einheitlichen, aus gelebten Erfahrungen strömenden Geist des ehrlichen, tapferen Ringens um Sinn und um Form des kulturellen Lebens« (ebd.: 11). Der Grund, der es zur »Ehrenpflicht« mache, das Buch posthum herauszugeben, liegt für Prinzhorn in der »Persönlichkeit« Seidels. »Es sei nämlich Alfred Seidel ein ganz ungewöhnlich reiner und klar überschaubarer Repräsentant für eine Menschenart, die für das Gesicht dieser Zeit charakteristisch und von beträchtlicher struktureller Bedeutung ist « (ebd.: 3-4). Diese Bedeutung rühre nicht nur von Seidels »typische[r] Seins- und Denkart, sondern weil eine bestimmte Einstellung zu den allgemeinen Pähnomenen des Lebens, der Kultur, der Gesellschaft ihm konstitutionell vorgegeben war, in den Zeitströmungen sich schicksalsmässig vertiefte und mit der schon fast grauenhaften Konsequenz eines nihilistischen Amor fati durchgehalten wurde bis zum Untergang - ein Selbstopfer als Warnung an den Zeitgeist « (ebd.: 4).

Auch in den zeitgenössischen Buchbesprechungen wird der exemplarische Status von Seidel und seiner Schrift ausnahmslos hervorgehoben. In einer Rezension schreibt Kracauer Bewußtsein als Verhängnis den »Rang eines zeitgeschichtlichen Dokuments « zu, »denn die gegenwärtige Situation ist in ihm exemplarisch erfahren und entschieden verworfen worden. Verworfen von einem Denker, der sich den modernen Gedanken bis zur Selbstaufgabe ausgesetzt hat « (Kracauer 2011 [1927]: 521). Auch Margarete Susman betont, dass Seidel in seinem Buch »den Charakter gerade des Bewußtseins unserer Zeit« umreiße (Susman 1927: 338). Ernst Bloch schreibt einige Jahre später (1938) in einem literarisch motivierten Aufsatz, dass »der Student Alfred Seidel [...] nur scheinbar eine abseitige Type « sei. »Er drückt vielmehr aus, was manche damals gelitten haben« (Bloch 1965: 67). Sowohl Bewußtsein als Verhängnis als auch Seidels persönliches Schicksal werden in den zeitgenössischen Rezensionen als Manifestation einer unheilvollen Situation wahrgenommen: »Und so vollzog Seidel das Gericht über seine Zeit an sich selbst. Hier schweigt die Frage nach Wahrheit oder Irrtum « (Susman 1927: 341).

Die Begriffe Wahrheit und Wahrhaftigkeit kommen in den Besprechungen auffällig häufig vor. Von »redlichem Wahrheitswillen « und einer »nicht hoch genug zu schätzenden Ehrlichkeit« ist die Rede (Klages 1928: 629) sowie von einem »neuen Werther «, den ein »selber nicht Entzauberbares « zu Tode brachte (Bloch 1965: 71). Bloch schreibt weiter: »Der Freitod des Studenten Seidel aus Alt-Heidelberg zeigt [...] mit Zuspitzung, wie damals sehr vielen jungen Menschen der bürgerlichen Intelligenz das Licht entseelt, die Wahrheit zum Ekel geworden und gemacht worden war« (ebd.: 68). Im Zusammenhang mit seiner »Wahrhaftigkeit« verkörpere Seidel sogar die Möglichkeit zum Widerstand: Im Gegensatz zu »vielen Minderen seiner Art«, so Bloch, 
rettete er sich nicht aus dem »Nichts zu den Nazis«, um dort »gläubig und gefährlich« zu werden. Gleichzeitig sei er weder vom »Münchner Fasching« eines Klages noch vom »seherischen Georgekreis « verführt worden (ebd.: 69). Bei Bloch nimmt Seidel und insbesondere dessen Selbstmord zugleich die Wendung zum Hoffnungsträger: Im Vergleich mit Goethes Werther wird Seidel hier zu einem Nihilisten stilisiert, »der weiß, was das heißt « (ebd.). Gerade ein solch wirklicher Nihilismus könne möglicherweise »zur Arbeit am keimenden Leben« führen (ebd.: 71). Einzig Kracauer verurteilt Seidels Selbsttötung, indem er diesem »Schwäche« vorhält - eine Schwäche freilich, die »aus der Enttäuschung einer ganzen Generation « stamme. Die »Unzufriedenheit mit den herrschenden Wissenschaftsübungen« hätte Seidel nicht zur Absage an die »vernunftmäßige Bewußtheit« führen dürfen, sondern »zum Kampf für die Vernunft $\ll$. Seidel habe

sehr scharf gesehen, daß die »aufgeklärten« wissenschaftlichen Lehren unserer Zeit vielfach lediglich ein Deckmantel für die sich selbst setzenden Triebe sind [...]; aber er hat nicht gesehen, daß sie die Seele und das Leben darum allein zersetzen, weil sie sich gegen die Vernunft verstocken. Von einer Bewußtheit übermannt, die gar nicht die echte ist, hat der Zerquälte das Bewußtsein überhaupt als das Übel erachtet und vor ihm sich in die Nacht zurückgezogen. (Kracauer $2011[1927]: 523-524)$

Seidel wird also bereits von seinen Zeitgenossen als eine Art verkörperter Zeitgeist wahrgenommen. »Insgesamt wurde Seidels posthum erschienenes $>$ Hauptwerk also als eine eigentümliche Verknüpfung von Theorie, Lebensabschlussbericht und epochentypischer Verzweiflung gedeutet, der eine repräsentative Bedeutung zukomme« (Voller 2017: 71).

Seidels Rezeptionsgeschichte ist in spezifischer Weise mit einer Pathologisierung verknüpft, die Prinzhorn in seinem Vorwort etabliert, aber bereits in Seidels Analysen angelegt ist: »Wieweit ist die Geisteskrankheit Bedingung zu geistigem Schaffen und warum wird sie bei dem einen fruchtbar zum geistigen Schaffen verwandt und warum bei dem andern nur in körperlichen und seelischen Symptomen erschöpft? «(Seidel 1927: 213). Seidel nimmt die für das 19. und 20. Jahrhundert zentrale Problematisierung von >Genie und Wahnsinn in seine Gedankengänge auf. Unter der Überschrift Genie und Wahnsinn (zu Kurt Hildebrandt) schreibt er beispielsweise:

Wahnsinn oder psychopathische Erscheinungen seien mehr Folge als Ursache oder Bedingung. - Unsinn! Eine conditio sine qua non. Der psychopathische Zwang als direkter Antrieb zur Produktion. Überwindung der Unlust und Sinnlosigkeitsgefühle der psychopathischen Erscheinungen; das Werk als Äquivalent. Die Sublimierung des Selbstmordes; eine Tat, um vor dieser Flucht in 
den eigenen Tod (vor den Qualen der Psychopathie) sich zu retten, bestimmt oft auch inhaltlich die Probleme. (ebd.: 214) ${ }^{34}$

Rezeptionsgeschichtlich ist es bemerkenswert, dass in Bezug auf Seidel und seinen Text zwar eine pathologisierende Komponente mitgedacht, diese aber über das Individuum Seidel hinausgehend als gesellschaftliches Krisenphänomen rezipiert wird. »Die Objektivität einer kritischen Distanznahme sollte so gerade durch den radikalen, unbedingt negativen Subjektivismus des depressiven Außenseiters ermöglicht werden, der Seidel selbst war. Theorie und Praxis fallen damit in eins und speisen sich gleichermaßen aus Veranlagung und Lebensstil «35 (Voller 2017: 79).

Die Auslegung, Seidel als eine Art >verkörperten Zeitgeist $<$ zu betrachten die Seidel selbst mit der Feststellung, dass nicht er selbst, sondern der Weltgeist in ihm dachte (ebd.: 45), angelegt hat -, wird von Georges Siegmund in den 196oer-Jahren weitergetragen. Er führt Seidels »Lebensschicksal« im Rahmen seines Buches Sein oder Nichtsein. Die Frage des Selbstmordes als einen »Beleg« an, dass »der Nihilismus in letzter Konsequenz bei der Selbstzerstörung endet [...]« (Siegmund 1970: 358). Seidel wird hier letztlich als ein typischer Fall für das »Grundleiden unserer Zeit, den Nihilismus« dargestellt (ebd.: 378). »Seidel gerät in den Sog einer Geistesströmung, welche in mächtiger Welle die nachkantische Philosophie und Weltanschauung beherrscht, wonach die Wahrheitsfrage der Religion endgültig verrammelt und nur noch eine entlarvende Psychologie möglich erscheint $[. ..] \ll($ ebd.: 367).

Eine politische Funktion nimmt Bewußtsein als Verhängnis 1979 in einer von Alfred Sohn-Rethel angeregten Neuauflage ein. ${ }^{36}$ Im Vorwort werden Seidel und sein Buch mit der linken politischen Bewegung der 1970er- bzw. 1980er-Jahre in einen Zusammenhang gebracht. ${ }^{37}$ W. Meier - der Verfasser des

34 Dem »Genie«, sagt Seidel in diesem Zusammenhang, sei es gelungen, »seine Psychopathien in seinen Lebensplan einzustellen und nicht den verflachenden Gesundmachern anheimzufallen [...]« (Seidel 1927: 214). Die gegenwärtige »Ideologie der Gesundheit und Natürlichkeit und der bewusste Kampf gegen die Psychopathien« sei einer der Gründe für die Seltenheit von »Genies in unserer Zeit« (ebd.).

35 Seidel berichtet über seine eigenen Depressionen in seinen Briefen. So etwa 1923: »Das Schrecklichste sind die durch keine äußeren Ursachen veranlassten endogenen Depressions- und Apathie-Zustände; im allgemeinen aber geht es mir psychisch bedeutend besser. Ich lasse mich nicht unterkriegen; auch kann ich sehr zufrieden sein, daß ich Menschen habe, die sich rührend um mich kümmern[,] und ich keineswegs mich als verlassen betrachten muß (Prinzhorn 1927: 33).

36 Seidel, Alfred (1927 [1979]: Bewußtsein als Verhängnis, herausgegeben und mit einem Vorwort versehen von W. Meier (d.i. Helmut Höge), Bremen: Impuls Verlag.

37 Durch die zunehmenden intellektuellen und künstlerischen Produktionen und Rezeptionen habe in der linken Bewegung eine Entwicklung eingesetzt, die soziale 
Vorwortes - beschreibt Seidel zwar als einen "politischen Seismographen«, der bereits Mitte der 1920er-Jahre »eine politische und soziale Entwicklung in Deutschland heraufziehen [sah], die Jahre später alle revolutionären Anstrengungen zur Sinnlosigkeit verurteilte«, strebt aber in keiner Weise an, aus Seidels Ausführungen theoretische Schlüsse irgendeiner Form zu präsentieren. Vielmehr wird hier der Seidel'sche Circulus vitiosus absichtlich vorangetrieben: Bewußtsein als Verhängnis werde »keine wesentlich neuen Erkenntnisse vermitteln (darin liegt ja gerade die Aktualität dieses Buches begründet), allerhöchstens, dass ihnen [den Gruppen und Zirkeln, MD] die Lektüre eine gewisse Genugtuung bereiten wird « (Meier 1979: o.S.). Seidels Projekt - das Bewusstsein mit dem Instrumentarium des Bewusstseins anzugehen - sei »weder unsinnig noch besonders neu: nicht >wer spricht?<, sondern >von wo aus« wird gesprochen? « (ebd.). Im Versuch, diese Frage zu beantworten, »könne natürlich das Problem auf den so Fragenden zurückschlagen« (ebd.). Seidel beantworte »die Frage damit, dass er Selbstmord begeht« (ebd.). Der Unsinn und die im Grunde pervertierte Sinnlosigkeit, ein Buch mit dem Titel Bewußtsein als Verhängnis überhaupt zu vertreiben bzw. zu lesen, wird zum Mittel für politischen Aktivismus. Seidel nimmt hier, wenn auch in anderer Form als in den bisherigen Rezeptionen, eine exemplarische Rolle ein: Er wird zum intellektuellen Vorzeige-Anarchisten für die Diskussionen der 198oer-Jahre stilisiert. ${ }^{38}$

Eine Besonderheit von Seidels Wirkungsgeschichte ist, dass sein Denken nicht von seinem Leben und Sterben loszulösen ist. Sein Denken zeichnet sich »auf eigentümliche Weise dadurch aus, die eigene Erfahrung und Stellung

Auseinandersetzungen immer mehr ausklammere. »Diese Entwicklung steht natürlich in dem engsten Zusammenhang mit der Profilierung eines Teils der ehemals aktiven Linken als Intellektuelle oder Künstler-Persönlichkeiten, die biographisch genau das zum Programm erheben, was sich der Leninist noch nicht einzugestehen wagte: die individuelle Karriere« (Meier 1979: Vorwort, o.S.). Diese »Hinwendung der Linken zur schönen Literatur« werde beispielsweise im Prinzip Hoffnung - »diesem scheißpathetischen Lyrismus « - manifestiert. In Bewußtsein als Verhängnis hingegen gehe es »um eine grundsätzliche Auseinandersetzung mit der Bedeutung [...] des `logos« « (ebd.).

38 Ein weiterer Bericht zu Seidel aus dieser Zeit stammt von Bettina Wassmann, Bremer Buchhändlerin: In Bezug auf die von ihr initiierte Festschrift L'invitation au voyage von 1979 für Alfred Sohn-Rethel erzählt sie: »Da ist ein Text dabei über Alfred Seidel, das war ein alter Freund von Alfred aus der Heidelberger Studienzeit, also aus den 2oer-Jahren, dieser Alfred gehörte damals schon in die Prinzhorn-Therapie, weil er unter schweren Depressionsattacken litt. Sohn-Rethel sagte immer, er habe nie jemand Schlaueren kennen gelernt, und das ohne jede Sinnlichkeit. Und der schrieb mit 23 Jahren ein Werk, das hieß >Bewusstsein als Verhängnis`« (Goettle 2005: 15-16). Darauf hätten die Gäste schallend gelacht, und Wassmann fuhr fort: »Alfred liebte ihn sehr. Eines Tages hat sich Alfred Seidel das Leben genommen. Und wisst ihr, wo? Auf dem Bahnhofsklo!« (ebd.). 
innerhalb der Gesellschaft zum Ausgangspunkt umfassender Zeitdiagnostik zu machen « (Voller 2017: 63). Insbesondere seine Selbsttötung unterstützt, dass Bewußtsein als Verhängnis als exemplarisch für die politische und gesellschaftliche Krise der Weimarer Zeit wahrgenommen wird. »Seidels Selbsttötung [...] trug Züge eines Fanals insofern, als sich objektive Krisentendenzen und individuelles Triebschicksal in ihr wechselseitig durchwirkten « (Voller 2012: 322-323). In diesem Zusammenhang steht auch die Feststellung, dass die Ahnung von Seidels Bedeutung »arkan« vermittelt werde (Frese 2001/o2: 47). ${ }^{39}$ »Arkan, das bedeutet, nicht nur abseitig und verborgen, sondern auch heimlichtuerisch und kultisch. Es schwingt da ein Ton mit, der sich dem Andenken allzu jung, zumal durch eigene Hand, Verstorbener leicht beimischt, und der stets etwas von Heiligenverehrung an sich hat« (Voller 2012: 316). Vollers Anliegen, diese Wirkungsgeschichte nicht blindlings fortzuschreiben, sondern sie selbst thematisch zu machen, wird hier geteilt: Seidel wird nicht als Prophet oder Philosoph verstanden, der die >Wahrheit< jener Zeit in tragischer Weise erfasst hat, sondern er wird als ein Autor gelesen, der zu verstehen hilft, mit welchen Herausforderungen sich Wissenschaftler und Wissenschaftlerinnen und insbesondere Philosophen und Philosophinnen in dieser Zeit konfrontiert sahen.

Gleichwohl fungiert die Figur Seidel im vorliegenden Buch nicht quasi als Antithese zu den Philosophen oder als Anti-Philosoph: An Seidel und seinem Text und an der Art und Weise, wie Biografie und Schrift kolportiert wurden, kann zugleich eine Art philosophische Wahrheitsevokation beobachtet werden: Gerade aufgrund seines >Scheiterns - exemplifiziert durch seine Biografie - erzeugt er Bedeutung und Sinn. ${ }^{40}$ Was Voller diesbezüglich als »Heiligenverehrung« bezeichnet, korreliert in der hier eingenommenen Perspektive mit der Suggestion, dass Seidel explizit für die Wahrheit gelebt hat und gestorben ist. Dies wird trotz oder wegen, jedenfalls in Kombination mit Tragik positiv kolportiert. Am deutlichsten drückt dies die Journalistin Susman aus: »Ganz bewusst wollte er [Seidel] durch diese Tat Sinn schaffen, den Sinn seines Lebens erhärten: die Analyse nicht nur für eine Person, sondern auch für seine Generation überwinden, indem er ihre zerstörende Wirkung an seiner eigenen Person aufwies« (Susman 1927: 341). Kurz: Seidels Biografie befördert die Auffassung oder Fiktion, dass er im Auftrag der Wahrheit geschrieben habe und gestorben sei: Er hatte, so wird suggeriert, keine andere Wahl. Dies

39 Bewußtsein als Verhängnis sei »ein geschmäcklerisch so genannter 〉Geheimtip« (Frese 2001/02: 47).

40 Der zentrale Aspekt, dass Seidel und sein Text eine spezifische Form philosophischer Wahrheit erzeugen, wird im Kapitel 5.4 wieder aufgegriffen (S. 180-188). 
wiederum verstärkt den Eindruck, dass das Bewusstsein (und in der hier vorgenommenen Übertragung: die Philosophie), wie es Seidel versteht, tatsächlich an einem Endpunkt angelangt ist. Seidels Rezeptionsgeschichte macht deutlich, dass philosophische >Wahrheiten innerhalb des philosophischen Diskurses oft personifiziert in Erscheinung treten. Wie erwähnt ist in keiner anderen wissenschaftlichen Disziplin die personenzentrierte Deutungsmacht derart ausgeprägt wie in der Philosophie (Schnädelbach 1983: 120). Dies verweist darauf, dass die Rückbindung der Philosophie an konkrete Personen für philosophische Erneuerungsprozesse ein notwendiges Kriterium zu sein scheint.

Sowohl die Person Seidel als auch sein Buch Bewußtsein als Verhängnis werden in der Literatur also als ein Beispiel für die kulturelle und politische Krise der Weimarer Zeit rezipiert. Diese Rezeption kann um einen weiteren Aspekt ergänzt werden: Seidels Schrift lässt sich zusätzlich als ein Beispiel für die Schwerpunktverlagerung philosophischer Themengebiete in andere Disziplinen verstehen. Erstens wird in Bewußtsein als Verhängnis greifbar, dass am Anfang des 2o. Jahrhunderts das Thema des Bewusstseins für die Naturwissenschaften, die Psychologie und die Soziologie an Bedeutung gewinnt. Und zweitens wird in diesem Text deutlich, dass die Verschiebung philosophischer Fragestellungen in andere disziplinäre Felder für die Philosophie problematisch und krisenbehaftet war.

\section{Verlust disziplinärer Standpunkte}

Seidels Schrift, so betont Frese, besitze eine "philosophiehistorisch bemerkenswerte Bedeutung « (Frese 2001/o2: 47). »Für die zukünftige Philosophiehistorie des 2o. Jahrhunderts (und für eine ganz unengagierte Ideologiekritik) bildet Seidel ein aufschließendes extremes Phänomen [...] « (ebd.: 61). Hier führe »ein Autor mit sich selbst ein Experiment durch [...], das ein Bündel von zusammengehörigen Theoremen so von den Bedingungen seiner ideologischen Rezipierbarkeit isolierte, dass eine nahezu ideologiefreie, aber zugleich unvollziehbare Synthese entstand [...]« (ebd.). Frese begreift Seidel und seinen Text folglich als eine Folie zur Untersuchung zeitgenössischer Theoriebildungen: An den jeweiligen Abweichungen vom Seidel'schen Idealtypus ließen sich Stellen identifizieren, wo diese Theorieströmungen »wesentlich Ideologien sind [...] « (ebd.). In der hier eingenommenen Perspektive ist nicht Freses Trennlinie zwischen Ideologien und Nichtideologien relevant, sondern seine Feststellung, dass Seidel für die Philosophiegeschichte des 20. Jahrhunderts eine Bedeutung besitze. Diese Bedeutung wird auch von Voller betont: »Bewußtsein als Verhängnis bietet nicht nur die Möglichkeit, das Zerbrechen und Auseinanderdriften der Kultur- und Sozialphilosophie seit Mitte 
der 1920er Jahre nachzuvollziehen, sondern könnte auch zum Ansatzpunkt für eine synthetisch orientierte Aufarbeitung dieser Geschichte genommen werden « (Voller 2012: 325). Diese Aufarbeitung wird hier zwar nicht, oder nur sehr punktuell, geleistet, die Beobachtungen von Frese und Voller stützen aber das Vorgehen, in Bewußtsein als Verhängnis philosophieinterne Krisen auszumachen, die für philosophische Erneuerungsansprüche in den 1920er-Jahren konstitutiv sind.

Seidel bezeichnet sich selbst, wie erwähnt, nicht als Philosoph, noch spricht er explizit von der Philosophie. Mit seinem Thema aber - mit der Frage nach dem Bewusstsein - begibt er sich in das philosophische Kernthema per se. Gerade weil er sein Themengebiet nicht vorgängig disziplinär eingrenzt, ist sein »philosophisches Durcharbeiten « (Voller 2012: 324) so aufschlussreich. Es offenbart dadurch nicht nur den »Zwischenstand einer geistesgeschichtlichen Entwicklung « (ebd.), sondern den einer philosophieinternen: Insbesondere die bereits zitierten Schlusspassagen aus Bewußtsein als Verhängnis verdeutlichen, wie die Erkenntnisse aus neu entstehenden Disziplinen traditionell philosophische Topoi infrage stellen: etwa die Identifikation von Wahrheit mit dem >reinen< Geist (darauf reagiert vor allem Husserl), die Infragestellung der Metaphysik als einer Wissenschaft (darauf reagiert vor allem der Wiener Kreis) oder die positive Wertung einer fortschrittlichen Vernunft (darauf reagiert vor allem die Kritische Theorie).

Ein genauer Blick auf Seidels Fragestellung hilft zu verstehen, vor welchen Herausforderungen Philosophen und Philosophinnen zu Beginn der 1920erJahren stehen, wenn sie den Wahrheitsanspruch ihrer eigenen Disziplin neu zu begründen und zu legitimieren versuchen: Auf der einen Seite stellt Seidel die Frage nach dem Bewusstsein ausgehend von den Erkenntnissen der neu entstehenden Wissenschaften: »Wir stehen also mit den Verteidigern der Wissenschaft auf dem Standpunkt, dass die Welt des Sozialen und Psychischen - innerhalb gewisser Grenzen - erkennbar sei, und dass schon vieles erkannt wurde « (Seidel 1927: 74). Auf der anderen Seite wiederum stellt er die Frage nach der Reflexion auf diese Wissenschaften: $»$ Wir stellen demgegenüber die Frage, ob die Erkenntnis der sozialen und psychischen Vorgänge nicht gerade ihre Beeinflussung unmöglich macht, zumindest hemmt - die Frage nach dem Bewußtsein als Verhängnis« (ebd.). In der hier angestrebten Lektüre können in Seidels Text zwei Ebenen der Analyse unterschieden werden: Einerseits stellt er seine Frage nach dem Bewusstsein ausgehend von den Erkenntnissen aus anderen Wissenschaften, andererseits aber hat er den Anspruch, diese Erkenntnisse zu reflektieren bzw. zu kritisieren. Er nimmt, mit anderen Worten, (neue) Erkenntnisse aus anderen Wissenschaften in seine Reflexionen über diese Wissenschaften auf. Aber er >scheitert< an diesem Anspruch. Denn 
von welcher Warte aus - so das Dilemma - können wissenschaftliche Erkenntnisse kritisch reflektiert werden, wenn sie zugleich umstandslos als gültig anerkannt werden? ${ }^{41}$ Seidels Circulus vitiosus kann folglich dahingehend interpretiert werden, dass er keine philosophische Position einnimmt, von der aus er eine metawissenschaftliche Reflexion vollziehen könnte. Seine Analysen verfangen sich beständig in naturwissenschaftlichen, psychologischen und soziologischen Begründungsversuchen, ohne dass diese stringent durchgeführt werden könnten (Wirkus 1996: 235). Die Krisen, die in Bewußtsein als Verhängnis manifest werden, sind die Verluste genuin philosophischer Standpunkte infolge der Erkenntnisse aus anderen Wissenschaften. Seidels Schrift verdeutlicht in diesem Zusammenhang, dass philosophisches Denken prekär sowie unsicher ist und sich innerhalb des Systems der Gesamtwissenschaften immer wieder neu zu behaupten hat.

Seidel, dies sei erneut betont, beschreibt diese Krisen nicht in systematischer oder objektivierter Weise. Die Krisen äußern sich anhand seiner Thematik, seines Schreibstils und seiner Gedankengänge, in denen er die Reflexion auf sein eigenes Denken nicht außen vor lässt. Der Text ist einerseits an den akademischen Gepflogenheiten seiner Zeit orientiert, bricht diese andererseits aber an genau jenen Stellen, wo wissenschaftliche Wahrheitsansprüche hinterfragt werden. Diese Eigenheit auf der textuellen Ebene vermag es, genau jene Unsicherheiten, Brüche und Widersprüche sichtbar zu machen, von denen in der Philosophie häufig nur als Gegenstand die Rede ist. Indem der Text immer wieder an seinen eigenen Ansprüchen scheitert, stellt er aus, dass philosophisches Denken fragil und gefährdet sein kann.

In den nachfolgenden Kapiteln wird an unterschiedlichen Beispielen dargelegt, wie Philosophen diese Prekarität in Anspruch nehmen, um philosophische Standpunkte argumentativ zu behaupten bzw. neu zu etablieren. Wie deutlich geworden ist, sind Philosophen und Philosophinnen am Anfang des 2o. Jahrhunderts mit der Aufgabe konfrontiert, jene Erkenntnisse aus anderen Wissenschaften aufzunehmen und zu reflektieren, die die Existenzberechtigung der Philosophie infrage stellen, und sie sind gleichzeitig gefordert, die Existenzberechtigung der Philosophie als eigenständige Disziplin neu zu begründen. Indem sie ihre eigene Position mit den neuen Herausforderungen aus anderen Wissenschaften anreichern, delegitimieren sie die Infragestellung

41 Voller schreibt, dass sich Seidel, wie die Autoren der Dialektik der Aufklärung, in eine argumentative Bredouille manövriere: »Von welcher Warte aus kann derjenige Kritik am wissenschaftlichen Fortschritt üben, der weder Feind des Fortschritts ist, noch grundsätzlich leugnet, dass der wissenschaftliche Fortschritt gültige Erkenntnisse liefert, also tatsächlich Fortschritt ist?« (Voller 2012: 318). 
ihrer eigenen Disziplin und evozieren dadurch neue, genuin philosophische Standpunkte. Das heißt, es wird sich zeigen, dass die untersuchten Philosophen sich gezielt mit den Angriffen aus anderen Wissenschaften auseinandersetzen und diese Auseinandersetzungen dafür nutzen, historisch gewachsene Selbstverständnisse der traditionellen Philosophie zu reaktivieren. Es wird sich auch zeigen, dass die daraus enstehenden Neupositionierungen untrennbar mit einem Anspruch auf Allgemeingültigkeit und Objektivität einhergehen. Besonders kompakt werden diese Zusammenhänge im disziplinären Selbstverständnis der Philosophie an einer Textstelle des Neukantianers Heinrich Rickert ersichtlich. Bevor im nächsten Kapitel als erstes Beispiel Husserls Selbstpositionierungsstrategien näher umrissen werden, lohnt ein kurzer Exkurs zu dieser Textstelle - erwähnt sei auch, dass Seidel bei Rickert Vorlesungen besucht hat und diesen als "raffinierten Impressionisten « (Prinzhorn 1927: 54) bezeichnet haben soll, aber Distanz wahrte: »Von Rickerts schön gefügtem System und seiner bestechenden Dozierweise ließ er sich keineswegs fangen $\ll($ ebd. $) .42$

\section{Das Weltganze zum Gegenstand machen}

In seinem Aufsatz »Vom Begriff der Philosophie« fragt Rickert: »Weshalb reden die Philosophen so viel von dem Begriff ihrer Wissenschaft, statt wie andere Forscher an die Bearbeitung ihrer Probleme zu gehen?« (Rickert 1910/11: 1). Rickert gibt folgende Antwort: Weil die Philosophie »das Ganze zu ihrem Gegenstande zu machen hat«, sich dieses »Ganze« aber aufgrund der ständigen Entwicklung der Einzelwissenschaften immer wieder verändere, müsse die Philosophie auch laufend sich selbst neu bestimmen und definieren. »Da die Spezialforschung Teile desselben Ganzen behandelt, muss mit ihrer Entwicklung und Ausbreitung der Begriff der Philosophie, die ursprünglich alle Wissenschaften einschloss, wechseln, und außerdem lassen sich nur von Teilen der Welt vor ihrer eingehenden Untersuchung Begriffe bilden, die bestimmt genug sind, um das Gebiet einer Wissenschaft eindeutig abzugrenzen« (ebd.). Die Einzelwissenschaften behandeln gemäß Rickert also jeweils einen Teil der Welt, die Philosophie jedoch die Welt in ihrer Totalität: »Was das Weltganze ist, gehört zu den Fragen, die erst von der Philosophie selbst beantwortet werden können « (ebd.). Dieser Gedankengang Rickerts zeigt beispielhaft, dass erst durch die Verhältnisbeschreibung

42 »Er [Seidel, MD] fühlte deutlich die journalistisch-popularphilosophische Routine, mit der R. [Heinrich Rickert, MD] die philosophiegeschichtliche Leistung seines Lehrers Windelband zu Kollegsensationen aufzog. Er spürte das verhängnisvolle Vorbeigehen an der Problematik« (Prinzhorn 1927: 54). 
zu den Einzelwissenschaften ein bestimmtes philosophisches Selbstverständnis erzeugt wird: Die Philosophie ist jene Wissenschaft, deren Gegenstand das »Weltganze« ist. Rickerts Frage deckt sich mit einem Interesse der nachfolgenden Kapitel: Warum reden Philosophen so viel von ihrer eigenen Disziplin? Welche Funktion hat diese Rede ${ }^{43}$ Rickerts Antwort jedoch weicht in drastischer Weise von der hier eingenommenen Perspektive ab: Wo er aus der Frage eine Bestimmung für die Philosophie ableitet, nämlich die Welt in ihrer Ganzheit zu erfassen, soll es hier um die Funktion solcher Bestimmungen für die Selbstdefinition der Philosophie gehen. Rickerts Gedankengang wird hier also gewissermaßen umgedreht: Durch ihre gezielte Auseinandersetzung mit anderen Wissenschaften, so die argumentative Stoßrichtung, aktualisieren Husserl, die Vertreter des Wiener Kreises sowie Horkheimer und Adorno je Positionen, die vorgeben, das »Weltganze« erfassen zu können.

43 Dass Philosophen das Selbstverständnis ihrer eigenen Disziplin zum Gegenstand von philosophischen Diskussionen machen, gehört selbst wiederum zum Selbstverständnis der Philosophie. »Manchmal scheint deren Arbeit [der Fachleute, MD] sich entsprechend im Streit um das Selbstverständnis der eigenen Wissenschaft zu erschöpfen« (Lembeck 2010: 13). 


\title{
Edmund Husserl: Abgrenzung
}

\author{
Wir stoßen damit auf eine Wissenschaft - von deren Umfang die Zeitgenossen \\ noch keine Vorstellung haben - die zwar Wissenschaft vom Bewusstsein und doch \\ nicht Psychologie ist, auf eine Phänomenologie des Bewußtseins gegenüber einer \\ Naturwissenschaft vom Bewußtsein. \\ Edmund Husserl, Philosophie als strenge Wissenschaft (1910/11)
}

\subsection{Herausforderung: Psychologisierung des Geistes}

Es sei, so schreibt Seidel in Bewußtsein als Verhängnis »eine methodisch notwendige Illusion der Psychologen, eine ewig gleichbleibende menschliche Seele anzunehmen und sich gegen eine historische Relativierung dieser Voraussetzung für die Allgemeingültigkeit ihrer kultur- und religionspsychologischen Untersuchungen mit allen Mitteln zu sträuben« (Seidel 1927: 118). Seidel bezeichnet die Annahme, dass die Seele keinem historischen Wandel unterworfen sei, zwar als illusionär, aber für die Psychologie als methodisch notwendig, denn »jede Wissenschaft muß schon aus einem natürlichen Selbsterhaltungswillen so für ihre Voraussetzungen kämpfen« (ebd.). Seine Auseinandersetzungen mit der Psychologie und der Psychoanalyse in Bewußtsein als Verhängnis erzeugen den Eindruck, dass er mit diesen Zugängen erkenntnistheoretisch in einen Teufelskreis gerät: »Je mehr man zwar Psychologie [...] mit Psychologie austreiben will, desto mehr wird man ja selbst psychologisch verseucht durch den Gebrauch der Psychologie. Den Teufel durch den Beelzebub, den obersten der Teufel auszutreiben: höchste Teufelei!« (ebd.: 212 $)^{44}$ »Das Wahrheitsproblem«, so treibt Seidel seinen Gedankengang weiter, »hat mit Psychologie nichts zu tun « (ebd.: 213).

In der erwähnten Passage in Bewußtsein als Verhängnis - es ist nur eine der vielen Stellen, die von dieser Problematik handeln - wird exemplarisch deutlich, dass die Wahrheitsansprüche der empirischen Psychologie ${ }^{45}$ und jene der Philosophie am Anfang des 2o. Jahrhunderts im Widerstreit waren. Die

44 Eine Kapitelüberschrift lautet: »Versuch einer Erklärung: Freud contra Freud« (Seidel 1927: 90).

45 Wie deutlich werden wird, legen Seidels Ausführungen nahe, dass nebst der empirischen Psychologie auch die Psychoanalyse für die Erneuerung philosophischer Standpunkte konstitutiv ist. Erarbeitet wird dies vor allem am Erneuerungsanspruch der Kritischen 
Kernpunkte der Problematik, die sich aus dem disziplinären Streit zwischen Philosophie und Psychologie ergeben und die bei Seidel in aller Schärfe zum Ausdruck kommen, werden in diesem Kapitel weiter nachgezeichnet. Dabei wird auf einen Protagonisten fokussiert, nämlich Edmund Husserl, der Ende des 19. und Anfang des 2o. Jahrhunderts zentrale Beiträge zu dieser Debatte geleistet hat. Mit ihm - so könnte man abgekürzt sagen - wurde der Kampfbegriff des Psychologismus nicht nur popularisiert, er wurde akademisch salonfähig. Bevor weiter - ausgehend von Seidel - auf Husserls Strategien in diesem Widerstreit eingegangen wird, muss ein Blick auf die Historiografie der Philosophie geworfen werden. Wie - so stellt sich die Frage - wird die Trennung zwischen Psychologie und Philosophie in der Philosophie dargestellt?

\section{Ein konstruktives Problem für die Philosophie: Psychologismus}

In der traditionellen Philosophiegeschichtsschreibung wird die Abtrennung der Psychologie von der Philosophie üblicherweise als ein einseitiger Emanzipationsprozesses dargestellt: ${ }^{46}$ Demnach habe sich die Psychologie - als Stichdatum gilt Wilhelm Wundts Gründung des ersten experimentellen psychologischen Instituts in Leipzig im Jahr 1879 - von der Philosophie kontinuierlich losgesagt und sich dadurch zu einer eigenständigen Disziplin entwickelt. Wie jedoch etwa Nicole D. Schmidt in ihrer Studie Philosophie und Psychologie. Trennungsgeschichte, Dogmen und Perspektiven (1995) verdeutlicht, handelt es sich bei diesem Prozess nicht um eine einseitige Emanzipationsbewegung: Auch die Philosophie musste sich fragen, »wie sie ihre psychologische Leerstelle füllen will « (Schmidt 1995: 9). Schmidt fokussiert somit die gegenseitige Irritation beider Disziplinen und hebt in ihrer Studie die wichtigen Rollen hervor, die in diesen Abgrenzungsprozessen Wundt und Husserl zukommen: »Das ohnehin nicht sehr gefestigte akademische Selbstbewusstsein der jungen Psychologie war durch Husserls >Logische Untersuchungen< mächtig irritiert worden. Wundt reagiert erst 1910, aber in der Vorgehensweise ähnlich wie zuvor viele Kollegen: Er sucht nach Inkonsistenzen in Husserls Konzept « ${ }^{47}$ (ebd.: 93).

Theorie. Hier werden lediglich die Erneuerungsstrategien fokussiert, die entlang der empirischen Psychologie sichtbar werden.

46 Ausnahmen sind etwa: Rath 1994; Kusch 1995/200o; Schmidt 1995; Jahnke et al. 1998; Dale 2003; Ziche 2008; Kaiser-el-Safti 2011.

47 Wundt selbst jedoch hat sich vehement gegen eine Trennung beider Disziplinen ausgesprochen. »Gerade darin, daß die Psychologie eine Teilwissenschaft der Philosophie und zugleich eine empirische Geisteswissenschaft ist, liegt ihr Wert für beide Teile, für die Philosophie wie für die empirischen Einzelwissenschaften, die hauptsächlichste Vermittlerin zwischen beiden zu sein « (Wundt 1913: 32). Wundt fordert, dass sich Philosophie und Psychologie gegenseitig ergänzen, sich aber keinesfalls voneinander abkoppeln sollten: »Wenn die Auseinandersetzung mit der Erkenntnistheorie den Anfang einer jeden 
Wundt, zu seiner Zeit ein bedeutender und berühmter Philosoph, wird heute kaum mehr als Philosoph, sondern als Begründer der empirischen Psychologie rezipiert.

Auch Martin Kusch betont in Psychologism. A Case Study in the Sociology of Philosophical Knowledge (Kusch 1995) die zentrale Rolle beider Autoren. Allerdings moniert er, dass in der traditionellen Philosophiegeschichte Husserl (und Gottlob Frege) quasi als isolierte Einzelkämpfer gegen den Psychologismus - also gegen die Meinung, dass erkenntnistheoretische Grundlagen auf empirische Gesetze der Psychologie rückführbar sind - dargestellt werden. Es sei überraschend (und falsch), wenn z.B. Herbert Schnädelbach schreibe, dass der Psychologismus seit der Jahrhundertmitte bis weit in unser Jahrhundert - gemeint ist das 20 . Jahrhundert - als communis opinio der Philosophen gelte, gegen die Frege und Husserl ziemlich isoliert angekämpft hätten (vgl. Kusch 2000: 18). Vielmehr sei der Psychologismus zwischen ca. 1880 und 1920 ein Thema, das die gesamte deutsche Philosophielandschaft intensiv umgetrieben habe. Beinah jeder Philosoph habe den jeweils anderen in unterschiedlichen Weisen des Psychologismus bezichtigt (ebd.: 17-18). Darüber, was Psychologismus ist, wer ihn betreibt und in welchen philosophischen Gebieten er stattfand, herrschte am Anfang des 20. Jahrhunderts also alles andere als ein Konsens: »Additionally, there were also many seperate criteria for psychologism in ethics and aesthetics that I shall not list here. Given these lists it becomes understandable that it was close to impossible for a philosopher in turn-of-century Germany to avoid being charged with psychologism « (ebd.: 18). Kusch macht deutlich, dass die Debatten rund um den Psychologismus mit dem politisch motivierten Kampf um Lehrstühle für die experimentelle Psychologie (als deren berühmtester Akteur Wundt gilt) zusammenhingen. »To understand why philosophers of that period were so eager to unmask their colleagues as advocates of psychologism, we have to turn to the central santidiscipline < of philosophy in this period, that is, experimental psychology« (Kusch 2000: 18).

wissenschaftlichen Psychologie bildet, die nicht auf der Oberfläche zufällig aneinandergereihter Beobachtungen stehen bleiben will, so mündet letzten Endes die Psychologie notwendig in jene Zweiggebiete der Philosophie ein, und nur dadurch kann sie mit Recht den Anspruch erheben, eine Grundlage der Geisteswissenschaften überhaupt zu sein« (ebd.). Obwohl Wundt sich also gegen die Trennung beider Disziplinen gewehrt hat, wird er rezeptionsgeschichtlich zu einer Projektionsfläche gegen den $>$ Psychologismus $<$, gegen die Vorstellung also, wonach die Logik und die Erkenntnistheorie auf empirische psychologische Gesetze reduziert werden können. Wie angesprochen werden diesbezüglich vor allem Wundts »großer Antipode« (Schnädelbach 1983: 126) Husserl als auch Gottlob Frege genannt. 
Das Bestreben, die experimentelle Psychologie als ein Teilgebiet der Philosophie zu verstehen (bzw. traditionelle philosophische Lehrstühle in Lehrstühle der experimentellen Philosophie umzubesetzen), sei in verschiedenster Weise attackiert worden. ${ }^{48}$ Für die Vielfalt der Argumente des Psychologismus waren, so Kuschs Argumentation, letztlich die »pure< philosophers « selbst verantwortlich, da sie sich einerseits in unterschiedlichen Weisen bemüht hätten, sich von der experimentellen Psychologie abzugrenzen: »On the one hand, their authors tried to show that experimental psychology was a natural science like physiology, or rather, that it was nothing but physiology « (ebd.: 20). Andererseits seien diese Abgrenzungen mit der Durchsetzung des jeweils eigenen Anliegens verknüpft gewesen: »On the other hand, every philosopher tried to set his own project enterprise, and by accusing others of being closet psychologicists « (ebd.). Daraus kann gefolgert werden, dass die Philosophen die Argumente für und gegen den Psychologismus selbst hervorgebracht haben: $»[\ldots]$ the plethora of criteria for psychologism was the result of pure philosophers' respective attempts to translate the >pure< philosophical community's interest in defending >pure< philosophy into an acceptance of their respective projects. Little suprise therefore that so many were both accuser and accused « (ebd.).

Vor dem Hintergrund von Kuschs Argumentation ist es erstens bemerkenswert, dass in der traditionellen Philosophiegeschichte, wenn es um das Psychologismusproblem geht, vorwiegend Husserl und Frege herangezogen werden und impliziert wird, diese hätten dieses aus der Psychologie stammende Problem gelöst. Zweitens ist es bemerkenswert, dass diese weitläufigen und intensiv geführten Diskussionen im Namen einzelner Personen (hier Husserl

48 Wundt reagiert 1913 mit seinem Text Die Psychologie im Kampf ums Dasein auf die umkämpften philosophischen Lehrstühle. »Die Philosophen sehen sich augenscheinlich in ihrem Besitzstand gefährdet: je weniger ihnen die neueren psychologischen Forschungsmethoden sympathisch sind, da sie außerhalb des Gesichtskreises ihrer eigenen Arbeit liegen, um so mehr sehen sie in den experimentellen Psychologen Eindringlinge, die den Lehrbetrieb der Philosophie und die emporstrebenden Dozenten der eigentlichen Philosophie benachteiligen. Sie betonen daher mit großer Emphase die Selbständigkeit der experimentellen Psychologie, empfehlen diese sogar den Regierungen zur geneigten Berücksichtigung; aber der Schwerpunkt ihrer Wünsche liegt doch in der mehr negativen Forderung: hinaus mit der Psychologie aus der Philosophie! Ganz anders die Psychologie, die fernerhin nur Psychologen sein wollen und sich von der Beschäftigung mit der übrigen Philosophie von Amts wegen befreit sehen möchten. Ihnen ist es wirklich um die Selbständigkeit der Psychologie zu tun. [...] Die experimentelle Psychologie fordere ihren Mann ganz, eine Spaltung seiner Arbeit nach beiden Seiten, der psychologischen und der philosophischen, würde eine unerhörte Belastung für den Psychologen sein. Hier lautet die Devise im Grunde umgekehrt wie oben: hinaus mit der Philosophie aus der Psychologie!« (Wundt 1913: 2-3). 
und Frege) ausgeklammert werden. Diese gingen, mit anderen Worten, als \Sieger aus dieser Debatte hervor. Das heißt auch, die Personifizierung philosophisch gewichtiger Argumente gegen den Psychologismus geht mit der Bestimmung einher, was der Psychologismus in philosophischer Hinsicht überhaupt ist: »Before the publication of Husserl's criticism, the word >psychologism< had been used somewhat vaguely« (ebd.: 22). Erst durch Husserls Texte, so Kusch, wäre der Begriff Psychologismus operationalisiert worden. Verkürzend ist Kuschs Antwort auf die Frage, weshalb aus dieser vielfältigen und kontroversen Debatte plötzlich einzelne Autoren und einzelne Argumente hervorgegangen seien, diese: »[...] Husserl's Prolegomena was very much a rhetorical masterpiece; the way the arguments were put was such that it simply forced others to react« (ebd.). Husserls Argumente - laut zeitgenössischen Reaktionen auf Husserl seien diese längst überkommen bzw. von anderen (z.B. den Neukantianern) übernommen worden - wurden in einer rhetorisch äußerst geschickten Weise arrangiert, sodass sie quantitativ Reaktionen anderer Philosophen initiiert haben.

To sum up: Husserl's Logical Investigations became the focus of attention in the border dispute between psychology and >pure it provided pure philosophers with a powerful argumentative weapon - both against each other and against experimental Psychology - but also because no one accused of psychologism could afford to ignore the accusation. Others could try, and indeed did try, to turn the charge back against Husserl himself, but whatever the style and direction of the various reactions, in subsequent generations of publications, Husserl's text could not be left unnoticed. (ebd.: 22-23)

In Kuschs Perspektive konnten die Argumente, wie sie Husserl in den Logischen Untersuchungen vorgebracht hat, im Kontext der damaligen Psychologismusdebatte schlicht nicht mehr ignoriert werden. Kusch betont also die Wichtigkeit des Kontexts, aus dem Husserl seine Argumentationen entwickelt hat: Husserls - für die Philosophie des 20. Jahrhunderts bahnbrechenden - Argumente, die darin münden, dass die theoretischen Fundamente der normativen Logik nicht empirisch-psychologischer Natur sind, resultierten aus dem Kontext der von Philosophen und Psychologen gleichermaßen geführten Psychologismusdebatte.

Auch Seidel hat Husserl nicht ignoriert: Er hat während seiner Freiburger Zeit bei ihm Vorlesungen besucht. ${ }^{49}$ Obwohl er Husserls Argumente also gekannt haben muss, lösten diese das Problem einer Psychologisierung des Geistes aus seiner Sicht aber nicht. 1916 und 1918. 


\section{„Der Geist als Sublimierung des hypertrophierten Trieblebens"}

Seidel zeichnet in Bewußtsein als Verhängnis die für das 20. Jahrhundert zentrale Herausforderung nach, nämlich dass psychologische und psychoanalytische Perspektiven die Unabhängigkeit des menschlichen Geistes und damit die Wissenschaft als eine potenziell unabhängige und potenziell >gute< Instanz grundsätzlich infrage stellen. Es sind u.a. die Psychologie, die zugespitzt - den Menschen insgesamt auf psychologische Prozesse zurückführt, und die Psychoanalyse, die den Geist als von einem unbewussten Trieb bestimmt sieht, die Seidels Überlegungen antreiben. »Die formale Struktur des Denkens ist der Ausdruck der seelischen Struktur des Erkennenden. Das gilt für den einzelnen Menschen, für Gruppen, für ganze Kulturen und Völker« (Seidel 1927: 123). Die »seelische Struktur « formiere also das Denken und nicht umgekehrt. »In dem Bewußtmachen an sich nicht bewußter Einstellungen und seelischer Vorgänge besteht die Haupttätigkeit des reflektierenden und analysierenden Bewußtseins [...] (ebd.: 125). Gleich im Anschluss an diesen Satz folgt emphatisch: »Wir betonen: dieses Bewußtsein ist selbst Symptom einer Kulturentwicklung, nämlich der Phase der entzauberten Psychologie bei einem Volke oder bei einzelnen Individuen« (ebd.). Das Bewusstwerden psychischer Prozesse wird von Seidel also dezidiert historisiert. Weil psychologische Erkenntnisse vorherrschend geworden seien, sei die Gegenwart eine Phase der Entzauberung. Wissenschaftliche Fortschrittsgedanken sind Seidel fremd:

Man wende nicht ein, daß die Schäden des Analysierens durch die bisherige Unzulänglichkeit unseres psychologischen Wissens und unseres praktischen Könnens bedingt seien. Vielmehr kann man behaupten, daß schon zu viel erkannt wurde. Wenn die Folgen noch relativ harmlos erscheinen, so verdanken wir dies lediglich der Tatsache, daß unser verhängnisvoll bewußtes analysierendes Durchschauen psychischer und sozialer Zusammenhänge sich vorläufig noch wenig entfaltet und verbreitet hat. (ebd.: 9o)

Seidel stellt die Psychologisierung bzw. Soziologisierung ${ }^{50}$ des Geistes als ein Problem dar, ohne dass er dieses aufzulösen beansprucht. Der Geist erscheint als eine Krankheit bzw. als Sublimation des (männlichen) Sexualtriebes. »Der Mensch ist ein an der Hypertrophie erkranktes Tier, an Satyriasis erkrankter Affe [...]. Wenn Geist die Sublimierung des hypertrophierten Trieblebens darstellt, ist Geist deshalb die schlimmste Krankheit der Tierspezies Mensch« (ebd.: 216).

$50 \quad$ Seidel nennt die Psychologie und die Soziologie häufig im Zusammenhang. Analog zur Psychologie sieht er auch in der Soziologie das Problem, dass diese den Geist als von sozialen Strukturen bestimmt sieht. Dieser Aspekt wird im Kapitel zur Kritischen Theorie fokussiert. 
Wie angesprochen beschäftigt sich Seidel in einzelnen Gedankengängen mit dem Zusammenhang zwischen Geisteskrankheit und wissenschaftlicher bzw. künstlerischer Produktion: Die Psychopathie, schreibt er, sei eine »Bedingung geistigen Schaffens, nicht aber der geistigen Begabung «(ebd.: 213). Es gebe »sehr viele begabte Menschen, die nie zu innerlich ernster Produktion kommen, weil sie nicht psychopathisch sind - weil der psychopathische Zwang nicht besteht «(ebd.). Bei vielen Menschen sei die geistige Produktivität in der Jugend lediglich »eine Neurose aufgrund der verdrängten Sexualität, die sie antreibt, sobald sie aber (bes. durch Heirat) diese Sexualität und Erotik nicht mehr zu verdrängen brauchen, verschwindet die Neurose, damit aber auch der Zwang zur Produktion und die Produktivität hört auf« (ebd.). Dies sei ein »psychischer Grund, warum so viele Produktive an ihrer Heirat zerbrechen, als Produktive - denn rein psychisch sind sie ja gesund geworden « (ebd.). Wissenschaft und Kunst werden von Seidel letztlich als Flucht, als Rettung vor dem Selbstmord interpretiert (ebd.: 214). ${ }^{51}$ In diesem Zusammenhang demonstriert er die Sublimierung des Selbstmordes als »die einzig mögliche psychische Grundlage richtiger Erkenntnisse« (ebd.).

\section{Ein »ausgesprochener Denkertyp «}

Obwohl Seidel, wie erwähnt, bei Husserl Vorlesungen besucht hat, übernimmt er dessen Lösung des Psychologismusproblems - in aller Kürze: dass logische Begriffe eigenständige und normative Kategorien sind - nicht. Eine mögliche Erklärung dafür ist, dass Seidels Interessen nicht philosophisch im engeren Sinne sind: Husserl stellt für Seidel mehr ein Forschungsobjekt denn einen Überbringer erkenntnistheoretischer Lösungen dar. Eine biografische Anekdote zu Seidel, die Prinzhorn in seinem Vorwort zu Bewußtsein als Verhängnis überliefert, legt dies zumindest nahe. In dieser Anekdote schildert ein Freund von Seidel ${ }^{52}$ dessen Eindruck von der Figur und dem Philosophen Husserl:

Und so war er [Seidel, MD] gegen Husserl, der im Sommersemester 1916 nach Freiburg übersiedelt war, viel aufnahmsbereiter [als gegenüber Rickert, MD] ... Er spürte den radikalen Umschwung der phänomenologischen Erkenntniskritik, die ehrliche Nüchternheit, sachliche Strenge und vielseitige Fruchtbarkeit dieser analytischen und logischen Methode, die eigenartige Kraft der Verbindung von psychologischer, geistesgesetzlicher und metaphysischer Motivation. [...] In Husserl erlebte er den ausgesprochenen Denkertyp, der ihm später so oft als charakteristisches Objekt und im Rahmen seiner kulturkritischen Arbeiten 
beschäftigte. Der Prototyp des Denkers, wie er ihn 1924 klar vor sich sah und mir in gelegentlichen Debatten auch an anderen Studiengenossen beleuchtete: schöpferisch, original, unbedingt sachlich, unanimalisch, einseitig, amusisch und je weniger sich dessen bewußt, umso besser. (Prinzhorn 1927: 54-55)

Folgt man der Erzählung dieses Freundes, soll Seidel im Gegensatz zu den neukantianischen Ansätzen ${ }^{53}$ auf Husserls Phänomenologie also positiv reagiert haben. Seidel interessiere sich sowohl für Husserls Denken und Philosophie als auch für den Typus des Denkenden, den er in Husserl personifiziert gesehen habe. Der von Prinzhorn zitierte Freund deutet Seidels Vorhaben wie folgt:

Und er [Seidel] spürte natürlich auch in sich selber sehr vieles von diesen Momenten [den sachlichen, unbedingten etc., MD]. Und wollte doch das typisch Denkerische in sich überwinden. Es in sich selber und objektiv als solches ad absurdum führen mit dessen eigenen Mitteln. Eine logische Deduktion, deren Paradoxie er dann um ihrer Paradoxie willen als Endresultat und Kernproblem seines Werkes erfasste [...]. (ebd.)

Laut diesem Freund hatte Seidel Philosophen wie Husserl vor Augen, wenn er mit den Mitteln des Denkens das »typisch Denkerische « zu analysieren suchte.

Diese biografische Anekdote macht auf den in der Einleitung erwähnten Kontrast zwischen Seidel und den für die vorliegende Arbeit ausgewählten kanonisierten Philosophen aufmerksam: Anders als die Philosophen positioniert Seidel seine eigenen Analysen nicht innerhalb der Philosophie. Wo die kanonisierten Philosophen die Standpunkte anderer Wissenschaften analytisch objektivieren, versucht Seidel philosophische Standpunkte seiner Zeit zu objektivieren. Analytisch gelingt ihm das nicht. Sein »Durcharbeiten« (Voller 2012: 324) aber veranschaulicht Krisen, die von Philosophen aufgrund ihrer innerdisziplinären Logik ausgeblendet werden: Er denkt Krisen dort zu Ende, wo Philosophen - hier Husserl - sie als Ausgangspunkte philosophischer Erneuerungsmöglichkeiten nehmen: Von welcher Position aus ist ein Denken legitimierbar, wenn durch psychologische und psychoanalytische Erkenntnisse sichtbar wird, dass die Unabhängigkeit des Geistes grundsätzlich infrage steht?

Seidel prangert diese Krisen in aller Vehemenz in jenen Passagen an, in denen er wissenschaftliche Produkte bzw. den Typus des Wissenschaftlers >psychologisiert: »Der Wissenschaftler«, schreibt er, »ist ein sublimierender Perverser« (Seidel 1927: 212). Wissenschaftler seien »gute, und zwar nicht nur

53 Wie betont, bezeichnet Seidel Rickert als einen »raffinierten Impressionisten« (Prinzhorn 1927: 54). 
gütige, sondern schwache gutmütige Menschen, weil sie ihre gesellschaftsfeindlichen, bösen Eigenschaften nicht ausleben müssen, wie der Militär, Wirtschaftsmensch, der Erzieher etc. p.p., sondern eben in ihren geistigen Tätigkeiten sublimieren; dafür haben diese Produkte dann aber eine umso zerstörendere Wirkung« (ebd.). Seidels Diagnose resultiert daraus, dass er wissenschaftlich-philosophische Produktionen (auch seine eigenen) mit psychologischen und psychoanalytischen Konzepten zu erfassen versucht und als Folge davon letztgültige Erkenntnisgrundlagen verliert. Er gibt keine Lösungen, sondern zeigt die Konsequenzen von Herausforderungen auf, welche Psychologie und Psychoanalyse für die Philosophie bedeuten: Sind empirisch feststellbare Kausalitäten in der Psyche letztgültige Prinzipien, von denen ausgehend das menschliche Denken erfasst werden kann? Von welcher Position aus sind Denken und Wissenschaft legitimierbar, wenn durch psychologische und psychoanalytische Erkenntnisse sichtbar wird, dass die Unabhängigkeit des Geistes grundsätzlich infrage steht? Indem Seidel diese Herausforderungen konsequent zu Ende denkt, wird greifbar, dass hier jemand schreibend und denkend um die Möglichkeit der Freiheit des Denkens ringt. Vice versa machen Seidels Gedankengänge innerphilosophische Dynamiken deutlich, die von kanonisierten Philosophen nicht erfasst werden: Sie zeigen, dass die Philosophie blinde Flecken dort generiert, wo sie sich mit sich selbst und einem Lösungsprimat beschäftigt. Die Orte, von denen aus Seidel denkt, sind gewissermaßen diese blinden Flecken - er denkt Krisen nicht als Erneuerungsmöglichkeiten, sondern letal bis ans Ende.

An Husserls Argumentationsstrategien hingegen kann idealtypisch nachgezeichnet werden, wie ein Philosoph mit und durch Krisen argumentativ einen neuen philosophischen Standpunkt erzeugt. Im Folgenden wird Kuschs wissenschaftssoziologische Perspektive aufgegriffen und weitergetrieben: Indem an Philosophie als strenge Wissenschaft (1910/11) herausarbeitet wird, wie Husserl seinen philosophischen Erneuerungsanspruch im Zusammenhang mit seiner Psychologiekritik entwickelt, ${ }^{54}$ werden jene Selbstpositionierungsstrategien beleuchtet, die als Abgrenzungsstrategien bezeichnet werden: Durch den Ausweis, dass eine andere diskursführende Wissenschaft (hier die Psychologie) in Bezug auf ein bestimmtes Thema (hier des Bewusstseins) fehlerhaft und ungenügend ist, werden Geltung und Relevanz eines neuen philosophischen Standpunkts hergeleitet, begründet und legitimiert. Husserls Begründung der

54 Wie in der Einleitung ausgeführt, ist der Begriff der Strategie nicht intentional zu verstehen, d.h., er ist nicht auf die bewussten Intentionen eines spezifischen Akteurs (hier Husserl) zurückzuführen. 
Phänomenologie, so also die Stoßrichtung der Argumentation, ist konstitutiv mit seiner Abgrenzung gegenüber der empirischen Psychologie verbunden.

\subsection{Philosophie als strenge Wissenschaft}

Husserl und sein Text Philosophie als strenge Wissenschaft führen nach Heidelberg, Freiburg und Göttingen in die frühen 1910er- bzw. 1920er-Jahre. Sein Artikel erschien im Frühjahr 1911 in der Zeitschrift LOGOS. Husserl, zu diesem Zeitpunkt 52-jährig und als ordentlicher Professor an der Universität Göttingen angestellt, hatte ihn - es wird in Werkbiografien immer wieder erwähnt - um die Jahreswende 1910/11 in wenigen Wochen niedergeschrieben. Die Gründe, weshalb es sich anbietet, den Erneuerungsanspruch Husserls gerade am Text Philosophie als strenge Wissenschaft zu erarbeiten, sollen kurz angesprochen werden.

Philosophie als strenge Wissenschaft ist ein programmatischer Text. Bereits im Titel wird der Anspruch deutlich: Es geht hier gewissermaßen ums Ganze, um eine wissenschaftliche Reform der Philosophie. Zudem ist der Text rhetorisch geschickt aufgebaut: Zentrale wissenschaftliche Problematiken und Debatten der Zeit finden sich in kondensierter Form darin wieder. Wenn Kusch Husserls Prolegomena zur reinen Logik wie erwähnt als ein »rhetorical masterpiece« (Kusch 2000: 22) bezeichnet, so kann dies ebenso von Philosophie als strenge Wissenschaft gesagt werden.

Der Aufsatz ist in einer aus heutiger Sicht "mythisch « stilisierten Zeitschrift erschienen. ${ }^{55}$ Der LOGOS, die »Internationale Zeitschrift für Philosophie der Kultur«, erschien erstmals 1910, letztmals 1933. Das Projekt wurde von fünf Doktoren der Philosophie gestartet, die alle in Heidelberg und Freiburg bei Wilhelm Windelband oder Heinrich Rickert studiert bzw. promoviert haben. Sie konnten für die Zeitschrift die Mithilfe der wissenschaftlichen Prominenz jener Zeit erwirken. Rüdiger Kramme, der die Entstehungsbedingungen des LOGOS untersucht hat, beschreibt diesen Umstand wie folgt: »Auf dem Titelblatt findet der Leser [...] einen kleinen >Who's Who< der deutschen Geistesgeschichte zu Beginn des 20. Jahrhunderts [...] «56 (Kramme 1995: 120). Philosophie als strenge Wissenschaft ist demnach in einem Kontext

55 Vgl. zum LOGOS die drei Aufsätze von Rüdiger Kramme 1995; 1996; 1997.

56 Als »Mitarbeiter « aufgelistet sind: die Philosophen Rudolf Eucken, Edmund Husserl, Heinrich Rickert, Georg Simmel, Ernst Troeltsch, Wilhelm Windelband, der Jurist Otto von Gierke, der Historiker Friedrich Meinecke, der Nationalökonom und Soziologe Max Weber und der Kunsthistoriker Heinrich Wölfflin. 
erschienen, der bereits im Vorfeld Aufmerksamkeit garantierte, da der LOGOS zu philosophischen Erneuerungen aufgerufen hatte. Darüber hinaus hatte die Zeitschrift einen stark ideellen Anspruch. »Ihr Spezifikum liegt in ihrem programmatischen Anspruch, Kultur mit philosophischen Mitteln zu schaffen und zu gestalten und dabei Internationalität als funktional und unverzichtbar und beide wiederum als interdependente Elemente zu begreifen. Damit wird versucht, praktische Philosophie grenzüberschreitend zu betreiben und dies zu institutionalisieren " (Kramme 1997: 124). Interdisziplinarität und Internationalität waren die zentralen Schlagworte des Zeitschriftenprojekts; insofern ist es wenig erstaunlich, dass der LOGOS heute als ein Gründungsorgan sowohl der Kulturphilosophie als auch der Kulturwissenschaften rezipiert wird.

Laut Kramme war Husserls Beziehung zum LOG OS ambivalent: Dass dieser ausgerechnet in einer kulturphilosophischen Zeitschrift mitgewirkt habe, sei von ihm selbst skeptisch beurteilt worden (ebd.). Dass er seine dezidierte Ablehnung der »Weltanschauungsphilosophie« in einer Zeitschrift publiziert hat, die mit dieser Art Philosophie affirmativ verbunden gewesen ist, könnte ein publikumswirksamer Faktor gewesen sein. In diesem Sinne stellte sein Aufsatz durchaus eine Provokation dar.

Ein weiteres Merkmal der Programmatik des Aufsatzes ist dessen Verbindung zu Wilhelm Dilthey. Philosophie als strenge Wissenschaft wird philosophiehistorisch als eine Replik auf Diltheys kurz zuvor erschienenen Aufsatz Die Typen der Weltanschauung und ihre Ausbildung in den metaphysischen Systemen (1911) rezipiert: Demnach reagiert Husserl in diesem Text auf einen etablierten, hoch angesehenen Wissenschaftler seiner Zeit. Darauf folgte ein direktes Nachspiel: Dilthey hat sich in einem Brief an Husserl gegen den Vorwurf des Skeptizismus und Historizismus zur Wehr gesetzt, »woraufhin Husserl eine Berichtigung dieses möglichen >Mißverständnisses > >sogleich im LOGOS versprach « (Kramme 1995: 142). Diese Richtigstellung jedoch ist - vermutlich aufgrund von Diltheys Tod im selben Jahr (1911) - nie erschienen. Auch dieses Detail belegt die richtungsweisende Funktion des Aufsatzes: Im Kontext der sich damals durchsetzenden Trennung zwischen Geistes- und Naturwissenschaften (für deren Etablierung Dilthey steht) positioniert Husserl die Philosophie explizit als Bindeglied beider Bereiche.

Husserls Text - es wird bereits im Titel deutlich - ist ein Plädoyer für eine Erneuerung der Philosophie im Sinne strenger Wissenschaftlichkeit. So heißt es denn in der Exposition programmatisch:»Die nachfolgenden Ausführungen sind von dem Gedanken getragen, daß die höchsten Interessen menschlicher Kultur die Ausbildung einer streng wissenschaftlichen Philosophie fordern; daß somit, wenn eine philosophische Umwendung in unserer Zeit Recht 
haben soll, sie jedenfalls von der Intention auf eine Neubegründung der Philosophie im Sinne strenger Wissenschaft beseelt sein muß «57 (Husserl 1910/11: 293). Husserl verteidigt also nicht nur eine streng wissenschaftliche Philosophie, es geht ihm gleichzeitig um eine Fundierung der Philosophie selbst. In Philosophie als strenge Wissenschaft können seine zentralen Argumentationsstrategien in kondensierter Form erfasst werden.

\section{Die »Wissenschaftlichkeit« kritisieren}

Der $5^{2}$ Seiten umfassende Text Philosophie als strenge Wissenschaft ist in drei Abschnitte aufgeteilt. Auf eine kurze Einführung, in der Husserl sein Thema und das Vorgehen erläutert, folgen zwei längere Kapitel, zuerst »Naturalistische Philosophie«, danach »Historizismus und Weltanschauungsphilosophie «. Wo im ersten Teil der Naturalismus selbst kritisiert wird, werden im zweiten Teil zeitgenössische Kritikpunkte am Naturalismus kritisiert: die Weltanschauungsphilosophien.

Husserl leitet seine Kritik am Naturalismus und am Historizismus bzw. an den Weltanschauungsphilosophien mit einer Kritik an den Natur- und Geisteswissenschaften ein. Der Naturalismus sei eine Folgeerscheinung der Entdeckung der Natur, so wie der Historizismus eine Folgeerscheinung der Entdeckung der Geschichte sei. »Den herrschenden Auffassungsgewohnheiten entsprechend, neigt eben der Naturwissenschaftler dazu, alles als Natur, der Geisteswissenschaftler als Geist, als historisches Gebilde anzusehen und demgemäß, was so nicht angesehen werden kann, zu missdeuten « (ebd.: 294). In ihrer Abgeschlossenheit seien beide verkürzend - sowohl geisteswissenschaftliche als auch naturwissenschaftliche Erklärungen.

Husserls Ausgangslage ist der zu seiner Zeit viel diskutierte Topos, der später als der der "zwei Kulturen« in die Geistes- und Kulturgeschichte eingehen wird. ${ }^{58}$ Husserl greift die Trennung der Wissenschaften in zwei weitgehend voneinander abgespaltene Bereiche auf, um zu kritisieren, dass sowohl geistesals auch naturwissenschaftliche Wissenschaftler und Wissenschaftlerinnen

57 Der Philosoph Werner Schneiders betont, dass der Wille nach strenger Wissenschaftlichkeit »merkwürdig unreflektiert« bleibt. »Dieser Trieb bzw. Wille, der hier merkwürdig unreflektiert immer wieder als letztes Motiv für Philosophie und Wissenschaft angesetzt ist, fällt nämlich mit den wahren Interessen der Menschheit zusammen, die jedoch von Husserl auch nur behauptet werden« (Schneiders 1998: 74).

$5^{8}$ Die These, wonach zwischen den Geisteswissenschaften einerseits (Verstehen) und den Naturwissenschaften andererseits (Erklären) eine grundsätzliche Dichotomie bestehe, wurde in den 196oer-Jahren zum Topos. Dafür spielte C. P. Snows The Two Cultures von 1959 eine entscheidende Rolle. Die Trennung zwischen Geistes- und Naturwissenschaften bzw. die Diskrepanz zwischen Verstehen und Erklären wird Ende des 19. Jahrhunderts akademisch etabliert. Wilhelm Dilthey kommt dabei eine Schlüsselrolle zu. 
es anstreben, >alles< erfassen zu wollen, es aufgrund ihrer Einseitigkeit aber nicht können. Alles - d.h. die Welt in ihrer Totalität. »Das Geistesleben der Menschheit >verstehen««, schreibt Husserl mit einem Seitenhieb gegen Dilthey, »ist sicherlich eine große und schöne Sache. Aber leider kann auch dieses Verstehen uns nicht helfen und darf nicht mit dem philosophischen verwechselt werden, das uns die Welt- und Lebensrätsel enthüllen soll« (ebd.: 336). Diese Aussage verweist darauf, dass Husserl nicht etwa den - zu dieser Zeit sich etablierenden - Geisteswissenschaften die Lösung der Weltund Lebensrätsel zuweist, sondern dafür eine spezifische Wissenschaft vorsieht: die Philosophie. ${ }^{59}$

Er zeichnet insgesamt ein alternativloses Szenarium. In ihren extremen Formen würden der Naturalismus in den Szientismus, der Historizismus bzw. die Weltanschauungsphilosophien in den Relativismus führen. Sowohl der Naturalismus als auch der Historizismus werden von Husserl als »erkenntnistheoretische Verwirrung « dargestellt, die vermöge ihrer »widersinnigen Konsequenzen [...] schroff abgelehnt werden müsse« (ebd.: 327). Allerdings hält er eine »philosophische Umwendung in unserer Zeit [1910, MD]« (ebd.: 293) für möglich. Die Absicht einer Neubegründung der Philosophie im Sinne strenger Wissenschaft sei der »Gegenwart keineswegs fremd«. Vielmehr sei sie »voll lebendig gerade innerhalb des herrschenden Naturalismus« (ebd.). Der Naturalismus gehe der »Idee einer streng wissenschaftlichen Reform der Philosophie nach und glaubt sogar jederzeit, [...] sie schon verwirklicht zu haben« (ebd.). ${ }^{60}$ Die Art und Weise jedoch, wie der Naturalismus diese Reform vollziehe, sei abwegig: »Der Naturalist ist, kann man alles in allem sagen, in seinem Verhalten Idealist und Objektivist« (ebd.: 295). Er »lehrt, predigt, moralisiert, reformiert « (ebd.). Anders aber als der antike Skeptizismus predige er nicht in expliziter Weise, dass es das einzig Vernünftige sei, die Vernunft zu leugnen. »Der Widersinn liegt bei ihm nicht offen, sondern ihm selbst verborgen darin, dass er die Vernunft naturalisiert« (ebd.: 295-296).

59 Hier taucht das Motiv, dass es der Philosophie und keiner anderen Wissenschaft zustehe, die Welt in ihrer Totalität erfassen zu können, wieder auf (siehe Unterkapitel »Das Weltganze zum Gegenstand machen«, S. 40-41).

6o An diesem Punkt tritt einer der entscheidenden Unterschiede zwischen dem Erneuerungsanspruch Husserls und demjenigen des Wiener Kreises hervor: Die Neubegründung der Philosophie im Sinne des Positivismus (wie sie vom Wiener Kreis verfolgt wird) ist in Husserls Perspektive schlicht unsinnig. Es wird weiter unten deutlich werden, dass im Unterschied zu Husserl die Vertreter des Wiener Kreises - wie Husserl - für eine grundsätzliche Wendung in der Philosophie argumentieren, diese aber aufgrund der Entwicklungen derWissenschaften als schon verwirklicht betrachten. Husserl opponiert hier also gegen jene Traditionslinie, in die sich die Vertreter des Wiener Kreises einschreiben werden. 
Der Naturalismus sei aber nicht nur »theoretisch von Grund auf verfehlt«, sondern bedeute gar "praktisch eine wachsende Gefahr für unsere Kultur« (ebd.: 293). An Kritiken gegen die »naturalistische Philosophie« fehle es aber keineswegs. Im Gegenteil: Die »vielbemerkte Umwendung unserer Zeit« sei »anti-naturalistisch « eingestellt (ebd.: 294). Die Krux ist für Husserl, dass diese Kritiken »von den Linien wissenschaftlicher Philosophie abführen und in bloße Weltanschauungsphilosophie einmünden [...] wollen «(ebd.). Kurz: Eine radikale Kritik an der naturalistischen Philosophie ist für ihn »heutzutage eine wichtige Angelegenheit«. Die - in seiner Perspektive durchaus vorhandene Kritik laufe jedoch Gefahr, ihren Anspruch auf Wissenschaftlichkeit preiszugeben. Es bedürfe folglich einer »positive[n] Kritik an den Grundlagen und Methoden « naturalistischer Philosophien (ebd.: 293). Denn nur diese könne »das Vertrauen auf die Möglichkeit einer wissenschaftlichen Philosophie« erhalten (ebd.: 293-294).

Die Situation, die Husserl präsentiert, ist komplex und soll kurz zusammengefasst werden: Zeitgenössische Tendenzen in den Wissenschaften, u.a. der »herrschende Naturalismus «, seien nicht nur widersinnig, sondern lösten sogar eine kulturelle Bedrohung aus. Dieser Bedrohung wiederum könne nur mit wissenschaftlicher Kritik - mit einer streng wissenschaftlichen Philosophie - begegnet werden. Die zeitgenössischen Versuche, den Naturalismus zu kritisieren, hält Husserl jedoch für ungenügend, wenn nicht gar bedenklich, weil diese Gefahr laufen würden, die Wissenschaftlichkeit preiszugeben. Da der »widersinnige« Ansatz des »Naturalismus« gerade durch seinen Anspruch auf Wissenschaftlichkeit eine Bedrohung darstelle, sei nicht nur eine wissenschaftliche Kritik am Naturalismus, sondern zugleich an den bestehenden wissenschaftlichen Kritiken am Naturalismus notwendig. Die Wissenschaftlichkeit steht also in doppelter Hinsicht im Zentrum von Husserls Überlegungen: Weil der wissenschaftliche Anspruch des Naturalismus schlicht »widersinnig « sei, müsse sowohl die vermeintliche Wissenschaftlichkeit des »Naturalismus« als auch die Wissenschaftlichkeit der Kritiken am Naturalismus (also an den Weltanschauungsphilosophien) kritisiert werden.

\section{Kritik am Naturalismus: Psychologiekritik}

»Indem die Kritik scheidet und klärt, indem sie dazu zwingt, dem eigentlichen Sinn der philosophischen Motive nachzugehen, die meist so vage und vieldeutig als Probleme formuliert werden, ist sie geeignet, die Vorstellungen besserer Ziele und Wege zu wecken und unser Vorhaben positiv zu fördern« (ebd.: 297). In dieser Formulierung Husserls wird die zentrale Argumentationsstrategie, nämlich die eigene Position durch die Kritik an der Wissenschaftlichkeit anderer Positionen hervorzubringen, deutlich. Aufschlussreich ist, 
dass sich seine Kritik letztlich als eine Kritik an den disziplinären Grundlagen der Psychologie herausstellt.

Im ersten Teil fordert Husserl eine Grundlagen- und Methodenkritik an der »naturalistischen Philosophie« ein:

Was alle Formen des extremen und konsequenten Naturalismus, angefangen vom populären Materialismus bis zum neuesten Empfindungsmonismus, charakterisiert, ist einerseits die Naturalisierung des Bewußtseins, einschließlich aller intentional-immanenten Bewußtseinsgegenbenheiten; andererseits die Naturalisierung der Ideen und damit aller absoluten Ideale und Normen. (ebd.: 294-295)

Husserl strebt eine »ausführliche Besprechung « des ersten Aspektes, also der Naturalisierung des Bewusstseins, an. »Die tieferen Zusammenhänge mit den berührten skeptischen Konsequenzen werden im folgenden von selbst hervortreten und ebenso die ganze Weite, in der unser zweiter Vorwurf, die Naturalisierung der Ideen anlangend, gemeint und zu begründen ist, verständlich werden « (ebd.: 297). Er geht also davon aus, dass sich entlang seiner Kritik an der Naturalisierung des Bewusstseins die »tieferen Zusammenhänge« von selbst erschließen. Durch die Kritik an zeitgenössischen Bewusstseinskonzepten werde, so legt er nahe, seine eigene Konzeption, die Phänomenologie, wie von selbst »hervortreten«.

Die hier entscheidende Frage ist demnach, wie Husserl die Kritik an der Naturalisierung des Bewusstseins formuliert. »Wir knüpfen unsere kritischen Analysen natürlich nicht an die mehr populären Reflexionen philosophierender Naturforscher an, sondern beschäftigen uns mit der mit wirklich wissenschaftlichem Rüstzeug auftretenden gelehrten Philosophie. Insbesondere aber mit einer Methode und Disziplin, durch welche sie glaubt, endgültig den Rang einer exakten Wissenschaft erklommen zu haben« (ebd.: 297). Die Rede ist hier von der experimentellen Psychologie.

Husserl kritisiert das abstrakte Konzept des Naturalismus also in Form einer Kritik an den Grundlagen der empirischen Psychologie. Die Trennung zwischen Psychologie und Philosophie ist, wie erwähnt, um 1910 weder institutionell noch ideell vollzogen. Die Unbestimmtheit, welche Konzepte der Psychologie und welche der Philosophie zugehörig sind, widerspiegelt sich in Husserls Text an vielen Stellen. Wenn er beispielsweise von der »mit wissenschaftlichem Rüstzeug auftretenden Philosophie« spricht und damit die experimentelle Psychologie meint, wird deutlich, dass sich die beiden Disziplinen in intensiven Abgrenzungsprozessen befinden. In den Textstellen, in denen er die exakte Psychologie beschreibt, wird die Virulenz dieser Debatten offenkundig: 
Sie sei die so lang gesuchte, nun endlich zur Tat gewordene exakt-wissenschaftliche Psychologie. Logik und Erkenntnistheorie, Aesthetik, Ethik und Pädagogik hätten durch sie endlich ihr wissenschaftliches Fundament gewonnen, ja sie seien schon im vollen Zuge, sich zu experimentellen Disziplinen umzubilden. Im übrigen sei die strenge Psychologie selbstverständlich die Grundlage aller Geisteswissenschaften und nicht minder auch der Metaphysik. In letzterer Hinsicht freilich nicht das bevorzugte Fundament, da in gleichem Umfange auch die physische Naturwissenschaft an der Fundamentierung dieser allgemeinsten Wirklichkeitslehre beteiligt sei. (ebd.: 297-298)

Husserl macht unmissverständlich klar, dass er den Anspruch der »strengen Psychologie«, letztlich das Fundament für alle anderen Wissenschaften darstellen zu können, abwegig findet. Dass er in seinen Sätzen den Konjunktiv verwendet, ist signifikant: Er sagt nicht explizit, wem er die Worte in den Mund legt; der - von ihm paraphrasierte - Anspruch, dass die Psychologie das Fundament nicht nur für philosophische Subdisziplinen, sondern auch für die Geisteswissenschaften generell und - gemeinsam mit den Naturwissenschaften sogar für die Metaphysik sein soll, scheint ihn aber zu empören.

Er vollzieht also, ohne dies zu explizieren, eine Distanzierungsbewegung: Statt direkt das Thema des Bewusstseins zu fokussieren und zu begründen, warum das Bewusstsein mit rein empirischen Mitteln nicht vollständig erfasst werden kann - wie dies an Seidels Bemühungen deutlich geworden ist -, beschäftigt er sich mit der aus seiner Sicht abwegigen Meinung, das Bewusstsein könne naturalisiert werden. Wer konkret diese Meinung vertritt, wird zwar nicht geklärt, dennoch wird dadurch argumentativ ein potenzieller Gegenpart aufgebaut. Pointiert gesagt: Da es - wie an Seidels zirkulären Argumentationsgängen sichtbar geworden ist - unmöglich ist, das Bewusstsein ohne erkenntnistheoretische Distanzierung zu bestimmen, argumentiert Husserl gegen die These, ebenjenes Bewusstsein könne mit experimentellen Mitteln erfasst werden. Für seine Argumentation ist eine systematische und dezidierte Wissenschaftskritik also konstitutiv.

\section{Auf die Angriffe aus der Psychologie reagieren}

Husserls Einwände gegen den »erkenntnistheoretischen Psychologismus und Physizismus« gehen nahtlos in seine eigene Konzeption über. Er setzt in seinen Einwänden die Psychologie mit den Naturwissenschaften gleich: »Jedes psychologische Urteil schließt die existenziale Setzung der physischen Natur in sich, ob nun ausdrücklich oder nicht« (ebd.: 299). Husserl wirft der Psychologie naturalistische Grundannahmen vor. Er konstatiert, dass es an Argumenten gegen naturwissenschaftliche Erkenntnistheorien keineswegs fehle. »Es genügt nur, an die >Naivität $<$ zu erinnern, mit der, gemäß dem oben 
Gesagten, Naturwissenschaft Natur als gegeben hinnimmt « (ebd.). Da Husserl in dieser Argumentationslinie die empirische Psychologie mit den Naturwissenschaften analogisiert, erweist sich seine Psychologiekritik gleichzeitig als eine Kritik am Wahrheitsanspruch der Naturwissenschaften generell. Diese Kritik wiederum ist, so macht der folgende Absatz deutlich, für Husserls eigene Positionierung entscheidend.

Eine empirische Disziplin vermöge es nicht, auf die Empirie als solche zu reflektieren. Jede erfahrungswissenschaftliche Methode führe letztlich auf Erfahrung zurück. »Es bedarf nur strenger Konsequenz in der Festhaltung des Niveaus dieser Problematik (einer Problematik, die freilich allen bisherigen Erkenntnistheorien gefehlt hat), um den Widersinn einer >naturwissenschaftlichen Erkenntnistheorie< einzusehen, also auch den jeder psychologischen « (ebd.: 30o). Seien gewisse Rätsel den Naturwissenschaften prinzipiell immanent, so seien ihr deren Lösungen selbstverständlich transzendent. »Die Lösung eines jeden Problems, das der Naturwissenschaft als solcher anhaftet also ihr durch und durch als solcher anhaftet - von der Naturwissenschaft selbst erwarten zu wollen, oder auch nur zu meinen, daß sie für die Lösung eines derartigen Problems irgendwelche Prämissen beisteuern könne, das heißt sich in einem widersinnigen Zirkel bewegen « (ebd.). ${ }^{61}$

Eine streng wissenschaftliche Philosophie darf in Husserls Perspektive also nicht von naturwissenschaftlichen bzw. psychologischen Prämissen ausgehen, weil eine naturwissenschaftliche bzw. psychologische Perspektive in sich selbst beschränkt sei. Es ist bezeichnend, dass Husserls intendierte Kritik am abstrakten Konzept Naturalismus bzw. am noch abstrakteren Konzept einer Naturalisierung des Bewusstseins in einer dezidierten Kritik an der experimentellen Psychologie mündet. Denn erst diese disziplinäre Grenzziehung ermöglicht es ihm, die Beschränktheit und Widersinnigkeit einer Perspektive aufzuzeigen, welche das Bewusstsein naturalisiere.

Husserls letzter Einwand gegen eine "psychologistische Erkenntnistheorie« führt nahtlos in sein eigenes Lehrgebäude: Wenn Erkenntnistheorie das Verhältnis von Bewusstsein und Sein erforschen wolle, so konstatiert er, dann komme sie nicht umhin, das »Sein « als das »Correlatum « zum Bewusstsein vor Augen zu haben, »als bewusstseinsmäßig 〉Gemeintes‘: als Wahrgenommenes, Erinnertes, Erwartetes, bildlich Vorgestelltes, Phantasiertes, Identifiziertes, Unterschiedenes, Geglaubtes, Vermutetes, Gewertetes usw.« (ebd.). Der an

61 Der Ausdruck des »widersinnigen Zirkels« ist an dieser Stelle interessant; er erinnert an Seidels Circulus vitiosus. Wie Husserl mit diesem Zirkel umgeht, wird weiter unten besprochen (siehe S. 71-74). 
dieser Stelle prompt einsetzende Umschwung in Husserls eigene Konzeption hinein liest sich wie folgt:

Man sieht dann, daß die Forschung gerichtet sein muß auf eine wissenschaftliche Wesenserkenntnis des Bewußtseins, auf das, was Bewußtsein in allen seinen unterscheidbaren Gestaltungen selbst, seinem Wesen nach, »ist«, zugleich aber auf das, was es »bedeutet«, sowie auf die verschiedenen Weisen, in denen es - dem Wesen dieser Gestaltungen gemäß - bald klar, bald unklar, bald gegenwärtigend oder vergegenwärtigend, bald signitiv oder bildlich, bald schlicht, bald denkmäßig vermittelt, bald in dem oder in jenem attentionalem Modus, und so in unzähligen anderen Formen, Gegenständliches meint, und es ev. als »gültig«, »wirklich« Seiendes »erweist«. (ebd.: 300-301)

Dieses Zitat verdeutlicht, dass erst mit Husserls Kritik an psychologischen Konzepten intelligibel wird, worauf es ihm ankommt: Die Forschung muss in seiner Perspektive auf das gesamte Bewusstsein gerichtet sein. Erst indem er nachweist, dass die empirische Psychologie in ihren Ansätzen nur einzelne Aspekte des Bewusstseins im Blick hat, wird eine andere, umfassendere Bewusstseinskonzeption sinnvoll. Die beiden Elemente - Kritik an einzelnen Disziplinen und Erneuerung der Philosophie insgesamt - sind in Husserls Argumentation untrennbar miteinander verbunden. Das Konstitutive beider Aspekte wird im folgenden Zitat auf den Punkt gebracht: »Die experimentelle Methode ist unerlässlich, wie überall, wo es sich um Fixierung von intersubjektiven Tatsachenzusammenhängen handelt. Aber sie setzt voraus, was kein Experiment zu leisten vermag, die Analyse des Bewußtseins selbst« (ebd.: 303).

Dass die Kritik an psychologistischen Erkenntnistheorien ein konstitutives und nicht etwa ein additives Merkmal von Husserls Phänomenologie ist, wird auch in folgender für seine Argumentation zentraler Textstelle deutlich:

Es würde sich schließlich voraussehen lassen, daß jede psychologistische Erkenntnistheorie dadurch zustande kommen muß, daß sie, den eigentlichen Sinn der erkenntnistheoretischen Problematik verfehlend, einer vermutlich naheliegenden Verwechslung zwischen reinem und empirischem Bewußtsein unterliegt, oder was dasselbe besagt: daß sie das reine Bewußtsein »naturalisiert«. (ebd.: 302, Herv. MD)

Wenn Husserl nachweist, dass die Psychologie das »reine« mit dem »empirischen« Bewusstsein verwechselt, macht er zugleich plausibel, dass es zusätzlich zum empirischen - ein reines Bewusstsein gibt. Damit wiederum erhält sein Argument, dass das Bewusstsein anderen Bedingungen als naturalistischen untersteht, nämlich phänomenologischen, Gültigkeit. Bewusstsein 
ist für Husserl folglich immer ein Bewusstsein »von etwas«. In der zitierten Textstelle wird darüber hinaus erkennbar, dass seine Psychologiekritik mit der Kritik am abstrakten Konzept des Naturalismus zusammenfällt. Er setzt die Naturalisierung des Bewusstseins analog zu den >Fehlern< oder >Lücken < einer psychologistischen Erkenntnistheorie.

Es wird folgender Argumentationsvorgang deutlich: Husserl weist auf theoretische Leerstellen in den Naturwissenschaften und der empirischen Psychologie hin, um diese neu zu besetzen. Durch seine Kritik an der empirischen Psychologie konzipiert er theoretische Leerstellen, um diese wiederum für die Philosophie produktiv zu machen: Er nimmt die von ihm sichtbar gemachten Leerstellen der Psychologie auf, um sie an ein für die Philosophie zentrales und philosophiehistorisch äußerst relevantes Erkenntnisobjekt zurückzubinden: an das Bewusstsein. Er rekonfiguriert durch diese Argumentationsstrategie das Bewusstsein nicht nur als das für die Philosophie grundlegende Forschungsobjekt, sondern rehabilitiert es als Grundbedingung der Erkenntnis.

Husserls Argumentationsstrategie ist bemerkenswert: Er nimmt den >Angriff< aus der empirischen Psychologie, nämlich die Erkenntnis, dass es den reinen Geist nicht geben kann, konstruktiv auf, indem er dieses Argument in einem ersten Schritt - philosophisch untermauert: Ein reines Bewusstsein könne es nicht geben, da das Bewusstsein immer ein Bewusstsein »von etwas « ist. Jedes Bewusstsein sei auf etwas bezogen; es sei immer »intentional«. In einem zweiten Schritt argumentiert er jedoch dezidiert dafür, dass dieses nicht reine intentionale Bewusstsein dennoch ganzheitlich analytisch erfasst werden kann und soll. Dafür jedoch benötige es eine eigene und neue Wissenschaft: die Phänomenologie. Wie deutlich geworden ist, verwendet Husserl in seiner Argumentation den für die Philosophie charakteristischen Anspruch, das >Ganze $<$ in den Blick zu nehmen: Indem er der empirischen Psychologie unterstellt, diese würde lediglich einzelne Teile des Bewusstseins in den Blick nehmen, argumentiert er für die Möglichkeit, dass die Philosophie das Bewusstsein in seiner Gesamtheit erfassen könne. Die Instrumentarien für diese neue Wissenschaft jedoch müssen gemäß Husserl erst noch geschaffen werden.

Seine Kritik an der »naturalistischen Philosophie« zielt also letztlich darauf, das Bewusstsein als eine Entität oder als Phänomen darzustellen, das systematisch erforscht werden kann. In Abgrenzung zur Psychologie argumentiert er für die Möglichkeit eines Standpunkts, der das Bewusstsein gleichzeitig objektiviert und subjektiviert - aber nicht vorgängig naturalisiert bzw. materialisiert. Eine entscheidende Strategie Husserls ist in der hier 
eingenommenen Perspektive, dass er die Herausforderungen der empirischen Psychologie - die Erkenntnis, dass das Bewusstsein empirisch vermessen werden kann - aufnimmt und ernst nimmt. Anders als es bei Seidel deutlich geworden ist, verzweifelt er aber nicht an der Erkenntnis, dass das Bewusstsein möglicherweise empirischen Kausalitäten unterworfen ist, sondern nimmt sie als Anstoß, um Argumente für eine philosophische Erneuerung zu entwickeln. ${ }^{62}$

\section{Wissenschaftliche Entscheidungen tragen den Stempel der Ewigkeit}

Husserls Kritik an den Weltanschauungsphilosophien wird in philosophiehistorischen Darstellungen wie erwähnt als eine Kritik an Diltheys »Weltanschauungslehre« rezipiert. »Eine >objektive< Geisteswissenschaft kann es [gemäß Husserl, MD] überhaupt nicht geben, weil der Geist überhaupt nie Objekt sein kann« (Schneiders 1998: 78). Wenn man die weiter oben geschilderte Episode beachtet, wonach Dilthey nach der Veröffentlichung von Husserls Aufsatz eine Richtigstellung verlangt hat, weil er fälschlicherweise dem Vorwurf von Skeptizismus und Historizismus ausgesetzt worden sei (und Husserl dies habe korrigieren wollen), erscheint Husserls Bezugnahme auf Dilthey in einem etwas anderem Licht: Husserl, so macht seine Argumentation deutlich, zielt hier nicht direkt gegen Dilthey, sondern er verweist auf ihn, um seine eigenen Argumente stärker und deutlicher hervorbringen zu können. Husserls zuweilen affirmative Bezugnahmen auf Dilthey stehen in keinem Verhältnis zu seiner dezidierten Argumentation gegen den »Historizismus «. Dieses Missverhältnis lässt bei dem oder der Lesenden, ohne dass dies das Thema des Aufsatzes wäre, die Annahme enstehen, dass Dilthey in Philosophie als strenge Wissenschaft als Husserls Opponent erscheint.

Husserls Philosophie als strenge Wissenschaft erscheint kurz nach Diltheys Aufsatz Die Typen der Weltanschauung und ihre Ausbildung in den metaphysischen Systemen. Dilthey argumentiert in diesem Aufsatz für eine Erneuerung der Philosophie im Sinne einer Historisierung:

So zerstört die Ausbildung des geschichtlichen Bewußtseins gründlicher noch als der Überblick über den Streit der Systeme den Glauben an die Allgemeingültigkeit irgendeiner der Philosophien, welche den Weltzusammenhang in zwingender Weise in einen Zusammenhang von Begriffen auszusprechen unternommen haben. Die Philosophie muß nicht in der Welt, sondern in

62 Die Herausforderung, der sich Husserl stellt, könnte auch mit einer von Sigmund Freuds berühmten narzisstischen Kränkungen der Menschheit parallelisiert werden: mit der Kränkung infolge der psychoanalytischen Theorie des Unbewussten, wonach der Mensch nicht Herr im eigenen Hause sei. 
dem Menschen den inneren Zusammenhang ihrer Erkenntnisse suchen. (Dilthey 1911: 6)

Dilthey formuliert eine Absage an die Allgemeingültigkeit philosophischer Systeme. Husserl geht in Philosophie als strenge Wissenschaft vom Gegenteil aus: Der Philosophie komme ein allgemeingültiger Anspruch zu. ${ }^{63}$ Dilthey galt bereits zu seiner Zeit als Vertreter einer genuin historischen Philosophie. Indem Husserl Dilthey in seinem Aufsatz als Anhänger des Historizismus auftreten lässt, stärkt er seine eigene Positionierung durch den Einbezug eines Autors, der bereits zu dieser Zeit als Exponent einer wissenschaftlichen Tradition galt. Dies wiederum - so wird auch in den folgenden Kapiteln weiter ausgeführt - ist für Husserls eigenen Einsatz konstitutiv. Wenn Philosophie als strenge Wissenschaft philosophiehistorisch stets als eine Replik auf Dilthey gedeutet wird, kann dies darüber hinaus als eine Reproduktion der bereits bei Husserl selbst angelegten Strategie verstanden werden, philosophische Positionen zu personifizieren.

Husserls Argumente gegen die Weltanschauungsphilosophien (und implizit auch gegen die Geisteswissenschaften) lauten verkürzt wie folgt: Weltanschauungsphilosophien seien ein »Kind « des »historizistischen Skeptizismus« (Husserl 1910/11: 328). Weltanschauungsphilosophien würden auf die Weisheit setzen, wohingegen eine wissenschaftliche Philosophie auf die Wissenschaft setze. Bis zum gegenwärtigen Zeitpunkt (1910) hätten sich Weltanschauungsphilosophien nicht mit strenger Wissenschaftlichkeit widersprochen. »Beide Ziele [Weltanschauung und strenge Wissenschaft, MD] waren entweder noch gar nicht oder nicht scharf geschieden« (ebd.: 332). In der Gegenwart jedoch sei dies anders geworden, da sich die Wissenschaften zu einer überzeitlichen Idee entwickelt hätten. »Das [die Untrennbarkeit, MD] hat sich seit der Konstitution einer überzeitlichen universitas strenger Wissenschaften gründlich geändert« (ebd.). ${ }^{64}$

Husserl bezeichnet Wissenschaft somit als eine überzeitliche Idee, Weltanschauung jedoch als eine historisch gebundene Idee. »Die >Idee< der Weltanschauung ist dabei für jede Zeit eine andere [...]. Die >Idee< der Wissenschaft hingegen ist eine überzeitliche, und das sagt hier, durch keine Relation auf den Geist einer Zeit beschränkt« (ebd.). Die Setzung der Wissenschaft - und damit der Wahrheit und Theorie (ebd.: 325) - als einer überzeitlichen Idee ist für

63 Husserls Befürchtung sei gewesen, so wird philosophiegeschichtlich stets betont, dass Dilthey in seinem Ansatz jegliche Objektivität preisgebe.

64 Inwieweit sich eine »überzeitliche Idee« überhaupt zeitlich zu entwickeln vermag - wie Husserl in diesem Zusammenhang impliziert -, ist eine andere Frage, auf die hier nicht eingegangen werden kann. 
Husserls Neupositionierungen zentral. Er begründet sie mit seiner Absetzung gegenüber den Weltanschauungstheorien. »Weltanschauungen können streiten, nur Wissenschaft kann entscheiden und ihre Entscheidung trägt den Stempel der Ewigkeit« (ebd.: 337). Seit der Entwicklung der neuzeitlichen Wissenschaft besitzen die Wissenschaften somit überzeitliche, d.h. absolute Gültigkeit: »Also wohin immer die neue Umwendung der Philosophie sich richten mag, es ist außer Frage, daß sie den Willen auf strenge Wissenschaft nicht preisgeben darf, vielmehr sich dem praktischen Weltanschauungsstreben als theoretische Wissenschaft gegenüberstellen und sich von ihm vollbewußt trennen muß « (ebd.: 337). Die Philosophie werde ihr Fundament verlieren, wenn sie sich nicht von den Weltanschauungsphilosophien absetzt und sich nicht in streng wissenschaftlicher, d.h. für Husserl in phänomenologischer Weise erneuert.

\section{Aus der Philosophie resultiert Wissenschaftlichkeit-und umgekehrt}

Aus der Trennung zwischen Weltanschauungsphilosophie und Wissenschaft leitet Husserl ein Wissenschaftsverständnis her, das wissenschaftliche Entscheidungen als absolut setzt.

Und sie [die Gegenwart, MD] leidet [...] an der zu geringen Entwicklung und Macht der Philosophie, die noch nicht weit, noch nicht wissenschaftlich genug ist, um den skeptischen Negativismus (der sich Positivismus nennt) durch den wahren Positivismus überwinden zu können. Unsere Zeit will nur an »Realitäten « glauben. Nun, ihre stärkste Realität ist die Wissenschaft, und so ist die philosophische Wissenschaft das, was unserer Zeit am meisten nottut. (ebd.: 340)

Weil den neuzeitlichen Wissenschaften Deutungsmacht zukomme, dürfe auch die Philosophie ihre Wissenschaftlichkeit nicht preisgeben, wenn sie ihre Deutungsmacht nicht verlieren wolle. Das Bestechende an Husserls Argumentation ist in der hier eingenommenen Perspektive, dass er nicht etwa die Wissenschaftlichkeit der Philosophie behauptet (wie dies weiter unten beim Wiener Kreis deutlich wird), sondern dafür argumentiert, dass die Philosophie an der Idee derWissenschaftlichkeit festhalten müsse. Es geht ihm nicht darum, ein bereits vorgefasstes Philosophieverständnis zu >verwissenschaftlichen<, sondern die Philosophie mit dem Prinzip der Wissenschaftlichkeit gleichzusetzen. Die Philosophie wird zum Mittel, die Wissenschaft generell zu verteidigen, und umgekehrt wird die Wissenschaft zum Mittel, die Relevanz der Philosophie zu verteidigen. Philosophie ist strenge Wissenschaft aus Prinzip. Weil die Wissenschaft eine überzeitliche Idee ist, ist es auch die Philosophie. Die Wissenschaftlichkeit der Philosophie resultiert für Husserl 
also gewissermaßen aus der Philosophie selbst, und umgekehrt resultiert aus echter Wissenschaftlichkeit Philosophie. Pointiert: Ohne Philosophie verliere die Wissenschaft ihren Grund und Boden, und ohne Wissenschaft verliere die Philosophie ihre Wissenschaftlichkeit.

Mit dieser programmatischen Bestimmung legitimiert Husserl zugleich die gesellschaftliche Relevanz der Philosophie. Denn Wissenschaft und Philosophie seien dasjenige, »was unserer Zeit am meisten nottut « (ebd.: 340). Mehr implizit als explizit trägt er eine gesellschaftlich-historische Komponente in seine Argumentation: Weil den »Siegeslauf« (ebd.: 296) der Wissenschaften nichts hemmen werde, muss auch die Philosophie an ihrem eigenen Anspruch der Wissenschaftlichkeit festhalten. »Vielleicht gibt es im ganzen neuzeitlichen Leben keine mächtiger, unaufhaltsamer vordringende Idee als die der Wissenschaft« (ebd.: 296). Es wird deutlich, warum es für Husserl so wichtig ist, die Philosophie als strenge Wissenschaft zu begründen: Weil der Bereich der Wissenschaften - zeitbedingt - die mächtigste aller »Realitäten « ist und also die stärkste Deutungsmacht besitzt, ist er zugleich die »Realität«, der am meisten Glaubwürdigkeit zukommt. Philosophinnen und Philosophen müssen also deswegen am Prinzip Wissenschaftlichkeit festhalten, weil sie ansonsten ihre Glaubwürdigkeit und dadurch ihre Wirkungsmacht verlieren würden. Für Husserl ist es zentral, dass die Philosophie auf ihrer eigenen, prinzipiellen Wissenschaftlichkeit beharrt. Er fordert ein Festhalten an der Wissenschaft als einer absoluten, d.h. zeit- und ortsunabhängigen Instanz. Dafür, so seine Argumentation, benötige es die philosophische Wissenschaft, da diese stärker als andere Wissenschaften das Potenzial einer »strengen Wissenschaft« in sich trage.

Husserl definiert die Philosophie als eine Möglichkeit, Sicherheit zu gewinnen: Mit streng philosophischen Methoden, so seine Implikation, kann echte Wissenschaftlichkeit hergestellt werden. Er bezieht sich dabei jedoch nicht auf bestehende philosophische Methoden, sondern argumentiert, dass diese Methoden erst entwickelt werden müssten. Der Weg dafür sei mit der Phänomenologie geebnet. »Nicht von den Philosophen[,] sondern von den Sachen und Problemen muß der Antrieb zur Forschung ausgehen « (ebd.: 340). Er leitet sein berühmt gewordenes Argument, man müsse in einer wissenschaftlich fundierten Philosophie von konkreten »Sachen « und Situationen und nicht von Theorien ausgehen, mit einer Absetzung der Philosophie von den anderen Wissenschaften her. Auch andere Wissenschaften, so sein Argument, untersuchten Phänomene - z.B. historische, psychologische oder naturwissenschaftliche -, die Art und Weise jedoch, wie diese Wissenschaften Phänomene konfrontieren, unterscheide sich davon, wie dies in 
der Philosophie angegangen werden müsse. In der neuen Philosophie, d.h. Phänomenologie, sei in Bezug auf Phänomene eine »ganz andere Einstellung « notwendig. In der Einleitung von Ideen zu einer reinen Phänomenologie und phänomenologischen Philosophie (1913) umschreibt er diesen Aspekt wie folgt:

Sie [die Phänomenologie, MD] nennt sich eine Wissenschaft von Phänomenen. Auf Phänomene gehen auch andere, längst bekannte Wissenschaften. So hört man die Psychologie als eine Wissenschaft von den psychischen, die Naturwissenschaften von den physischen »Erscheinungen« oder Phänomenen bezeichnen; ebenso ist gelegentlich in der Geschichte die Rede von historischen, in der Kulturwissenschaft von Kultur-Phänomenen; und ähnlich für alle Wissenschaften von Realitäten. Wie verschieden in solchen Reden der Sinn des Wortes Phänomen sein und welche Bedeutungen es irgend noch haben mag, es ist sicher, daß auch die Phänomenologie auf all diese »Phänomene« und gemäß allen Bedeutungen bezogen ist: aber in einer ganz anderen Einstellung, durch welche sich jeder Sinn von Phänomen, der uns in den altvertrauten Wissenschaften entgegentritt, in bestimmter Weise modifiziert. Nur als so modifizierter tritt er in die phänomenologische Sphäre ein. Diese Modifikationen verstehen, oder, genauer zu sprechen, die phänomenologische Einstellung vollziehen, reflektiv ihre Eigenart und diejenige der natürlichen Einstellungen in das wissenschaftliche Bewußtsein erheben - das ist die erste und keineswegs leichte Aufgabe, der wir vollkommen genugtun müssen, wenn wir den Boden der Phänomenologie gewinnen und uns ihres eigentümlichen Wesens wissenschaftlich versichern wollen. (Husserl 1913: 1, Herv. MD)

Der von Husserl behauptete prinzipielle Unterschied zwischen der Philosophie und anderen Wissenschaften ist für seine Neupositionierung der Philosophie als Phänomenologie zentral. Zwar untersuche auch die Philosophie Phänomene, sie müsse dies jedoch in einer ganz anderen Weise als die anderen Wissenschaften tun, nämlich indem sie - im Unterschied zu den anderen Wissenschaften - zugleich reflektiere, wie Phänomene dem menschlichen Bewusstsein überhaupt zugänglich werden. Deswegen müsse in der Philosophie untersucht werden, was das Bewusstsein erkennen kann und wie es erkennt. In dieser »ganz anderen Einstellung « der Philosophie sei das Bewusstsein - wie erläutert - immer ein Bewusstsein »von etwas«. Das 〉innere Bewusstsein erscheint nicht etwa als ein von der ‘äußeren < Welt abgetrennter Bereich, sondern beide Dimensionen - Welt und Bewusstsein - beeinflussen sich wechselseitig. Husserl weist der Philosophie die Aufgabe zu, genau diese Wechselseitigkeit in den Blick zu nehmen. Das heißt, es geht ihm darum, das Wesen eines Phänomens erfassbar zu machen und dabei beide Seiten -Subjekt und Objekt, inneres und äußeres Erleben, Welt und Bewusstsein - im Blick zu behalten. Um dieser Beidseitigkeit gerecht zu werden, sind gemäß Husserl 
neue phänomenologische Methoden erforderlich. An dieser Stelle wird ein Aspekt erkennbar, der in den weiteren Kapiteln noch näher ausgeführt wird: Ein Erneuerungsanspruch der Philosophie geht jeweils mit der Begründung einer neuen philosophischen Methode einher. Bei Husserl heißt diese Methode »Wesensanalyse des Bewusstseins« bzw. »eidetische Reduktion«. An dieser Stelle soll jedoch nicht tiefer in seine Konzeption eingedrungen, sondern weiterhin die Ebene der Positionierungsstrategien verfolgt werden.

\section{Krisen und ein »Heilmittel«}

Husserls Ausführungen erzeugen nicht nur den Eindruck, dass die Philosophie gänzlich vom Weg der Wissenschaftlichkeit abkommen und zur puren Weltanschauung verkommen könnte, sondern es wird nebst der philosophischen Krise auch eine gesellschaftliche Krise diagnostiziert:»Die geistige Not unserer Zeit ist in der Tat unerträglich geworden. Wäre es doch nur die theoretische Unklarheit über den Sinn der in den Natur- und Geisteswissenschaften erforschten `Wirklichkeiten<, was unsere Ruhe störte [...]. Es ist vielmehr die radikalste Lebensnot, an der wir leiden, eine Not, die an keinem Punkte unseres Lebens halt macht « (Husserl 1910/11: 336). Er fordert eine Erneuerung der Philosophie nicht nur deswegen, weil ansonsten die Philosophie und die Wissenschaft ihr Fundament verlieren würden, sondern damit zusammenhängend, weil sonst die gesamte Menschheit in eine Krise geraten könnte. Indem er eine in diesem Sinne alternativlose Situation zeichnet, erscheint sein Vorschlag einer Aktualisierung der Philosophie als Phänomenologie als umso notwendiger.

Ohne dass Husserl die »geistige Unerträglichkeit« in sozialer, ökonomischer, gesellschaftlicher oder psychologischer Hinsicht ausführt, wird deutlich, dass er die Krise der Philosophie als eine gesamtgesellschaftliche Krise versteht. »Ich meine«, schreibt er, »unsere Zeit ist ihrem Berufe nach eine große Zeit - nur leidet sie am Skeptizismus, der die alten, ungeklärten Ideale zersetzt hat« (ebd.: 340). Die »geistige Not« erscheint als eine Not der Gegenwart. Die Herkunft dieser Not konstatiert er in der Wissenschaft, wie sie von den Naturalisten und Historizisten betrieben werde:

Die Not stammt hier von der Wissenschaft. Aber nur Wissenschaft kann die Not, die von Wissenschaft stammt, endgültig überwinden. Löst die skeptische Kritik der Naturalisten und Historizisten die echte objektive Gültigkeit in allen Sollensgebieten in Widersinn auf; hemmen unklare, unstimmige [...] Begriffe der Reflexion ein Verständnis der Wirklichkeit [...]; wird eine spezielle [...] methodische Einstellung gewohnheitsmäßig geübt [...] und hängen mit solchen Vorurteilen das Gemüt bedrängende Widersinnigkeiten der Weltauffassung 
zusammen - so gibt es gegen diese und alle ähnlichen Uebel nur Ein [sic!] Heilmittel: wissenschaftliche Kritik [...]. (ebd.: 337)

Husserl plausibilisiert die Notwendigkeit einer neuen Philosophie mit der Kritik an den zeitgenössischen Wissenschaften und Philosophien. In den folgenden Kapiteln wird sich zeigen, dass diese Strategie auch bei den anderen Neupositionierungen zentral ist. In diesem Zitat Husserls ist zudem die aus dem Bereich der Krankheiten stammende Wortwahl interessant: Es wird suggeriert, dass das »Übel«, das durch die Wissenschaft ausgelöst wird, »geheilt« werden könne: durch die Philosophie. Die Wissenschaften seien an einem Umschlagpunkt angelangt; entweder die Lage verbessere sich, und die Wissenschaften werden »geheilt«, oder sie schlägt in die Katastrophe um.

Wenn Husserl schreibt, das Übel widersinniger wissenschaftlicher Konzepte könne mit wissenschaftlicher Kritik geheilt werden, erscheint das »Heilmittel« - die Kritik - in einem doppelten Licht: Zum einen stellt er die »streng wissenschaftliche Philosophie« als ein Instrument dar, um auf Skeptizismus, Relativismus und Positivismus in den Wissenschaften zu reagieren. Zum anderen beschreibt er sie als Mittel, um das grundsätzliche »Leiden« der Gegenwart zu mindern. Er stellt somit eine unausgesprochene Verbindung zwischen den wissenschaftlichen Konzepten und den gesellschaftlichen Umständen seiner Zeit her. Ohne es im Detail auszuführen, betont Husserl an vielen Stellen in seinem Text, dass der Philosophie eine über die Wissenschaft hinausgehende Verantwortung zukomme: Es müsse, sagt er beispielsweise, »darauf bestanden werden, dass wir auch der Verantwortung eingedenk bleiben, die wir hinsichtlich der Menschheit haben « (ebd.: 337). Er ruft dazu auf, an wissenschaftlichen Prinzipien im Sinne der Ewigkeit festzuhalten: Um der Zeit willen dürfen wir die Ewigkeit nicht preisgeben, unsere Not zu lindern, dürfen wir nicht Not um Nöte unserer Nachkommen als ein schließlich unausrottbares Übel verderben« (ebd.). Diese Appelle enthalten nicht nur Aussagen über die Wichtigkeit der Philosophie, sondern stellen sie zugleich her. Indem Husserl sich selbst und der Philosophie in dieser Weise Verantwortung zuweist, positioniert er sie zugleich als Retterin. »Der Philosoph wird in diesem Sinne [...] zum Lehrer und Führer der Menschheit« (Schneiders 1997: 77-78). Husserl konstatiert - mehr implizit als explizit - Krisen, um davon ausgehend eine neue Philosophie zu entwickeln. Die Rede über Krisen enthält ein legitimatorisches Potenzial. Indem er impliziert, dass sowohl die Gesellschaft als auch die Philosophie bzw. ihre Wissenschaftlichkeit in der Krise stecken, erscheint eine Erneuerung der Philosophie als umso notwendiger. Durch seine Gleichsetzung der Philosophie mit Wissenschaftlichkeit überhaupt stellt 
er zugleich das Primat der Philosophie gegenüber anderen Wissenschaften heraus und bekräftigt dadurch argumentativ die Stellung der Philosophie als $>$ Erste Wissenschaft<.

\subsection{Fundierung durch Abgrenzung}

Husserls Argumente können als eine Reaktion auf die Herausforderung verstanden werden, dass die Unabhängigkeit des menschlichen Geistes am Anfang des 2o. Jahrhunderts durch die Erkenntnisse aus der Psychologie und Psychoanalyse grundsätzlich infrage steht. Die potenziell experimentelle Vermessbarkeit des Bewusstseins beschreibt für die Philosophie eine Krise: Welche Funktion kann Philosophie innerhalb der Wissenschaften noch einnehmen, wenn das Bewusstsein bzw. der menschliche Geist potenziell von den Naturwissenschaften erklärt werden kann?

Husserls Argumentationsstrategien zielen darauf, das Bewusstsein als einen für die Philosophie zentralen Gegenstand zurückzuerobern, indem er nachweist, dass nicht nur naturwissenschaftlich-psychologische Erklärungsmodelle zu kurz greifen, sondern ebenso die Kritiken an diesen Modellen, die in historizistischen bzw. relativistischen Ansätzen münden würden. Ausgehend von der empirischen Psychologie teilt er die Wissenschaften seiner Zeit entweder in »naturalistische« oder »historizistische« Erklärungsmodelle ein und kritisiert beide als je unzulänglich. Er zeichnet eine verfahrene Situation, indem er die Entweder-oder-Haltung - entweder Naturalismus oder Historizismus - als aporetisch darstellt. Er argumentiert für die Notwendigkeit einer neuen Philosophie, die gewissermaßen als verbindendes Element beider Pole einen Ausweg aus dieser als alternativlos erscheinenden Situation bieten soll. Als Folge präsentiert er seine eigene Position als dritten Weg gegenüber zwei etablierten philosophischen Positionen: Er konstituiert die Phänomenologie als Alternative sowohl zum Szientismus bzw. zu den Naturwissenschaften als auch zum Historizismus bzw. zu den Geisteswissenschaften. ${ }^{65}$

Husserl schreibt dieser neuen Philosophie das Vermögen $\mathrm{zu}$, bestehende Dualismen - Empirie und Theorie, Natur und Geist, Naturalismus und Historizismus, Subjekt und Objekt, Naturwissenschaften und

65 Eine aktualisierte Version dieser Strategie kann an Bruno Latour beobachtet werden, der die Wissenschaftsforschung als verbindendes Element zwischen Geistes- und Naturwissenschaften versteht und sich selbst explizit als Philosoph positioniert (Dätwyler 2018). 
Geisteswissenschaften - überwinden zu können. ${ }^{66}$ Das Bewusstsein ist der Dreh- und Angelpunkt dieser Argumentation. Die »Wesensanalyse des Bewusstseins « stelle eine Alternative zur empirischen Vermessbarkeit des menschlichen Geistes auf der einen Seite und zum historischen Relativismus auf der anderen Seite dar. Am Bewusstsein werde gewissermaßen prototypisch greifbar, dass Subjekt und Objekt eine Korrelation bilden und nicht unabhängig voneinander gedacht werden können. Er plausibilisiert seine Argumente maßgeblich mit einer Psychologiekritik. Indem er empirisch-psychologischen Erklärungsansätzen unterstellt, diese würden nicht das »Ganze« erfassen können, rehabilitiert er die Möglichkeit, dies durch eine neue philosophische Methode leisten zu können. Für dieses Selbstverständnis einer streng wissenschaftlichen Philosophie gelte es einzustehen. Erst indem er an zeitgenössischen Strömungen deren Unzulänglichkeiten reaktiv aufzeigt, erzeugt er einen fundierenden Standpunkt - und der liege in der Phänomenologie. Dieser Standpunkt wiederum wird prospektiv verstanden: Er lässt sich nur in Relation zu den anderen Wissenschaften entwickeln. Indem Bestehendes kritisiert wird, wird etwas Zukünftiges behauptet. Der letzte Satz aus Philosophie als strenge Wissenschaft bringt diese Gleichzeitigkeit von Reaktion und Prospektion auf den Punkt:

[...] es ist der größte Schritt, den unsere Zeit zu machen hat, zu erkennen, daß mit der im rechten Sinne philosophischen Intuition, der phänomenologischen Wesenserfassung, ein endloses Arbeitsfeld sich auftut und eine Wissenschaft, die ohne alle indirekt symbolisierenden und mathematisierenden Methoden, ohne den Apparat der Schlüsse und Beweise, doch eine Fülle strengster und für alle weitere Philosophie entscheidender Erkenntnisse gewinnt. (Husserl 1910/11: 341)

Wenn durch die »im rechten Sinne philosophische Intuition« erkannt werde, dass mit der phänomenologischen Wissenschaft streng wissenschaftliche Erkenntnisse gewonnen werden, dann erst werde deutlich, dass die Phänomenologie den richtigen Weg weise.

Die Überwindung von Dualismen könne nur dann gelingen, wenn die Philosophie das Prinzip der Wissenschaftlichkeit grundsätzlich in sich aufnehme bzw. daran festhalte. Husserl begründet die Wissenschaftlichkeit der Philosophie mit dem Prinzip der Philosophie selbst: Philosophie sei

66 Die Selbstpositionierungsstrategien des Szientismus werden im weiteren Verlauf dieses Buches durch das Beispiel des Wiener Kreises, der Historizismus hingegen durch das Beispiel der Kritischen Theorie thematisiert. 
strenge Wissenschaft per Definition. ${ }^{67}$ In diesem Zusammenhang ist seine Setzung zu verstehen, dass an der Idee der Überzeitlichkeit von Wissenschaft und Philosophie festgehalten werden müsse. Ausgehend von dieser Setzung argumentiert er für die Wissenschaftlichkeit seiner neuen, genuin philosophischen Methode. Er verteidigt, dass es wissenschaftliche Wahrheit unabhängig von empirischen Erklärungsansätzen gibt und geben muss. Die Setzung ist reaktiv; die Wahrheit liegt darin, dass es eine andere wissenschaftliche Wahrheit gibt. Diese Wahrheit wiederum wird als etwas Zukünftiges vorgestellt: Sie werde sich, so Husserl, in der Methode der Phänomenologie bzw. in einer streng wissenschaftlichen Philosophie verwirklichen.

Es sei der Philosophie vorbehalten, die Welt- und Lebensrätsel in ihrem Grund enthüllen zu können. In der Philosophie liegt für Husserl die Wahrheit. Der Status der Philosophie als Königin der Wissenschaften und damit ihr Machtanspruch über die anderen Wissenschaften wird von Husserl selbstverständlich vorausgesetzt und verteidigt. Ähnlich wie es am Beispiel des Wiener Kreises deutlich werden wird, begründet er diesen Status mit dem wissenschaftlichen Fortschritt insgesamt: Ohne Philosophie als regulierende Instanz verliere die Wissenschaft ihre Wissenschaftlichkeit. Dadurch aktualisiert er gleichzeitig den Führungsanspruch der Philosophie: Als Modell der Wissenschaftlichkeit per se nimmt die Philosophie die Rolle der Retterin der Wissenschaften im Allgemeinen ein. Die propagierte Wissenschaftlichkeit nimmt bei ihm die Züge eines ethos an: Während - wie im nächsten Kapitel deutlich wird - die Vertreter des Wiener Kreises Wissenschaftlichkeit nach dem Vorbild der exakten Wissenschaften verstehen, bleibt bei Husserl relativ offen, was darunter zu verstehen ist. Vermutlich ist es dieser Offenheit zuzuschreiben, dass bei ihm die Kopplung von Philosophie mit Kritik eine breite Bestimmung erhält: Da Philosophie im Prinzip Wissenschaft ist - und als Kehrseite davon die Wissenschaften im Prinzip philosophisch zu sein haben -, weist Husserl den Wissenschaften und der Philosophie generell eine kritische Funktion zu. Hier liegt die Stärke des Erneuerungsanspruchs der Phänomenologie: Durch die Rehabilitation der Philosophie als Wissenschaft im Prinzip wird ein philosophischer Standpunkt legitimiert, der unabhängig von den empirischen Wissenschaften Wissenschaftlichkeit beansprucht und beanspruchen kann.

Husserl reaktiviert und aktualisiert dadurch in zweierlei Hinsicht ein traditionelles philosophisches Selbstverständnis: erstens die Philosophie als Modell, an dem sich alle andere Wissenschaften zu orientieren haben, und

67 Dies markiert einen zentralen Unterschied zu den Erneuerungsstrategien des Wiener Kreises: Dessen Vertreter begründen die Wissenschaftlichkeit der Philosophie nicht mit dem Prinzip der Philosophie selbst, sondern mit den exakten Naturwissenschaften. 
zweitens die Philosophie als kritisches Moment. Die Kritik, die Husserl fordert, ist »eine radikale, eine von unten anhebende, in sicheren Fundamenten gründende und nach strengster Methode fortschreitende Wissenschaft: die philosophische Wissenschaft, für die wir hier eintreten« (ebd.: 337). Die Philosophie, so die Implikation, sei radikaler, tiefer, fundamentaler und strenger als die anderen Wissenschaften. Das philosophische Selbstverständnis, das bei Husserl ersichtlich wird, ist paradigmatisch für die Philosophie: Die Philosophie ist jene Wissenschaft, die »tief« blickt. So habe sich für »Tieferblickende« der Glaube, dass den Naturwissenschaften die Aufgabe zukomme, die Rätsel der Wirklichkeit zu enträtseln, als »Aberglaube« enthüllt (ebd.: 336). Die Philosophie als tiefe und fundamentale Wissenschaft habe das Vermögen, anderen Wissenschaften ihre Mängel vorzuwerfen: Die Philosophie ist - ihrem Selbstverständnis nach - jene Wissenschaft, die andere Wissenschaften kritisieren kann, soll und darf. Husserl stellt die Philosophie als Korrektiv für die anderen Wissenschaften dar. ${ }^{68}$

Der Philosoph Thomas Rentsch konstatiert, dass Husserls Phänomenologie etwas von der »Rückgewinnung eines Geheimnisses der Wirklichkeit nach dem Schwund aller metaphysischen und weltanschaulichen Systemkonstruktionen an sich [hatte]: und dies als strenge Analyse « (ebd.: 33). In der Tat: Indem Husserl anderen Positionen Leerstellen nachweist, ohne die Philosophie >an sich in diese Kritik miteinzubeziehen, gelingt es ihm paradoxerweise, einen alten Kernbegriff der Philosophie so zu aktualisieren, dass sich daraus neue Forschungsfelder etablieren. Er reklamiert für die Philosophie tatsächlich ein »Geheimnis« (zurück), das es philosophisch zu erforschen gilt: das Bewusstsein.

\section{Husserls Denken setzt dort ein, wo Seidels Denken sich vollzieht}

Im Vergleich zu Seidels Bewußtsein als Verhängnis können diese Schlussfolgerungen zugespitzt werden. Im Gegensatz zu Husserl ringt Seidel mit der Befürchtung, dass die Wissenschaften, die Philosophie und dadurch auch seine eigenen Forschungen verheerend und verhängnisvoll sein könnten. Denn von welchem Standpunkt aus kann die Kritik an anderen Wissenschaften legitimiert werden, wenn Erkenntnisstandpunkte lediglich Produkte psychologischer Prozesse sind - Resultate eines »Grübelzwangs« (Seidel 1927: 100) »sublimierender Perverser« (ebd.: 212)? Was garantiert unter diesen

68 Es wird sich zeigen, dass die Rolle der Philosophie als Korrektiv für die anderen Wissenschaften vorwiegend in der Kritischen Theorie argumentativ rehabilitiert wird, während die Aktualisierung der Philosophie als Fundament aller Wissenschaften vorwiegend bei Husserl und dem Wiener Kreis erkennbar ist. 
Voraussetzungen, dass der eigene Standpunkt richtig ist? Der erkenntnistheoretische und existentielle Circulus vitiosus, der aus Seidels Befürchtung resultiert, ist in Husserls Argumentation nicht vorhanden. Husserl kritisiert zwar die »Wissenschaftsverfallenheit« seiner Zeit, er nimmt die Philosophie, d.h. die neue, streng wissenschaftliche Philosophie, auf deren Standpunkt er sich stellt, aber davon aus. Die Problematik, die aus Seidels Überlegungen herauszulesen ist, nämlich der Verlust eines objektiven Standpunkts durch die Psychologisierung des Geistes, scheint Husserl nicht direkt zu affizieren, sondern stellt im Gegenteil die produktive Grundlage seiner Erneuerung dar. Es stellt sich somit die Frage, wie Husserl mit dem von Seidel geschilderten Dilemma umgeht. Wie löst er das Problem der Infragestellung eines objektiven philosophischen Standpunkts durch andere Wissenschaften?

Nun, Husserl erschafft einen solchen Standpunkt. Er behauptet und setzt eine Position, indem er sich auf ein bestimmtes Philosophieverständnis bezieht. Was für Seidel erklärungsbedürftig scheint, nämlich die Setzung der Philosophie als einer Wissenschaft, die im Prinzip mit Wahrheit gleichzusetzen ist, ist für Husserl eine Ausgangslage. Er spricht jedoch nicht ausgehend von einer >sicheren < disziplinären Position, sondern evoziert diese im Vollzug seiner Analysen, d.h. durch seine Absetzung von anderen Wissenszugängen. Indem er naturwissenschaftliche und psychologische Erkenntnisse in systematischer Weise ad absurdum führt, entsteht erst eine philosophische Position; eine Position, die impliziert, dass es eine andere wissenschaftliche Wahrheit potenziell gibt. Husserl argumentiert für einen Standpunkt, der das Bewusstsein >von außen < zu betrachten beansprucht, gerade weil er Erkenntnisse aus der empirischen Psychologie in seine Argumentation aufnimmt, ernst nimmt und philosophisch unterlegt. Dieser Standpunkt ermöglicht, dass das Bewusstsein auch unabhängig von naturwissenschaftlich-psychologischen Erkenntnissen als ein relevantes Forschungsobjekt erscheint, und stellt gleichzeitig eine Neupositionierung der Philosophie dar.

Genau diese Möglichkeit ist in Seidels Bewußtsein als Verhängnis nicht vorhanden. Er hat die Distanzierung zu den eigenen Denkbewegungen, die bei Husserl sichtbar wird und letztlich in der Behauptung eines vom Forschungsobjekt (hier: vom Bewusstsein) unabhängigen Erkenntnisstandpunktes besteht, nicht vorgenommen. Anders als Husserl hat er Erkenntnisse aus anderen Wissenschaften (z.B. die Naturalisierung des Bewusstseins) nicht objektiviert oder kritisiert, sondern diese in seine Überlegungen mit einbezogen. Er hat zwar, genau wie Husserl, die »Wissenschaftsverfallenheit« seiner Zeit kritisiert, aber, anders als Husserl, die Wissenschaft und die Philosophie nicht als objektive und unabhängige Instanz der Erkenntnis vorausgesetzt. Seidel »stempelt« die Wissenschaft und Philosophie nicht mit der 
Ewigkeit. Vielmehr hat er, über Husserl hinausgehend, »überhaupt an dem Werte des Bewusstseins gezweifelt « (Seidel 1927: 75). Husserls Voraussetzung die Setzung der Philosophie als eine wahre und gute Wissenschaft bzw. die potenzielle Gleichsetzung von Philosophie und Wahrheit - ist in Bewußtsein als Verhängnis nicht vorhanden. Im Gegenteil führt Seidels Frage, inwiefern das Bewusstsein negativ wirkt, letztlich zur Frage nach der Möglichkeit von Wahrheit selbst.

Husserl ist Seidels Teufelskreis somit entgangen. Er wird in Philosophie als strenge Wissenschaft nicht müde zu betonen, wie »widersinnig « es sei, das Bewusstsein mit empirischen Methoden erfassen zu wollen. Der Zirkelschluss, der in den Denkbewegungen von Bewußtsein als Verhängnis deutlich geworden ist, erscheint bei Husserl als Ausgangslage, d.h. als etwas, was es zu widerlegen gilt: der Widersinn, ein Problem, das den Naturwissenschaften als solchen anhaftet, naturwissenschaftlich lösen zu wollen (Husserl 1910/11: 300). Seidel hat sich argumentativ also in genau jener Thematik aporetisch verfangen, die Husserl stillschweigend voraussetzt. Auch Seidel spricht von den Wissenschaften als »Realitäten«, er behauptet aber im Gegensatz zu Husserl, dass durch die wissenschaftlichen Realitäten die zeitlosen Ideen »entthront« worden seien: »Die Entthronung der absoluten Ideen durch die Bejahung der Realitäten - heißen diese nun Leben, Macht, Sexualität einerseits oder Nation und Klasse andererseits - ist Zeichen der Auflösung der Kultur. Die Spannung zwischen Idee und Realität wird aufgehoben, die Realität selbst zur Idee erhoben [...] (Seidel 1927: 202). ${ }^{69}$ Die wissenschaftlichen Realitäten seien, so Seidel, an die Stelle der absoluten Ideen getreten, und die Spannung zwischen Realität und Idee sei verschwunden. Anders als Husserl, der an dieser Spannung festhält und dadurch wissenschaftliche und philosophische Entscheidungen autorisiert, sieht Seidel keine Möglichkeit, wie die Gültigkeit wissenschaftlicher Erkenntnisse epistemologisch noch legitimiert werden könnte.

Husserl setzt diese Möglichkeit, hält an ihr fest und entwickelt daraus sein Argumentarium. Sein Denken beginnt dort, wo Seidels Denken bereits stattfindet. Er nimmt einen erkenntnistheoretischen Standpunkt jenseits des Seidel'schen endlosen Regresses ein: Er setzt die Möglichkeit, dass andere, neue Wahrheiten gültig werden könnten. Was für Husserl eine Ausgangslage war, war für Seidel eine Konsequenz: Andere Wahrheiten als die bestehenden gibt es in der hier vorgenommenen Interpretation für Seidel nicht. Wo er die Möglichkeit anderer Wahrheiten schwinden sieht, stellt Husserl sie her. Wenn

69 Dieses Zitat wurde auf S. 30 im Zusammenhang mit Seidels erkenntnistheoretischer >Bodenlosigkeit< besprochen. 
Prinzhorn Seidel in seinem Vorwort in paternalistischer Weise »als reine[n] Tor « bezeichnet, der »mit dem schwersten Rüstzeug des Geistes allzu ernsthaft spielte « (Prinzhorn 1927: 68), kann im Kontrast dazu festgestellt werden, dass Husserl mit großer Ernsthaftigkeit die richtigen Setzungen vorgenommen und diese gemäß den disziplinären Spielregeln seiner Zeit verteidigt hat. Die philosophischen Inhalte, die dadurch aktualisiert wurden, gelten bis heute.

\section{Aktualität}

An Husserls Text werden Positionierungsstrategien sichtbar, die - vor allem im Kontext neurophilosophischer Debatten - höchst aktuell sind. Ein Beispiel soll als Abschluss dieses Kapitels kurz vorgestellt werden. Die Philosophin Patricia Churchland ${ }^{70}$ veröffentlicht 1986 ihr Buch Neurophilosophy (1986): Da das materielle Gehirn Träger aller mentalen Zustände ist - so Churchlands Thesen des »eliminative materialism « in verknappter Form -, gelte es, die »Alltagspsychologie« (folk psychology) sukzessive durch neurowissenschaftliche Modelle zu ersetzen. Diese Position wiederum wird innerhalb des Gebietes der Philosophy of Mind als Extremposition gehandelt - offensichtlich stellt sie eine Provokation dar: zum einen, wie es Jerry Fodor ausdrückt, in Form einer grundsätzlichen intellektuellen Katastrophe:»[...] if commonsense intentional psychology were to collapse, that would be, beyond comparison, the greatest intellectual catastrophe in the history of our species; if we're that wrong about the mind, then that's the wrongest we've ever been about anything " (Fodor 1987: xii). Zum anderen wird der »eliminative materialism « als eine Bedrohung für die Philosophie selbst dargestellt. Jasper Liptow bemerkt am Schluss seiner Philosophie des Geistes zur Einführung:Wenn die vorangehenden Überlegungen nicht völlig verkehrt sein sollten, »[...] dann zielt der eliminative Materialismus nicht nur auf das Ende des Geistes, wie wir ihn kennen, sondern auch auf das Ende der Philosophie des Geistes, wie wir sie kennen« (Liptow 2013: 180). Georg Northoff, sowohl Hirnforscher als auch Philosoph, sagt diesbezüglich lapidar in einem Interview: Nach Churchland $»[. .$.$] ersetzen die Neuro-$ wissenschaften die Philosophie, die kein eigenständiges Existenzrecht mehr hat « (Northoff 2008: 68).

Diese Episode bringt exemplarisch zutage, dass die Psychologisierung und Naturalisierung des Geistes bzw. des Bewusstseins für philosophische

70 In diesem Beispiel wird eine genealogische Linie von Wundt zu Churchland sichtbar. Olaf Breidbach verortet die Anfänge der aktuellen Neurophilosophie bei Wundt: »Im Vergleich der Bücher von Wundt und Churchland zeigt sich, daß auch der von der Neurophilosophie reklamierte Stellenwert des Neuronalen keineswegs neu und für die philosophische Diskussion innovativ ist« (Breidbach 1997: 393). 
Erneuerungsansprüche bis heute ein produktives Gebiet sind. Northoff etwa fordert eine neue philosophische Methode: »Aufgrund der unterschiedlichen Geltungsansprüche, Bedingungen und Problemstellungen in der Philosophie und den Neurowissenschaften können philosophische Theorien nicht durch neurowissenschaftliche Befunde verifiziert oder falsifiziert werden. Zur Vermeidung von solchen interdisziplinären Reduktions- bzw. Identifizierungsversuchen muss eine spezielle Methodik, die `Neurophilosophie<, entwickelt werden [...] « (Northoff 2000: 169). Um den Herausforderungen aus der Hirnforschung begegnen zu können, ist für Northoff die Entwicklung einer neuen Methodik unerlässlich. ${ }^{71}$ In struktureller Hinsicht wird am hier aufgegriffenen Beispiel aus der Decade of the Brain seit den 199oer-Jahren eine ähnliche Argumentationskonstellation deutlich, wie sie an Husserl erarbeitet wurde: Die Möglichkeit, von einer empirischen Wissenschaft (hier den Neurowissenschaften) gewissermaßen >geschluckt $`$ zu werden, wird für Philosophinnen und Philosophen zum Anlass, neue philosophische Arbeitsgebiete zu entwickeln (hier in Form der Neurophilosophie) - und zwar, indem sie sich mit genau diesen Herausforderungen auseinandersetzen. Northoff weist reaktiv aus, dass eine rein neurowissenschaftliche Perspektive Reduktionismen unterliegt bzw. keine adäquate Methode ist, die das menschliche Bewusstsein erfassen könnte, und entwickelt davon ausgehend die Methode der Neurophilosophie.

Es wird also eine ähnliche Argumentationsstruktur deutlich, wie sie in diesem Kapitel am Beispiel von Husserl herausgearbeitet wurde: Ein naturalistischer Ansatz wird als verkürzt abgelehnt, um davon ausgehend neue philosophische Methoden zu entwickeln. Wo gegenwärtig das Gehirn im Mittelpunkt steht, stand am Anfang des 20. Jahrhunderts die Psyche im Fokus des Forschungsinteresses. Die für Philosophen und Philosophinnen zentralen Fragen jedoch betreffen heute wie damals das gleiche Thema, nämlich die potenzielle empirische Vermessbarkeit des menschlichen Bewusstseins. Indem sie sich in zeitgenössische Debatten einschreiben, aktualisieren sie die Philosophie als jene zentrale Instanz, die das menschliche Bewusstsein zu bewahren und zu verteidigen beansprucht.

In der philosophischen Erneuerung, die am Beispiel von Husserl deutlich geworden ist, wird eine Form von Wahrheit verteidigt, die sich den naturwissenschaftlich-empirischen Wissenschaften nicht widersetzt, sondern die Absolutheit der Wahrheitsansprüche dieser Wissenschaften infrage stellt. Im nächsten Kapitel wird am Beispiel des Wiener Kreises eine philosophische Erneuerung beleuchtet, die - wie der Erneuerungsanspruch der

71 Weitere gegenwärtig bekannte Partizipanten an dieser Debatte sind etwa Daniel Dennett, David Chalmers oder Gerhard Roth und Wolf Singer. 
Phänomenologie - einen fundierenden Anspruch erhebt, diese Fundierung aber mit gänzlich anderen Strategien erzielt: Die Vertreter des Wiener Kreises intendieren eine Neufundierung der Philosophie nicht durch die Abgrenzung gegenüber den Naturwissenschaften, sondern durch die Identifikation mit den Methoden ebendieser Wissenschaften. Sie reagieren damit auf die Gefahr, die Philosophie könne aufgrund des Deutungsanspruchs der Naturwissenschaften ihre wissenschaftliche Objektivität verlieren. 


\title{
Wiener Kreis: Identifikation
}

\author{
Philosophie betreiben bedeutet nichts anderes als: die Begriffe und Sätze \\ der Wissenschaft durch logische Analyse klären. \\ Rudolf Carnap, Die alte und die neue Logik (1930/31)
}

\subsection{Herausforderung: Verlust wissenschaftlicher Objektivität}

Im Gegensatz zu den anderen beiden Fallbeispielen (Husserl und Kritische Theorie) gibt es zwischen Alfred Seidel und dem Wiener Kreis weder eine biografische noch eine im engeren Sinne philosophietheoretische Verbindung. Seidel, der, wie im dritten Beispiel deutlich werden wird, als Vorläufer der Kritischen Theorie verstanden werden kann, nimmt keine direkten Bezüge zum Korpus, in dessen Tradition der Logische Positivismus steht. Meiner Interpretation nach subsumiert Seidel generell unter >Positivismus< das, was späterhin als die Maximen des Wiener Kreises bekannt wurde. >Positivismus< wiederum, verstanden als ahistorische, keiner potenziellen Revision bedürftige Wahrheit, ist für Seidel unakzeptabel. Er sei überzeugt, schreibt er, »dass alle Meinungen und Empfindungen, sogar die Ergebnisse der exakten Wissenschaft, einem räumlich und zeitlich begrenzten Kulturkreise angehören « (Seidel 1927: 122, Herv. MD). Dies wiederum lege den Schluss nahe, dass »die eigene Weltanschauung nur Ausdruck einer Zeitepoche ist, dass auch sie überholt werden wird, wie so manche Auffassung, die mit Emphase als letzte Wahrheit verkündet wurde« (ebd.).

Seidels Diagnose kann als Ausdruck eines allgemeineren Verständnisses gesehen werden, dass nämlich am Anfang des 20. Jahrhundert auch die exakten Wissenschaften Krisen erfahren. Bevor die Analysen zum Wiener Kreis beginnen, soll an einem Beispiel - an zwei Textausschnitten aus dem Band Krise und Neuaufbau in den exakten Wissenschaften (1933) - in knapper Form greifbar gemacht werden, was damit gemeint ist. Die Verfasser des Vorworts ${ }^{72}$ dieses Buches schreiben: »In Wahrheit sind die exakten Wissenschaften vor Krisen

72 Die Verfasser des Vorworts werden nicht angegeben. Der Band enthält fünf Vorträge (»Die Erschütterung der klassischen Physik durch das Experiment« von Hermann Mark, »Die Wandlung des Begriffssystems der Physik« von Hans Thirring, »Die Krise der Anschauung « von Hans Hahn, »Die vierte Dimension und der krumme Raum« von Georg Nöbeling sowie »Die neue Logik« von Karl Menger). 
keineswegs gesichert und gerade in den letzten Jahrzehnten sind sie von der theoretischen Physik bis hinein in die Logik von schweren Krisen erschüttert worden « (Deuticke 1933: o.S.). Was bisher als exakt angesehen worden sei, könne heute nur noch als durchschnittlich gelten, was als apriorisch gegolten habe, werde heute als empirischer Nachprüfung bedürftig erkannt. Wo früher nach Sicherem gefragt worden sei, frage man heute nach Wahrscheinlichem, und wo eine Erklärung gesucht wurde, suche man heute nach einer Beschreibung (ebd.). »Ja selbst in vielem, was man bewiesen zu haben glaubte, können wir nichts anderes mehr erblicken, als eine Transformation gewisser Ausgangssätze in gewisse andere Sätze, wobei sowohl die Ausgangssätze als auch die Transformationsregeln abänderbar sind « (ebd.). Kurz: Die hier exemplarisch zitierte Textstelle verdeutlicht eine Krise, nämlich dass die exakten Wissenschaften durch ihre eigene Ausdifferenzierung und Spezialisierung qua Anspruch auf Exaktheit nicht mehr exakt, apriorisch, sicher, erklärend und beweisend sind. Im Gegensatz zu Seidel, der durch Befunde dieser Art die wissenschaftliche Wahrheit und die Funktion der Wissenschaften allgemein infrage gestellt sah, verkünden die Verfasser des Vorworts von Krise und Neuaufbau in den exakten Wissenschaften - gleich nachdem sie die Symptome der Krise aufgelistet haben - optimistisch: »Aber ein Neuaufbau hat auf der ganzen Linie bereits erfolgreich begonnen!« (ebd.).

Die Verfeinerung unserer experimentellen Hilfsmittel hat zu außerordentlicher Reichweite und Genauigkeit unserer Beschreibungen geführt; Beobachtungen und Entdeckungen haben riesige neue Gebiete der Forschung entstehen lassen; ungeahnte Zusammenhänge wurden erkannt und führten zu neuen Begriffen und Begriffssystemen; die Argumentationen der Mathematik erreichten völlige logische Strenge; jenseits der Anschauung wurden rein deduktiv neue mathematische Systeme entwickelt, die sich vielfach physikalischer Anwendungen fähig erwiesen; und endlich wurden - zum ersten Male seit undenklichen Zeiten - wesentliche neue Erkenntnisse über das logische Schließen selbst gewonnen. (ebd.: o.S.)

Der Neuaufbau in den exakten Wissenschaften wird als unaufhaltsam beschrieben: »Es gibt kein Gebiet der exakten Wissenschaften, in dem die Bestrebungen eines Neuaufbaues nicht von Erfolg begleitet worden wären« (ebd.).

DieSelbstpositionierungsstrategien desWiener Kreises sindinnerhalbdieser »Linie«, die durch den wissenschaftlichen Fortschrittsgedanken geprägt ist, verortet. Seidel war dieser wissenschaftliche Optimismus fremd. Im Gegenteil drehen sich seine Fragen in Bewußtsein als Verhängnis immer wieder um das Problem, wie wissenschaftliche Erkenntnisse noch legitimierbar sind, wenn 
deren Objektivität grundlegend infrage gestellt wird. In letzter Konsequenz zeichnet er diesbezüglich ein Szenario der Unmöglichkeit. Die Problematik ist bereits in seinen Anfangssätzen angelegt, in denen er die allgemein feststellbare Glorifizierung und Verherrlichung des wissenschaftlichen Fortschritts entschieden als zu kurz gegriffen auffasst. »Alles glaubt man auf Grund ihrer Erkenntnisse [der Wissenschaft, MD] erreichen zu können. Daß dieses Wissen aber auch andere als die gepriesenen Wirkungen haben kann, das soll hier [in Seidels Buch, MD] gezeigt werden « (ebd.: 71). Seidel kritisiert - mit Husserl die »Wissenschaftsverfallenheit« seiner Zeit: »Wie kindlich optimistisch sind die Zeiten des Rationalismus in dem überschwänglichen Glauben an die Wirkungen des Erkennens; trotz aller Kritik ist noch heute das Pathos der Wissenschaft vielfach von diesem Glauben getragen « (ebd.: 75).

Im Unterschied jedoch zu Husserl, dessen Positionierungsstrategien u.a. auf die Legitimierung eines unabhängigen Status der Philosophie zielen und der die Haltung vertritt, dass wissenschaftliche Entscheidungen den »Stempel der Ewigkeit « besitzen (Husserl 1910/11: 337), macht Seidel klar, dass seine Untersuchungen nicht wertneutral sind. »Wertfreiheit bei charakterologisch gemeinten Untersuchungen wie der vorliegenden kann es nicht geben - noch viel weniger als bei den anderen Geisteswissenschaften « (Seidel 1924: 75). Ebenso unmöglich sei eine »metaphysikfreie Behandlung der Probleme« (ebd.). Zwar habe er die metaphysische Grundlage seiner Arbeit bewusst »herausgezogen « (da es sich bei der Untersuchung um eine psychologische und soziologische Fragestellung handele), sie mache sich aber »sofort bemerkbar, wo Erklärungen gegeben werden« (ebd.: 71-72). Metaphysische Voraussetzungen, so impliziert Seidel auf der einen Seite, durchzögen die Wissenschaften und die Philosophie zwingend. Auf der anderen Seite seien metaphysische Voraussetzungen nie »wertneutral«, d.h. nie objektiv. Das Seidel'sche Dilemma wird hier besonders deutlich: Von welchem Standpunkt aus können wissenschaftliche Erkenntnisse kritisch reflektiert werden, wenn diese umstandslos als gültig anerkannt werden? In seiner Fragestellung bringt Seidel das Dilemma auf den Punkt: »Wir stehen also mit den Verteidigern der Wissenschaften auf dem Standpunkt, daß die Welt des Sozialen und Psychischen - innerhalb gewisser Grenzen - erkennbar sei, und daß schon vieles erkannt wurde. Wir stellen demgegenüber die Frage, ob die Erkenntnis der sozialen und psychischen Vorgänge nicht gerade ihre Beeinflussung unmöglich macht, zumindest hemmt - die Frage nach dem Bewußtsein als Verhängnis« (ebd.: 74).

Weiter oben wurde argumentiert, dass in dieser Frage die Verluste philosophischer Standpunkte sichtbar werden: Seidel nimmt keine 
metawissenschaftliche philosophische Position ein, von der aus er eine Reflexion auf andere Wissenschaften vollziehen könnte. Als Folge davon verfängt er sich in einem erkenntnistheoretischen Zirkel, aus dem er keinen Ausweg weiß. An den Vertretern des Wiener Kreises kann eine Reaktion auf genau dieses Dilemma beobachtet werden: Sie aktualisieren in ihren Erneuerungsstrategien die Möglichkeit einer metawissenschaftlichen Position, der ein objektiver und universeller Status zukommt. Wie im Folgenden gezeigt wird, ist dafür zum einen eine Identifikation der Philosophie mit den exakten Wissenschaften, zum anderen die radikale Ausklammerung alles Metaphysischen aus dem Bereich des Wissenschaftlichen leitend.

Der Wiener Kreis gilt in der Philosophiegeschichte als Ursprung des Logischen Positivismus bzw. Logischen Empirismus ${ }^{73}$ und demnach als wichtiger Wegbereiter für die Entwicklung der Wissenschaftstheorie und der sogenannten analytischen Philosophie. ${ }^{74}$ Genau wie die Phänomenologie und die Kritische Theorie ist diese Tradition ein fixer Bestandteil des philosophischen Kanons des 2o. Jahrhunderts. Die analytische Philosophie gilt darüber hinaus als jene Tradition, die heute die philosophischen Fakultäten dominiert. Analog zu den anderen beiden Kapiteln werde ich im Folgenden im ersten Teil mein Untersuchungsmaterial vorstellen und daraus meine Hypothesen entwickeln (4.2). In einem zweiten Teil werde ich die Erneuerungsstrategien des Wiener Kreises an konkreten Textstellen nachzeichnen (4.3). In einem dritten Teil werde ich die bisherigen Ergebnisse meiner Arbeit in einem kurzen Zwischenfazit zusammenfassen (4.4). In einem letzten Teil schließlich, der gleichzeitig als Überleitung zum Kapitel über die Kritische Theorie fungiert, gehe ich auf die Gründe für die große Wirksamkeit der Erneuerungsstrategien des Wiener Kreises ein (4.5).

\subsection{Eine eigene Zeitschrift, Kongresse und eine Werbebroschüre}

Im Jahr 1895 wurde der Physiker Ernst Mach auf einen eigens für ihn eingerichteten Lehrstuhl der Philosophie an die Universität Wien berufen. Diese Berufung wird in der Philosophie- und Wissenschaftsgeschichte als wichtiges Ereignis wahrgenommen: »Dass ein Naturwissenschaftler philosophisch dilettierte, mochte noch angehen; doch dass er eine philosophische

73 Die Begriffe Logischer Positivismus und Logischer Empirismus werden hier synonym verwendet.

74 Ernest Nagel hat den Wiener Kreis bereits in seinen Impressions and Appraisals of Analytic Philosophy in Europe von 1936 als »analytische Philosophie« bezeichnet (Nagel 1936: 9). 
Lehrkanzel übernahm, ohne je über Kantianer oder Scholastiker examiniert worden zu sein, schien schon allerhand « (Sigmund 2015: 12). Mach und auch seinem Nachfolger Ludwig Boltzmann wird ein »disziplinüberschreitende[r] Einfluss « (Stadler 1993: 17) zugesprochen, der für die Entwicklung der Wissenschaftstheorie ausgehend vom Wiener Kreis entscheidend gewesen sei.

Naturwissenschaftler wie Mach, Fechner, Helmholtz oder Boltzmann treten in den philosophischen Diskurs ein, obwohl sie akademisch nicht dem Fachbereich Philosophie zugordnet sind beziehungsweise erst durch speziell eingerichtete Institutionalisierungsformen wie die Wiener Professur für »Philosophie, insbesondere Geschichte und Theorie der induktiven Wissenschaften « innerhalb der Philosophie institutionell sanktioniert werden. (Ziche 2008: 73)

Dieser institutionell verankerte disziplinäre Zusammenschluss zwischen Naturwissenschaften und Philosophie bot später für den Wiener Kreis die Gelegenheit, das breite Interesse an einer >wissenschaftlichen Philosophie< zu begründen: »Das Wirken der Physiker Mach und Boltzmann auf philosophischer Lehrkanzel läßt es begreiflich erscheinen, daß für die erkenntnistheoretischen und logischen Probleme, die mit den Grundlagen der Physik zusammenhängen, lebhaftes Interesse herrschte« (Neurath/Hahn/Carnap 1929: 302).

Die Traditionslinie von Mach bzw. Boltzmann zum Wiener Kreis, die bereits vom Wiener Kreis selbst angelegt worden ist, wird in der Philosophiegeschichtsschreibung bis heute fortgeschrieben: Die Geschichte des Wiener Kreises beginnt mit der Philosophie Machs. Innerhalb dieser Traditionslinie wiederum gilt der Wiener Kreis als entscheidender Wegbereiter für die Etablierung einer neuen, die Philosophie des 20. Jahrhunderts prägenden Subdisziplin der Philosophie: der Wissenschaftstheorie. »Tatsächlich aber etablierte sie [die Gruppe von Philosophen, Mathematikern, Physikern und Sozialwissenschaftlern, MD] innerhalb kurzer Zeit von zwanzig Jahren die Disziplin der Wissenschaftstheorie, die vordem als ein bloßer Annex der LogikLehrbücher in Erscheinung getreten war, als das bevorzugte Gebiet philosophischer Analyse. Damit führte sie die mit Mach begonnene Tradition zu einem sich weltweit auswirkenden Erfolg« (Haller 1993: 2-3). Als Stichdatum für die Entwicklung der Wissenschaftstheorie, die vom Wiener Kreis ausgeht, gilt das Jahr 1929. ${ }^{75} »$ Die internationalen Kongresse für Logik, Methodologie und Philosophie der Wissenschaften, die in unserer Zeit alle vier Jahre

75 Die Geschichte des Wiener Kreises wird üblicherweise wie folgt beschrieben: der »erste Wiener Kreis« (1907-1912), »Konstituierungsphase« (1918-1924), »nicht öffentliche Phase« (1924-1928) und »öffentliche Phase« (1928-1934). 
stattfinden, sind die Fortsetzung der von den Wiener und Berliner logischen Empiristen veranstalteten Konferenzen, die 1929 ihren Anfang nahmen" (ebd.: 3). Dieses Datum fällt mit der »1. Internationalen Tagung für Erkenntnislehre der exakten Wissenschaften ${ }^{76}$ zusammen, die unter der Leitung des Mathematikers und Physikers Philipp Frank in Prag stattgefunden hat. Mit dieser Tagung hat sich der Wiener Kreis erstmals an eine breitere wissenschaftliche Öffentlichkeit gewandt. ${ }^{77}$ Dieser erste >öffentliche Auftritt< des Wiener Kreises wird in zwei Publikationen manifest. Zum einen erscheint 1930/31 der erste Band der neu lancierten Zeitschrift »Erkenntnis«, herausgegeben von Rudolf Carnap aus Wien und Hans Reichenbach aus Berlin, zum anderen 1929 die Broschüre Wissenschaftliche Weltauffassung. Der Wiener Kreis. Beide Publikationen dienen als Grundlagen für die Analysen dieses Kapitels und sollen kurz vorgestellt werden.

\section{Die erste Ausgabe der »Erkenntnis«}

Die »Erkenntnis« ging aus der Zeitschrift »Annalen der Philosophie« hervor, die seit 1919 im Verlag von Felix Meiner erschien. Im Zusammenhang mit der »1. Internationalen Tagung für Erkenntnislehre der exakten Wissenschaften « lernte Felix Meiner einige Mitglieder des Wiener Kreises und der Berliner Gruppe kennen. ${ }^{78}{ } \gg$ Dabei muss auch das starke Interesse von Reichenbach und Carnap an einer redaktionellen Übernahme der in Schwierigkeiten steckenden Zeitschrift deutlich geworden sein, während andererseits Felix Meiner offenbar den Eindruck gewann, durch enge Anbindung der Zeitschrift an die Bewegung des Logischen Empirismus die Zeitschrift sinnvoll weiterführen zu können « (Hegselmann/Siegwart 1991: 463). Reichenbach als Vertreter der Berliner Gruppe und Carnap als Vertreter des Wiener Kreises übernahmen als Herausgeber die »Annalen«, führten sie aber als »Erkenntnis« weiter. Träger der Zeitschrift waren die »Gesellschaft für empirische Philosophie« aus Berlin

76 Es handelte sich dabei um die »Jahrestagung der Deutschen Physiker und Mathematiker«. Weitere Tagungen und Kongresse: 1934 - Prager Vorkonferenz des Internationalen Kongresses für Einheit der Wissenschaft; 1935 - Paris, Erster Internationaler Kongress für Einheit der Wissenschaft; 1936 - Kopenhagen, Zweiter Internationaler Kongress für Einheit der Wissenschaft; 1937 - Paris, Dritter Internationaler Kongress für Einheit der Wissenschaft; 1938 - Cambridge, Vierter Internationaler Kongress für Einheit der Wissenschaft: die wissenschaftliche Sprache; 1939 - Cambridge Mass., Fifth International Congress for the Unity of Science; 1941 - Chicago, Sixth International Congress for the Unity of Science (Stadler 1997: 427-436).

77 Bereits ein Jahr vorher, 1928, erschien das erste Buch einer vom Wiener Kreis zwischen 1928-1937 herausgegebenen Buchreihe: Schriften zur wissenschaftlichen Weltauffassung, hrsg. von Philipp Frank und Moritz Schlick.

78 Das Verhältnis der beiden Gruppen wird weiter unten thematisiert. 
(als das öffentliche Forum der Berliner Gruppe) und der »Verein Ernst Mach « aus Wien (als das öffentliche Forum des Wiener Kreises). Obwohl Reichenbach und Carnap beide als offizielle Herausgeber fungierten, soll Reichenbach an der Edition weitaus mehr beteiligt gewesen sein als Carnap ${ }^{79}$ (Milkòv 2011: XVII). Reichenbach ist es auch, der in der ersten Ausgabe den Beitrag »Zur Einführung « verfasst, in dem das neue Programm der »Erkenntnis « vorgestellt wird. Reichenbach stellt einen Bezug zur Vorgängerzeitschrift, zu den »Annalen der Philosophie « her: »War es schon immer das Programm der >Annalen $<$ gewesen, Philosophie nicht als isolierte Wissenschaft, sondern im engsten Zusammenhang mit den einzelnen Fachwissenschaften zu treiben, so darf der Wechsel in der Schriftleitung als eine Unterstreichung dieses Standpunktes betrachtet werden « (Reichenbach 1930/31: 1). Werden jedoch die Programme der beiden Zeitschriften miteinander verglichen, wird ein entscheidender Unterschied deutlich. Hans Vaihinger und Raymund Schmidt, die Herausgeber der »Annalen«, betonen 1919 in ihrer ersten Ausgabe die Wichtigkeit einer Zusammenarbeit zwischen Philosophie und empirischen Fachwissenschaften:»Bisher hat es an einer fruchtbaren Wechselwirkung zwischen Einzelwissenschaften und Philosophie gefehlt. Wohl haben gelegentlich und mehr zufällig solche gegenseitigen Förderungen stattgefunden, aber es fehlte an einem gemeinsamen Platze, auf dem Philosophen einerseits und Vertreter der einzelnen Fachwissenschaften andererseits zusammen kommen und zusammen arbeiten konnten « (Vaihinger/Schmidt 1919: V). Im Unterschied zu den Herausgebern der »Annalen «, die eine Zusammenarbeit zwischen Philosophen und Einzelwissenschaftlern angestrebt haben, stellt Reichenbach in seiner Ankündigung - wenn auch etwas vorsichtig - als Ziel die Auflösung der Fächergrenzen in den Vordergrund. »Es ergibt sich [...] aus unserer Zielsetzung, daß der Schwerpunkt der Zeitschrift in den Arbeiten liegt, die ihre Quellen in dem ertragreichen Boden der Empirie haben; der Strom philosophischer Erkenntnisse, der in unserer Zeit reicher als je aus den Einzelwissenschaften fließt, soll in unserer Zeitschrift ein Bett finden, das ihn fasst und weiterführt und ihm geordnete Bahnen weist « (Reichenbach 1930/31: 1). Philosophie, so die Implikation, bestehe nicht aus einer Einzeldisziplin, sondern aus einer Tätigkeit, die sich in den Fachwissenschaften aufzulösen habe. »Die jetzigen Herausgeber haben es von jeher als Aufgabe betrachtet, Philosophie im Sinne von Wissenschaftskritik zu treiben und durch wissenschaftsanalytische Methoden diejenigen Einsichten in Sinn und Bedeutung menschlicher Erkenntnis zu gewinnen, welche die in immer neuen Systemen

79 Die ungleiche Rollenverteilung der beiden Herausgeber widerspiegelt sich in den ungleich groß gedruckten Namen auf den Deckblättern der ersten vier Ausgaben. 
formulierte, auf ein angenommenes Eigenrecht der Vernunft gegründete Philosophie der historischen Schulen vergeblich gesucht hatte« (ebd.). Wissenschaftsanalytische Methoden, so Reichenbach, bärgen das Potenzial, die >alte< und überholte Philosophie zu ersetzen. »Es ist unsere Überzeugung, daß [...] die Philosophie als Wissenschaft eine neue Grundlegung erfahren wird « ${ }^{80}$ (ebd.: 2). Während Vaihinger und Schmidt die »Annalen« als Forum lanciert haben, in dem Einzelwissenschaftler und Philosophen zusammenkommen können, präsentiert Reichenbach die »Erkenntnis« als Forum, in dem Einzelwissenschaftler philosophische Erkenntnisse vorstellen sollen. Dadurch wiederum, so Reichenbach, erfahre die Philosophie eine neue Grundlegung. Die Verschiebung in der Programmatik, wie sie in den beiden Vorwörtern der Zeitschriften augenscheinlich wird, verdeutlicht exemplarisch, worin der Erneuerungsanspruch des Wiener Kreises besteht: Durch ihre Rückbeziehung auf die Einzelwissenschaften kann sich die Philosophie neu fundieren. Umgekehrt bedeutet dies auch, dass die analytisch informierte Wissenschaftsphilosophie die >alte< und überholte Philosophie ersetzen soll. ${ }^{81}$

ImerstenBand der»Erkenntnis «sind Reden und Aufsätzepubliziert, indenen dieser Erneuerungsanspruch - wenn auch in verschiedenen Nuancierungen programmatisch vertreten wird. Insbesondere Schlicks »Die Wende der Philosophie « und Carnaps »Die alte und die neue Logik« sind kanonisch geworden und werden heute als Standardaufsätze des Wiener Kreises behandelt. Ein weiterer berühmter Aufsatz wurde im Folgeband von 1931 erstmals veröffentlicht: Carnaps »Überwindung der Metaphysik durch logische Analyse der Sprache «. In der »Erkenntnis« sind zudem die Kongresse des Wiener Kreises dokumentiert. Es seien diese Kongressdokumentationen gewesen - so betonen Rainer Hegselmann und Geo Siegwart -, die dafür verantwortlich waren, dass die »Erkenntnis« während ihrer Laufzeit von 1930 bis 1939 die Rolle des Zentralorgans des Logischen Empirismus eingenommen hat (Hegselmann/ Siegwart 1991: 464). Kurz: Es handelt sich bei der »Erkenntnis« um einen geglückten Versuch einer Neulancierung. An den hier versammelten Texten

8o Eine solche direkte Aussage über die Erneuerung der Philosophie, wie sie Reichenbach trifft, ist in den untersuchten Texten selten. Üblicherweise wird nicht die Erneuerung der Philosophie, sondern ihre Verabschiedung betont, da unter einer logischen bzw. sprachanalytischen Perspektive beinahe jegliche bisherige Philosophie den Stempel der Metaphysik erhält. Die Verwendung des Philosophiebegriffs wird, wie weiter unten deutlich wird, von Reichenbach und Carnap bzw. vom Wiener Kreis unterschiedlich beurteilt.

81 »Denn mit dem expliziten Auftreten der Wissenschaftstheorie als eigener systematischer Disziplin verband sich von allem Anfang an auch die Idee einer totalen Ersetzung der alten Philosophie durch eine neue. So erklärt Carnap ganz ausdrücklich [in Logische Syntax der Sprache, MD]: >An die Stelle des unentwirrbaren Problemgemenges, das man Philosophie nennt, tritt die Wissenschaftslogik« (Oeser 2003: 93). 
wird die Formierung eines bestimmten »Denkstils« besonders deutlich (Fleck $1980[1935]) .^{82}$

\section{Ein Manifest}

1929 erschien unter der Herausgeberschaft des »Verein Ernst Mach« die Broschüre Wissenschaftliche Weltauffassung. Der Wiener Kreis. Das Werk habe »keine offiziell genannten Verfasser« und sei »Moritz Schlick gewidmet« (Neurath/Hahn/Carnap 1929: 299). Als Verfasser gelten Hans Hahn, Rudolf Carnap und Otto Neurath; die Studierenden Friedrich Waismann und Herbert Feigl sollen ebenso dazu beigetragen haben wie Maria Kaspar (Sigmund 2015: 127). Die Programmatik des Textes ist signifikant:

Die wissenschaftliche Weltauffassung ist nicht so sehr durch eigene Thesen charakterisiert als vielmehr durch die grundsätzliche Einstellung, die Gesichtspunkte, die Forschungsrichtung. Als Ziel schwebt die Einheitswissenschaft vor. Das Bestreben geht dahin, die Leistungen der einzelnen Forscher auf den verschiedenen Wissenschaftsgebieten in Verbindung und Einklang miteinander zu bringen. Aus dieser Zielsetzung ergibt sich die Betonung der Kollektivarbeit [...]. Sauberkeit und Klarheit werden angestrebt, dunkle Fernen und unergründliche Tiefen abgelehnt. In der Wissenschaft gibt es keine »Tiefen«; überall ist Oberfläche [...]. Alles ist dem Menschen zugänglich; und der Mensch ist das Maß aller Dinge. [...] In solcher Weise wird durch die logische Analyse nicht nur die Metaphysik im eigentlichen, klassischen Sinne des Wortes überwunden, insbesondere die scholastische Metaphysik und die der Systeme des deutschen Idealismus, sondern auch die versteckte Metaphysik des Kantischen und des modernen Apriorismus. Die wissenschaftliche Weltauffassung kennt keine unbedingt gültige Erkenntnis aus reiner Vernunft, keine "synthetischen Urteile a priori«, wie sie der Kantischen Erkenntnistheorie und erst recht aller vor- und nachkantischen Ontologie und Metaphysik zugrunde liegen [...]. Die wissenschaftliche Weltauffassung kennt nur Erfahrungssätze über Gegenstände aller Art und die analytischen Sätze der Logik und Mathematik. (Neurath/Hahn/ Carnap 1929: 305-307)

Der Wiener Kreis tritt mit dem Anspruch auf, die abendländische Metaphysik mit den Mitteln der logischen Analyse ein für alle Mal überwinden zu können. Gemäß Karl Mengers Erinnerungen ist diese Schrift entstanden, weil Schlick die damalige Zentralfigur des Wiener Kreises - sich entschieden hatte, einen Ruf nach Bonn abzulehnen, um in Wien zu bleiben:

82 Der Bezug auf Flecks Konzept des Denkstils bzw. Denkkollektivs vermag hier der Schwierigkeit zu begegnen, dass es sich beim Wiener Kreis um eine Ansammlung unterschiedlicher Autoren handelt. Den Wiener Kreis als eigentliches >Agens` gibt es nicht. Formulierungen, die im Folgenden in diese Richtung zielen, sind mit Rückbezug auf das Konzept von Fleck zu verstehen. 
Groß war die Freude aller von uns, als wir erfuhren, dass Schlick sich entschieden hatte, weiter in Wien zu bleiben. »Das muss gefeiert werde[n] «, sagte Neurath, und wir stimmten zu. »Wir müssen ein Buch verfassen, das unsere Ansichten darstellt - ein Manifest des Kreises - und es Schlick zu seiner Rückkehr im Herbst widmen«, fügte Neurath hinzu. Und mit der ihm üblichen Geschäftigkeit und Energie ging er ans Werk. (Karl Menger, zitiert nach Sigmund 2015:126)

Das »Manifest « war sowohl innerhalb als auch außerhalb des Wiener Kreises umstritten und hat damals enervierte Reaktionen ausgelöst. Carnap bereitet Schlick in einem Brief umsichtig auf die Lektüre vor: »Ich werde dir jetzt dein Exemplar übersenden, an dem du dein blaues Wunder erleben wirst; hoffentlich nur äußerlich. Den Inhalt betrachte bitte nicht zu kritisch, sondern mit deinem gewohnten Wohlwollen und Nachsicht. Es ist von Feigl, Neurath und mir mit vereinten Kräften und mehr gutem Willen als Qualität geschaffen worden« (Carnap an Schlick, 30.o9.1929, zitiert nach Sigmund 2015: 128). Carnap habe wohl geahnt, so der Mathematiker Karl Sigmund, der sich mit der Geschichte des Wiener Kreises auseinandergesetzt hat, »dass Schlick sich an einigen ziemlich reklamehaften Passagen und dogmatischen Äußerungen stoßen könnte [...] (Sigmund 2005: 129). Menger wiederum habe aus der Schrift Konsequenzen gezogen: Er wollte nach der Lektüre nicht mehr als Mitglied des Wiener Kreises, sondern nur noch als ein dem Kreis Nahestehender gelten (ebd.). Am heftigsten soll jedoch Ludwig Wittgenstein reagiert haben. ${ }^{83}$ An Friedrich Waismann schrieb er: »Das ist eine schwere Geschichte. Und es ist mir sehr unangenehm zu denken, dass hier wieder einmal ein an sich guter Grund als Anlass zu G'schaftlhuberei benutzt werden soll« (Wittgenstein an Waismann, Juli 1929, zitiert nach Sigmund 2015: 129). Schlick verdiene es,

dass man sich davor hütet, ihn und die Wiener Schule, deren Exponent er ist, »in guter Absicht« durch Großsprecherei lächerlich zu machen. Wenn ich sage Großsprecherei, so mein ich damit jede Art der Selbstbespiegelung. »Absage an die Metaphysik«! Als ob das was Neues wäre! - Das Lob, das eine Schule sich selbst spendet, stinkt wie jedes Eigenlob. (ebd.)

83 Die Beziehung zwischen Wittgenstein und dem Wiener Kreis wird von Schnädelbach wie folgt beschrieben: »Der >Tractatus wird vom Logischen Empirismus des Wiener Kreises gewissermaßen okkupiert und zu seiner Gründungsurkunde erklärt « (Schnädelbach 1992: 310). Zum Verhältnis Wittgenstein - Wiener Kreis vgl. z.B. Stadler 1997: 467-488. »Aus wissenschaftssoziologischer Sicht kann man - im Anschluss an die Arbeiten von Ludwik Fleck und Thomas S. Kuhn - vom Aufeinanderprallen zweier Denkstile beziehungsweise eines Denkkollektivs und eines Individualisten sprechen; ein Gegensatz, der aber von einer durchaus bewusst partiellen Rezeption Wittgensteins durch einen Teil des Wiener Kreises mitbestimmt ist« (ebd.: 481). 
Das »Manifest «, so wird erkennbar, ist eine Schrift, deren Polemik von einigen Mitgliedern des Wiener Kreises und auch von Wittgenstein abgelehnt worden ist. Als eine Art Werbebroschüre spielte sie im Zusammenhang mit der genannten Tagung und der Lancierung einer eigenen Schriftenreihe im Übergang von der >privaten $<$ zur >öffentlichen< Phase des Wiener Kreises jedoch eine wichtige Rolle. »Eigene Zeitschrift, Tagung, Werbebroschüre, vor allem aber ein publikumswirksamer Name - alles trug dazu bei, um den Schlick-Zirkel (in Wien hieß er naturgemäß weiter so) von der privaten Phase zur öffentlichen überzuleiten« (Sigmund 2005: 128). Das »Manifest« verdeutlicht exemplarisch, dass die »wissenschaftliche Weltauffassung « - wie Donata Romizi schreibt als eine Botschaft für die Gesellschaft gemeint war (Romizi 2012:146).

\section{Die Berliner Gruppe und der Wiener Kreis}

Nikolay Milkòv, der sich in jüngerer Zeit um eine Wiederveröffentlichung und Neubewertung von Reichenbachs Schriften bemüht hat, betont, dass die Veröffentlichung des »Manifests« »die nachfolgende Wahrnehmung der Bewegung, die heute als logischer Empirismus verstanden wird, entscheidend beeinflusst [hat] « (Milkòv 2015: XXI). Vor der Veröffentlichung sei nämlich Reichenbach - und nicht Carnap oder Schlick - in Deutschland der Hoffnungsträger für die Etablierung einer wissenschaftlichen Philosophie gewesen (ebd.). Milkòvs Bemerkung verweist erstens auf die grundsätzliche Tatsache, dass nicht etwa lediglich der Wiener Kreis für die Entwicklung der Wissenschaftstheorie verantwortlich ist, sondern sich eine große Anzahl von Wissenschaftlern und Wissenschaftlerinnen aus unterschiedlichsten Disziplinen mit dem Thema der Verbindung von Naturwissenschaften und Philosophie auseinandergesetzt hat. Die Bemerkung verweist zweitens auf die zentrale Rolle Reichenbachs für den Wiener Kreis. Zwar haben - wie erwähnt - offiziell Carnap und Reichenbach gemeinsam die Herausgeberschaft der »Erkenntnis« übernommen, die Zeitschrift wurde jedoch von Berlin aus geleitet, d.h., Reichenbach war inoffizieller Hauptherausgeber. 1938 schrieb Reichenbach in einem Brief: »I may add here the remark that >Erkenntnis〈 was not a foundation of the Vienna group, but of the Berlin group, and that I invited the Vienna group to collaborate in the edition of this journal Schlick refused to accept because of the differences in his views and mine « (Reichenbach an Max Black, 18.04.1938, zitiert nach Milkòv 2015: XII).

Reichenbach war die zentrale Figur der sogenannten Berliner Gruppe. Diese Gruppe umfasste u.a. Reichenbach, Walter Dubislav, Kurt Grelling, Kurt Lewin und gilt gemeinsam mit dem Wiener Kreis als entscheidende Vorstufe für die Entstehung des Logischen Empirismus. Die Unterschiede zwischen der 
Berliner Gruppe und dem Wiener Kreis ${ }^{84}$ verweisen auf einen Zusammenhang, der für die Argumentation des vorliegenden Kapitels zentral ist: Die Berliner Gruppe hielt - im Gegensatz zum Wiener Kreis - am Begriff der Philosophie fest. ${ }^{85}$ So habe Reichenbach für die »1. Tagung für Erkenntnislehre der exakten Wissenschaften « einen Titel vorgeschlagen, der von Carnap und Schlick aufgrund der Begriffsverwendung »Philosophie« abgelehnt worden ist: »Kongress für Naturphilosophie, oder naturphilosophischer Kongress « (zitiert nach Milkòv 2015:XVIII). Für Reichenbach kulminierte der Zusammenschluss der exakten Wissenschaften mit der Philosophie im Begriff der Naturphilosophie. Seinen Aufsatz »Ziele und Wege der heutigen Naturphilosophie«, der gemäß Milkòv als Programmschrift der »Gesellschaft für empirische Philosophie « verstanden werden sollte (Milkòv 2011: XXXV), beginnt Reichenbach mit folgenden Worten:

\begin{abstract}
Der Name Naturphilosophie gewinnt in unseren Tagen einen neuen Klang. Herausgewachsen aus den Resultaten naturwissenschaftlicher Forschung, beginnt eine neue philosophische Wissenschaft, erfüllt von Intensität und Strenge, ihr Dasein zu gestalten; sie hat bereits eine Reihe von alten Problemen zu ungeahnter Wendung geführt und ebenso eine Anzahl neuartiger Probleme aufgewiesen, deren Existenz man früher übersehen hatte. Es ist diese Naturphilosophie, deren Problemlage in dem folgenden Umriss dargestellt werden soll. (Reichenbach 2011 [1931]: 47)
\end{abstract}

Für den Wiener Kreis hingegen galt es, den Begriff der Naturphilosophie wie den der Philosophie überhaupt zu vermeiden. Neurath kommentiert Reichenbachs Aufsatz entsprechend mit folgenden Worten: » Naturphilosophie< ist an sich ein irreführender Ausdruck, weil er so klingt, als ob es neben wissenschaftlichen Sätzen noch sinnvolle philosophische [Sätze] geben könne «(Neurath an Meiner, ohne Datum, zitiert nach Milkòv 2015:XVIII). Zuerst soll Reichenbach empört reagiert und mit der Auflösung der Zeitschrift gedroht haben. In einem Brief an Carnap schreibt er schließlich: »Ich habe zu den Veröffentlichungen des Wiener Kreises bisher geschwiegen, obwohl manches schwerwiegende Fehler zu enthalten scheint « (Brief von Reichenbach an Carnap, 22.08.1931, zitiert nach Milkòv 2015: XVIII-XIX). Er plädierte für »gegenseitige Duldung«

\footnotetext{
$84 \quad$ Zur Berliner Gruppe und zum Unterschied zwischen der Berliner Gruppe und dem Wiener Kreis vgl. Milkov 2015. Unter dem Einfluss von Hans Reichenbach wurde die Berliner Gesellschaft 1931 in »Gesellschaft für wissenschaftliche Philosophie« umbenannt.

85 Die Ablehnung des Philosophiebegriffs bzw. dessen radikale Umbenennung ist eine wirkungsvolle Argumentationsstrategie und wird weiter unten wieder aufgenommen (siehe Kapitel »Philosophische Altlasten aus dem Weg räumen: Metphysikkritik«, 10o105, und Fazit, S. 193-194).
} 
(ebd.), nicht für mehr. Der Bund zwischen dem Wiener Kreis und der Berliner Gruppe war - so resümiert Milkòv - »offensichtlich nichts anderes als eine Zweckehe« (Milkòv 2015:XIX).

Vermutlich spielte diese »Zweckehe« für die öffentliche Wirkung des Wiener Kreises eine nicht unerhebliche Rolle. Die Programmatik des Wiener Kreises die Ersetzung der bisherigen Philosophie durch die Wissenschaftstheorie wurde dadurch sowohl durch internationale Vernetzung als auch durch andere wissenschaftstheoretische Ansätze legitimatorisch abgestützt. Denn trotz ihrer Unterschiede werden in den beiden Gruppierungen die gleichen Erneuerungsstrategien sichtbar: die Identifikation der Philosophie mit den exakten Wissenschaften auf der einen Seite und die Abgrenzung von der Metaphysik, d.h. der traditionellen Philosophie, auf der anderen Seite.

\section{Identifikation mit den Naturwissenschaften, Abgrenzung von der Philosophie}

Die Nähe zu den exakten Wissenschaften widerspiegelt sich bereits in den Promotionsfächern der Kernmitglieder des Wiener Kreises. ${ }^{86}$ So wurden Gustav Bergmann, Philipp Frank, Kurt Gödel, Hans Hahn, Olga Hahn-Neurath, Karl Menger, Richard von Mises, Marcel Natkin und Theodor Radaković in Mathematik oder Physik promoviert, Moritz Schlick, Rudolf Carnap, Herbert Feigl und Victor Kraft hingegen erhielten ihrer Doktorgrad in Philosophie. Otto Neurath wiederum hat in Nationalökonomie promoviert. ${ }^{87}$ Diese disziplinäre Zusammensetzung ist bezeichnend für die Erneuerungsstrategien des Wiener Kreises: Im Unterschied zu Husserl und zur Kritischen Theorie wird der Erneuerungsanspruch der Philosophie hier wesentlich aus einem

86 Diese Liste repräsentiert die Mitglieder, wie sie im »Manifest« als Kernmitglieder aufgelistet werden. Zum engeren Kern gehörten weiter Béla Juhos, Felix Kaufmann, Rose Rand, Josef Schächter, Edgar Zilsel.

87 Aufgelistet ist zusätzlich Friedrich Waismann. Er hat Mathematik, Physik und Philosophie studiert, aber nie eine Doktorarbeit eingereicht. Bekanntheit erlangt hat er u.a. durch die sogenannten Waismann-Protokolle: Zwischen 1927 und 1936 führte Waismann mehrere Gespräche mit Wittgenstein, die 1967 posthum unter dem Titel Ludwig Wittgenstein und der Wiener Kreis veröffentlicht wurden. Wittgenstein soll ein anspruchsvoller Gesprächspartner gewesen sein: »Jedes Mal, wenn er [Wittgenstein, MD] Waismanns Manuskript zu Gesicht bekam, verlangte er drastische Änderungen, und gelegentlich wieder Rückänderungen, oder einen komplett anderen Aufbau. [...] Wittgenstein war kaum je mit Waismanns Darstellung einverstanden, selbst wenn ihm dieser penibel nachweisen konnte, dass es sich um eine wortgetreue Niederschrift früherer Äußerungen handelte (Sigmund 2015: 229). Wittgenstein und Waismann hatten darüber hinaus den Plan, gemeinsam ein Buch zu verfassen. Das Projekt scheiterte schließlich an den philosophischen Differenzen von Wittgenstein und Waismann. 2003 wurden die Texte des Projekts veröffentlicht (Baker 2003). 
interdisziplinären Zusammenschluss heraus entwickelt und begründet. ${ }^{88}$ So handelte es sich bei der genannten Initialtagung in Prag um die Jahrestagung der »Deutschen Physiker und Mathematiker«. Philipp Frank, damals Physikprofessor in Prag und Organisator der Tagung, erinnert sich:

The arrangement of the meeting was not so easy. The ordinary regular philosophy meetings followed the traditional lines and would hardly have given us enough scope. By a happy coincidence I was just in 1929 arranging a meeting of the physicists and mathematicians from the German-speaking regions in Central Europe. The meeting was to be held in my place of residence, Prague, the capital of Czechoslovakia. The German Physical Society, which was the official sponsor of this meeting, did not particularly like the idea of combining this serious scientific meeting with such a foolish thing as philosophy. However, I was the chairman of the local committee in Prague and they could not refuse my serious wish to attack a meeting with the topic, »Epistemology of the Exact Sciences«. (Frank 1949: 39-40)

Franks Schilderung zeigt, dass sich die Vertreter des Wiener Kreises von den bestehenden philosophischen Kontexten distanzierten, um ihr Anliegen einer >reinen< wissenschaftlichen Philosophie im Kontext der Mathematik und Physik zu positionieren. Offensichtlich barg diese Einbringung philosophischer Themen in den Kontext der exakten Wissenschaften ein provokatives Potenzial.

There is no doubt that quite a few people in the audience were shocked by my blunt statements that modern science is incompatible with the traditional system of philosophy. Probably, most of the scientists had not been accustomed to thinking of philosophy and science as one coherent system of thought. Philosophy had been for them what the Sunday sermon is for a businessman who is only interested in profit. Philosophy had been required not to be »true « but to give emotional satisfaction. (ebd.: 41)

Frank erinnert nicht nur an die für den Wiener Kreis charakteristische Überschreitung der Disziplinengrenzen, sondern er verweist zugleich auf die zentrale - und im Folgenden weiter auszuführende - Argumentationsstrategie, nämlich genau dadurch eine philosophische Position sui generis zu restabilisieren. Die genuin interdisziplinär angelegte Situation im

88 Freilich werden auch die Erneuerungsansprüche der Kritischen Theorie mit dem Argument der Interdisziplinarität vorangetrieben. Wie jedoch im dritten Kapitel deutlich wird, entwickeln Horkheimer und Adorno ihre Erneuerungsansprüche nicht ausgehend von den zeitgenössischen soziologischen Diskussionen, sondern sie fordern eine Kooperation der Philosophie mit ebendiesen. Genau darin liegt ein wesentlicher Unterschied zwischen der Kooperationsstrategie (wie sie idealtypisch an der Kritischen Theorie deutlich wird) und der Identifikationsstrategie (wie sie idealtypisch am Wiener Kreis deutlich wird). 
Erneuerungsanspruch des Wiener Kreises verweist somit auf ein Modell der Identifikation: Durch die Identifikation ihrer eigenen philosophischen Position mit Methoden und Modellen aus der Physik und Mathematik, so die argumentative Stoßrichtung dieses Kapitels, stabilisieren und rehabilitieren die Vertreter des Wiener Kreises den Wahrheits- und Objektivitätsanspruch nicht nur der Philosophie, sondern der Wissenschaft im Allgemeinen.

Dass sich die Vertreter des Wiener Kreises in expliziter Weise von der traditionellen Philosophie distanzierten, indem sie sich nicht als Philosophen identifizierten, ist ein zentraler Bestandteil dieser Strategie. Ein Beispiel sei kurz vorgestellt: Jonas Cohn, ein Freiburger Neukantianer, soll 1935 bei Reichenbach angefragt haben, ob die Zeitschrift »Erkenntnis« bereit sei, eine Kritik des Wiener Kreises zu veröffentlichen. Carnap schreibt diesbezüglich in einem Brief an Neurath: »Reichenbach findet es nicht so schlimm und meint, die Einwände seien typisch und daher lohne es sich, sie zu bringen. Ich finde das Ganze viel zu philosophisch und für unsere Leser nicht aufklärend. Ich möchte lieber ablehnen. Was meinst du? Sollen wir Wert darauf legen, mit Philosophen zu diskutieren?« (Carnap an Neurath, 23.01.1935, zitiert nach Hegselmann/Siegwart 1991: 464). In Carnaps Bemerkung wird eine klare Distanzierung zu den »Philosophen« deutlich. Wo Carnap eine Diskussion mit den Philosophen jedoch noch in Erwägung zieht, betrachtet Neurath ein solches Unterfangen schlicht als Zeitverschwendung: »Ad Jonas Coh. Ich hälte [sic!] es für abwegig, in der Erkenntnis Auseinandersetzungen mit der traditionellen Philosophie zu bringen. Man hat kaum Raum für die internen Sachen ... Wir haben gar kein Interesse daran, uns mit stypischen Einwänden auseinanderzusetzen « (Neurath an Carnap, 28.01.1935, zitiert nach Hegselmann/Siegwart 1991: 464). Neurath beendet die Debatte, indem er die Absetzung von den Philosophen affirmiert: Dringlicher als die Diskussion mit den Philosophen seien die eigenen Anliegen.

Im Folgenden wird an konkreten Textstellen nachgezeichnet, wie diese Erneuerungsansprüche entwickelt werden. Da hier das Ziel verfolgt wird, argumentative Strategien zu erfassen, mit denen sich der Wiener Kreis im Kontext anderer Disziplinen legitimiert, wird nicht auf die inhaltlichen Differenzen bzw. auf die inhaltlich und methodologisch zuweilen stark divergierenden Positionen eingegangen. Das Ziel ist das Herausarbeiten eines bestimmten Denkstils. In einem ersten Schritt werde ich Auszüge aus Schlicks programmatischem Aufsatz »Die Wende der Philosophie« hinsichtlich seines Erneuerungsanspruchs analysieren. Mit diesem ersten Aufsatz - »einer von Wittgenstein inspirierten, euphorischen Bestandsaufnahme des >linguistic turn « (Stadler 1993: 24) - wird die »Erkenntnis« als die neue Plattform der wissenschaftlichen Philosophie vorgestellt (ebd.). Auf Schlicks Aufsatz folgt 
in der ersten Ausgabe der »Erkenntnis« Carnaps Beitrag »Die alte und die neue Logik«. An diesem Aufsatz zeichne ich in einem zweiten Schritt nach, wie der Wiener Kreis die Identifikation seiner philosophischen Position mit den Naturwissenschaften herleitet, nämlich durch eine Transponierung neuer Befunde aus der Mathematik in den Bereich der Philosophie. In einem dritten Schritt werde ich an Carnaps »Überwindung der Metaphysik durch logische Analyse der Sprache« darstellen, wie der Wiener Kreis seine eigene Position von der philosophischen Tradition absetzt. Schließlich wird gezeigt, dass der Wiener Kreis seinen Erneuerungsanspruch der Philosophie dadurch begründet, dass er die Philosophie als eine Methode, d.h. als logische Analyse, definiert. Mit dieser Bestimmung der Philosophie, die mit der Forderung nach einer Auflösung der Philosophie als einer eigenen Fachwissenschaft einhergeht, begründet der Wiener Kreis nicht nur seinen Anspruch, die Philosophie in jeder anderen Wissenschaft anwenden zu können, sondern er rehabilitiert darüber hinaus die philosophische Tätigkeit als - in Schlicks Worten - »Alpha und Omega aller wissenschaftlicher Erkenntnis«(Schlick 193o/31: 8).

\subsection{Philosophie als logische Analyse}

\section{Eine grundsätzliche Wende der Philosophie}

Die Feststellung, dass die Philosophie gegenwärtig eine totale und endgültige Wende erfahre, ist in den untersuchten Texten ein wiederkehrendes Moment. Schlicks Aufsatz »Die Wende der Philosophie« ist dafür paradigmatisch. ${ }^{89}$ »Ich bin [...] überzeugt, dass wir in einer durchaus endgültigen Wendung der Philosophie mitten darin stehen und dass wir sachlich berechtigt sind, den unfruchtbaren Streit der Systeme als beendigt anzusehen « (Schlick 1930/1931: 5). Er sei sich der »Tragweite« und »Inhaltsschwere« dieser Aussage bewusst, sagt Schlick, denn schließlich seien solche radikalen Erneuerungsansprüche der Philosophie überhaupt eigen: »Aber gerade die besten Köpfe unter den Denkern glaubten selten an unerschütterliche, bleibende Ergebnisse des Philosophierens früherer Zeiten und selbst klassische Vorbilder; dies erhellt daraus, dass im Grunde jedes neue System wieder ganz von vorn beginnt, dass jeder Denker seinen eigenen festen Boden sucht und sich nicht auf die Schultern seiner Vorgänger stellen mag « (ebd.: 4-5). Schlick betont, dass »fast alle großen Denker [...] eine radikale Reform der Philosophie für notwendig

89 Moritz Schlick war aufgrund eines Aufenthalts in Amerika bei der Tagung nicht persönlich anwesend. Sein Text »Die Wende der Philosophie« wurde jedoch in die Publikation mit aufgenommen. 
gehalten und selbst versucht [haben] (ebd.: 5). Deswegen könnten im Grunde »alle Versuche, dem Chaos der Systeme ein Ende zu machen und das Schicksal der Philosophie zu wenden [...], so scheint eine Erfahrung von mehr als zwei Jahrtausenden zu lehren, nicht mehr ernst genommen werden « (ebd.). Obwohl Schlick also betont, dass die Behauptung einer grundlegenden Wende der Philosophie ein internes Merkmal der Philosophie selbst ist, gilt dies aus seiner Perspektive für die gegenwärtige Wende nicht. Diese unterscheide sich von allen vorherigen Reformversuchen und sollte durchaus ernst genommen werden. Ob Schlick dieses offensichtliche Spannungsverhältnis absichtlich herstellt, wird im Text nicht ersichtlich. Seine Behauptung jedoch enthält rhetorische Schlagkraft: Die gegenwärtige philosophische Wendung erscheint umso plausibler, gerade weil er sie von allen vergangenen Reformversuchen der Philosophie absetzt. Insofern zielt sie auf die alarmistische Behauptung von Aktualität.

Schlicks Überzeugung einer nun endgültigen - im Gegensatz zu jeder früheren - Wende der Philosophie resultiert aus der Annahme, dass die Entwicklung der Wissenschaften es inzwischen möglich gemacht hat, die Wissenschaftlichkeit der Philosophie endgültig zu beurteilen. Der wissenschaftliche Fortschritt, so die Implikation, belege, dass die herkömmliche und bestehende Philosophie wissenschaftlichen Kriterien nicht genüge. Aus der Entwicklung derWissenschaften sei ein Standpunkt emergiert, von dem aus diese Bewertung möglich geworden ist: »Daß die Lage wirklich einzigartig und die eingetretene Wendung wirklich endgültig ist, kann nur eingesehen werden, indem man sich mit den neuen Wegen bekannt macht, und von dem Standpunkte, zu dem sie führen, auf alle die Bestrebungen zurückschaut, die je als >philosophische< gegolten haben « (ebd.: $\left.5^{-6}\right)$. Ausgehend von diesem objektiven Standpunkt könne, so Schlick, der »Streit der [philosophischen] Systeme« endgültig beendet werden. Im Prinzip sei ein solcher Standpunkt bereits vorhanden. »Die Gegenwart ist, so behaupte ich, bereits im Besitz der Mittel, die einen derartigen Streit [den Streit der Systeme, MD] im Prinzip unnötig machen; es kommt nur darauf an, sie entschlossen anzuwenden « (ebd.: 5$){ }^{90}$

Woraus bestehen diese Mittel für Schlick und die Vertreter des Wiener Kreises insgesamt? »Die Wege gehen von der Logik aus (ebd.: 6). Die Logik sei - so Schlick - jene Methode, mit der die gesamte bisherige Philosophie

9o Der Aspekt der Prospektion, der im Kapitel zu Husserl herausgearbeitet wurde, wird auch in Schlicks Argumentation sichtbar: Eine grundlegende Wendung der Philosophie werde dann realisiert, so die Implikation, wenn die richtigen Mittel, d.h. die richtigen Methoden, angewendet werden; erst dann nämlich werde es möglich, alle früheren philosophischen Streitereien überblicken und beenden zu können. 
überwunden werden könne. Schlick gibt in seinem Aufsatz lediglich ein paar einordnende Hinweise dazu, was er unter »Logik« versteht. Er verweist auf Leibniz, Frege, Russell und schließlich auf Wittgenstein, der in seinem Tractatus logico-philosophicus von $1922 »$ bis zu der entscheidenden Wendung [...] vorgedrungen« sei (ebd.). ${ }^{91}$ Die Überzeugung, dass die Logik das letzte und sichere Fundament wissenschaftlicher Erkenntnis darstelle, steht somit in einem direkten Wechselverhältnis zur Überzeugung, dass eine endgültige Wende der Philosophie bevorstehe. Beide Argumente stützen sich gegenseitig: Wenn die Logik sogar die Philosophie als Ganze in noch nie da gewesener Weise erneuern kann, dann muss die Logik tatsächlich grundlegende Evidenz besitzen. Und umgekehrt: Wenn die Logik eine derart evidente Methode ist, dann ist es nicht erstaunlich, dass die Philosophie eine grundsätzliche Wende erfährt.

Für Schlick scheint also klar: Die Logik birgt das Potenzial, die gesamte Philosophie auf eine neue wissenschaftlich gültige Grundlage zu stellen. Die von Schlick in seinem Text eingeführte Trennung zwischen der Methode der Logik und der Einsicht in das Logische selbst erhärtet diese Überzeugung: »Ist nun diese Logik«, fragt Schlick, »das große Mittel, von dem ich vorhin sagte, es sei imstande, uns im Prinzip aller philosophischer Streitigkeiten zu entheben, liefert sie uns etwa allgemeine Vorschriften, mit deren Hilfe alle traditionellen Fragen der Philosophie prinzipiell aufgelöst werden können?« (ebd.). Diese Frage wird verneint. »Wäre dies der Fall, so hätte ich kaum das Recht gehabt zu sagen, daß eine völlig neue Lage geschaffen sei, denn es würde dann nur ein gradueller, gleichsam technischer Fortschritt erzielt sein, sowie etwa die Erfindung des Benzinmotors schließlich die Lösung des Flugproblems ermöglichte« (ebd.). Schlick führt die eingetretene Wende der Philosophie also nicht nur (wie Carnap) der wissenschaftshistorischen Entwicklung der Logik als Methode zu - »durch die bloße Ausbildung einer Methode kann niemals etwas so Prinzipielles geleistet werden« - , sondern »etwas ganz anderem, das durch sie wohl erst möglich gemacht und angeregt wurde, aber in einer viel tieferen Schicht sich abspielt: das ist die Einsicht in das Wesen des Logischen selber« (ebd.).

Dass die Logik ein sicheres und endgültiges Mittel für die wissenschaftliche Wahrheitsfindung ist, wird als unanfechtbare Tatsache präsentiert, die weder

91 Schlick zeigte sich wie auch andere Mitglieder des Wiener Kreises von Wittgensteins Tractatus tief beeindruckt. Er bezeichnet sich selbst als »Bewunderer« von Wittgenstein. Umgekehrt soll auch Wittgenstein Schlick geschätzt haben und ihn nicht zur »Clique«, wie er den Kreis rund um Hahn und Carnap bezeichnet hat, gerechnet haben (Sigmund 2015: 130). 
einer Legitimation noch eines weiteren Beweises bedarf. Schlick erläutert den Inhalt dieser »schlichten Einsicht« wie folgt:

Der Weg der Klarheit darüber geht von der Tatsache aus, daß jede Erkenntnis ein Ausdruck, eine Darstellung ist. Sie drückt nämlich den Tatbestand aus, der in ihr erkannt wird, und dies kann auf beliebig viele Weisen, in beliebigen Sprachen, durch beliebige willkürliche Zeichensysteme geschehen; alle diese möglichen Darstellungsarten, wenn anders sie wirklich dieselbe Erkenntnis ausdrücken, müssen eben deswegen etwas gemeinsam haben, und dies Gemeinsame ist ihre logische Form. So ist alle Erkenntnis nur vermöge ihrer Form Erkenntnis; durch sie stellt sie die erkannten Sachverhalte dar, die Form selbst aber kann ihrerseits nicht wieder dargestellt werden; auf sie allein kommt es bei der Erkenntnis an, alles übrige daran ist unwesentlich und zufälliges Material des Ausdrucks, nicht anders als etwa die Tinte, mit der wir einen Satz niederschreiben. (ebd.)

Erkennbar seien also lediglich Darstellungen und Ausdrücke. Diese Darstellungen und Ausdrücke wiederum besitzen eine logische Form. Diese Form könne selbst nicht wieder dargestellt werden, denn sie impliziere gewissermaßen die Erkenntnis selbst. Schlick geht also von einer unwiderlegbaren und überhistorischen Trennlinie zwischen wissenschaftlich Erkennbarem (bzw. Darstellbarem) und wissenschaftlich nicht Erkennbarem aus. Dass er in seiner Argumentation von einer »schlichten Einsicht« mit »Folgen allergrößte[r] Tragweite« spricht, stützt die Unwiderlegbarkeit und Evidenz seiner Aussage rhetorisch - dass nämlich die »logischen Formen« die (neuen) nicht weiter zu hinterfragenden Grundlagen der Philosophie seien. Der Grund für diese Überzeugung liegt - so wird der folgende Abschnitt deutlich machen - in einer neuen Verhältnisbestimmung zwischen Mathematik und Logik:

Bekanntlich haben die Mathematiker in den letzten Jahrzehnten neue logische Methoden entwickelt, zunächst zur Lösung ihrer eigenen Probleme, die sich mit Hilfe der überlieferten Formen der Logik nicht bewältigen ließen; dann aber hat die so entstandene Logik (siehe den Artikel von Carnap in diesem Heft) auch sonst ihre Überlegenheit über die alten Formen längst bewiesen und wird diese zweifellos bald ganz verdrängt haben. (ebd.)

Der von Schlick angesprochene Artikel von Carnap dient als Leitfaden für den nächsten Abschnitt. Er gibt Antworten auf die Frage, warum die Vertreter des Wiener Kreises von der Überlegenheit der Logik gegenüber anderen Wissenszweigen derart überzeugt waren.

\section{Die Genese der Logik aus der Mathematik}

Die neue Logik sei, schreibt Carnap in seinem Aufsatz »Die alte und die neue Logik«, »nicht mehr bloß eine philosophische Disziplin neben anderen, 
sondern wir können geradezu sagen: die Logik ist die Methode des Philosophierens" (Carnap 1930/131: 12). Carnap stellt die Logik als die (einzig noch mögliche) Methode »des Philosophierens « vor. Wie tut er das? Wie begründet er den Singularitätsanspruch der Logik?

Entscheidend in der Argumentation Carnaps ist dessen Zweiteilung der Logik in einen alten und einen neuen Bereich. Die »alte Logik « allein - gemeint ist die formale Logik aristotelisch-scholastischer Tradition - genüge nicht, die Logik als Methode der Philosophie zu etablieren. »Der Wunsch, an Stelle metaphysischer Begriffsdichtung eine streng wissenschaftliche Methode des Philosophierens zu setzen, wäre ein frommer Wunsch geblieben, wenn man als logisches Werkzeug nur das System der traditionellen Logik zur Verfügung gehabt hätte« (ebd.: 12-13). Denn die alte Logik »war gänzlich außerstande, den Ansprüchen an inhaltlichen Reichtum, formale Strenge und technische Brauchbarkeit zu genügen, die die neue Aufgabe an sie stellen mußte« (ebd.: 13). Diese alten Werke der Logik enthielten zwar »manche bemerkenswerte Überlegungen, standen aber in Bezug auf Begriffsbildung und Gründlichkeit der Analyse auf ziemlich primitiver Stufe« (ebd.). Carnap betont ausdrücklich, dass darin kein »Vorwurf gegen diese Werke« liege, sondern dass »dieser Zustand der angewandten Logik [...] durch die Unzulänglichkeit der formalen Grundlage [bedingt war] « (ebd.). Erst die neue Logik - sie sei vor ca. 50 Jahren, d.h. um 188o, entwickelt worden - enthielte die Möglichkeit, den geforderten Ansprüchen zu genügen. Diese neue Logik sei - dies ist der hier zentrale Aspekt - nicht von den Logikern alter Prägung, sondern von Mathematikern entwickelt worden:

An Stelle des unbrauchbaren alten Werkzeuges ein leistungsfähiges neues zu schaffen, hätte wohl lange Zeit erfordert. Und vielleicht darf man zweifeln, ob die Logiker aus eigenen Kräften zu diesem Werk überhaupt imstande gewesen wären. Zum Glück fand man ein Werkzeug schon vor, eine neue Logik, die in den letzten 50 Jahren entwickelt worden ist, und zwar durchweg von Mathematikern. Den Anlaß hierzu gaben Schwierigkeiten innerhalb der Mathematik; an eine philosophisch bedeutsame allgemeinere Anwendung war zunächst nicht gedacht worden. (ebd.)

Carnap führt die Entwicklung der neuen Logik also auf mathematik-interne Diskussionen ab ca. 1850 zurück. »Der wichtigste Anlaß zur Ausbildung der neuen Logik lag in der Notwendigkeit, die Grundlagen der Mathematik kritisch nachzuprüfen « (ebd.: 14). Die Mathematik hätte durch Leibniz und Newton »einen ungeheuren Aufschwung genommen« und »eine Fülle neuer Erkenntnisse gewonnen « (ebd.). »Die Sicherung der Fundamente hatte jedoch mit diesem schnellen Wachsen des Gebäudes nicht Schritt gehalten« (ebd.). 
Aus diesem Grund habe ca. um 1830 eine stärkere Bemühung um die Klärung der Grundlagen der Mathematik begonnen. »Man begnügte sich nicht damit, die verschiedenen Begriffe der Analysis auf Zahlbegriffe als die Fundamentbegriffe der Mathematik zurückzuführen, sondern stellte sich die Aufgabe einer logischen Klärung der Zahlbegriffe selbst « (ebd.: 14, Herv. MD). Aus fachinternen Problemstellungen der Mathematik, so impliziert Carnap, habe sich die Notwendigkeit einer neuen Logik entwickelt. »Diese Untersuchungen der logischen Grundlage der Arithmetik mit dem Ziel der logischen Analyse der Zahl erforderten unumgänglich ein durch Umfang und Schärfe leistungsfähiges System « (ebd.: 14). Ein besonders starker Antrieb zur Entwicklung dieses System sei durch die Untersuchungen von Peano, Frege, Whitehead, Russel und Hilbert erfolgt. Die weitere fachinterne Entwicklung, so fährt Carnap weiter, erfordere schließlich eine »gründliche Neugestaltung der Logik« selbst: »Dringender noch wurde die Notwendigkeit eines Neuaufbaus der Logik, als man gewisse Widersprüche (`Antinomien $<$ ) zunächst auf mathematischem Gebiete bemerkte, die sich aber bald als solche allgemein-logischer Natur herausstellten. Sie konnten nur durch gründliche Neugestaltung der Logik überwunden werden« (ebd.: 15).

Aus Carnaps kurzem Abriss der Entwicklung der Logik lässt sich folgendes historiografisches Modell ablesen: Um fachinterne Grundlagenprobleme der Mathematik zu lösen, haben Mathematiker ein Instrument entwickelt, welches diese Probleme zu lösen vermochte: die Logik. Mit anderen Worten, Mathematiker benötigten ein neues Instrument, um fachinterne Unklarheiten beheben zu können. Die Logik wird von Carnap also zwar als das neue Fundament der Mathematik vorgestellt, selbst aber nicht als Mathematik definiert. ${ }^{92}$ Das »große Hauptwerk der neuen Logik« sei die Principia Mathematica (19101913) von Alfred North Whitehead und Bertrand Russell. »Alle weiteren Arbeiten der neuen Logik stützen sich auf dieses Werk; sie versuchen entweder, es zu ergänzen, oder, es umzubauen « (ebd.:14). ${ }^{93}$ Die Principia Mathematica stellt für Carnap den einschneidenden Schnitt zwischen der »alten« und der »neuen« Logik dar. Mit dieser Schrift, so kann Carnap paraphrasiert werden, vollzieht sich ein Paradigmenwechsel innerhalb der Mathematik: Die Mathematik wird - mithilfe der Typenlehre - neu fundiert, d.h., sie wird nun aus logischen Axiomen hergeleitet. Dieses neue und asymmetrische Verhältnis zwischen

92 Argumentationsstrategisch wird an dieser Stelle eine Analogie zu Husserl deutlich: Die Notwendigkeit einer neuen Philosophie - hier der Logik - wird mit den fachinternen Krisen einer anderen Wissenschaft - hier der Mathematik - begründet.

93 Carnaps historische Herleitung der neuen Logik zeigt sich hier als eine Vorwegnahme der zeitlich später einsetzenden - Ursprungserzählungen der sanalytischen Philosophieく. 
Logik und Mathematik wird von Carnap in verschiedenen Formulierungen wiederholt. So stellt er die Mathematik dezidiert als einen "Zweig der Logik « dar. »Es zeigt sich nämlich, daß jeder mathematische Begriff aus den Grundbegriffen der Logik abgeleitet werden kann, und daß jeder mathematische Satz [...] aus den Grundsätzen der Logik abgeleitet werden kann « (ebd.: 20). Kurz: Carnaps wissenschaftshistorische Darstellung zielt auf die Darstellung der Logik als neues Fundament der Mathematik.

In der hier eingenommenen Perspektive ist nun entscheidend, wie Carnap diese neuen Befunde aus dem Bereich der Mathematik argumentativ in den Bereich der Philosophie rücktransponiert. Die neue Logik, so behauptet er zu Beginn des Textes in programmatischer Weise, vermöge die »alte Philosophie aus den Angeln zu heben« (ebd.: 13).

In dieser neuen Logik liegt - das ist auch vielen ihrer Vertreter noch nicht bewußt - der Punkt, von dem aus die alte Philosophie aus den Angeln zu heben ist. Alle Philosophie im alten Sinne, knüpfe sie nun an Plato, Thomas, Kant, Schelling oder Hegel an, oder baue sie eine neue »Metaphysik des Seins « oder eine »geisteswissenschaftliche Philosophie« auf, erweist sich vor dem unerbittlichen Urteil der neuen Logik nicht etwa nur als inhaltlich falsch, sondern als logisch unhaltbar, daher sinnlos. (ebd.: 13)

Die neue Logik wird von Carnap also nicht nur als das neue Fundament der Mathematik dargestellt, sondern zugleich als ein Instrument, das auf andere Wissenschaften angewendet werden kann: Das neue Instrument der Logik vermag auszuweisen, dass alle bisherigen philosophischen Bemühungen »inhaltlich falsch«, »logisch unhaltbar« und daher »sinnlos« seien. Interessant ist hier, wie Carnap die in Anführungszeichen gesetzten Begriffe der »Metaphysik des Seins« bzw. der »geisteswissenschaftlichen Philosophie« verwendet: Er referiert auf Heidegger bzw. auf Dilthey, ohne deren Namen direkt zu nennen. Sowohl die Philosophie Heideggers als auch jene Diltheys erweisen sich gemäß Carnap als logisch unhaltbar, d.h. sinnlos, wenn die Methoden der neuen Logik auf sie angewendet werden.

Die Atributte »inhaltlich falsch«, »logisch unhaltbar« und »sinnlos« stehen für Carnap gleichbedeutend mit nicht wissenschaftlich. Er wendet diese Atributte auf andere Philosophien an und transponiert dadurch die neuen Befunde aus der Mathematik, nämlich, dass mit der Logik mathematische Grundlagenprobleme gelöst werden können, in den Bereich der Philosophie. Diesen Transfer begründet er aus dem Potenzial der neuen Logik selbst: »Die neue Logik unterscheidet sich von der alten [...] vor allem durch umfangreiche Gebietserweiterungen « (ebd.: 16). Als die wichtigsten »Gebietserweiterungen« nennt er die »Theorie der Beziehungssätze« und die »Theorie der variablen 
Satzfunktionen «. Es kommt an dieser Stelle nun nicht darauf an, Carnaps Argumentationen im Detail nachzuvollziehen, sondern es gilt festzuhalten, dass er in der »neuen Logik« nicht nur ein für die Mathematik fundierendes Element sieht, sondern dies zugleich auf den Bereich der Sprache und den Bereich der Wissenschaften allgemein ausweitet. Letzteres führt zu der Annahme, dass alle wissenschaftlichen Bestrebungen letztlich auf eine gemeinsame Basis zurückgeführt werden können. »Bei der Analyse der wissenschaftlichen Begriffe hat sich ergeben, daß alle Begriffe, mögen sie nun nach üblicher Einteilung zum Gebiet der Naturwissenschaften, der Psychologie oder der Sozialwissenschaften gehören, auf eine gemeinsame Basis zurückgehen $[\ldots]$ « (ebd.: 24). Potenziell, so folgt daraus, ließe sich ein abstraktes Formelsystem finden, das alle Wissenschaften logisch miteinander verbindet. »So führt die logische Analyse mit den Mitteln der neuen Logik zur Einheitswissenschaft. Es gibt nicht verschiedene Wissenschaften mit grundsätzlich verschiedenen Methoden oder gar verschiedenen Erkenntnisquellen, sondern nur die eine Wissenschaft« (ebd.: 24-25) ${ }^{94}$ Unter diese eine Wissenschaft fällt für Carnap auch die Philosophie. »Es gibt keine Philosophie als Theorie, als System eigener Sätze neben denen der Wissenschaft« (ebd.: 26). Und dennoch weist Carnap der Philosophie eine klare, sich von den Aufgaben der Einzelwissenschaften abhebende Bestimmung zu: »Philosophie betreiben bedeutet nichts anderes als: die Begriffe und Sätze der Wissenschaft durch logische Analyse klären« (ebd.). Auf der einen Seite wird die Philosophie als eine eigene Wissenschaft zurückgewiesen, um sie auf der anderen Seite als Methode für die Fundierung aller anderen Wissenschaften wieder zu rehabilitieren.

Gemäß der hier gezeichneten Argumentationslinie von Schlick und Carnap birgt die Logik einen objektiven Standpunkt, von dem ausgehend die Wissenschaftlichkeit der Philosophie ein füralle Mal beurteiltwerden kann. Hergeleitet und begründet wird dieser Befund mit der Letztgültigkeit der Logik selbst: Ausgehend von mathematikinternen Entwicklungen wird sie in den Bereich der Philosophie transponiert: Der Wiener Kreis nimmt die neuen Befunde aus der Mathematik, dass nicht mathematische, sondern logische Prinzipien die Mathematik fundierten, auf und überträgt sie auf andere Wissensgebiete.

94 Die »Einheitswissenschaft« wird vor allem von Neurath verteidigt und verfochten. Sie ist mit politischen Ansprüchen eng verbunden: »Was [...] im traditionellen Sprachgebrauch >Philosophie $<$ heißt [...], heißt später `Einheitswissenschaft<, wobei Wissenschaft als kollektive Tätigkeit begriffen wird, als bewusst geplante und betriebene, zusammenhängende, gemeinsame Arbeit der verschiedenen Spezialisten, als Beitrag zur Verbesserung des menschlichen Daseins. Wissenschaft soll nicht länger abgehoben und getrennt sein vom Alltagsleben der Masse der Bevölkerung «(Dvořák 1985: 132). 
Die Logik stelle - so die Argumentation - nicht nur die neue Grundlage der Mathematik dar, sondern zugleich die Grundlage jeder Wissenschaft, d.h. auch der Philosophie. Der Wiener Kreis begründet seinen Erneuerungsanspruch also nicht dadurch, dass er - wie Husserl oder die Kritische Theorie - der Philosophie in expliziter Weise Relevanz für die Wissenschaften und die Gesellschaft zuweist, sondern vielmehr dadurch, dass er mit der Logik einen neuen, objektiv gültigen Standpunkt behauptet. Das heißt, nicht das Herausstellen der Spezifika der Philosophie gegenüber anderen Wissenschaften, sondern die Rehabilitation der philosophischen Methode als objektiv gültiges Kriterium ist die entscheidende Strategie. Erkennbar wird diese Erneuerungsstrategie auch darin, dass die Vertreter des Wiener Kreises jeder herkömmlichen und zeitgenössischen Philosophie ihre wissenschaftliche Objektivität absprechen. Das dezidierte Bestreben, die Metaphysik als unwissenschaftlich auszuweisen, ist dafür besonders aufschlussreich.

\section{Philosophische Altlasten aus dem Weg räumen: Metaphysikkritik}

Die »wissenschaftliche Weltauffassung « wird von ihren Vertretern in einen scharfen Kontrast zur Metaphysik gestellt. Eine Formulierung aus dem »Manifest « lautet: »Die Vertreter der wissenschaftlichen Weltauffassung stehen entschlossen auf dem Boden der einfachen menschlichen Erfahrung. Sie machen sich mit Vertrauen an die Arbeit, den metaphysischen und theologischen Schutt der Jahrtausende aus dem Weg zu räumen « (Neurath/Hahn/ Carnap 1929: 314). Eines der erklärten Hauptziele des Wiener Kreises ist es laut dem »Manifest«, sowohl die Wissenschaften als auch die Philosophie von Metaphysik zu $»$ reinigen $\ll .{ }^{95}$

Carnaps Artikel »Überwindung der Metaphysik durch logische Analyse der Sprache«, in dem er seine berühmt gewordene Kritik an Heidegger entwickelt, ${ }^{96}$ ist 1931 in der »Erkenntnis« erschienen. Wie erwähnt hat bereits Wittgenstein auf die programmatische Ansage des Wiener Kreises, die Metaphysik mit Logik überwinden zu wollen, irritiert und verärgert reagiert. Diese Irritation spiegelt sich auch in der Rezeptionsgeschichte von Carnaps Schriften: Dass sein Anspruch, »die ganze Metaphysik aus der Philosophie zu verbannen,

95 Der Begriff der »Reinigung « erscheint im Manifest an zwei Stellen. »Er [Ernst Mach, MD] war besonders darum bemüht, die empirische Wissenschaft, in erster Linie die Physik, von metaphysischen Gedanken zu reinigen« (Neurath/Hahn/Carnap 1929: 302). Und: »Hier [in den Sozialwissenschaften, MD] ist zwar noch nicht derselbe Grad der Reinigung wie in der Physik erreicht; andererseits ist hier vielleicht die Reinigungsaufgabe weniger dringend « (ebd.: 313).

96 Das Schisma zwischen kontinentaler und analytischer Philosophie wird u.a. auf den >Streit` zwischen Carnap und Heidegger zurückgeführt (Friedman 20oo). 
weil sich ihre Thesen nicht rational rechtfertigen lassen « (Carnap 1928: V), überzogen bis "peinlich « sei, ${ }^{97}$ wird häufig betont. Hätte man Kenntnisse über die Geschichte der Metaphysik, so etwa das Argument von Eckehart Köhler, wüsste man, dass die Natur der Metaphysik seit Aristoteles in der Akzeptanz von Prinzipien a priori liege. Die Mitglieder des Wiener Kreises aber waren keineswegs gegen solche Prinzipien, im Gegenteil: Sie fanden diese Prinzipien in logischen und empirischen `Sätzen< (Köhler 1995: 191-192). »Carnaps vermeintliche >Überwindung der Metaphysik««, so folgert Dieter Thomä, »entpuppt sich als Strategie, die auf einer zutiefst metaphysischen Voraussetzung beruht, also - horribile dictu - selbstwidersprüchlich ist. [...] Carnap bereitet nicht der >Überwindung der Metaphysik durch logische Analyse der Sprache< den Weg, sondern vielmehr der Etablierung einer eigenen Metaphysik durch ebendiese logische Analyse« (Thomä 2018: 104).

Gerade aufgrund dieser Befunde lohnt sich eine erneute Lektüre der betreffenden Stellen, jedoch gewissermaßen in umgedrehter Funktion: Der Überwindungsanspruch der Metaphysik ermöglicht es Carnap - so die These, die im Folgenden erläutert wird -, die logische Analyse als neue philosophische Position zu behaupten. Carnaps »Überwindung der Metaphysik« erweist sich in dieser Perspektive - wie Thomä es ausdrückt - allerdings selbst als eine Strategie, wiederum - wenn auch unterschwellig und nicht explizit eine eigene Metaphysik in Form ebendieser logischen Analyse zu lancieren.

Carnaps programmatisch gewordene Definition der Metaphysik - »Metaphysiker sind Musiker ohne musikalische Fähigkeit « (Carnap 1931: 240) zielt darauf, der traditionellen Philosophie eine wissenschaftlich informierte Methode abzusprechen. Die bisherige Philosophie besitze gewissermaßen kein solides Grundhandwerk. Metaphysik gebe zwar vor, Theorie zu sein, in Wirklichkeit diene sie aber lediglich zum Ausdruck des Lebensgefühls (ebd.: 238). In diesem Sinne sei sie - verkürzt gesprochen - schlechte Kunst. Metaphysiker würden für ihr Anliegen die falsche Form wählen: Sie täten besser daran, ihr Lebensgefühl mittels Literatur, Musik oder Poesie auszudrücken! Es sei zwar keineswegs falsch, so Carnap, ein Lebensgefühl ausdrücken zu wollen, nur dürfe dies nicht im Namen der Wissenschaft und der Philosophie geschehen. »Bei der Metaphysik liegt jedoch die Sache so, daß sie durch die Form ihrer Werke etwas vortäuscht, was sie nicht ist « (ebd.: 239-240). Metaphysik gebe nämlich einen theoretischen Inhalt vor, in Wirklichkeit sei dies aber eine Täuschung.

97 »Für einen Sympathisanten des Wiener Kreises, der auch nur ein wenig in der Geschichte der Metaphysik bewandert ist, ist es nachgerade peinlich[,] feststellen zu müssen, daß dieses a priori Gültige bereits bei Aristoteles, [sic!] gerade schon als das Wesen der Metaphysik angesehen wird « (Köhler 1995: 192). 
»Der Metaphysiker glaubt sich in einem Gebiet zu bewegen, in dem es um wahr und falsch geht. In Wirklichkeit hat er jedoch nichts ausgesagt, sondern nur etwas zum Ausdruck gebracht, wie ein Künstler« (ebd.: 240). Anders als der Künstler wisse der Metaphysiker nicht, »daß er sich im Gebiet der Kunst und nicht in dem der Theorie befindet « (ebd.: 240). Carnap bedient sich in seiner Argumentation eines gängigen Topos, nämlich der Trennung zwischen Kunst und Wissenschaft, um die Metaphysik als unwissenschaftlich zu disqualifizieren. Mit anderen Worten, durch seine Parallelisierung der Metaphysik mit den Künsten wird die Metaphysik aus dem Bereich der Philosophie ausgeschlossen. Metaphysische Sätze sind für Carnap Scheinsätze, d.h., sie sind konstitutiv bedeutungs- und sinnlos.

Da die Metaphysik weder analytische Sätze sagen, noch ins Gebiet der empirischen Wissenschaft geraten will, so ist sie genötigt, entweder Wörter anzuwenden, für die keine Kriterien angegeben werden und die daher bedeutungsleer sind, oder aber bedeutungsvolle Wörter so zusammenzustellen, daß sich weder ein analytischer (bzw. kontradiktorischer) noch ein empirischer Satz ergibt. In beiden Fällen ergeben sich notwendig Scheinsätze. (ebd.: 236)

Scheinsätze seien weder analytisch noch empirisch. »Die logische Analyse spricht somit das Urteil der Sinnlosigkeit über jede vorgebliche Erkenntnis, die über oder hinter die Erfahrung greifen will« (ebd.: 237). Metaphysik ist für Carnap alles Nichtempirische, das vorgibt, Erkenntnis zu sein. Erst indem er alles Nichtempirische aus dem Bereich der Philosophie auslagert, kann er seine eigene Position begründen. Er >arbeitet< folglich mit einer Strategie der Auslagerung: Indem er die Metaphysik, verstanden als traditionelle Philosophie, mit dem Argument der Unwissenschaftlichkeit aus dem Bereich des Philosophischen auslagert, argumentiert er für eine neue, nun wissenschaftliche philosophische Position.

Dass die »Überwindung der Metaphysik« als eine argumentative Strategie fungiert, Carnaps eigene Position zu begründen, wird vor allem daran deutlich, dass er den Begriff der Metaphysik als selbstevident voraussetzt. Seine Andeutungen über die Metaphysik als das Nichtempirische oder als schlechte Kunst werden nicht weiter erläutert. Erst durch seine logische Analyse wird es möglich, Sätze als metaphysisch zu entlarven. Seine These - »dass die angeblichen Sätze der Metaphysik sich durch logische Analyse als Scheinsätze enthüllen« (ebd.: 220) - setzt also bereits voraus, dass klar sei, welche Sätze zumindest potenziell - metaphysisch sind und welche nicht. ${ }^{98}$ Gerade indem

98 Hier wird eine Argumentationsstrategie deutlich, die bereits im Falle von Husserl erkennbar geworden ist und im Kapitel zur Kritischen Theorie vertieft wird: Der Wahrheitsgehalt 
Carnap nicht explizit ausführt, was unter Metaphysik zu verstehen ist oder warum Metaphysik in der Philosophie überhaupt eliminiert werden muss, nimmt sie eine wichtige Funktion in seiner Argumentation ein: Als Chiffre der Unwissenschaftlichkeit fungiert die Metaphysik als Abgrenzungsfolie für die Plausibilisierung einer neuen, nunmehr nicht metaphysischen, d.h. wissenschaftlichen Grundlegung. Die neue Logik ist dafür das entscheidende Instrument:

Der Unterschied zwischen unserer These und der der früheren Antimetaphysiker ist jetzt deutlich. Die Metaphysik gilt uns nicht als »bloßes Hirngespinst« oder »Märchen«. Die Sätze eines Märchens widerstreiten nicht der Logik, sondern nur der Erfahrung; sie sind durchaus sinnvoll, wenn auch falsch. Die Metaphysik ist kein »Aberglaube«; glauben kann man an wahre und an falsche Sätze, aber nicht an sinnlose Wortreihen. (ebd.: 232)

Liest man dieses Zitat gegen den Strich, wird abstrahierend vor allem die Unterscheidung zwischen sinnlos/sinnvoll augenscheinlich. Im Zusammenhang mit den anderen Textstellen könnte man die Textstelle also dahingehend deuten, dass ein Märchen zwar durchaus logisch sein kann, da es sich lediglich mit der Erfahrung widerspricht, die Metaphysik hingegen sei logisch falsch. Deswegen, so Carnaps Folgerung, könne sie ohne weitere Diskussion ad acta gelegt werden. Mit dem (logischen) Urteil der Sinnlosigkeit schließt Carnap bestimmte Wissenstraditionen gänzlich aus dem wissenschaftlichen und philosophischen Geltungsbereich aus. Ist etwas lediglich falsch - wie etwa das Märchen - verbleibt es doch immerhin noch im Bereich des wissenschaftlich Überprüfbaren. Ist etwas jedoch wissenschaftlich sinnlos - wie laut Carnap die Metaphysik -, ist es von vornherein aus dem Bereich der Wissenschaften und der Philosophie ausgeschlossen.

Carnap erhärtet die Grenzziehung zwischen wissenschaftlicher und metaphysischer Philosophie, wie erwähnt, mit einer Kritik an Heidegger. ${ }^{99}$

anderer zeitgenössischer Philosophien wird mit einer neu entwickelten Methode infrage gestellt. Die Strategie, die neu entwickelte Methode auf die Philosophie selbst anzuwenden und gerade dadurch eine philosophische Erneuerung zu evozieren, erweist sich als eine eminent wichtige Argumentationsstrategie (siehe dazu das Fazit, v.a. S. 192).

99 Michael Friedman versteht diese Wahl innerhalb des politischen Kontextes: »And I think there is no doubt that this social and political dimension of their disagreement represents at least part of the explanation for the circumstance that Carnap chooses precisely Heidegger for his examples of metaphysical pseudo-sentences« (Friedman 2000: 18). Thomä diskutiert im Zusammenhang mit Heideggers Urfassung von Was ist Metaphysik? dessen politisch höchst problematische Stellung im Zusammenhang mit Carnaps Kritik. »Gespiegelt auf Heidegger heißt dies [dass Carnap als Gönner versagt hat, mit seinen Sorgen aber recht hat, MD], dass er in dem Maße, wie Carnap Unrecht hat, weiterhin als 
Heideggers Philosophie sei jene »metaphysische[] Lehre, die gegenwärtig in Deutschland den stärksten Einfluss ausübt« (ebd.: 229). Carnap unterzieht einzelne Aussagen aus Heideggers Aufsatz Was ist Metaphysik? (1929) einer sprachlogischen Analyse. Diese ergibt, dass Sätze wie z.B. Das Nichts selbst nichtet inhaltsleer und sinnlos sind. Gleichzeitig betont er, dass Heidegger selbst feststelle, dass »seine Fragen und Antworten mit der Logik und der Denkweise der Wissenschaft nicht vereinbar sind « (ebd.: 232). Heidegger gehe, wie alle Metaphysiker, also durch und durch antilogisch und antiwissenschaftlich vor. Bereits deren Fragestellungen seien logisch sinnlos. Begriffe wie »Gott«, »Ursprung «, »Idee«, »das Absolute«, »das Unbedingte«, das »Unendliche«, das »Sein des Seienden«, »Ding an sich«, »absoluter Geist«, »objektiver Geist«, »Wesen «, »Ansichsein «, »Anundfürsichsein «, »Emanation «, »Manifestation «, »Ausgliederung «, »das Ich«, das »Nicht-Ich« usw. seien »spezifisch metaphysische Termini ohne Bedeutung « (ebd.: 227). Mit solchen Wörtern verhalte es sich nicht anders als mit einem willkürlich erfundenen Wort wie z.B. »babig « (dessen Bedeutungslosigkeit Carnap an einer anderen Stelle in seinem Text logisch belegt hat).

Carnaps »Überwindung der Metaphysik« geht also nicht nur mit einem direkten Angriff auf einen zeitgenössischen Philosophen - Heidegger - einher, sondern zugleich mit dem Angriff auf Kernbegriffe des abendländischen philosophischen Denkens. Seine Metaphysikkritik hat zur Folge, dass beinahe der gesamte philosophische Diskurs als metaphysisch und daher als sinnlos beurteilt wird. Carnap unterstreicht dies explizit: Sein Urteil treffe »jede spekulative Metaphysik, jede vorgebliche Erkenntnis aus reinem Denken oder aus reiner Intuition, die die Erfahrung zu entbehren glaubt« (ebd.: 237). Das Urteil treffe aber auch jede Metaphysik, die von der Erfahrung ausgehend das »außer oder hinter der Erfahrung Liegende erkennen will [...] « (ebd.), sowie jegliche Wert- oder Normphilosophie und jede Ethik oder Ästhetik. Darüber hinaus seien auch der Realismus, subjektive Idealismus, Solipsismus, Phänomenalismus und (der frühe) Positivismus vom Urteil der metaphysischen Sinnlosigkeit betroffen. Kurz: Indem Carnap gewissermaßen den gesamten philosophischen Kanon unter Metaphysik fasst, setzt er seine eigene Position von ebendiesem Kanon ab. Das Disqualifizieren von bestehenden »sinnlosen « - Philosophien und die Fundierung von neuen - »sinnvollen « Positionen sind zwei Seiten desselben Argumentationsprozesses.

Wie beschreiben die Vertreter des Wiener Kreises aber diese neue Philosophie, die in der Selbstbeschreibung der Gruppe mit der alten so gar nichts

jemand, der einen philosophischen Beitrag leistet, gelten darf, und dass er in dem Maße, wie Carnap Recht hat, aus der Philosophie herausfällt« (Thomä 2018: 101). 
zu tun hat? »Was aber bleibt dann für die Philosophie überhaupt noch übrig, wenn alle Sätze, die etwas besagen, empirischer Natur sind und zur Realwissenschaft gehören? « (ebd.). Carnaps dezidierte Antwort lautet: »Was bleibt, sind nicht Sätze, keine Theorie, kein System, sondern nur eine Methode, nämlich die der logischen Analyse (Carnap: 1928: 237).

\section{Die Philosophie als Methode bzw. Tätigkeit}

Wie also wird der Philosophie, wenn sie aus Sicht des Wiener Kreises in ihrer herkömmlichen Form doch strikt abgelehnt werden muss, dennoch ein eigenständiger und von den Fachwissenschaften unterscheidbarer Bereich zugewiesen? Wie wird die durch die Identifikation mit den Wissenschaften "gereinigte $« 100$ Philosophie neu >besetzt $\ll$ ? Wo an Carnaps Texten ein historiografisches Modell sichtbar wurde, das die Letztinstanz der Logik aus der Mathematik extrapoliert, wird im Folgenden an Neurath, Frank und Reichenbach die methodologische Ebene hervorgehoben: Die als neu postulierte philosophische Methode, so wird deutlich werden, habe sich an der Physik zu orientieren.

In seinem Beitrag Wege der wissenschaftlichen Weltauffassung sagt der Sozialökonom Neurath: »Die Vertreter der wissenschaftlichen Weltauffassung, die alles Erfahrbare in sich aufnimmt, verhalten sich wie Physiker « (Neurath 1930/1931: 106). Auch hier wird die Transponierung naturwissenschaftlicher Modelle in den Bereich der Philosophie offensichtlich, die bereits weiter oben deutlich geworden ist. Wo Carnap in seinem Text Die alte und die neue Logik die Gültigkeit mathematischer Erkenntnisse auf die Wissenschaften allgemein übertragen hat, geht es hier - wie Neurath selber sagt - um ein Vorbild bezüglich der Arbeitsweisen: Die Physik, so Neurath, sei eine Disziplin »mit sehr sauberen Begriffen«; Physiker seien »aktiv und gegenwartsnah, auch wenn sie sich in abstrakten Sphären bewegen. Sie bemühen sich weniger um die Geschichte ihrer Gedankengänge als um neue Einsichten, die sie in klaren Sätzen zu formulieren suchen. Bei den erlangten Ergebnissen bleibt man nicht stehen, die Formulierungen werden weiter geführt und von Jahr zu Jahr verbessert« (ebd.). Die Arbeitsweise der Physiker müsse, so impliziert Neurath, auf die Arbeitsweise der Philosophie übertragen werden. Keinesfalls gehe es aber darum, dass Philosophen physikalische Probleme behandeln sollten, im Gegenteil: Es seien die Fachwissenschaftler selbst, die üblicherweise als >philosophisch < deklarierte Probleme bearbeiten und beantworten sollen.

Dieser Anspruch auf eine Überwindung der Fächergrenzen in Bezug auf die Methode wird auch von Frank in seiner Eröffnungsansprache aufgegriffen:

100 Zum Begriff der »Reinigung« siehe Fn. 95. 
»Der Physiker ist oft zu folgender Auffassung geneigt: Wenn man tiefer gräbt, so stößt man immer auf Fragen, die der Physik nicht mehr zugänglich sind, sondern zu denen eine ganz andere Methode, die philosophische, gehört. Diese Meinung ist umso mehr verbreitet, je weniger man sich mit den Grundlagenproblemen beschäftigt « (Frank 1930/1931: 95). Diese Meinung jedoch sei falsch: »Jede tiefere Beschäftigung muß meiner Ansicht nach zu der Überzeugung führen, daß alle Probleme, die von der Physik und Mathematik aufgeworfen werden, auch nach den Methoden der exakten Wissenschaften gelöst werden können und müssen « (ebd.). Im nächsten Satz bringt Frank sein Anliegen wie folgt auf den Punkt: »Der Physiker braucht sich nicht, wenn er an einer gewissen Grenze angekommen ist, blindlings in die Arme einer veralteten Philosophie zu werfen « (ebd.). Frank kritisiert somit Physiker dahingehend, dass diese bestimmte Fragen fälschlicherweise aus ihrem Fachgebiet auslagerten. Die Physik könne zwar an ihre Grenzen stoßen, es sei aber nicht wie eine verbreitete Meinung sage - die Aufgabe von Philosophen, die Fragen, die jenseits dieser Grenze liegen, zu beantworten, sondern es sei die Aufgabe der Fachwissenschaftler selbst, diese Grenze zu überwinden. Es gebe »heute schon genug Bestrebungen, auch die Grundbegriffe und -probleme nach rein wissenschaftlichen Methoden zu bearbeiten « (ebd.). Frank verknüpft diese Auffassung mit einem Ziel der gesamten »Tagung für Erkenntnislehre der exakten Wissenschaften«:

Und wenn diese Tagung so ausfällt, wie sie, meiner Ansicht nach, einen Sinn für Mathematiker und Physiker haben kann, so muß sie in ihnen nicht die Überzeugung erwecken, daß man eine ihnen fremde Philosophie braucht, aber anstatt dessen einen Zweig der exakten Wissenschaften, der die Grundprobleme mit derselben Strenge, mit derselben erbarmungslosen Forderung nach Klarheit behandelt, die der Physiker und Mathematiker im Inneren seiner Wissenschaft von jeher zu fordern gewohnt ist. (ebd.)

Die Tagung soll laut Frank zeigen, dass nicht eine der Mathematik und Physik äußerliche Philosophie für die vorerst unerklärbaren Probleme der Physik zuständig ist, sondern es seien Mathematiker und Physiker selbst, die diese Aufgaben zu lösen haben. Wie weiter oben bereits thematisiert, wird ein ähnlicher Gedanke auch von Reichenbach in seiner Ansprache »Zur Einführung« aufgeworfen: Für die Philosophie seien einzig jene Erkenntnisse relevant, die aus den Fachwissenschaften resultierten. Diese aus den Einzelwissenschaften gewonnenen Erkenntnisse sollen laut Reichenbach in einer neuen Zeitschrift, der »Erkenntnis«, ein Organ finden (Reichenbach 1930/31: 1). Sowohl in Neuraths als auch in Franks und Reichenbachs Bemerkungen wird also die Ansicht deutlich, dass es zwar durchaus genuin philosophische Erkenntnisse 
gibt, dass diese aber ausgehend von den fachwissenschaftlichen Methoden selbst bearbeitet und behandelt werden sollen. Die Beispiele verdeutlichen, dass die Fächergrenzen zwischen der Philosophie und den Fachwissenschaften aufgelöst werden, ohne die Relevanz genuin >philosophischer Erkenntnisse< infrage zu stellen.

Worin genau diese aus den Fachwissenschaften stammenden philosophischen Erkenntnisse jedoch bestehen bzw. wie sie sich von anderen Erkenntnissen unterscheiden, wird nicht weiter thematisiert. Argumentativ wird also lediglich der >Ort<, wo diese aufzufinden sind, verlagert: Im Verständnis der herkömmlichen Philosophie seien sie in der Fachwissenschaft Philosophie aufzufinden, im Verständnis der neuen - wissenschaftlichen Philosophie hingegen in den (naturwissenschaftlichen) Fachwissenschaften. Negiert wird also lediglich die Möglichkeit der Philosophie als einheitliche Wissenschaft (»Systemphilosophie«) und nicht etwa die Existenz genuin philosophischer Erkenntnisse.

Der zentrale Unterschied zwischen der herkömmlichen Philosophie und der neuen wissenschaftlichen Weltauffassung sei - so schreiben auch die Autoren des »Manifests « -, dass die wissenschaftliche Weltauffassung ${ }^{101}$ keinen eigenen Gegenstand und kein eigenes Erkenntnisobjekt besitze, das sie untersuchen könnte: »Rückblickend wird uns nun das Wesen der neuen wissenschaftlichen Weltauffassung im Gegensatz zur herkömmlichen Philosophie deutlich: Es werden nicht eigene >philosophische Sätzeく aufgestellt, sondern nur Sätze geklärt; und zwar Sätze der empirischen Wissenschaft, wie wir es bei den verschiedenen, vorhin erörterten Problemgebieten [Grundlagen der Arithmetik, Physik, Geometrie, Biologie, Psychologie und Sozialwissenschaften, MD] gesehen haben« (Neurath/Hahn/Carnap 1929: 314). Die >Auflösung der Philosophie in die Fachwissenschaften und die Konzeptualisierung der Philosophie als einer Methode im Dienste dieser Wissenschaften sind zwei Seiten derselben Medaille.

Dass die Vertreter des Wiener Kreises philosophische Erkenntnisse mit den Ergebnissen aus den Fachwissenschaften identifizieren, ohne dass aus ihrer Sicht damit einherginge, dass die Philosophie ihre Eigenständigkeit einbüßte,

101 Dass die Vertreter des Wiener Kreises von »Weltauffassung « und nicht etwa von »Weltanschauung« sprechen, ist zentral. Im Zusammenhang mit seiner Metaphysikkritik schreibt Carnap: »Hierbei [wie sich in Stil und Art des Kunstwerkes das Lebensgefühl kundgibt, MD] wird häufig der Ausdruck >Weltanschauung gebraucht; wir vermeiden ihn lieber wegen seiner Zweideutigkeit, durch die der Unterschied zwischen Lebensgefühl und Theorie verwischt wird, der für unsere Analyse gerade entscheidend ist« (Carnap 1931: 239). 
wird - paradoxerweise - durch folgende Aussage Schlicks offenkundig: »Hier dürfen wir noch hinzufügen, dass die ganz entscheidenden, epochemachenden Fortschritte der Wissenschaft immer von dieser Art sind, daß sie eine Klärung des Sinnes der fundamentalen Sätze bedeuten und daher nur solchen gelingen, die zur philosophischen Tätigkeit begabt sind; das heißt: der große Forscher ist immer auch Philosoph «(Schlick 1930/31: 10).

Die Argumentationsstrategien der Vertreter des Wiener Kreises zielen auf eine neue Absteckung der Geltungsbestimmungen der Philosophie: In den Geltungsbereich der Philosophie eingeschlossen werden lediglich wissenschaftlich bereits erhärtete Erkenntnisse. Ob es sich dabei um Erkenntnisse aus den Natur- oder den Geisteswissenschaften handelt, spielt, wie etwa Reichenbach sagt, nur eine untergeordnete Rolle.

Solange die Naturwissenschaften wie bisher den weitaus größten Teil an Erkenntnissen in die Philosophie hereintragen, solange werden sie deshalb den Schwerpunkt der Zeitschrift bestimmen; aber an sich scheint uns eine Befruchtung der Philosophie durch die Geisteswissenschaften, die wir überhaupt nur in arbeitstechnischem Sinne von den Naturwissenschaften abtrennen möchten, in gleicher Weise möglich, und wir hoffen, von solcher Philosophie der Geisteswissenschaften ebenfalls Zeugnisse bringen zu können. (Reichenbach 1930/ 31: 1-2)

Die Trennlinie, die Reichenbach hier für die Geltungsbestimmung der Philosophie produktiv macht, liegt also nicht zwischen verschiedenen Disziplinen, sondern zwischen wissenschaftlichen und nicht wissenschaftlichen Befunden. Philosophisch relevant, so die Implikation, sind alle wissenschaftlich erhärteten Erkenntnisse.

An dieser Stelle erhalten die Erneuerungsstrategien des Wiener Kreises ihre Form: Der Philosophie bzw. ihrer Methode (der logischen Analyse) wird die Aufgabe zugewiesen, die Grenzen zwischen wissenschaftlich und nicht wissenschaftlich endgültig ziehen zu können. Durch ihre Identifizierung der philosophischen Tätigkeit mit einer mathematisch-physikalischen Methode grenzen die Vertreter des Wiener Kreises die Philosophie nicht nur von allen anderen Wissenschaften ab, sondern installieren sie darüber hinaus als Fundament dieser Wissenschaften. Gerade indem die Vertreter des Wiener Kreises vor allem durch ihre Metaphysikkritik - die philosophische Tätigkeit auf den Bereich der Wissenschaften einschränken, rehabilitieren sie argumentativ ein traditionelles Merkmal der Philosophie, nämlich über alles, d.h. über alles Wissenschaftliche, sprechen zu können. Durch die strikte Ablehnung der Philosophie als eigenes Fach und ihre Einschränkung auf eine Methode oder 
Tätigkeit wird ihr Geltungsbereich gewissermaßen auf alle Wissenschaften übertragen.

Dieser Erneuerungsanspruch, der mit der Identifikation der philosophischen Tätigkeit mit der Logik legitimiert wird, wird von Schlick wie folgt auf den Begriff gebracht: »Erkennbar ist alles, was sich ausdrücken lässt, und das ist alles, wonach man sinnvoll fragen kann. Es gibt daher keine prinzipiell unbeantwortbaren Fragen, keine prinzipiell unlösbaren Probleme «102 (Schlick 1930/31: 7). Das »Wesen der Dinge« durch Erkenntnisse ausdrücken zu wollen, so Schlick, sei schlichter Unsinn. »Es war einer der schwersten Irrtümer vergangener Zeiten, dass man glaubte, den eigentlichen Sinn und letzten Inhalt wiederum durch Aussagen zu formulieren, also in Erkenntnissen darstellen zu können: es war der Irrtum der >Metaphysik« (ebd.: 8-9). Das Streben der Metaphysiker sei seit jeher auf ein »widersinniges Ziel« gerichtet, nämlich darauf, »das Unsagbare zu sagen«103 (ebd.: 9).

Die Grenzziehung zwischen dem >Sagbaren < und dem >Unsagbaren < und die Rückführung des `Sagbaren` auf die Wissenschaft und die Sprache wird durch die Transponierung von Erkenntnissen und Modellen aus den exakten Wissenschaften in den Bereich der Geisteswissenschaften hergeleitet und begründet. Der Anwendungs- und Geltungsbereich der Philosophie wird neu abgesteckt. Erst innerhalb dieser wissenschaftlich aktualisierten Anwendungsbereiche

102 Schlick soll Wittgenstein, wie erwähnt, regelrecht verehrt haben. Es sei vor allem ihm zuzuschreiben, dass Wittgensteins Tractatus in den Sitzungen des Wiener Kreises über zwei Semester Satz für Satz diskutiert worden sei. Folgende Anekdote wird kolportiert: »Aber nicht alle verfielen Wittgensteins Zauber: So blieb etwa Otto Neurath dagegen völlig immun. Er witterte Metaphysik hinter den meisten Sätzen des Traktats, und rief das immer wieder lautstark in die philosophische Runde. Schließlich ersuchte ihn Schlick, doch der Kürze halber nur mehr >M! zu rufen. Neurath konterte, dass es noch kürzer wäre, >non-M! zu rufen, und zwar nach jenen Sätzen Wittgensteins, die nicht metaphysische waren« (Sigmund 2015: 119).

103 Diese Passage erinnert an einen der wohl berühmtesten Sätze der Philosophie des 20. Jahrhunderts, nämlich an Wittgensteins Schlusssatz des Tractatus: »Was sich überhaupt sagen lässt, lässt sich klar sagen; und wovon man nicht sprechen kann, darüber muss man schweigen «(Wittgenstein 1984 [1922]: 85). Die Unterschiedlichkeit in den Fokussierungen von Wittgensteins und Schlicks Aussagen kann als Widerspiegelung der ambivalenten Rolle gelesen werden, die Wittgenstein im Wiener Kreis einnimmt: Wo Wittgensteins Satz die Trennung zwischen »Sagbarem « und »Unsagbarem« fokussiert, die Relevanz des »Unsagbaren« aber keineswegs infrage stellt, fokussiert Schlick auf die Begründung des »Sagbaren« als Erkenntnis und auf die Gleichsetzung des »Unsagbaren« mit Metaphysik. Was bei Wittgenstein gewissermaßen wertneutral daherkommt, ist bei Schlick mit einem Imperativ verbunden: Metaphysik muss überwunden, wissenschaftliche Erkenntnis aber gefördert werden. 
wird der Philosophie ihre tradierte Rolle als »Alpha und Omega aller wissenschaftlicher Erkenntnis« (Schlick 1930/31: 8) zugestanden und zugesprochen.

\section{Kein eigenes Fach, aber Königin aller Fächer!}

Die Ablehnung der Philosophie als eigenständige Wissenschaft geht im Wiener Kreis so weit, dass die Nichtverwendung des Begriffes Philosophie zur Debatte stand. »Manche Vertreter der wissenschaftlichen Weltauffassung wollen, um den Gegensatz zur Systemtheorie noch stärker zu betonen, für ihre Arbeit das Wort >Philosophie< überhaupt nicht mehr anwenden « (Neurath/Hahn/ Carnap 1929: 314). Die Auffassung, dass es sich bei der Philosophie um eine Art Universal- oder Grundwissenschaft handele, wird verworfen: »Es gibt keine Philosophie als Grund- oder Universalwissenschaft neben oder über den verschiedenen Gebieten der einen Erfahrungswissenschaft; es gibt keinen Weg zu inhaltlicher Erkenntnis neben dem der Erfahrung; es gibt kein Reich der Ideen, das über oder jenseits der Erfahrung stände « (ebd.). Eine Sonderstellung der Philosophie gegenüber den anderen Wissenschaften wird abgelehnt: Die Philosophie sei den Wissenschaften gegenüber weder über- noch untergeordnet, sondern gehe - im Gegenteil - ganz in den Einzelwissenschaften auf. Diese Ablehnung ist umso bemerkenswerter, weil die Vertreter des Wiener Kreises in der Logik ja genau dasjenige Potenzial erkennen, das sie der herkömmlichen Philosophie, d.h. der Metaphysik, absprechen, nämlich das Potenzial, Erkenntnisse letztgültig klären zu können. Die Zurückweisung der Metaphysik ist in diesem Sinne als ein Frontalangriff auf die Philosophie und allgemein als eine Provokation zu verstehen.

Die Ablehnung der herkömmlichen und die Installierung einer neuen Philosophie sind zwei Seiten derselben Argumentationsstrategie. Die Vertreter des Wiener Kreises verteidigen dadurch die Möglichkeit letztgültiger, strikt wissenschaftlicher Erkenntniskriterien, ohne dass dabei der Bereich der Metaphysik tangiert wird. Schlick schreibt in seinem Beitrag: »Wir erkennen jetzt in ihr [der Philosophie, MD] - und damit ist die große Wendung in der Gegenwart positiv gekennzeichnet - anstatt eines Systems von Erkenntnissen ein System von Akten; sie ist nämlich diejenige Tätigkeit, durch welche der Sinn der Aussagen festgestellt oder aufgedeckt wird « (Schlick 1930/31: 8). Die »neue«, nun wissenschaftliche Philosophie, so Schlick, habe die Aufgabe, die Sinnhaftigkeit der Wissenschaft zu garantieren. »Durch die Philosophie werden Sätze geklärt, durch die Wissenschaften verifiziert. Bei diesen handelt es sich um die Wahrheit von Aussagen, bei jener aber darum, was die Aussagen eigentlich meinen« (ebd.). Weil »Inhalt, Seele und Geist der Wissenschaften« natürlich in dem stecke, was mit ihren Sätzen letztlich gemeint ist, sei die philosophische Tätigkeit der Sinngebung aller Anfang und aller Ende wissenschaftlicher Tätigkeit. 
Dass die philosophische Tätigkeit das Alpha und Omega aller wissenschaftlichen Erkenntnis ist, habe man geahnt, »wenn man sagte, die Philosophie liefere sowohl die Grundlage wie den Abschluss des Gebäudes der Wissenschaften; irrig war nur die Meinung, daß das Fundament von >philosophischen Sätzen gebildet werde (den Sätzen der Erkenntnistheorie), und daß der Bau auch von einer Kuppel philosophischer Sätze (genannt Metaphysik) gekrönt werde« (ebd.). Laut Schlick ist die Philosophie also zwar Anfang und Ende aller wissenschaftlichen Erkenntnis, selbst jedoch sei sie keine Wissenschaft. ${ }^{104} »$ Jede Wissenschaft [...] ist ein System von Erkenntnissen, d.h. von wahren Erfahrungssätzen; und die Gesamtheit der Wissenschaften, mit Einschluss der Aussagen des täglichen Lebens, ist das System der Erkenntnisse; es gibt nicht außerhalb seiner noch ein Gebiet > philosophischer Wahrheiten, die Philosophie ist nicht ein System von Sätzen, sie ist keine Wissenschaft « (ebd.: 7-8). Die traditionelle Philosophie jedoch, so impliziert Schlick, behaupte genau dies; sie gebe vor, eine Wissenschaft, d.h. ein System von sinnvollen Sätzen, zu sein, in Wirklichkeit sei sie das aber nicht. »Was ist sie aber dann?«, fragt Schlick in Bezug auf die »neue« Philosophie und antwortet: »Nun, zwar keine Wissenschaft, aber doch etwas so Bedeutsames und Großes, daß sie auch fürder, wie einst, als Königin der Wissenschaften verehrt werden darf; denn es steht ja nirgends geschrieben, daß die Königin der Wissenschaften selbst auch eine Wissenschaft sein müsste (ebd.: 8). In der hier eingenommenen Lesart trägt diese Wendung Schlicks nahezu absurde Züge. Allerdings zeigt sie anschaulich, wie der Wiener Kreis - gerade auch durch seine Ablehnung der traditionellen Metaphysik - die Philosophie als eine metaphysische Wissenschaft rehabilitiert. In Michael Festls Worten: »Die Philosophie bestimmt, was Wissenschaft überhaupt sein kann und was die Wahrheitskriterien einer bestimmten Wissenschaft sind (Festl 2018: 272-273). Das bedeutet umgekehrt auch, dass die Philosophie als unabhängige Instanz vorgestellt wird. Alfred Jules Ayer, dessen Buch Language, Truth and Logic (1936) wesentlich zur Popularisierung des Logischen Empirismus (vor allem in den USA) beigetragen hat, beschreibt diesen Aspekt wie folgt:

[...] the propositions of philosophy are not factual, but linguistic in character that is, they do not describe the behavior of physical, or even mental, objects; they express definitions, or the formal consequences of definitions. Accordingly, we may say that philosophy is a department of logic. For we shall see that the characteristic mark of a purely logical enquiry is that it is concerned with the

104 Argumentationsstrategisch ist hier der Unterschied zu Husserl aufschlussreich: Husserl positioniert die Philosophie explizit als eigenständige Wissenschaft, wohingegen die Vertreter des Wiener Kreises der Philosophie diesen Status absprechen. 
formal consequences of our definitions and not with questions of empirical fact. It follows that philosophy does not in any way compete with science. The difference in type between philosophical and scientific propositions is such that they cannot conceivably contradict one another. And this makes it clear that the possibility of philosophical analysis is independent of any empirical assumptions. That it is independent of any metaphysical assumptions should be even more obvious still. (Ayer 1967 [1936]: 57, Herv. MD)

Es mutet fast ironisch an, dass der Wiener Kreis, der vordergründig den unabhängigen Status der Philosophie attackiert, der Philosophie schließlich diesen Status wieder zuspricht. Die argumentative Eliminierung der Fachwissenschaft Philosophie und die Rehabilitation der Philosophie als Königin unter den Wissenschaften und für die Wissenschaften sind zwei Seiten desselben Argumentationsprozesses.

\section{Allgemeingültigkeit}

Die Rückführung des philosophischen Anwendungs- und Geltungsbereichs auf alles >Sagbare<, d.h. auf sprachliche und wissenschaftstheoretische Aspekte, ermöglicht - so ist deutlich geworden - gleichzeitig eine Aktualisierung der Philosophie als grundlegende Instanz. Die Logik wird als unabhängig sowohl von den Fachwissenschaften als auch von der Metaphysik vorgestellt, gerade weil sie aus den exakten Wissenschaften extrapoliert wird, denen wiederum ein absoluter Wahrheitsanspruch zukommt.

Die neue Funktion der Philosophie liegt gemäß diesem Erneuerungsanspruch darin, alle anderen Wissenschaften logisch miteinander zu verbinden. Diese Idee einer »Einheitswissenschaft «105 wiederum setzt den Anspruch auf Allgemeingültigkeit und in diesem Sinne Objektivität voraus. Reichenbach etwa führt in seiner Ansprache »Zur Einführung« den »Verzicht auf Allgemeingültigkeit« auf eine »Einengung des Blicks« zurück, der »die Unterschiede philosophischer Systeme in perspektivischer Verzerrung zu groß sieht und die Menge des bestehenden gemeinsamen Erkenntnisgutes zu gering veranschlägt« (Reichenbach 1930/31: 2). Würde man sich auf dasjenige konzentrieren, was man bereits weiß, »so bemerkt man auch auf

105 Die »Einheitswissenschaft« war ein umstrittenes Konzept, das, wie erwähnt, vor allem von Neurath verfochten wurde. Kurt Lewin, ein Vertreter der Berliner Gruppe, spricht sich explizit gegen die »Einheitswissenschaft « aus: »Ich habe nicht die Absicht, aus der Geschichte der Physik deduktiv zu schließen, was die Biologie tun >sollk. Denn ich bin nicht der Meinung, dass es letzten Endes nur eine einzige empirische Wissenschaft, die Physik, gibt, auf die alle übrigen zurückgehen« (Lewin 1930/31: 423). Siehe dazu auch Peters 2016: 53-54. 
philosophischem Gebiet eine weitreichende Übereinstimmung « (ebd.). Wenn man sich aber wie die Systemphilosophie auf dasjenige konzentriere, was man noch nicht weiß, habe man »nur zu reichlich Gelegenheit, Richtungen und Standpunkte in die Welt zu setzen « (ebd.). Je weiter man sich von der Philosophie in die Einzelwissenschaften hineinbewege, so Reichenbach, »und den Gedankengehalt aufzudecken versucht, der von den Forschern im Zusammenhang ihrer fachwissenschaftlichen Resultate als philosophischer Rahmen mitgedacht wird«, umso mehr werde man gemeinsam erarbeitete Wissensbestände finden. Dann werde man »nicht länger zweifeln können, daß es auch in der Philosophie eine objektive Erkenntnis gibt« (ebd.). Der Verzicht auf Allgemeingültigkeit ist gemäß Reichenbach lediglich einer Gewöhnung geschuldet: »Man hat sich in der Philosophie so sehr an Spaltung in Richtungen und Systeme gewöhnt, daß man darüber den Gedanken an eine einheitliche philosophische Wissenschaft nahezu aufgegeben hat und es als eine Besonderheit der Philosophie hinzustellen versuchte, daß es in ihr nur Lehrmeinungen, aber keine Lehre, daß es nur Standpunkte, aber keine Erkenntnis gibt« (ebd.). Reichenbach als Vertreter der Berliner Gruppe unterscheidet sich (wie weiter oben gezeigt) von den Vertretern des Wiener Kreises zwar hinsichtlich seines Philosophieverständnisses, nicht aber hinsichtlich seines Anspruchs auf Objektivität. Sowohl die Berliner Gruppe als auch der Wiener Kreis argumentieren in Übereinstimmung für die Möglichkeit nicht nur wissenschaftlicher, sondern davon ausgehend auch philosophischer Allgemeingültigkeit, Objektivität und Universalität.

Aus Sicht des Wiener Kreises und der Berliner Gruppe widerspricht dieser Anspruch auf Allgemeingültigkeit der Einsicht in die grundsätzliche Begrenztheit von Erkenntnis nicht. »Unser Denken ist ein Werkzeug, es ist abhängig von sozialen und geschichtlichen Verhältnissen. Man sollte das nie vergessen. Wir können nicht gleichzeitig den Ankläger und den Angeklagten spielen und uns überdies noch auf den Stuhl des Gerichts setzen« (Neurath 1930/31: 123). Für die wissenschaftliche Weltauffassung sei es entscheidend, »die Enge und Begrenztheit der Erkenntnis zum Bewußtsein zu bringen [...], weil sonst die Gefahr besteht, daß man durch das Postulat der völligen Bestimmtheit ein neues Idol schafft, das dann an die Stelle des alten Apriori, des Unendlichen und der Gottheit treten würde « (ebd.). Carnap will die neue Logik explizit nicht als Apriori verstanden wissen, dem ein quasi göttlicher Status zukommt. »Wo früher der Priester oder Philosoph stand, würde der Professor stehen. Von solchen übereilten Postulaten müssen wir uns fernhalten « (ebd.). Auch Reichenbach betont diesen Punkt in seinem später verfassten Buch Der Aufstieg der wissenschaftlichen Philosophie: 
Im Gegensatz dazu [zu spekulativen Systemen, MD] weigert sich die wissenschaftliche Philosophie, irgendeine Erkenntnis über die physikalische Welt als absolut sicher anzusehen. Die Gesetze der Logik und der Mathematik sind das einzige Gebiet, auf welchem Gewissheit erreicht werden kann [...]. Die wissenschaftliche Philosophie hat den Plan, ethische Vorschriften zu geben, völlig aufgegeben und betrachtet moralische Ziele als Ergebnisse von Willensakten, nicht aber als Gegenstand der Erkenntnis. (Reichenbach 1977 [1951]: 346)

Der Erneuerungsanspruch des Wiener Kreises erhält seine Wirkkraft dadurch es wird hier erneut deutlich -, dass er den Absolutheitsanspruch der herkömmlichen Philosophie ablehnt, den exakten Wissenschaften aber zugleich die Fähigkeit zuspricht, absolute Gewissheit im Prinzip erreichen zu können. Aber durch die Identifikation nun auch der Philosophie mit dieser Fähigkeit wird ebendiese gleichfalls als Möglichkeit rehabilitiert, absolutes und objektives Wissen erreichen zu können. Die Vertreter des Wiener Kreises wehren sich gegen die Auffassung, dass die Philosophie einen eigenen Zugang zur Wahrheit besitze, und forcieren die Möglichkeit, dass mit einer auf logischen Prinzipien aufbauenden Philosophie die Wahrheit gefunden werden kann.

\subsection{Zwischenfazit: Fundierung durch Identifikation}

Im Erneuerungsanspruch des Wiener Kreises wird eine Kombination verschiedener Strategien manifest: Mit der Abgrenzung gegenüber der Metaphysik auf der einen Seite und der Identifikation mit den philosophischen Methoden der exakten Wissenschaften auf der anderen Seite begründen die Vertreter des Wiener Kreises argumentativ ein neues Fundament der Philosophie. Die in vielen traditionellen philosophischen Konzepten enthaltene Vorstellung der Philosophie als Hüterin von Objektivität und Universalität wird über eine Identifizierung der philosophischen Position mit den exakten Wissenschaften legitimiert. Der gewissermaßen aus einem singulären Geist (der Metaphysik) stammende Objektivitätsanspruch wird zunächst zwar abgelehnt, um ihn dann jedoch durch eine Identifikation der Philosophie mit Modellen aus der Mathematik und Physik zu rehabilitieren. Eine Pointe der Neupositionierung des Wiener Kreises liegt darin, dass hier metaphysische Standpunkte mit den Mitteln der >harten`Wissenschaften wie Mathematik und Physik begründet werden. Allgemeingültig und objektiv sind aus Sicht der Vertreter des Wiener Kreises nicht philosophische Systeme, sondern das Gesamtsystem der Wissenschaften, dessen Fundierung Aufgabe der Philosophie ist. Die Philosophie wird folglich als unverzichtbar für das Gesamtsystem der Wissenschaften 
vorgestellt, und ihr Selbstbild als Königin der Wissenschaften wird gewissermaßen durch die Hintertüre der Wissenschaftstheorie reaktiviert.

Werden die Neupositionierungsstrategien des Wiener Kreises mit jenen von Husserl verglichen, zeigen sich sowohl Analogien als auch Unterschiede. Wie Husserl proklamieren auch die Vertreter des Wiener Kreises eine grundsätzliche Wende der Philosophie. Wie Husserl begründen sie diese Wende mit den Entwicklungen der Wissenschaften. Wo Husserl jedoch die Wissenschaftlichkeit der Philosophie quasi als immanente Notwendigkeit voraussetzt, weil ansonsten die Philosophie ihre Glaubwürdigkeit und dadurch ihre Wirkmacht verlieren würde, wird die Wissenschaftlichkeit der Philosophie von den Vertretern des Wiener Kreises demgegenüber mit dem Fortschritt der Wissenschaften begründet. Während es für Husserl gilt, den neuen philosophischen Standpunkt im Zusammenhang mit den gesamtwissenschaftlichen Entwicklungen kontinuierlich (prospektiv) zu entwickeln, ist er aus Sicht der Vertreter des Wiener Kreises bereits da: Er liegt in der Logik. Kurz: Für Husserl ist eine Umwendung der Verhältnisse in der Philosophie als anstehende historische Neuorientierung möglich, für den Wiener Kreis ist diese bereits vollzogen.

Sowohl Husserl als auch der Wiener Kreis wollen die Philosophie neu fundieren.Jedoch dominiert im Fundierungsanspruch des Wiener Kreises nicht wie bei Husserl eine Strategie des >Lücken- und Fehlerausweisens<, sondern eine der >Auslagerung : Durch die Auslagerung der Metaphysik (und dadurch beinahe der gesamten philosophischen Tradition) aus dem Bereich des Wissenschaftlichen wird der neue - mit der neuen Logik identifizierte - Standpunkt begründet. In beiden Strategien wird die Philosophie also gewissermaßen »gereinigt «; 106 bei Husserl von den Fehlern der empirischen Psychologie, beim Wiener Kreis von der gesamten Metaphysik und den damit verbundenen Traditionen.

In beiden Erneuerungsansprüchen ist das Selbstbild der Philosophie als Fundament aller Wissenschaften enthalten. Sowohl bei Husserl als auch beim Wiener Kreis wird also die Deutungsmacht der Philosophie im Zusammenhang mit den anderen Wissenschaften hergeleitet, wobei eine Hierarchisierung sichtbar wird: Während Husserl den Machtanspruch der Philosophie damit begründet, dass der Philosophie per se ein privilegierterer Zugang zur Wahrheit inhärent sei - anders als in anderen Wissenschaften -, argumentieren die Vertreter des Wiener Kreises mit dem Wahrheitsanspruch der Logik selbst: Da die Logik mit einem wissenschaftlichen Wahrheitsanspruch überhaupt

106 Zum Begriff der »Reinigung« siehe Fn. 95. 
gleichgesetzt wird, kommt ihr gleichzeitig die Macht über alle anderen Wissenschaften zu.

Beide Erneuerungsansprüche reagieren auf philosophieinterne Krisen. Husserls Erneuerungsanspruch kann als eine Reaktion auf die Bedrohung verstanden werden, die Philosophie könne aufgrund der potenziellen empirischen Vermessbarkeit des menschlichen Geistes überflüssig werden. Der Erneuerungsanspruch des Wiener Kreises wiederum kann als eine Reaktion auf die Bedrohung verstanden werden, dass die Philosophie ihren objektiven Status aufgrund des wissenschaftlichen Fortschritts verlieren könnte. In beiden Beispielen zeigte sich, dass andere Wissenszugänge für die Begründung der je neuen Position konstitutiv sind: Husserl kann sein Veto, dass rein empirische Argumente für die Erfassung des Bewusstseins ungenügend seien, erst durch die Aufnahme psychologischer Aspekte in seine Argumentation ausweisen. Am Beispiel des Wiener Kreises wiederum ist deutlich geworden, dass Carnap die Evidenz der Logik ausgehend von Diskussionen herleitet und begründet, die aus der Mathematik stammen.

In beiden Beispielen sind sowohl Abgrenzungs- als auch Identifikationsstrategien aufzufinden: Während Husserl sein eigenes Philosophieverständnis mit der philosophischen Tradition identifiziert, grenzen die Vertreter des Wiener Kreises ihr Philosophieverständnis von ebendieser Tradition ab. In beiden Erneuerungsansprüchen ist die Überzeugung vorhanden, dass sich ausgehend vom je neuen Standpunkt ein unendlich weites Arbeitsfeld eröffnet: Für Husserl liegt es in der Phänomenologie, für die Vertreter des Wiener Kreises in der Analyse der Sprache. In beiden Erneuerungsansprüchen wird eine Konzeptualisierung der Philosophie als einer neuen Methode sichtbar: Während jedoch Husserl seine Phänomenologie als »Wesensanalyse vom Bewußtsein « als eine Wissenschaft - und zwar als erste Wissenschaft - verstanden wissen möchte, lehnt der Wiener Kreis diesen Anspruch ab, um die Logik als das Fundament aller Wissenschaften zu behaupten. An die Stelle der Fachwissenschaft Philosophie tritt hier das Bestreben, alle anderen Wissenschaften auf ihre logische Struktur und ihren gemeinsamen Zusammenhang hin zu bestimmen, d.h., die Funktion der Philosophie wird explizit als eine Methode für die anderen Fachwissenschaften konzipiert.

Sowohl Husserl als auch die Vertreter des Wiener Kreises stecken das Anwendungsgebiet für die Philosophie argumentativ neu ab: Während Husserl das Bewusstsein bzw. das Sein (Phänomene) durch eine Abgrenzung gegenüber der empirischen Psychologie als privilegierten philosophischen Anwendungsbereich konstituiert, konstituieren die Vertreter des Wiener Kreises die Struktur der Wissenschaften und der Sprache als neues philosophisches Arbeitsgebiet. Durch das Argument, dass lediglich wissenschaftlich bereits 
erhärtete Erkenntnisse für die Philosophie relevant sein können, beschränkt der Wiener Kreis den Anwendungsbereich der Philosophie auf den Bereich der Wissenschaften und der Sprache. Die Rolle, die die Philosophie innerhalb dieses Anwendungsbereichs aus Sicht des Wiener Kreises einnehmen soll, nämlich die Klärung, ob Erkenntnisse wahr oder falsch, sinnvoll oder sinnlos sind, bedeutet die Reaktivierung einer traditionellen Aufgabe der Philosophie: endgültige Erkenntniskriterien zu bestimmen. In beiden Traditionen wird also das Gebiet des Philosophischen neu abgesteckt und neu definiert. Gleichzeitig sind beide Definitionen von einer Offenheit, im Prinzip von einer Unbegrenztheit bestimmt: Sowohl Husserls Phänomenologie als auch die analytische Sprachphilosophie können ausgehend von ihrer Selbstbeschreibung auf unbeschränkt viele Themengebiete angewandt werden.

In beiden Fällen kann die Reaktivierung eines traditionellen Selbstverständnisses beobachtet werden: Während Husserl die Wissenschaftlichkeit der Philosophie rehabilitiert, indem er sie als Verbindungsglied zwischen Geistes- und Naturwissenschaften positioniert, rehabilitiert der Wiener Kreis die Philosophie als Instanz, die einen neutralen und unabhängigen Blick auf wissenschaftliche Vorgänge einnehmen kann. Dass die Mitglieder des Wiener Kreises die Philosophie explizit nicht als Fachwissenschaft verstanden wissen möchten, sondern als Methode, die in allen anderen Fachwissenschaften anzuwenden sei, ist bezeichnend. Die Vertreter des Wiener Kreises wenden eine Spezifik der Philosophie, nämlich per Definition keinen eigenen wissenschaftlichen Gegenstand zu besitzen, produktiv um, indem sie die Logik als notwendiges Prinzip aller Wissenschaften rehabilitieren. ${ }^{107}$ Die Logik fungiert im Erneuerungsanspruch des Wiener Kreises auf der einen Seite als sicheres, nicht weiter zu hinterfragendes und ahistorisches Prinzip, um richtige philosophische Probleme von falschen bzw. sinnlosen zu unterscheiden. Auf der anderen Seite nimmt die Logik die Funktion eines neuen philosophischen Gegenstandes ein; als Grundstruktur aller Wissenschaften bietet sie Philosophen und Philosophinnen bis heute eine unendliche Aufgabe, nämlich diese Struktur enträtseln und bestimmen zu können.

107 Die Philosophie als Methode zu definieren, die auf andere Wissenschaften kritisch angewendet werden kann, ist eine Erneuerungsstrategie, die auch bei Husserl und der Kritischen Theorie vorhanden ist. 


\subsection{Eine politisch und wissenschaftlich neutrale Instanz}

In inhaltlicher Hinsicht steht die Neubestimmung der Philosophie des Wiener Kreises in einem diametralen Gegensatz zur Neubestimmung der Philosophie der Kritischen Theorie, wie sie im letzten Kapitel vorliegender Arbeit untersucht wird. Wo die Vertreter des Wiener Kreises die Philosophie in positiver Weise als mathematische Logik definieren, definieren Horkheimer und Adorno die Philosophie in negativer Weise als Kritik. Der Gegensatz beider Neubestimmungen wird im sogenannten Positivismusstreit manifest, der in den 1930er-Jahren mit einem Aufsatz von Horkheimer beginnt ${ }^{108}$ und 1961 in Form einer Auseinandersetzung zwischen Adorno und Karl Popper seinen Höhepunkt erfährt. ${ }^{109}$ Jedoch seien seit dem Ende der 1970er-Jahre - so schreibt Hans-Joachim Dahms - »eine ganze Reihe von Publikationen erschienen [...], die zeigen, dass die Bewegung des logischen Positivismus und insbesondere der Wiener Kreis ähnliche politische Perspektiven verfolgt hat wie die Frankfurter Schule - und dies, wie ich im Vorgriff hinzufügen möchte, häufig praktisch weitaus aktiver als letztere« (ebd.: 15-16). Diese Feststellung ist im Hinblick auf einen Vergleich zwischen den unterschiedlichen Selbstpositionierungsstrategien zentral.Im Folgenden wird deshalb - gewissermaßen als Überleitung zum nächsten Kapitel - auf die politischen Implikationen des philosophischen Erneuerungsanspruches des Wiener Kreises eingegangen.

Wie deutlich geworden ist, nimmt der Wiener Kreis innerhalb der Philosophiegeschichte des 20. Jahrhunderts eine spezielle Rolle ein, da es sich hier um eine Gruppe und nicht um eine Einzelperson handelt. Diese Spezifik widerspiegelt ein zentrales Anliegen der untersuchten Autoren: Philosophie soll nach dem naturwissenschaftlichen Modell als ein Projekt verstanden werden, an dem kollektiv gearbeitet wird. Die Konnotation dieses Modells mit sozialistischer Politik ist naheliegend. Innerhalb der Rezeptionsgeschichte des Wiener Kreises kann diesbezüglich eine Art Paradigmenwechsel beobachtet werden: Bis ungefähr 1970 wurde der Wiener Kreis als ein rein akademischer Zirkel betrachtet und behandelt, der sich mit Logik, Sprachphilosophie und Erkenntnistheorie beschäftigt und eine empiristische, antimetaphysische und

\footnotetext{
108 Es handelt sich um den Aufsatz »Der neueste Angriff auf die Metaphysik« (Horkheimer 1988 [1937]).

109 Der Positivismusstreit sei - zumindest in der Bundesrepublik Deutschland - als Thema »völlig in den Hintergrund getreten«, »allerdings nicht etwa deswegen, weil man zu einer genauen Definition der Problembereiche oder gar zur einvernehmlichen Lösung einzelner Fragen gelangt wäre, sondern mehr weil die begonnene Diskussion im Alltagsbetrieb der Massenuniversitäten ins Stocken geraten und dann gänzlich versandet ist « (Dahms 1994: 15).
} 
formale Philosophie vertreten hat, wobei der soziale und politische Kontext der Gruppe eine untergeordnete Rolle spielte. Das politische Engagement einzelner Mitglieder erschien als eine Beschäftigung, die die eigentliche Philosophie des Wiener Kreises nicht essenziell berührte. Ein Beispiel für diese Art der Rezeption ist das oben zitierte Buch von Ayer Language, Truth and Logic. Der politische und soziale Kontext des Wiener Kreises rückte erst ab den 1970er-Jahren in den Fokus des Interesses. Der allgemeine Ton war: Die Philosophie des Wiener Kreises lässt sich ohne Einbezug ihres kulturellen und politischen Kontextes nicht verstehen. Johann Dvořáks Aufsätze (Dvořák 1985; 1993) sind für diese Art der Rezeption exemplarisch: Laut Dvořák »bemühten sich Vertreter der wissenschaftlichen Weltauffassung des Wiener Kreises um eine nicht-kapitalistische Vergesellschaftung der Wissenschaften« (Dvořák 1985: 133). »Der wahre Radikalismus der wissenschaftlichen Weltauffassung des Wiener Kreises«, schreibt Dvořák, »bestand keineswegs im Physikalismus oder in diversen Parteizugehörigkeiten[,] sondern in der Neubestimmung der gesellschaftlichen Stellung und Aufgaben der Wissenschaft, einer systematischen Verbindung von Wissenschaft, Bildung und Arbeitsleben« (ebd.). Eine weitere frühe Studie dieser Richtung ist das Buch Wittgenstein's Vienna von Allan Janik und Stephen Toulmin. ${ }^{110}$ Janik und Toulmin argumentieren, Wittgensteins Tractatus »should be considered as emerging from a particular cultural milieu « (Janik/Toulmin 1974: 25). In der Rezeptionsgeschichte des Wiener Kreises wird also ein Spannungsverhältnis deutlich: Auf der einen Seite ist er von einer gewissen politischen Aura umgeben, auf der anderen Seite erscheint seine Philosophie als Inbegriff einer formalen, logischen und in diesem Sinne neutralen Philosophie. Innerhalb dieses Spannungsfeldes, so meine Vermutung, liegt die Stärke des Erneuerungsanspruches des Wiener Kreises. Seine Vertreter und Vertreterinnen haben gerade deswegen eine wirkungsvolle philosophische Erneuerung evoziert, weil sie in einer politisch äußerst aufgeladenen Zeit das philosophische Selbstverständnis von Politik entkoppelt haben. Sie verstanden ihre wissenschaftlich-philosophische Arbeit als unpolitisch, aber sie sahen eine soziale Verantwortung in genau diesem Anspruch. Diese These möchte ich zum Abschluss dieses Kapitels und als Überleitung zum nächsten erläutern:

Die Vertreter des Wiener Kreises haben ihre wissenschaftliche Arbeit stets im Kontext gesamtgesellschaftlicher Entwicklungen betrachtet. Beispielsweise schreibt Carnap 1928 im Vorwort zu Der logische Aufbau der Welt:

110 Das Buch von Janik und Toulmin gilt zugleich als ein früher >Klassiker der Wissenschaftsforschung. 
Wir spüren eine innere Verwandtschaft der Haltung, die unserer philosophischen Arbeit zugrundeliegt, mit der geistigen Haltung, die sich gegenwärtig auf ganz anderen Lebensgebieten auswirkt; wir spüren diese Haltung in Strömungen der Kunst, besonders der Architektur, und in den Bewegungen, die sich um eine sinnvolle Gestaltung des menschlichen Lebens bemühen: des persönlichen und gemeinschaftlichen Lebens, der Erziehung, der äußeren Ordnungen im Großen. Hier überall spüren wir dieselbe Grundhaltung, denselben Stil des Denkens und Schaffens. Es ist die Gesinnung, die überall auf Klarheit geht und doch dabei die nie ganz durchschaubare Verflechtung des Lebens anerkennt, die auf Sorgfalt in der Einzelgestaltung geht und zugleich auf Großlinigkeit im Ganzen, auf Verbundenheit der Menschen und zugleich auf freie Entfaltung des Einzelnen. Der Glaube, daß dieser Gesinnung die Zukunft gehört, trägt unsere Arbeit. (Carnap 1928: V-VI)

Carnap stellt eine »innere Verwandtschaft« zwischen der »philosophischen Arbeit« und anderen - sowohl gesellschaftlichen als auch individuellen zeitgenössischen Lebensbereichen fest. ${ }^{111}$ Seine Bemerkung ist zentral; sie verdeutlicht, dass er seine eigene philosophische Arbeit zwar innerhalb gesamtgesellschaftlicher Prozesse verortet, sie aber nicht direkt in den Dienst der Gesellschaft stellt: Im Unterschied zu den Erneuerungsstrategien der Kritischen Theorie, die im nächsten Kapitel untersucht werden, zielt der Wiener Kreis nicht vordergründig darauf, die Philosophie in den Dienst praktisch-gesellschaftlicher Verhältnisse zu stellen. Carnap etwa schreibt in seiner Intellectual Autobiography: »Die meisten von uns, ich eingeschlossen, waren Sozialisten. Aber wir wollten unsere philosophische Arbeit von unseren politischen Zielen getrennt halten. Unserer Ansicht nach waren Logik, auch angewandte Logik, Erkenntnistheorie, Sprachanalyse oder Methodologie der Wissenschaften, wie die Wissenschaften selbst, praktischen Zielen gegenüber neutral, ob moralischen des Einzelnen oder politischen der Gesellschaft« (Carnap 1993 [1963]: 36). ${ }^{112}$ Die Inhalte, Diskussionen, Thesen und Themen des Wiener Kreises waren nicht politisch intendiert, gleichzeitig

111 Auch im »Manifest« wird die enge Beziehung zwischen philosophischen Forderungen und allgemeinen »Lebensfragen« hervorgehoben: »So zeigen zum Beispiel die Bestrebungen zur Neugestaltung der wirtschaftlichen und gesellschaftlichen Verhältnisse, zur Vereinigung der Menschheit, zur Erneuerung der Schule und zur Erziehung einen inneren Zusammenhang mit der wissenschaftlichen Weltauffassung; es zeigt sich, dass diese Bestrebungen von den Mitgliedern des Wiener Kreises bejaht, mit Sympathie betrachtet, von einigen auch tatkräftig gefördert werden « (Neurath/Hahn/Carnap: 304). Gemeint sind hier sozialistische Ideen und Bewegungen dieser Zeit. Das »Manifest« endet mit den Worten: »Die wissenschaftliche Weltauffassung dient dem Leben und das Leben nimmt sie auf« (ebd.: 315).

112 Paul Neurath schreibt dezidiert, dass die meisten Mitglieder Sozialdemokraten waren: »Einige Mitglieder des Kreises [...] waren in der Tat politisch sehr interessiert und zwar 
sahen viele seiner Mitglieder explizit eine soziale und politische Verantwortung in ihrer Arbeit. ${ }^{13}$ Der Erneuerungsanspruch des Wiener Kreises erlangt seine argumentative Stärke gerade aufgrund dieses Zieles, nämlich für die Trennung zwischen Wissenschaft und Gesellschaft bzw. Politik einzustehen. In der Rezeptionsgeschichte des Wiener Kreises verliert die aus Sicht der Gruppe selbst wichtige Trennlinie zwischen gesellschaftspolitischer und philosophischer Arbeit oftmals ihre Kontur: Die Autoren des Kreises werden mithin verallgemeinernd als eine politische Gruppe und ihre Philosophie als politisch intendiert dargestellt. Ein Beispiel ist Michael Friedmans Buch $A$ parting of the ways. Hier erscheint Carnap als ein politischer Denker, der in direkter Opposition zu Heidegger steht: »Carnap and Heidegger are therefore not only at opposite ends of the spectrum philosophically, they are at opposite ends of the spectrum in social and political terms as well« (Friedman 2000: 18). Diese Beobachtung hat durchaus ihre Richtigkeit. Allerdings geht in dieser Art der Rezeption ein zentraler Aspekt verloren, nämlich dass die Wirkkraft der Position des Wiener Kreises gerade darin liegt, gegen die Vereinnahmung der Philosophie durch Politik Stellung zu beziehen. Wie deutlich geworden ist, glauben die Vertreter des Wiener Kreises, mit der Logik ein unabhängiges und neutrales philosophisches Analysemittel gefunden zu haben, wobei dieser Aspekt innerhalb des Kreises - wie oft ausgehend von Neurath - kontrovers diskutiert worden ist. Carnap schreibt etwa in seinen Erinnerungen: »Diese neutralistische Haltung [unserer philosophischen Arbeit] kritisierte Neurath scharf. Wir bestanden aber darauf, daß das Eindringen praktischer und insbesondere politischer Gesichtspunkte die Reinheit der philosophischen Methode trüben sollte« (Carnap 1993 [1963])).

Paul Neurath, Soziologe und Sohn von Otto Neurath, moniert in einem Aufsatz von 1993, dass derWiener Kreis generalisierend als politische Gruppierung wahrgenommen wird und betont das genuin Unpolitische der Gruppe:

als Sozialdemokraten. Ich weiß von keinem der bedeutenderen Mitglieder des Kreises, dass er Kommunist gewesen wäre« (P. Neurath 1993: 637).

113 Die enge Verbindung, die einige Mitglieder des Wiener Kreises zur Volkshochschule eingingen, unterstreicht diesen Punkt. »Vertreter der Wissenschaftlichen Weltauffassung, wie eben Otto Neurath, Edgar Zilsel, Friedrich Waismann, Viktor Kraft, unterrichteten an den Wiener Volkshochschulen. [...] Die Volkshochschule erreichte damals alle Schichten der Bevölkerung. Arbeiter und Angestellte waren in manchen Jahren sogar - verglichen mit ihrem Anteil an der Gesamtbevölkerung - erheblich überrepräsentiert « (Dvořák 1985: 136). Diesbezüglich war Edgar Zilsel das wohl exponierteste Mitglied des Wiener Kreises. »Philosophie ist bei Zilsel an menschliches Handeln und menschlicher Handlungsfähigkeit orientiert, sie soll Zusammenhänge herstellen zwischen den einzelnen Wissenschaftsdisziplinen ebenso wie zwischen Wissenschaft und Alltagsleben« (ebd.: 132). 
Wie aus der einschlägigen Literatur bekannt, waren Entstehung und Thematik des Wiener Kreises von Anfang an und bis zum Schluss völlig apolitisch und hatten mit Politik, weder im parteipolitischen, noch in irgendeinem weiteren gesellschaftspolitischen Sinn überhaupt nichts zu tun. Wie bekannt, entstand der Kreis ursprünglich aus einem privaten Kolloquium im Hause Schlick im Anschluss an seine Philosophischen Vorlesungen an der Universität. [...] Die Thematik, das ist ebenfalls bekannt, konzentrierte sich jahrelang auf eine beinahe satzweise Diskussion von Wittgensteins Tractatus logico-philosophicus. Wer ein noch unpolitischeres Diskussionsthema kennt oder ein solches auch nur erfinden kann, sei hiermit herzlichst eingeladen, das vorzubringen. (Neurath P. 1993: 636-637)

Paul Neurath argumentiert, dass die Philosophie des Wiener Kreises insgesamt nicht politisch motiviert gewesen, sondern es der politisch hoch aufgeladenen Situation zuzurechnen sei, dass sie und insbesondere die Metaphysikkritik des Kreises als linksorientiert wahrgenommen wurden. ${ }^{114}$ Der gesellschaftspolitische Aspekt sei aus einer völlig anderen Richtung gekommen, nämlich aus dem politischen Interesse einiger Mitglieder. Insbesondere die politische Aktivität von Neurath und Hahn habe als Beweis »für die Richtigkeit dieser politischen Einordnung einer im Grunde völlig unpolitischen Gruppe, die regelmäßig zu völlig unpolitischen gelehrten Diskussionen über für die Außenwelt zum Teil recht abstrus und scholastisch klingende Themen zusammenkam«, gegolten (ebd.: 636). Paul Neuraths teilweise polemisch vorgetragene Erinnerungen verweisen aber auf einen zentralen Aspekt im Erneuerungsanspruch des Wiener Kreises: Auf der einen Seite wurde in der Gruppe die Haltung vertreten (und mit einer Identifikation der Philosophie mit den Naturwissenschaften begründet), dass die eigene philosophische Arbeit politisch neutral sei, auf der anderen Seite waren einige Mitglieder des Kreises politisch

114 Paul Neurath stellt fest, dass die Haltung gegen oder für die Metaphysik in der Weimarer Zeit quasi ein politisches Statement bedeutet hat. »Es war aber in jener politisch sehr aktiven Zeit, in der alles, was überhaupt irgendwie zur Diskussion stand, immer auch gleich politisch eingeordnet wurde, so, dass die prononcierten Vertreter einer betont metaphysisch orientierten Philosophie und Wissenschaft zumeist, wenn auch gewiss nicht immer, in politisch konservativen, oftmals auch im aggressiv antidemokratischen Lager zu finden waren, während umgekehrt prononcierte Vertreter einer metaphysikfreien Wissenschaft, soweit sie überhaupt politisch interessiert waren, zumeist, obwohl auch hier gewiss nicht ohne Ausnahmen, demokratischen Gruppierungen oder Parteien angehörten oder solchen zumindest nahestanden oder, wenn sie politisch nicht interessiert waren, doch zumindest eine Art von apolitisch liberalem Standpunkt vertraten, sodass also eine Gruppe wie der Wiener Kreis, die in Wort und Schrift konsistent eine aggressiv anti-metaphysische oder zumindest eine metaphysikfreie Orientierung in Philosophie und Wissenschaft vertrat, sogleich in den Geruch kam, eine linksorientierte Organisation zu sein« (P. Neurath 1993: 635-636). 
aktiv. Im Wiener Kreis und seiner Philosophie, so kann gefolgert werden, wird die Forderung nach einer Unterscheidung zwischen >reiner Wissenschaft und den Bedingungen, unter denen diese Wissenschaft entsteht und besteht, exemplarisch sichtbar. ${ }^{115}$ Schlick macht diese Trennung in einer Klammerbemerkung explizit: »Jede Wissenschaft (sofern wir bei diesem Worte an den Inhalt und nicht an die menschlichen Veranstaltungen zu seiner Gewinnung denken) ist ein System von Erkenntnissen, d.h. von wahren Erfahrungssätzen [...]« (Schlick 1930/31: 7-8). Diese wissenschaftsanalytische Trennung erwies sich im Kontext der 1930er-Jahre in Deutschland - paradoxerweise als politisch aufgeladen. ${ }^{116}$ Ernest Nagel beschreibt in seinen Impressions and Appraisals of Analytic Philosophy in Europe 1936 die Eindrücke, die er bezüglich dieser politischen Dimension während seiner Europareise gesammelt hatte:

It occurred to me that although I was in a city foundering economically, at a time when social reaction was in the saddle, the views presented so persuasively from the Katheder were a potent intellectual explosive. I wondered how much longer such doctrines would be tolerated in Vienna. And I thought I understood at least the partial reason for the vitality and appeal of analytical philosophy. Analytical philosophy is ethically neutral formally [sic!]; its professors do not indoctrinate their students with dogmas as to life, religion, race, or society. But analytical philosophy is the exercise of intelligence in a special field, and if the

115 Diese Unterscheidung wiederum wurde bereits in den 1930er-Jahren operationalisiert. Die Unterscheidung zwischen einem »context of discovery« und einem »context of justification « geht auf Reichenbachs Experience and Prediction von 1938 zurück und ist innerhalb der Philosophy of Science bis heute gültig (Barker/Kitcher 2014: 13). Für die Wissenschaftstheorie - so lautet Reichenbachs Argument verkürzend - sei nur der »context of justification « relevant, also der logische und mathematische Rechtfertigungsvorgang einer neuen wissenschaftlichen Hypothese. Der »context of discovery«, also der psychologische (oder auch historische bzw. soziologische) Entstehungszusammenhang der betreffenden Hypothese, liege nicht im Zuständigkeitsbereich der Wissenschaftstheorie bzw. der Philosophie. Die Frage nach den Entstehungsbedingungen philosophischen Wissens wird anderen Disziplinen zugewiesen. Indem Reichenbach den »context of discovery « aus dem Bereich des philosophisch Relevanten ausschließt, wird umgekehrt argumentativ die Möglichkeit einer Instanz generiert, der wissenschaftliche Neutralität und Objektivität inhärent ist.

116 Der Student Johann Nelböck, der Schlick 1936 erschossen hat, soll beim nachfolgenden Prozess als Motiv angegeben haben, Schlicks Philosophie würde die Jugend verführen (P. Neurath 1993: 636). Zwar wurde Nelböck wegen Mordes und unerlaubten Waffenbesitzes zu zehn Jahren Haft verurteilt, er wurde jedoch nach 18 Monaten aufgrund eines Gnadengesuchs wieder entlassen. »Beim Mord habe es sich um ein Notdelikt gehandelt ein Delikt aus weltanschaulicher und politischer Not. [...] Von diesen weltanschaulichen und politischen Motiven hatte damals [während des ersten Prozesses 1936, MD] nicht gesprochen werden dürfen. Deshalb hatten diese Motive bei dem Prozess nicht berücksichtigt werden können « (Sigmund 2015: 301). 
way of intelligence becomes part of the habitual nature of men, no doctrines and no institutions are safe from critical reappraisals. Because traditional philosophy has so often been practiced as a species of obscurantism, it has become the bete noire of the Wiener Kreis. (Nagel 1936: 9)

Nagel macht die Beobachtung, dass - im Unterschied zur traditionellen metaphysischen Philosophie - die Vertreter und Vertreterinnen der neuen »analytischen« Philosophie ihre Studierenden nicht mit Dogmen bezüglich der Lebensführung, Religion, >Rasse` oder Gesellschaft indoktrinieren würden. Gerade darin liege, so Nagel, die »intellektuelle Sprengkraft« dieser Philosophie. Paradoxerweise ist es also gerade das Formale und Neutrale der analytischen Philosophie, dem Nagel - selbst ein Philosoph der analytischen Richtung - in positiver Weise Sprengkraft zuschreibt. Er fährt wie folgt fort:

I am persuaded that this tension [between speculative and analytical philosophy] exists not merely because traditional speculative philosophy frequently cultivates mystification and conscious irrationalism in matters of strict philosophy, but because it has repercussions upon social theory and practice, as recent events have amply shown. (ebd.)

Nagel führt die »Spannung « zwischen traditioneller spekulativer Philosophie (oder: Metaphysik) und der neuen analytischen Philosophie auf die politische Situation in Europa zurück. Auf der einen Seite bringt er die traditionelle spekulative Philosophie mit den »jüngsten Ereignissen« (vermutlich meint er die Machtübernahme der Nationalsozialisten) in eine Verbindung, auf der anderen Seite beschreibt er die analytische Philosophie wie folgt:

\begin{abstract}
Analytical philosophy has thus a double function: it provides quite green pastures for intellectual analysis, wherein its practitioners can find refuge from a troubled world and cultivate their intellectual games with chess-like indifference to its course; and it is also a keen, shining sword helping to dispel irrational beliefs and to make evident the structure of ideas. It is at once the pastime of a recluse and a terribly serious adventure: it aims to make as clear as possible what it is we really know. (ebd.: 9)
\end{abstract}

Analytische Philosophie biete einen Rückzugsort für abgehobene intellektuelle Spiele und sei gleichzeitig ein Instrument, um irrationalen Überzeugungen ein Ende zu machen. Sie sei ein naiver Zeitvertreib und ein »äußerst ernstes Abenteuer«. Es wird eine Wechselwirkung zwischen beiden Aspekten impliziert: Analytische Philosophie sei gerade deswegen ein »scharfes glänzendes Schwert«, weil sie abgehoben und intellektuell sei. Nagel stellt also fest, dass auch die analytische Philosophie Effekte auf die Praxis hat. Im Gegensatz 
zur traditionellen spekulativen Philosophie werden diese Effekte aber als neutral und in dieser Neutralität als positiv konnotiert; als ein "Schwert«, mit dem gegen irrationale Überzeugungen angekämpft werden könne. Nagel impliziert, dass in der analytischen Philosophie die Möglichkeit einer politisch und ethisch neutralen Instanz enthalten ist.

Der Kampf des Wiener Kreises gegen die Metaphysik erscheint in dieser Perspektive auch als ein Kampf gegen die durch Wertungen und Dogmen geprägte Philosophie der Zeit. Die Ablehnung der Metaphysik ist als Reaktion auf eine Krise zu verstehen, die durch die Verluste wissenschaftlicher und philosophischer Neutralität und Objektivität beschrieben werden kann. Die Bezugnahme auf Alfred Seidel verdeutlicht dies: Seidel hat, wie zu Beginn des Kapitels festgestellt, gewissermaßen zugegeben, dass seine eigene Arbeit von metaphysischen Voraussetzungen durchzogen, d.h. nicht »wertneutral« sei, obwohl es sich nicht um eine metaphysische Fragestellung handele. ${ }^{117}$ Seine Parallelisierung von Metaphysik mit Wertung ist insofern signifikant, weil sie eine für diese Zeit zentrale Herausforderung formuliert: Wie kann die Philosophie ihre wissenschaftliche Objektivität und politische Neutralität noch legitimieren, wenn in den realen gesellschaftspolitischen Verhältnissen sichtbar wird, dass Philosophie mit Wertungen verbunden ist? In der hier eingenommenen Perspektive erscheint die Verfemung der Metaphysik, wie sie der Wiener Kreises vollzieht, nicht nur als »eine Abwehr gegen philosophische Strömungen, die nicht Schritt hielten mit dem damaligen Umschwung der Wissenschaft« (Köhler 1995: 191), sondern gleichzeitig als ein Einstehen für die Neutralität und Objektivität der Wissenschaft und als ein Kampf gegen die Vereinnahmung der Philosophie durch Politik insgesamt. Insofern wird im Erneuerungsanspruch des Wiener Kreises, der durch eine Identifizierung der Philosophie mit den exakten Wissenschaften begründet wird, der Anspruch auf eine Entpolitisierung der Philosophie sichtbar. Die Mitglieder des Wiener Kreises wollen die Philosophie nicht nur von Metaphysik, sondern zugleich von ihrer Verstrickung in die Politik »reinigen «. ${ }^{118}$ In diesem Sinne wiederum ist der Anspruch auf eine formale und neutrale Philosophie, wie sie der Wiener Kreis eingefordert hat, höchst politisch.

An seinem Beispiel, so kann geschlussfolgert werden, wird aufgrund einer Identifikation der Philosophie mit den exakten Wissenschaften die Erneuerung eines traditionellen Selbstverständnisses der Philosophie sichtbar: Philosophie als eine intellektuelle Instanz, die einen neutralen und unabhängigen Blick

117 Siehe S. 11 und 79.

118 Siehe Fn. 95. 
auf politische und wissenschaftliche Vorgänge einnehmen kann. Im nächsten Kapitel wird gewissermaßen das Pendant zum Wiener Kreis thematisiert: Der Erneuerungsanspruch der Kritischen Theorie nimmt seinen Anfang in der Einsicht, dass Philosophie immer mit Politik und Politik immer mit Philosophie verbunden ist. 


\title{
Kritische Theorie: Kooperation
}

\author{
Kritik der bestehenden Philosophien plädiert nicht für das Verschwinden von \\ Philosophie oder gar ihren Ersatz durch Einzeldisziplinen wie die Sozialwissen- \\ schaft. Sie möchte formal und material eben jener Gestalt geistiger Freiheit helfen, \\ die in den herrschenden philosophischen Richtungen keine Stelle hat. \\ Theodor W. Adorno, Wozu noch Philosophie? (1962)
}

Die philosophische Erneuerung durch die Kritische Theorie unterscheidet sich von den philosophischen Erneuerungen durch die Phänomenologie und den Logischen Positivismus insofern, dass sie erst in der Mitte des 20. Jahrhunderts ausformuliert worden ist. Da jedoch die Schwerpunktverlagerung des Marxismus »hin zur Philosophie « (Anderson 1978 [1976]: 77), wie sie in den 192oer-Jahren an Georg Lukács und Karl Korsch sichtbar wird, für den Erneuerungsanspruch der Kritischen Theorie entscheidend ist, korrespondiert auch der Erneuerungsanspruch von Theodor W. Adorno und Max Horkheimer mit philosophieinternen Krisen, die an Alfred Seidels Bewußtsein als Verhängnis ablesbar sind. Analog zu den anderen beiden Kapiteln dieser Arbeit werden in einem ersten Teil diese Herausforderungen bzw. Krisen im Zusammenhang mit Seidel skizziert (5.1), um in einem zweiten Schritt die Erneuerungsstrategien der Kritischen Theorie an Lukács und Korsch (5.2) und darauf aufbauend an Adorno und Horkheimer (5.3) nachzuzeichnen.

\subsection{Herausforderung: Verlust gesellschaftlicher Legitimität}

Die Person Seidel und deren Text Bewußtsein als Verhängnis nehmen in diesem Kapitel einen etwas anderen Stellenwert ein als in den anderen beiden Kapiteln, da hier direkte philosophiehistorische Verbindungen bestehen: In der hier eingenommenen Perspektive ist zum einen die Verbindung zwischen Seidel und der Kritischen Theorie und zum anderen die Verbindung zwischen Seidel und derWissenssoziologie Karl Mannheims zentral. Beide Verbindungen werden im Folgenden näher umrissen. 


\title{
Weder Adorno noch Mannheim
}

Das Typoskript zu Seidels von Alfred Weber betreuter Dissertation Produktivkräfte und Klassenkampf - sie wurde 2008 posthum veröffentlicht (Seidel 2008) ${ }^{119}$ - zirkulierte seit 1922 in den intellektuellen Kreisen in Frankfurt am Main. »Seidel findet damit viel Zuspruch, findet überdies in Heidelberg Anerkennung und intellektuellen Anschluß (Velarde 2008: 180). Es handele sich bei seiner Dissertation um einen Versuch, eine Soziologie der Soziologie zu umreißen; der kritische Marxismus wird zum Gegenstand der Kritik (ebd.: 181). »Ich will nicht«, schreibt Seidel in seinem Vorwort, »die so beliebte Marx-Scholastik treiben, sondern die innere, den Denkern selbst oft nicht bewußte Struktur ihrer Gedanken zu erforschen suchen, vor allem aber die >petitiones principii<, deren es bei Marx eine Menge gibt« (Seidel 2008: 187). Als erste Referenz führt Seidel Lukács' 1921 erschienenen Aufsatz »Rosa Luxemburg als Marxist« an. Die enge Verbindung zu Lukács wird auch von Frese hervorgehoben: "Seidels Dissertation ist das früheste mir bekannte Echo auf Lukács' frühen Marxismus, der in breiteren Kreisen erst nach $1924 \mathrm{zu}$ wirken begann« (Frese 2001/02: 50-51).

Seidels Dissertation hat Spuren hinterlassen. »Hinweise auf eine Lektüre finden sich [...] bei Adorno, Benjamin, Sohn-Rethel und Löwenthal, diese beschränken sich jedoch auf die Nennung von Schlagworten, in aller Regel dem von der Metaphysik der Produktivkräfte« (Voller 2017: 72). Insofern Seidels Dissertation mit Lukács' Geschichte und Klassenbewußtsein (1923) als auch mit Karl Korschs Marxismus und Philosophie (1923) korrespondiert, habe er in seiner Dissertation erstmals Gedankengänge formuliert, die für die Argumentationsstrategien der Kritischen Theorie wegweisend waren.

\begin{abstract}
Stellt man in Rechnung, dass Seidels Arbeit zwar nicht gedruckt wurde, allerdings genau in jenem Milieu zirkulierte, aus dem sich die Kritische Theorie dann entwickelte, so wäre Produktivkräfte und Klassenkampf durchaus als eine Schrift zu begreifen, die zusammen mit Lukács' Geschichte und Klassenbewußtsein und Karl Korschs Marxismus und Philosophie einen frühen Einfluss auf die Gedankenentwicklungen ausübte, die dann zur Etablierung der Kritischen Theorie führten. (ebd.: 84)
\end{abstract}

Aus Seidel ließe sich, so sagt Jürgen Frese schon in den 1970er-Jahren, »leicht eine Vorgeschichte der >Kritischen Theorie〈 basteln [...], in der Seidel als deren mythischer Ahnherr figurieren würde [...]«(Frese 2001/o2: 47). Kurz: Die Kritik

119 Siehe Fn. 33. 
am Marxismus, die Seidel in Produktivkräfte und Klassenkampf formuliert, steht mit der Entstehung der Kritischen Theorie in einer direkten Verbindung. ${ }^{120}$

Seidels Dissertation allerdings scheint mir theoriegeschichtlich vor allem insofern von Interesse zu sein, als sie sehr früh [...] eine Kritik instrumenteller Technikauffassungen, marxistischer Fortschrittsgläubigkeit und schematischer Auslegung des historischen Materialismus vorschlug. Beide Ansätze sind zu Grundpfeilern kritischer Theoriebildung geworden, die sich in nahezu allen dem Umfeld der Gründungsgeneration des Instituts für Sozialforschung zuzurechnenden Arbeiten wiederfinden. (Voller 2017: 84)

Die philosophiehistorische Verbindung zwischen Seidel und der Kritischen Theorie wird durch ein weiteres schriftliches Zeugnis belegt, nämlich durch einen Brief Seidels an Adorno, datiert auf den 8. September 1922. Dieser einzig erhaltene Brief wurde 2017 von Christian Voller und Dirk Braunstein erstmals veröffentlicht. ${ }^{121}$ Unter anderem schreibt Seidel hier:

Warum muß der Mensch um seine Krankheit überwinden zu können, d.h. warum muß er zur Sublimierung sich ein falsches Bild von sich und der Welt, ja von seinem individuellen Ich sogar machen, warum muß er sich eine transcendente Welt erbauen, damit die Welt, das Leben und er selbst einen Sinn bekommt; warum darf er nicht immanent bleiben und das Leben an sich bejahen; oder warum kann er nicht mit einer untranscendenten Weltanschauung, nachdem er nun einmal d. Verruchtheit der Erkenntnis begonnen hat, leben. Die phänomenologische Aufzeigung durch den Untergang der Kulturen bei Verlust der einheitlichen transcendenten Findung genügt mir natürlich nicht, sondern ich muß das immanent-teleologische Warum wissen. (Voller/Braunstein 2017: 93-94)

Seidel begnügt sich nicht damit, den Verlust einer einheitlichen Transzendenz festzustellen, sondern möchte wissen, warum dies so ist. Die Antwort Adornos auf Seidels Frage kennen wir nicht. Gemäß Braunstein und Voller konnte nicht ermittelt werden, worauf Seidel in dieser und der folgenden Passage anspricht; in der hier eingenommenen Perspektive sind sie jedoch signifikant, auch wenn offen bleibt, warum sich Seidel gemäß seiner eigenen Selbstbeschreibung von Adorno »unterscheidet $\ll$.

120 Bereits Frese betont, dass es sich bei Seidels Texten um ein »Stück Geschichtsphilosophie« handele und nicht etwa um eine »lebensphilosophische Kulturtheorie« à la Ludwig Klages bzw. nicht um eine »Ontologie des Verhältnisses von Geist und Leben«, wie es eine oberflächliche Assoziation vermuten ließe (Frese 2001/o2: 52-53).

121 Der Brief umfasse im Original vier Seiten auf zwei Blättern, die Seidel »mit äußerst nachlässiger Handschrift gefüllt hat« (Voller/Braunstein 2017: 89). 
Es gibt gerade für Sie viel brennendere Probleme, aber Sie werden sie ja mehr als genug haben und unter ihnen eins, um das alle so gern herumgehen, nicht aus Ehrfurcht, wie es scheinen möchte, sondern aus - Feigheit. Und manchmal möchte es mir so scheinen, [als] ob alle anderen Probleme nur Ablenkung von diesem einzig zentralen Problem sind. Sie wissen ganz genau, was ich meine und worin wir uns ja unterscheiden. (ebd.: 9o-91)

Obwohl es eine Leerstelle bleibt, worin Seidel den Unterschied seiner eigenen Gedankengänge $\mathrm{zu}$ denen Adornos sieht, ist diese Passage bezeichnend. Viele seiner Zeitgenossen - so sagt Seidel - würden aus Feigheit bestimmte Probleme umgehen. Adorno hingegen stelle sich diesen Problemen, komme aber zu anderen Ergebnissen als er selbst. In Seidels Formulierung wird eine Art Pathos deutlich: Wo andere zu feige seien, seien Adorno und er selbst mutig genug, bestimmte Probleme zu artikulieren. Der Briefausschnitt macht deutlich, dass Seidel sein Denken einerseits in einer Verbindung zu Adornos Denken sieht, andererseits aber eine Differenz dazu herstellt. ${ }^{122}$

Wie erwähnt ist für Seidel auch die Verbindung zum Wissenssoziologen Karl Mannheim - er soll ihm besonders wohlgesinnt gewesen sein (Prinzhorn 1927: 2o) - zentral. Aber auch Mannheim - Georg Lukács' Mentor und Opponent der Kritischen Theorie - bietet Seidel offensichtlich keine befriedigenden >Lösungen<. Seidel und Mannheim haben sich um 1920 in Freiburg kennengelernt. Mannheim war damals Privatdozent in Heidelberg, Seidel stand am Ende seiner Promotion (Frese 2001/2002: 51). Wie Mannheim soll sich auch Seidel für eine Soziologie der Intelligenz interessiert haben. »Viele Passagen in den frühen programmatischen Arbeiten von Mannheim lesen sich wie Reminiszenzen an die zahlreichen Diskussionen, die er mit Seidel über Ideologie, Utopie und Intelligenz führte « (ebd.). ${ }^{123}$ Wo Mannheim jedoch dezidiert feststellt, dass eine »Soziologie des Geistes « nun als eine »eindeutig formulierbare und in Einzelheiten erforschbare Fragestellung «(Mannheim 1929:40) auftauche, hadert Seidel - wie gezeigt - mit solchen programmatischen Ansagen, da die Fragen nach der Letztbegründung eines soziologischen Standpunkts für ihn gewissermaßen nicht zu Ende gedacht sind. »Die Gesellschaft selbst kann wohl nur zum Problem werden, wenn sie selbst problematisch geworden ist, wenn sich ihr organischer Zusammenhang aufzulösen beginnt. - Dies wäre der Grundgedanke zu einer »Soziologie der Soziologie« (Seidel 1927: 174).

122 Voller beginnt seinen Aufsatz mit der Anekdote, wonach Adorno in einer Vorlesung von 1965 an seinen »verstorbenen Jugendfreund namens Seidel« erinnert, der den Begriff der »Metaphysik der Produktivkräfte« in die Kritik des Marxismus eingeführt habe (Voller 2017: 60).

Frese weist nicht aus, woher er diese Information hat. 
Mannheim hingegen war - wie das folgende Beispiel zeigt - von der Möglichkeit einer >Soziologie des Geistes< überzeugt. In seiner Rede Die Bedeutung der Konkurrenz im Gebiete des Geistigen, die Mannheim 1928 am 6. deutschen Soziologentag in Zürich gehalten hat, wird dies exemplarisch deutlich. Mannheim stellt das Thema der Konkurrenz in diesem Vortrag nicht nur »als Phänomen der ökonomischen Sphäre« (Mannheim 1929: 39) zur Debatte, sondern er betrachtet Konkurrenz »als Phänomen des gesamten gesellschaftlichen Lebens « (ebd.). Er möchte die Konkurrenz also dort aufweisen, »wo sie bisher am wenigsten beobachtet wurde: im Gebiete des geistigen Lebens in ihrer konstitutiven Bedeutung [...] (ebd.). Mannheim macht hier zweierlei: Erstens bestimmt er das »geistige Leben« als etwas Gesellschaftliches, und zweitens verknüpft er dieses mit Konkurrenzverhalten. Er stellt fest:

Um das Wichtigste dieses denksoziologischen Tatbestandes hervorzuheben denksoziologisch, wenn man den historischen Gesamtzusammenhang stets im Auge hat -, kämpfen eigentlich gar nicht Erkenntnistheorien gegen Erkenntnistheorien, wie es zunächst den Anschein hat, sondern je daseiende verschiedene Denkweisen, Paradigmata gegeneinander, die durch die dazugehörigen Erkenntnistheorien erst legitimiert werden sollen. Im historisch-sozialen Zusammenhang sind Erkenntnistheorien nur vorgeschobene Posten im Kampfe der Denkstile. (ebd.: 81)

Werden Erkenntnistheorien in einen historischen und sozialen Kontext gestellt, seien sie also lediglich vorgeschobene Posten, d.h. Wächter für Denkstile.124 Nicht auf der Ebene von Erkenntnistheorien werden weiterführende wissenschaftstheoretische Einsichten gewonnen - so die Implikation -, sondern auf der Ebene von Denkstilen. Diese Aussage hinterfragt den Wahrheitsgehalt von Erkenntnistheorien auf einer prinzipiellen Ebene und eröffnet Perspektiven, die das Denken und die Philosophie wissenssoziologisch wenden. Mannheims Vortrag galt, so stellt der Historiker Reinhard Laube fest, sofort als spektakulär und erhitzte die Gemüter (Laube 2004: 519/521). »Die wissenssoziologische Fragestellung bedroht die vermeintlich festen Bastionen hierarchisierter Beobachtungsverhältnisse $[\ldots]$ (ebd.: 520).

Mannheim ging als einer der >Gründerväter der Wissenssoziologie in die Wissenschaftsgeschichte ein. In seinen eigenen, programmatischen Worten: »Auf die Spitze getrieben und auf eine prägsame Formel gebracht, das Problem einer Soziologie des Geistes taucht als eine eindeutig formulierbare und in Einzelheiten erforschbare Fragestellung auf« (Mannheim 1929:

124 Mannheim soll als erster Ludwik Flecks Begriff des »Denkstils« in seinem Aufsatz »Das Problem einer Soziologie des Wissens« (1925) rezipiert haben (Sauerland 2017: 42, Fn. 11). 
40). Diese Aussage enthält eine Setzung, die zugleich eine Ausgangslage für wissenssoziologische Fragestellungen schafft: die Möglichkeit, Erkenntnisse aus einer soziologischen Perspektive zu untersuchen. ${ }^{125}$ Für Seidel hingegen schien Mannheims Standpunkt zu kurz gegriffen zu sein, da die »Soziologie des Geistes « zwar geistige Produkte als etwas Gesellschaftliches bestimmt, nicht aber das Problem löst, das daraus folgt: Wie soll damit umgegangen werden, dass genau diese, d.h. die eigenen Gedanken gesellschaftlich bestimmt und dadurch möglicherweise verfälscht sind? Seidels Versuch einer »Soziologie der Soziologie « wollte die kognitive Perspektive des (marxistisch) Fragenden nicht außer Acht lassen (Velarde 2008: 181). »Wie dann aber erkennen, wenn die eigene Perspektive der fundamentalen Kritik unterzogen wird und sie zu einem verzerrten Bewußtsein führe?«(ebd.).

Wie deutlich geworden ist, schließt sich Seidel bereits in seiner Dissertation weder einer "parteiorthodoxen « noch einer "pragmatischen « Lesart des Marxismus im Sinne der Wissenssoziologie Karl Mannheims an (Velarde 2008: 181). »Zwischen beiden Perspektiven gab es keinen >goldenen< Mittelweg. Seidel schlug einen eigenen, in den Abgrund führenden Weg ein. Der Ansatz ging zu weit, um >rational< ausbaufähig zu werden, erstickte in sich selbst, selbst wenn man Seidel als >Geheimtip < der deutschen Wissenssoziologie betrachtete (ebd.: 182). ${ }^{126}$

Wie sich Seidel bei seinem Versuch einer »Soziologie der Soziologie « gedanklich verheddert - warum er sich also keinem der zeitgenössischen Theorieangebote letztgültig anschließen konnte oder wollte -, soll im Folgenden an konkreten Textstellen aus Bewußtsein als Verhängnis nachgezeichnet werden. Dabei wird gleichzeitig eine u.a. durch die Soziologie ausgelöste Krise für die Philosophie ersichtlich: Wie kann der eigene wissenschaftliche Erkenntnisstandpunkt noch legitimiert werden, wenn der Geist durchweg von sozialen Strukturen bestimmt wird?

125 Diese Rolle kommt bei Mannheim der »freischwebenden Intelligenz« zu. »Ihr Ziel müsse sein, die vorreflexiven Denkvoraussetzungen aller partikularen Anschauungen ins Bewusstsein zu heben und den Grund für diese Evidenz zu zeigen« (Maasen 20og: 26; siehe auch Fn. 129).

126 Die Quellen dieses Gerüchts sind laut Frese Peter Christian Ludz und Kurt Lenk (mündlich 1968). Dass Seidel - in gewissem Sinne bis heute - als »Geheimtip« (Frese) gilt, wird durch das Gerücht gestützt, dass Adornos Fangfrage in Bezug auf die Wissenssoziologie stets gelautet haben soll: Kennen Sie Seidel? (vgl. auch Frese 2001/2002: 62, Fn. 3). 


\section{Erstarren vor der Kompliziertheit, Ekel vor der Banalität, Versinken im Relativismus}

In Seidels Schrift fehlen im Unterschied sowohl zu Mannheims als auch Adornos bzw. Horkheimers Schriften programmatische Aussagen über ein neues Forschungsfeld sowie rhetorische Wendungen, die seine eigenen Gedanken als wissenschaftlich, gesellschaftlich oder politisch relevant ausweisen. Im Gegenteil denkt Seidel nebst der 〉Psychologisierung` des Geistes wie sie vor allem am Beispiel von Husserl deutlich geworden ist - konsequent auch die >Soziologisierung < des Geistes radikal weiter: Was bedeutet es für das (eigene) Denken, wenn das Bewusstsein als von sozialen Strukturen bestimmt gedacht wird? Seidel will keine Antworten auf diese Frage geben, vielmehr durchdenkt er die Konsequenzen dieser Problematik.

»Im allgemeinen «, schreibt er, »handelt der Mensch ohne nähere Untersuchung der psychischen und sozialen Bedingungen, in denen er lebt « (Seidel 1927: 118). Würden diese Bedingungen aber bewusst gemacht, könnten drei Folgen eintreten: das Erstarren vor der Kompliziertheit, der Ekel vor der Banalität und das Versinken im Relativismus (ebd.: 118-124). Im ersten Fall könne die Bewusstheit psychischer und sozialer Vorgänge zu »Hemmungen des Handelns « führen. »Rationalisten glauben [...], die sogenannte Blindheit des instinktiven Handelns durch den Überblick und die Klarheit des Bewusstseins zu überwinden und so ein zweckmäßiges Handeln zu ermöglichen« (ebd.: 118-119). Jedoch verleite der »überschwengliche Glaube an die Allmacht des Wissens [...] zu Fehlgriffen« (ebd.: 119). Als »typischen Fall« bezeichnet Seidel hier Marxisten, »die auf Grund von Wissenschaft oder vielmehr Theorie Politik treiben wollen« (ebd.). Dass Marxisten »so geringen Erfolg haben«, führt er darauf zurück, dass »sie zu viel erkannt haben« (ebd.). Im zweiten Fall führt die Bewusstmachung psychischer und sozialer Zusammenhänge zu einem Ekel vor der Banalität. Wo der erste Punkt insbesondere soziologisches Wissen betrifft, betrifft dieser zweite psychoanalytisches:

Beginnt einmal diese psychologische »Selbst- und Fremdzerfleischung «, so wird sie so leicht kein Ende finden [...]. Steigt man in die Abgründe des Unbewußten hinab, so vergeht oft jeder Schimmer des Wertes, der vorher alles Tun umstrahlte. [...] Wenn wirklich die in rücksichtsloser Analyse gefundenen Motive, seien es nun Machtgier oder Sexualität, die bestimmenden sind, so bedeutet das für die Einzelnen, daß sie bisher in Illusionen gelebt haben. (ebd.: 120)

Die Bewusstwerdung, dass die eigenen Motive mit Macht und Sexualität verstrickt sind, würden »Wahrheitsfanatiker begrüßen«, doch für »Menschen, die unter illusionären Wertungen und Weltbildern ihr Leben aufgebaut haben«, bedeute sie eine »schwere Erschütterung, vorausgesetzt, daß sie die Richtigkeit 
und Bedeutung der Analyse zugeben und sie nicht einfach als unsinnig oder belanglos abweisen [...] «(ebd.).Zum Beispiel müsse allein die religionspsychologische »Andeutung, daß zwischen der Ekstase der Heiligen und sexuellen Erregungszuständen Beziehungen bestehen, [...] einen Katholiken aufs tiefste verletzen« (ebd.: 121). Die gleiche Desillusionierung jedoch könne »bei allen geistigen Leistungen eintreten, sobald sie dem Prozeß der Analyse unterworfen werden « (ebd.). Wahrscheinlich - so bringt Seidel seinen Gedankengang auf den Punkt - geschehen »die wertvollsten Leistungen [...] unter illusionären Vorstellungen« (ebd.). Er behauptet hier, dass die Bewusstmachung psychoanalytischer und soziologischer Vorgänge eine geistige Leistung sei, dass aber genau diese Leistung wiederum die geistige Produktivität hemmen bzw. zerstören könne. Im dritten Fall - Versinken im Relativismus -, der wiederum die Soziologie fokussiert, führe das Bewusstsein psychischer und sozialer Zusammenhänge zu einer Erschütterung des Weltbildes. Hier bringt Seidel allgemeine Fragehorizonte seiner Zeit gewissermaßen auf den Punkt. Der Prozess der Selbstanalyse führe

zur Einsicht, daß Charaktereigenschaften durch Klasse und Volk mitbedingt sind. Man erkennt die Abhängigkeit einer politischen Wertung von der eigenen Klassenlage und gibt bei einiger Ehrlichkeit zu, daß man andere Staatsund Gesellschaftsideale hätte, wenn man in einer anderen Klasse geboren wäre. Völlig relativiert wird eine Weltanschauung durch den Vergleich mit anderen historischen Epochen. Die Überzeugung, daß alle Meinungen und Empfindungen, sogar die Ergebnisse der exakten Wissenschaft, einem räumlich und zeitlich begrenzten Kulturkreise angehören, legt den Schluß nahe, daß auch die eigene Weltanschauung nur Ausdruck einer Zeitepoche ist, daß auch sie überholt werden wird, wie so manche Auffassung, die mit Emphase als letzte Wahrheit verkündet wurde. (ebd.: 122)

Die Wendung, die Seidel hier nimmt, ist symptomatisch für die Formulierung seiner Gedanken: seine Überzeugung, dass Wahrheitsansprüche - auch die eigenen - immer ausgehend von einer spezifischen historischen und sozialen Situation formuliert werden, bestimmt weitgehend seine Problematisierungen. Das Erstarren vor der Kompliziertheit, der Ekel vor der Banalität und das Versinken im Relativismus erscheinen in seinen Überlegungen als Folgen eines Bewusstseins, das den eigenen Wahrheitsanspruch gnadenlos seziert. ${ }^{127}$

127 Wie bereits angedeutet, wird Seidels Nähe zu Nietzsche an vielen Textstellen deutlich. Unter der Überschrift »Schopenhauer, Nietzsche und ich « grenzt Seidel seine eigene Position explizit von derjenigen Nietzsches und Schopenhauers ab: »Ich: Das Leben ist zu verneinen, wie bei Schopenhauer, aber um des Lebens willen und zwar des nicht 
Die hier beispielhaft zitierten Stellen deuten die Verbindung zwischen Marxismus und Psychoanalyse an, die für Seidels Gedankengänge - wie auch für die Ausformung der Kritischen Theorie - bestimmend ist:

Kultur, so referiert er [Seidel, MD] in Bewußtsein als Verhängnis den »Forschungsstand « seiner Zeit, bedeute wesentlich Sublimierung, Verdrängung und Umweg: Sublimierung des hypertrophierten Sexualtriebs, Verdrängung des produktiven Grundes kapitalistischer Vergesellschaftung im kulturellen Überbau und Umwege auf dem Weg zu Zielen, die in letzter Instanz der Wille zur Macht setze, wie Nietzsche ihn interpretiert hatte. (Voller 2017: 75)

Verdrängte Triebenergien äußern sich für Seidel also auf einer gesellschaftlichen Ebene - entweder als Sublimierung oder Neurosen, wobei beides nicht eindeutig zu unterscheiden sei. ${ }^{128}$ Analysen können Sublimierungen und Neurosen zwar auflösen, gleichzeitig würde dabei aber auch die Kultur aufgelöst. »Die unter Seidels Zeitgenossen verbreitete Angst, durch die psychoanalytische Methode von bestimmten Neurosen zwar geheilt, seiner Potentiale und Kreativität jedoch genau dadurch beraubt zu werden, wird somit auf das Feld des Gesellschaftlichen transponiert« (ebd.: 76). Laut Seidel kann die moderne Wissenschaft diesen Vorgang eines möglichen Kulturzerfalls zwar analytisch durchschauen, eine Veränderung oder eine Durchbrechung des »blinden Triebes« entziehe sich aber der modernen Ratio. Denn »auch das reflektierende Bewußtsein [...] hat nur auflösende Wirkung, weil es immer wieder in den Mittelpunkt einer Persönlichkeit gestellt und damit Selbstzweck wird. Dann verfängt sich das Leben in der Reflexion «(Seidel 1927: 97).

Seidels Überlegungen zur Reflexion als Selbstzweck sind im hier vorgestellten Zusammenhang zentral. »Es gibt aber auch Menschen, die über das Reflektieren nicht hinauskommen [...]. Das müssen wir dann aber als Symptom einer an sich gehemmten Persönlichkeit auffassen, die man im stärkeren Grade als psychopathisch bezeichnen könnte« (ebd.: 99-100). In

gesteigerten Lebens, sondern des harmonischen, ruhigen, in Gemeinschaft gebundenen. Das übersteigerte Leben heißt der Tod « (Seidel 1927: 219). »So ist Nietzsches Position im Unterschied zu der meinigen eine Ablehnung der Gemeinschaft und der Religion aus Bejahung des Willens zur Macht und (bei der Gleichsetzung beider auch) aus Lebensbejahung« (ebd.: 218).

128 »Diese verdrängten Triebenergien können sich in Phänomenen auswirken, die nach Freud teils als Neurosen, teils als Sublimierungen bezeichnet werden. Die Unterscheidung ist in concreto schwer zu treffen: man könnte einzelne Kulturphänomene mehr als Neurose, denn als Sublimierung ansprechen, es kommt oft nur auf die Umstände an und ist wohl überhaupt nur eine Frage der Wertung « (Seidel 1927: 96). 
der psychiatrischen Literatur trete diese Erscheinung unter dem Namen des »Grübelzwanges« auf (ebd.: 100). Der Subtext von Seidels Überlegungen ist auch hier - wie es im Kapitel über Husserl deutlich geworden ist - eine Analyse des Typus des Wissenschaftlers. Solche »dauernd gehemmte[n] Typen« seien natürlich zu jeder Zeit möglich, sie werden aber »in bestimmten Epochen ganz besonders stark vertreten sein « (ebd.). In Zeiten, in denen es »bindende Weltbilder« gibt, in denen die »Illusions- und Glaubensfähigkeit stärker, wo die Ernüchterung noch nicht an jeder Häuserfassade zu spüren ist [...], sind diese Menschen eingebettet in den Kreis der gebundenen Gemeinschaft« (ebd.). In individualistischen Zeiten hingegen sei »jeder auf sich selbst angewiesen, und somit werden diese Typen sich in ihrer privaten Reflexion verfangen und bei der bestehenden Meinungsfreiheit sie zur öffentlichen erheben" (ebd.: 100-101). Lapidar fügt Seidel an: »Man glaubt dann noch mit ihrer Hilfe alles verbessern zu können, indem man selbst an ihr zugrunde geht « (ebd.: 101). »Der aktive Psychologe oder Gelehrte kann sich zwar dadurch retten, daß er die Erkenntnisse der Reflexion gestaltet oder verwendet, daß er sie also in Tätigkeit umsetzt und sich so von ihnen befreit. Die Reflexion wird ihm dadurch zum Mittel. Zum leeren Selbstzweck wird sie nur dem, der um diese letzte Rettung nicht weiß, der in der Reflexion gefangen bleibt« (ebd.: 97).

Letztlich gelte es, diesen Typus des Analytikers in sich selbst aufzulösen, indem man die »Analyse gegen die Analyse « treibe. Dieser neue »Typus" wiederum müsse »auf Grund seiner Wesensveranlagung aus innerer Notwendigkeit negativ sein, aber gegen die Negativität, nihilistisch gegen den Nihilismus « (ebd.: 204). Jedoch wird selbst die Nihilisierung des Nihilismus es klingt hier deutlich Hegels Modell der »Negation der Negation « an - von Seidel durch eine reflexive Schleife gezogen:»Aber - ist das keine pragmatische Verzweiflung mit einem Schielen auf ihre möglichen positiven Wirkungen? [...] Läuft aber nun dieser gegen den eigenen Typus gerichtete Kampf nicht darauf hinaus, den Teufel durch Beelzebub zu vertreiben « (ebd.)? In den letzten Sätzen seines Manuskripts legt Seidel nahe, dass selbst eine »Analyse der Analyse « lediglich sichtbar mache, dass die Wirkungen des Bewusstseins verhängnisvoll sind. »Nur der Analytiker, nur derjenige, der in der Reflexion positiv sein zu können glaubt, wird sich in sie [die Reflexion, MD] hinein vertiefen und sie wird ihn erläutern (?) [sic!] soweit er ehrlich ist, und dann möglicherweise negativ auf ihn wirken, d.h. ihm seinen Glauben an die Wirkungen des Bewußtseins erschüttern. Und das wäre der schönste Erfolg « (ebd.: 205). An dieser Stelle wird die Grenze sichtbar, vor der Seidel - im Unterschied sowohl zu Adorno und Horkheimer als auch Mannheim - keinen Halt macht: $\mathrm{Er} »$ rettet« sich in keinen Zweck, sondern führt selbst die »Analyse der Analyse« analytisch ins Bodenlose. 


\section{Selbstreflexiver Kollaps}

Aus Seidel ließe sich, so sagt Jürgen Frese schon in den 1970er-Jahren, »leicht eine Vorgeschichte der >Kritischen Theorie< basteln [...], in der Seidel als deren mythischer Ahnherr figurieren würde [...] (Frese 2001/o2: 47). Jedoch gebe es einen Differenzpunkt, der Seidel nicht nur von Adorno, sondern auch von anderen >kritischen Theoretikern ₹ wie Horkheimer, Bloch, Benjamin, Kracauer, Sohn-Rethel, Marcuse und Fromm unterscheide: »Seidels Selbstkritik der sich durchschaut habenden Aufklärung macht vor sich selbst nicht halt und lässt kein geschichtsphilosophisches Reservat für den kritischen Kritiker übrig: Auch Seidels Buch ist noch Symptom und Beschleunigungsmoment eines Verfallsprozesses - und nicht Herr seiner eigenen Wirkungen« (ebd.: 61). Wo genau, so muss gefragt werden, liegt dieser Punkt, vor dem Seidel nicht haltmacht - die Begründer der Kritischen Theorie aber sehr wohl? Und wie lässt sich davon ausgehend die Krise beschreiben, die Seidel sichtbar macht?

Seine Rückbezüge auf die Wissenschaft bzw. den Typus des Wissenschaftlers und insbesondere seine Reflexionen auf sich selbst als Forschender sind diesbezüglich erhellend. »Der Wissenschaftler«, so stellt er mit seinem üblichen Bezug auf psychologische und psychoanalytische Denkmodelle fest, »ist ein sublimierender Perverser« (Seidel 1927: 212.).

Gerade die Wissenschaftler haben es so nötig, den Wert ihrer Erkenntnisse zu betonen, da sie eben die entgegengesetzte Wirkung haben, was sie vor sich nicht wahr haben wollen, da sie de facto die Wissenschaft um anderer Motive willen betreiben, welche besonders bei der »Wissenschaft« um ihrer selbst willen« zu verdecken sind - aus Wahrheitssadismus und Machtstreben. (ebd.: 212)

Wird der Wissenschaftler sich der psychologischen und soziologischen Motive der eigenen Tätigkeit bewusst - so implizieren Seidels Ausführungen -, wird deutlich, dass Wahrheitssadismus und Machtstreben die Motive dieser Arbeit sind. Im Unterschied etwa zu Mannheim, der die wissenschaftliche Tätigkeit als solche objektiviert, ${ }^{129}$ bezieht Seidel zugleich seinen eigenen Standpunkt als Wissenschaftler in seine Analysen mit ein. Daraus resultiert seine Diagnose, dass Machtstreben, Sexualität und Wahrheitssadismus für die Wissenschaftsproduktion wesentliche Antriebe sind, dass Wissenschaftler diese Motive aber verdecken, da ansonsten Erkenntnisse ihren Wert verlieren.

129 Mannheim löst das Problem, in das sich Seidel verstrickt, mit dem von Alfred Weber geprägten Terminus der »frei schwebenden Intelligenz«: Den Angehörigen der >frei schwebenden Intelligenz gelinge es eher als anderen Gruppen, sich von der Ideologiehaftigkeit des Wissens zu befreien. Die »frei schwebende Intelligenz« sei also eine relativ klassenlose Schicht, die gebildeter, sozial ungebundener und unvoreingenommener im Hinblick auf spezifische Interessen ist (Maasen 2009: 25). 
Die Krise, die hier deutlich wird, betrifft die Legitimation des eigenen philosophischen Standpunkts. Wenn sichtbar wird, dass der eigene Erkenntnisstandpunkt mit der je eigenen sozialen Situation zusammenhängt, kommt auch die Annahme eines absoluten, von sozialen Faktoren unabhängigen Geistes in Bedrängnis. Welche Bedeutungen haben Erkenntnisse, wenn sie durch Kategorien wie »Klasse«, »Volk« und »Kultur « formiert werden? Seidel nimmt sich wie gesagt nicht aus dieser Diagnose aus. Auch er selbst gehöre zu »diesem Typus der analytischen Wissenschaftler, der Wahrheitssadisten «, ja, er sei »davon ein ausgesprochener Typ« (Prinzhorn 1927: 31). Er nimmt den Terminus der Selbstkritik bzw. Selbstreflexion in radikaler Weise ernst und konfiguriert Selbstkritik nicht abstrakt als Möglichkeit oder Modus philosophisch-denkerischen Schaffens (wie es weiter unten in Bezug auf die Kritische Theorie deutlich wird), sondern wendet sie, gewissermaßen ungefiltert, auf sich selbst und auf seinen eigenen Schaffensprozess an. Der Einsatz seiner Analysen sei - so pointiert Voller - sein eigenes Denken und Leben: »Indem er rational gegen die Ratio zu Felde zog - >auf eine Weise, die es sich etwas kosten ließ<, wie Bloch anmerkte -[,] machte der Theoretiker Seidel allerdings stets den ganzen Menschen Seidel zum Einsatz seiner intellektuellen Gefechte« (Voller 2017: 79). So analysiert er die »Ideologien der Gegenwart«130 ausgehend von seinen eigenen Erfahrungen. In Vollers Worten:

Jugendbewegung, Psychoanalyse, Marxismus und revolutionärer Sozialismus, reaktionäre Kulturkritik und verschiedene ästhetische Strategien und Avantgarde-Bewegungen der 1920er Jahre werden als durchlebte und durchschaute Stationen des eigenen Lebens- und Denkweges analysiert. Durchweg macht Seidel damit die eigene Erfahrung - und das bedeutet in erster Linie die Leiderfahrung des (drohenden) Wahnsinns und die daraus resultierende Position des Außenseiters - zur Grundlage einer Methode, die objektive Einsichten durch radikalen Subjektivismus ermöglichen soll. (ebd.: 82)

Der »radikale Subjektivismus«, der in den fahrigen und (selbst-)kritischen Skizzen erkennbar ist, wird von Seidel selbst allerdings in keiner Weise zum Programm erhoben oder als Lösungsstrategie vorgestellt. Vielmehr wird dieser Subjektivismus in der permanenten Selbstreflexion greifbar, die sich im Text zuweilen fast verselbstständigt. Es ist darum die Art und Weise, wie Seidel beständig und teilweise zirkulär seine selbstreflexiven Denkbewegungen ausformuliert, die diesen Subjektivismus so radikal erscheinen

130 Wie bereits angesprochen diskutiert Seidel in diesem Zusammenhang den »MarxismusSozialismus«, die »Neuromantik« (die Gemeinschaft, die Religion, das Kulturgewollte, die Ideologie der Natürlichkeit, das Erlebnis, die Frauenbewegung), den »Nationalismus«, den »Pazifismus« und die »Untergangsidee« im Sinne Oswald Spenglers (Seidel 1927: 166-202). 
lässt. Selbst sprachlich wird der finalen Erkenntnis und der absoluten Wahrheit kein Refugium mehr eingeräumt. Die doppelte Negation wird nicht in die Affirmation aufgelöst. Sie stellt lediglich eine Drehung in einem fatalen denkerischen Reigen dar, der in der unablässigen Bewusstwerdung und Infragestellung der eigenen existenziellen und auch theoretischen Position nie zum Stillstand kommt.

Es ist diese Nähe zu den eigenen Denkbewegungen, die verhindert, dass der Text Bewußtsein als Verhängnis insgesamt als kulturpessimistisches Pamphlet erscheint. »Was sie [die (selbst-)kritische Skizze, MD] jedoch davor feit, sich in tragischer Spekulation gänzlich zu verlieren und ihre analytische Schärfe über alle Fahrigkeit hinweg verbürgt, ist die Nähe, aus der sie geführt wird. Durch die Lehren, die er so unnachgiebig seziert, ist Seidel selbst gegangen « (Voller 2017: 82). Er denkt nicht in Mustern möglicher akademischer Profilierung, er denkt so könnte pointiert werden - um des Denkens willen. Seine Reflexionen und Selbstreflexionen über das Bewusstsein machen keinen Halt vor der eigenen Position und verfangen sich in einem Circulus vitiosus. Weder synthetisiert er seine Gedankengänge, noch löst er sie auf. Philosophische Lösungserwartungen werden dadurch nicht befriedigt: In philosophischer Hinsicht kollabieren seine Analysen gewissermaßen infolge der eigenen Selbstkritik.

Seidels Gedankengänge, die sich jedem strategischen Denken entziehen, verdeutlichen, dass angesichts soziologischer und psychoanalytischer Theorien die Legitimität philosophischer Positionen fundamental herausgefordert wird: Wie lässt sich ein philosophischer Standpunkt sui generis rechtfertigen, wenn der Geist maßgeblich aus gesellschaftlichen Strukturen besteht und durch die Sublimationen von Triebenergien bestimmt wird? Wie lässt sich wissenschaftliche Tätigkeit legitimieren, wenn klar ist, dass der Geist weitestgehend ein gesellschaftliches Produkt ist? Die Frage, wie es Adorno und Horkheimer gelingt, ausgehend von solchen Herausforderungen einen philosophischen Erneuerungsanspruch argumentativ zu formulieren, ist vor dem Hintergrund von Seidels Bewußtsein als Verhängnis signifikant. Wie gehen sie es an, Selbstkritik zum Programm einer philosophischen Erneuerung zu erheben, ohne in das geschilderte Dilemma zu geraten?

\section{Thesen und Vorgehen}

Die Geschichtsschreibung der Kritischen Theorie beginnt mit der »Marxistischen Arbeitswoche«, die an Pfingsten 1923 in einem Bahnhofshotel in Thüringen stattgefunden hat. ${ }^{131}$ Unter den rund 20 Personen, die an dieser

131 »Unter den Teilnehmern waren noch nicht diejenigen, deren Namen später mit der Kritischen Theorie identifiziert werden sollten, wie Horkheimer, Adorno und Marcuse, sondern vor allem politisch aktive Wissenschaftler, wie Korsch und Wittfogel, außerdem 
informellen Konferenz teilgenommen haben, ${ }^{132}$ befinden sich auch Georg Lukács und Karl Korsch. ${ }^{133}$ Korschs Manuskript seines bekannten Aufsatzes Marxismus und Philosophie soll die Textgrundlage für die Diskussionen auf dieser Tagung gewesen sein. ${ }^{134}$ Die Tatsache, dass die beiden Autoren, die nebst Antonio Gramsci - als Begründer des sogenannten >westlichen Marxismus< gelten, ${ }^{135}$ bei der Initialveranstaltung der Kritischen Theorie anwesend gewesen sind, trägt für sich symptomatische Züge - aber auch für die Argumentation des vorliegenden Kapitels: Sie verweist auf die Kontinuitäten zwischen der keineswegs homogenen Gruppe von Intellektuellen, die sich in den 1920er-Jahren um eine Neuinterpretation von Marx' Schriften bemüht hatten, und den wenig später initiierten theoretischen Ansätzen der Kritischen Theorie, wie sie vor allem mit den Namen Horkheimer und Adorno verbunden sind (insbesondere dazu: Fracchia 1987). Wie Martin Jay betont, äußerten sich das Institut für Sozialforschung und Lukács »von der Basis einer gemeinsamen Tradition aus zu denselben Problemen«(Jay 1981 [1973]: 211).

z.B. Richard Sorge und Friedrich Pollock, und schließlich Georg Lukács« (van Reijen 1984: 24). »Während der EMA [Ersten Marxistischen Arbeitswoche, MD] war Weil [Felix Weil, MD] die Idee einer festeren Institution gekommen; verschiedene Freunde an der Frankfurter Universität bestärkten ihn darin, und in gemeinsamen Überlegungen kristallisierte sich rasch eine klare Vorstellung davon heraus« (Jay 1981 [1973]: 24). Siehe auch: Wiggershaus 1986: 25-26; Buckmiller 1988. Offiziell gegründet wurde das Institut 1923: »Die offizielle Gründung des Instituts fand am 3. Februar 1923 aufgrund einer Verfügung des Kultusministeriums statt« (Jay 1981 [1973]: 28).

132 Die Teilnehmenden bestanden hauptsächlich aus (Ehe-)Paaren: Christiane und Richard Sorge, Hedda und Karl Korsch, Käthe und Felix Weil, Rose und Karl August Wittvogel, Friedrich Pollock, Gertrud und Ludwig Alexander (inklusive Kind), Konstantin Zetkin, Georg Lukács, Hede Massing und Julian Gumperz, Margarete Lissauer und Béla Fogarasi, Karl Schmückle und Fukumoto Kazuo.

133 Korsch gilt als »geistige[r] Initiator« der Marxistischen Arbeitswoche (Buckmiller 1988: 156).

134 »Es wurde diskutiert über Korschs `Marxismus und Philosophie` und es war die erklärte Absicht der Diskussionsrunde, die verschiedenen Marxauffassungen, die damals existierten, auf eine gemeinschaftliche Basis zu stellen« (van Reijen 1984: S. 24). »Den größten Teil der Zeit verbrachte man mit der Diskussion von Korschs noch nicht veröffentlichtem Manuskript >Marxismus und Philosophie« (Jay 1981 [1973]: 23). Der Text kann darüber hinaus als Leitlinie für den Forschungsrahmen des Instituts für Sozialforschung der ersten Jahre interpretiert werden (van Reijen/Schmid Noerr 1988: 172).

135 Der von Maurice Merleau-Ponty in den 195oer-Jahren aufgebrachte Begriff (MerleauPonty 1968 [1955]: 39-72) wurde in den 197oer-Jahren durch Perry Andersons Buch Über den westlichen Marxismus populär (Anderson 1978 [1976]). Anderson nennt Lukács, Korsch und Gramsci als »die wirklichen Begründer des ganzen Modells des westlichen Marxismus« (ebd.: 51). 
Die neue Verhältnisbestimmung zwischen Philosophie und Marxismus, wie sie an Lukács und Korsch beobachtet werden kann, ist - so die argumentative Stoßrichtung - für Horkheimer und Adorno eine entscheidendeVoraussetzung, damit sie ihr neues theoretisches Programm (die Kritische Theorie) als Philosophie präsentieren und positionieren können (etwa durch das gemeinsam verfasste Buch Dialektik der Aufklärung (1944), Adornos Minima Moralia (1951) oder dessen Negative Dialektik (1966)). Lukács' Aufsatzsammlung Geschichte und Klassenbewußtsein wird denn auch vielerorts als ein zwingender Einflussfaktor für die Entwicklung der Kritischen Theorie dargestellt. ${ }^{136}$ Vor allem Lukács (und weniger Korsch) bemüht sich explizit um eine philosophische Fundierung des Marxismus. Horkheimer und Adorno wiederum nehmen diese Fundierung auf und formulieren auf dieser Basis einen Erneuerungsanspruch der Philosophie insgesamt. Die Schwerpunktverlagerung des Marxismus »hin zur Philosophie« (Anderson 1978 [1976]: 77) ist für den Erneuerungsanspruch der Kritischen Theorie entscheidend. Diese Entwicklung kann nicht nur in ideeller, sondern auch in institutioneller Hinsicht beobachtet werden. »Der auffallendste Zug der gesamten Tradition [des westlichen Marxismus, MD] ist die überwältigende Dominanz von Berufsphilosophen. Gesellschaftlich gesehen bedeutete das eine immer stärkere Verankerung der in dieser Epoche produzierten Theorie im akademischen Bereich « (ebd.: 55$)$.

Im Folgenden wird an Lukács und Korsch in einem ersten Schritt deutlich gemacht, wie diese den Marxismus gewissermaßen re-philosophieren. Ihr zentrales Anliegen ist die Rückbindung der Philosophie an materielle Verhältnisse, um sie davon ausgehend als Ideologie der bürgerlich-kapitalistischen Gesellschaft zu entlarven. Philosophiekritik (Theorie), so folgt daraus, ist mit Gesellschaftskritik (Praxis) untrennbar verbunden. Lukács und Korsch aktualisieren damit das Marx'sche Theorem der Verwirklichung der Philosophie in der Praxis. Danach wird gezeigt, wie Adorno und Horkheimer vom Ausgangspunkt des Scheiterns dieses Theorems in der Praxis ihren philosophischen Erneuerungsanspruch formulieren. »Philosophie«, so die ersten Sätze aus Adornos Negativer Dialektik, »die einmal überholt schien, erhält sich am Leben, weil der Augenblick ihrer Verwirklichung versäumt ward. Das summarische Urteil, sie habe die Welt bloß interpretiert, sei durch Resignation vor der Realität verkrüppelt auch in sich, wird zum Defaitismus der Vernunft,

136 »Ohne seinen [Lukács', MD] inspirierenden Geist wäre auch die kritische Theorie nicht zu begreifen, die wir ohne `Geschichte und Klassenbewußtsein` gar nicht verstehen können« (Claussen 2015: 175). Auch Jay betont, »daß viel von dem, was die Paramarxisten geschrieben haben, ohne gewisse Schriften von Lukács in dieser Weise gar nicht denkbar wäre« (Jay 1981 [1973]: 210). 
nachdem die Veränderung der Welt misslang « (Adorno 1966: 15). Adorno und Horkheimer nehmen die von Lukács und Korsch konzeptualisierte gegenseitige Durchdringung von Gesellschaft und Philosophie insofern affirmativ auf, dass sie die Philosophie mit den zeitgenössischen Sozialwissenschaften verbinden, diese aber dezidiert von der als relativistisch verstandenen Wissenssoziologie abgrenzen. Auf dieser Basis wiederum formulieren sie ihren Erneuerungsanspruch: Die einzige noch legitime Aufgabe der Philosophie bestehe in der Kritik an der Gesellschaft.

\subsection{Die Philosophie als Problem der Gesellschaft (Lukács und Korsch)}

Sowohl Lukács' Aufsatzsammlung Geschichte und Klassenbewußtsein als auch Korschs Aufsatz Marxismus und Philosophie sind 1923 erschienen. Beide Schriften gelten - wie es Hanno Plass jüngst formulierte - als »Wendepunkt in der marxistischen Theorie nach dem Ersten Weltkrieg« (Plass 2015: 303-304). Obwohl Marxismus und Philosophie in den 1920er-Jahren ebenso bekannt gewesen sein soll wie Geschichte und Klassenbewußtsein (Claussen 2015: 175), nimmt letzteres Buch in der Rezeptionsgeschichte des Verhältnisses von Marxismus und Philosophie eine ungleich bedeutendere Rolle ein. Die beiden Schriften unterscheiden sich hinsichtlich ihres Umfangs, ihrer Themen und ihrer Fragestellungen. ${ }^{137}$ Dass die beiden Texte in der Fachliteratur kontinuierlich als Gründungsdokumente des westlichen Marxismus genannt werden, verweist jedoch darauf, dass sie sich trotz ihrer Unterschiede in einem zentralen Aspekt überschneiden. Er wurde bereits angesprochen: Sowohl in Lukács' als auch in Korschs Schriften wird der Marxismus in bestimmter Weise philosophisch unterlegt. Beide Autoren fordern den Einbezug der Philosophie in die zeitgenössische marxistische Theorie (vor allem Korsch) bzw. eine philosophische Fundierung des Marxismus (vor allem Lukács). Bezüglich Korsch schreibt etwa Erich Gerlach: »Indem Korsch nachweist, daß die >Verflachung< des Marxismus durch das Nichtverstehen seines philosophischen Gehalts >vermittelt ist und daß vom Standort des so veränderten Marxismus der wirkliche Zusammenhang von Theorie und Praxis unbegreifbar geworden ist, hat er zugleich begründet, daß zur >Wiederherstellung « des >unverfälschten< Marxismus auch die Klärung seines wirklichen Verhältnisses zur Philosophie erforderlich ist « (Gerlach 1966: 12). Und in Bezug auf Lukács schreibt Eberhard Braun: »Mit `Geschichte und Klassenbewusstsein« setzt die ausdrücklich

137 Der Eindruck von Fabian Kettner, wonach Korsch weniger als Lukács unter dem »Bann« der marxistischen Orthodoxie gestanden habe, wird hier geteilt (Kettner 2012: 379). 
philosophische Marx-Interpretation ein, die vor allem Marxens Verhältnis zur deutschen spekulativen Philosophie, insbesondere zu der Hegelschen, ins Zentrum ihres Interesses rückt. Lukács kommt das kaum zu überschätzende Verdienst zu, die Diskussion als erster auf das angemessene Niveau gehoben zu haben « (Braun 1992: 173). Kurz: Sowohl Lukács als auch Korsch wird das Verdienst zugeschrieben, den Marxismus philosophisch fundiert bzw. die marxistische Philosophie für das 20. Jahrhundert aktualisiert zu haben. ${ }^{138}$

Wenn im Folgenden einzelne Textstellen aus Geschichte und Klassenbewußtsein und Marxismus und Philosophie hinsichtlich der Frage interpretiert werden, wie Lukács und Korsch den Marxismus philosophisch unterlegen, um genau dadurch ein Instrument an der Hand zu haben, mit dem es möglich wird, die Philosophie als ein Produkt der bürgerlichen Gesellschaft zu kritisieren, ist es unvermeidlich, dass die betreffenden Aussagen zuweilen aus ihrem Gesamtzusammenhang gerissen werden. ${ }^{139}$ Gerechtfertigt ist dieses Vorgehen durch das Ziel, bestimmte Argumentationsstrategien herauszuarbeiten: Mit welchen Argumentationsstrategien konstituieren Korsch und Lukács die Philosophie als ein gesellschaftliches Problem? Und wie bestimmen sie damit zusammenhängend die Philosophiekritik als wichtigen Aspekt marxistischer Theorie? Eine zentrale Ausgangslage der Argumentation von Lukács und Korsch - so wird der folgende Abschnitt deutlich machen - liegt in der Annahme, dass die Methode von Marx unanfechtbar die richtige Methode ist.

\section{Ausgangslage: Materialistische Dialektik}

Korsch und Lukács monieren in ihren Schriften, dass Marx und Engels in der zeitgenössischen Literatur sowohl von marxistischer als auch von bürgerlicher Seite verkürzt, entstellt oder schlicht falsch rezipiert werden. Es gebe, sagt Korsch in seinem 1922 veröffentlichten Text Kernpunkte der materialistischen Geschichtsauffassung, »unter den Schriften über die materialistische Geschichtsauffassung, die in deutscher Sprache vorliegen, nur sehr wenige Werke, in

138 In der Sekundärliteratur gibt es unzählige Textstellen, die diesen Aspekt betonen. Die Forderung von Geschichte und Klassenbewußtsein bzw. Marxismus und Philosophie sei gewesen, so sagt etwa Detlev Claussen, »den philosophischen Kern aus der Marx'schen Theorie wieder hervor[zu]holen, denn dieser philosophische Kern [sei] der emanzipatorische « (Claussen 2015: 175). »Korsch war neben Lukács der bedeutendste jener Marxisten, die sich bemühten, die originale Philosophie - oder vielmehr AntiPhilosophie-Marxens [...] zu rekonstruieren und auf dieser Grundlage eine revolutionäre [...] Strategie des Klassenkampfes zu entwickeln« (Kolakowski 1979 [1978]: 337). Maurice Merleau-Ponty spricht bezüglich Lukács von einer "philosophischen Lektüre der Geschichte« (Merleau-Ponty 1978 [1976]: 55-57).

139 Es geht also um die Überschneidung beider Schriften und nicht um einen Vergleich oder um eine Auslegung der Texte. 
denen der Grundgedanke von Marx nicht entweder außerordentlich versimpelt oder aber förmlich entmannt worden ist « (Korsch 1922: 5). In politischer Hinsicht kritisieren Korsch und Lukács die Gründung und Verbreitung der Unabhängigen Sozialdemokratischen Partei Deutschlands (USPD). Sie wenden sich sowohl gegen die »Revisionisten « (um Eduard Bernstein) als auch gegen die »Zentristen « (um Karl Kautsky). Lukács schreibt in seinem Aufsatz »Was ist orthodoxer Marxismus?«:»[...] auch die Gegner Bernsteins, die Hüter der angeblichen Orthodoxie des Marxismus, Kautsky und die VulgärMarxisten, haben die dialektische Methode und mit ihr den revolutionären Schwung des Sozialismus verflacht« (Lukács 2013 [1923]: 63). Korsch untermauert dieselbe Kritik mit einem Gleichnis: »So entsteht denn auch hier, wie in so vielen anderen philosophischen Debatten, das betrübliche Schauspiel, dass >der eine den Bock melkt, und der andere ein Sieb darunter hält< (Kant) « (Korsch 1922: 5). ${ }^{140}$ Sowohl die Auslegungen der »zentristischen Bockmelker« (Kautsky) als auch jene der »reformistischen Siebunterhalter« (Bernstein) würden darauf hinauslaufen, die Grundgedanken von Marx zu verfälschen (ebd.). ${ }^{141}$ Lukács und Korsch kritisieren darüber hinaus die Bestrebungen, das Prinzip der materialistischen Dialektik in eine »ökonomistische« oder »darwinistisch-biologistische Metaphysik« (ebd.) umzuwandeln. Die Notwendigkeit einer philosophischen Unterlegung des Marxismus wird also mit der Kritik an den in je unterschiedlichen Varianten praktizierten Verwissenschaftlichungen des Marxismus dieser Zeit begründet.

Einig sind sich Lukács und Korsch nicht nur über die Verflachung der materialistischen Dialektik in der zeitgenössischen Literatur, sondern auch darin, wie dieser Verflachung zu begegnen sei, nämlich durch eine Rückbesinnung auf die Methoden von Marx und Engels selbst: »Bei diesem Stand der Dinge«, schreibt Korsch, »bleibt der einzige Weg, wie man sich des wirklichen Sinnes des Marxschen >Materialismus< bemächtigen kann, eine Vertiefung in die Art und Weise, wie Marx und Engels ihr materialistisches

140 Dieses auf die Antike zurückgehende Bild verdeutlicht die lächerliche Szene, wie auf eine sinnlose Ausgangsfrage (einen Bock melken) eine sinnlose Antwort folgt (mit einem Sieb die Milch auffangen). Kant nimmt dieses Gleichnis in der Kritik der reinen Vernunft in Bezug auf die Frage >Was ist Wahrheit? $<$ auf.

141 Die Veröffentlichung von Marxismus und Philosophie fiel in eine Zeit, in der Korsch politisch äußerst aktiv gewesen ist. Dies widerspiegelt sich u.a. in den Auseinandersetzungen mit Karl Kautsky. Beide haben die politische Absicht des jeweils anderen scharf kritisiert (u.a. Kautsky 1924; Korsch 1971 [1929]). 
Prinzip in ihren Werken selber angewendet haben « (ebd.). ${ }^{142}$ Es müsse um die Anwendung des materialistischen Prinzips gehen, behauptet Korsch. In seinem Aufsatz Marxismus und Philosophie wendet er denn auch »das materialistischdialektische Prinzip Marxens auf die gesamte Geschichte des Marxismus « an (Korsch: 1966 [1923]: 97).143 Auch für Lukács gilt es, »das Wesen der Methode von Marx richtig zu verstehen und richtig anzuwenden, keineswegs aber sie in irgendeinem Sinne zu >verbessern « (Lukács 2013 [1923]:164). Auf die zu dieser Zeit breit diskutierte Frage, worin die Orthodoxie des Marxismus eigentlich bestehe, gibt Lukács folgende Antwort:

Orthodoxer Marxismus bedeutet also nicht ein kritikloses Anerkennen der Resultate von Marx' Forschung, bedeutet nicht einen »Glauben« an diese oder jene These, nicht die Auslegung eines »heiligen« Buches. Orthodoxie in Fragen des Marxismus bezieht sich vielmehr ausschließlich auf die Methode. Sie ist die wissenschaftliche Überzeugung, daß im dialektischen Marxismus die richtige Forschungsmethode gefunden wurde, daß diese Methode nur im Sinne ihrer Begründer ausgebaut, weitergeführt und vertieft werden kann. Daß aber alle Versuche, sie zu überwinden oder zu »verbessern « nur zur Verflachung, zur Trivialität, zum Eklektizismus geführt haben und dazu führen mußten. (ebd.: 171)

Lukács bezieht seine Rückbesinnung auf Marx also lediglich auf dessen Methode. Ágnes Heller, einst Assistentin von Lukács, fasst diesen Aspekt pointiert zusammen: »Die >dialektische< Methode [...], das ist die Totalität, das Ganze, das Wahre« (Heller 2015: 14). Wie im nächsten Abschnitt deutlich wird, eröffnet Lukács' und Korschs Argumentationsstrategie, aus Marx' Theoriegebäude lediglich dessen materialistisch-dialektische Methode gelten zu lassen, weitreichende und neue Perspektiven auf die Philosophie selbst. Die in den Kapiteln zu Husserl und zum Wiener Kreis herausgearbeitete Strategie, philosophische Erneuerung durch philosophische Methoden zu legitimieren, begegnet hier erneut: Durch ihre Anwendung der materialistischen Dialektik auf den Marxismus (Korsch) und die Philosophie (Lukács) wird gleichzeitig die marxistische Philosophie aktualisiert. ${ }^{144}$

142 In seinem Text Kernpunkte der materialistischen Geschichtsauffassung >materialisiert< Korsch diesen Anspruch gewissermaßen, indem er nach einem 18-seitigen Einleitungsteil lediglich Originalzitate hauptsächlich von Marx und Engels auflistet.

143 Mit seinem Vorgehen sucht Korsch Antworten auf die >Krise des Marxismus«. Korsch und auch Lukács fassen diese Krise - sie drückt sich für sie vor allem im Scheitern der Zweiten Internationale aus - somit als ein Produkt historischer Entwicklungen auf.

144 Die Analogie zu den anderen beiden Kapiteln ist augenscheinlich: Offensichtlich ist die Entwicklung und/oder Vertiefung bestimmter Methoden ein für philosophische Erneuerungspraktiken wesentliches Element: Wo Husserl auf die Phänomenologie und 


\section{Argumentativer Rückgriff auf die Soziologie}

Weder Lukács noch Korsch streben - selbstredend - eine Interpretation oder Erweiterung des marxistischen Theoriegebäudes an, so wie sie es den »zentristischen « wie »reformistischen « »Marx-Apologeten « unterstellen, sondern sie unterziehen den Marxismus (vor allem Korsch) und die Philosophie (vor allem Lukács) einer materialistisch-dialektischen Analyse.

Lukács' Analysen über die >Antinomien des bürgerlichen Denkens` im Aufsatz »Die Verdinglichung und das Bewusstsein des Proletariats « gehören mutmaßlich zu seinen für die Philosophie einflussreichsten Textstellen. Er tritt hier mit dem Vorhaben auf, die Widersprüche der modernen idealistischen Philosophie aus den gesellschaftlichen Verhältnissen heraus zu erklären, indem er die materialistische Dialektik auf die Philosophie selbst anwendet. Die Widersprüche der idealistischen Philosophie, so Lukács, seien keineswegs der »Unfähigkeit der Philosophen« geschuldet, sondern sie seien »die logischmethodologische Formulierung des modernen Gesellschaftszustandes« (Lukács 2013 [1923]: 307).

Lukács beginnt seine Analyse der modernen idealistischen Philosophie mit der »Kopernikanischen Wendung « (ebd.: 287). Mit diesem Ausdruck habe Immanuel Kant klar ausgesprochen, dass die moderne Philosophie die Welt nicht mehr »als ein unabhängig vom erkennenden Subjekt entstandenes (z.B. von Gott geschaffenes) Etwas « hinnehme, sondern »sie vielmehr als eigenes Produkt « begreife (ebd.: 287-288). Die ganze moderne Philosophie von Descartes über Hobbes, Spinoza und Leibniz habe sich dieses Problem gestellt, dass »der Gegenstand der Erkenntnis deshalb und insofern von uns erkannt werden kann, weil und inwiefern er von uns selbst erzeugt worden ist « (ebd.: 288). Dieses Motiv, das die gesamte idealistische Philosophie durchziehe, hat jedoch gemäß Lukács einen blinden Fleck: Es setzt die formell-mathematische, rationale Erkenntnis mit Erkenntnis überhaupt gleich. »Die Frage, warum und mit welchem Rechte der menschliche Verstand gerade solche Systeme der Formen als sein eigenes Wesen (im Gegensatz zum >gegebenen<, fremden, unerkennbaren Charakter der Inhalte dieser Formen) auffasst, taucht nicht auf « (ebd.).

Lukács bezeichnet diese Gleichsetzung von rationaler Erkenntnis mit Erkenntnis überhaupt als naiv und dogmatisch. »Und wenn wir die Frage so stellen, so erscheint die (selbst bei den >kritischsten< Philosophen) naive und dogmatische Gleichstellung von formell-mathematischer, rationaler Erkenntnis

der Wiener Kreis auf die Logik als die einzig richtige Methode für die Philosophie >pocht<, pochen Lukács und Korsch (und in veränderter Form auch Horkheimer und Adorno) auf die Dialektik als richtige philosophische Methode. 
einerseits mit Erkenntnis überhaupt, andererseits mit >unserer Erkenntnis als das charakteristischste Kennzeichen dieser ganzen Epoche« (ebd.: 289). Die gesamte moderne Philosophie erkenne nicht, dass es Rationalismus zwar in jeder historischen Epoche gebe, esjedoch darauf ankäme, »auf welches Material dieser Rationalismus bezogen wird und welche Rolle ihm im Gesamtsystem der menschlichen Erkenntnisse und Zielsetzungen zugemutet wird« (ebd.: 29o, Herv.i.O). Bisher sei jeder Rationalismus stets nur ein »Teilsystem « gewesen. Heute jedoch trete er von den Philosophen unbemerkt als das herrschende Erkenntnisprinzip auf. »Das Neue im modernen Rationalismus bestehe darin, daß er - im Laufe der Entwicklung in steigendem Maße - mit dem Anspruch auftritt, das Prinzip des Zusammenhanges sämtlicher Phänomene, die sich dem Leben des Menschen in Natur und Gesellschaft gegenüberstellen, entdeckt zu haben « (ebd.). Kurz: Die klassische Philosophie habe den Rationalismus »zu einem überhistorischen Prinzip im Wesen des menschlichen Denkens« gemacht. ${ }^{145}$ Ein Schlüsselbegriff in Lukács' Kritik an der Philosophie - so wird deutlich - ist der Begriff der Rationalisierung.

Dass Lukács seine zentralen Thesen in seinem Verdinglichungsaufsatz im Rückgriff auf die Soziologie Max Webers vorbringt, ist in unzähligen Publikationen dargestellt (z.B. Fetscher 1973; Beiersdörfer 1986; Fechner 2012). An dieser Stelle kommt es lediglich darauf an, hervorzuheben, dass Webers Theoreme für Lukács Argumente konstitutiv sind. Lukács nutzt Webers Rationalisierungstheorie nicht lediglich als Untermauerung seiner Thesen, sondern sie ist ein konstitutives theoretisches Element für seine eigene Theorie. Philosophische, marxistische und soziologische Perspektiven werden von ihm inhärent miteinander verknüpft. Er nimmt also zeitgenössische soziologische Wissensperspektiven konstruktiv auf, um marxistische Denkformen zu aktualisieren. Kurt Beiersdörfer, der in den 198oer-Jahren die Beziehung zwischen Lukács und Weber untersucht hat, untermauert diesen Aspekt, wenn er schreibt: »Indem Lukács die positiven Resultate von Webers soziologischer Marx-Kritik zu integrieren versucht, entwickelt er eine gesellschaftstheoretische Auffassung, die - trotz aller ostentativ vorgetragenen Marx-Orthodoxie - eine qualitativ neue Variante des Marxismus darstellt« (Beiersdörfer 1986: 166). Erst mit dem Rückgriff auf philosophieexterne Theoreme gelingt es Lukács, theoretisch-methodische Instrumentarien zu entwickeln, mit denen der Marxismus philosophisch aktualisiert werden

145 Am klarsten trete diese Problematik in der Bedeutung, die der Begriff des $>$ Dinges an sich bei Kant habe, zutage (Lukács 2013 [1923]: 291). 
kann. ${ }^{146}$ Das Konzept der Gesellschaft nimmt innerhalb dieser Aktualisierung eine Schlüsselrolle ein.

\section{Das Problem: Verdinglichte Gesellschaft als Totalität ${ }^{147}$}

»Die Kategorie der Totalität, die allseitige, bestimmende Herrschaft des Ganzen über die Teile ist das Wesen der Methode, die Marx von Hegel übernommen und originell zur Grundlage einer ganz neuen Wissenschaft umgestaltet hat« (Lukács 2013 [1923]: 199). ${ }^{148}$ Die Totalität ist für Lukács die Gesellschaft. »Die dialektische Methode bei Marx geht auf die Erkenntnis der Gesellschaft als Totalität aus « (ebd.: 199-200). Die Gesellschaft erscheint bei Lukács als eine übergeordnete Einheit, als eine Kategorie, die - in ihren Gesamtzusammenhängen - potenziell analysiert werden kann. Diese Einheit wiederum ist gemäß Lukács verdinglicht, d.h., sie wird von der bürgerlichkapitalistischen Warenstruktur hervorgebracht und bestimmt. Kapitalistische Gesellschaftsstrukturen durchdringen nicht nur die ökonomischen Verhältnisse, in denen Menschen leben, sondern zugleich alle Formen von Subjektivität und theoretischer Wissensproduktion. »Lukács versuchte so [durch die Thematisierung der Warenanalyse und der in ihr formulierten Einheit von Gesellschafts- und Erkenntniskritik, MD] die scheinbar voneinander getrennten subjektiven und objektiven Momente der kapitalen Vergesellschaftung als unterschiedliche Ausdrücke der kapitalistischen Totalität zu kritisieren « (Fechner 2012: 225). Mit anderen Worten, das Bewusstsein der Menschen ist ebenso verdinglicht wie die gesellschaftlichen Warenverhältnisse. Im Unterschied zu den anderen beiden Fallbeispielen vorliegender Arbeit wird hier die Vorstellung eines >reinen<, von anderen Faktoren unabhängigen Bewusstseins verabschiedet. Die Philosophie wird als Ausdruck

146 Wie weiter unten deutlich werden wird, setzen sich Horkheimer und Adorno im Unterschied zu Lukács weniger inhaltlich mit zeitgenössischen soziologischen Konzepten auseinander, als dass sie die Soziologie in generalisierender Weise als eine produktive Wissenschaft verstehen, mit der es sich zu verbinden gilt.

147 Die Zitate in diesem Abschnitt stammen entweder aus Lukács' Aufsatz »Rosa Luxemburg als Marxist« oder aus »Die Verdinglichung und das Bewußtsein des Proletariats«, seinem wohl berühmtesten Aufsatz aus Geschichte und Klassenbewußtsein.

148 Es wird vielerorts betont, dass es ein Verdienst von Geschichte und Klassenbewußtsein gewesen sei, den (Hegel'schen) Begriff der Totalität wieder in die Diskussionen eines kritischen Marxismus eingeführt zu haben (z.B. Müller/Rhein 2005: 219). Auch Lukács selbst betont diesen Aspekt 1967 in seinem Vorwort zur Neuauflage seines Buches: »Es ist sicher ein großes Verdienst von >Geschichte und Klassenbewußtsein<, dass es der Kategorie der Totalität, die die >Wissenschaftlichkeit $<$ des sozialdemokratischen Opportunismus ganz in Vergessenheit drängte, wieder jene methodologische Zentralstelle zuwies, die sie in den Werken von Marx immer hatte« (Lukács 1967: 22). 
einer tiefer liegenden Struktur verstanden. »Aus der verdinglichten Struktur des Bewusstseins ist die moderne kritische Philosophie entstanden « (Lukács 2013 [1923]: 287). Es wird klar, worin Lukács' zentrale Argumentationsstrategie besteht: Er argumentiert für die Annahme einer Struktur, die grundlegender ist als die Philosophie. Diese Struktur ist die kapitalistische Warenstruktur bzw. die gesellschaftliche Struktur. Umgekehrt versteht er die Philosophie nach Marx' Theorem, wonach das Sein das Bewusstsein bestimme und nicht umgekehrt - als Ausdruck der gesellschaftlichen Totalität.

Die Konsequenzen, die Lukács aus dieser Einsicht zieht, ergeben eine scheinbar ausweglose Situation, die an Seidels verhängnisvollen Zirkel erinnert: Die durchrationalisierten, auf kapitalistische Nutzenmaximierung ausgerichteten gesellschaftlichen Verhältnisse erscheinen den einzelnen Menschen als eine Art »zweiter Natur « ${ }^{149}$ Lukács verbindet hier Hegels Überlegungen zum Verhältnis zwischen Natur und Geist mit Marx' Überlegungen zu einer Kritik an der politischen Ökonomie, d.h., er verwendet den Begriff der »zweiten Natur « im Zusammenhang mit seiner Kritik an einer entfremdeten und verdinglichten Welt. Der Ablauf der »selbsterschaffenen, >selbsterzeugten< Wirklichkeit« trete den Menschen »mit derselben unerbittlichen Gesetzmäßigkeit« entgegen, »wie es früher die irrationellen Naturmächte (pünktlicher: die in dieser Form erscheinenden gesellschaftlichen Verhältnisse) getan haben « (ebd.: 307). Menschen seien also gleichsam in ihrer »zweiten Natur« gefangen, gesellschaftlichen Abläufen scheinbar machtlos ausgeliefert. ${ }^{150}$ So wie die Philosophie nur ein Ausdruck gesellschaftlicher Verhältnisse ist, ist es auch der einzelne Mensch bzw. sein Bewusstsein. Wie, so fragt sich dann aber, lässt sich der verhängnisvollen kapitalistischen Gesellschaftsentwicklung entgehen, wenn die einzelnen Menschen diesen Vorgängen blind ausgeliefert sind? Wie >löst` Lukács das für Seidel unausweichlich scheinende Problem, nämlich

149 Der Ausdruck der »zweiten Natur« hat als Folge des Buches Mind and World von John McDowell (1994) ein Revival erfahren. »Die daran anschließende Diskussion hat zudem dazu beigetragen, das Interesse in Richtung einer Aktualisierung der Hegelschen Konzeption zu lenken« (Ranchio 2016: 27).

150 Stefan Müller und Johannes Rhein fassen die Situation etwa wie folgt zusammen: Die gesellschaftliche Totalität, die doch nur historisches Produkt der Menschen sein kann, steht den zum bloßen Anhängsel degradierten Menschen, die als Vereinzelte über dieses ihr Produkt keine Verfügung haben, als »zweite Natur« gegenüber. In dieser Verkehrung produziert jenes Produkt sogar alle Formen von Subjektivität, in der die Menschen zu leben und jene Verhältnisse zu reproduzieren gezwungen sind. Gesellschaft als Totalität heißt auch: Kein einziges ihrer Momente kann unmittelbar herausgelöst und zum erkenntnisleitenden oder gar emanzipatorischen Prinzip erklärt werden. Sie bleiben stets verdinglichte, isolierte Momente, die unmöglich das ihnen gegenüber verselbständigte Ganze ergreifen können (Müller/Rhein 2005: 219-220). 
dass der menschliche Geist durchgängig von gesellschaftlichen Strukturen bestimmt ist?

Anders, als es möglicherweise zu erwarten wäre, ist es für Lukács keineswegs die Philosophie, der das Vermögen zukommt, dem verhängnisvollen Zirkel gesellschaftlicher Totalität zu entgehen. Im Gegenteil: »Die kapitalistische Trennung des Produzenten vom Gesamtprozeß der Produktion, die Zerstückelung des Arbeitsprozesses in Teile, die die menschliche Eigenart des Arbeiters unberücksichtigt lassen, die Atomisierung der Gesellschaft in planlos und zusammenhanglos drauflosproduzierende Individuen usw. mußte auch das Denken, die Wissenschaft und Philosophie des Kapitalismus tiefgehend beeinflussen« (ebd.: 307). Der Philosophie, als ein Zweig der bürgerlichen Wissenschaft, sei es strukturell verwehrt, die gesellschaftliche Totalität erfassen zu können. Im Zuge der Herausbildung der bürgerlich-kapitalistischen Gesellschaft habe sie sich zwar insofern spezialisiert, dass sie »die Einzelheiten ihres gesellschaftlichen Daseins im steigenden Maße beherrscht«, gleichzeitig aber habe sie »die Möglichkeit zur gedanklichen Bewältigung der Gesellschaft als Totalität und damit die Berufung zu ihrer Führung [...] « verloren (ebd.: 299). Kurz: In der kapitalistischen Gesellschaft habe die bürgerliche Philosophie den Blick auf das »Ganze« und damit ihre Berufung - die »Führung« - verloren.

\section{Die Lösung: Klassenrevolution}

»Lukács' politisches Denken während der Weimarer Republik«, schreibt Michael Festl, »besteht aus zwei Teilen: einer soziologischen Analyse der Verdinglichung und einer philosophischen Entschlüsselung des geschichtlichen Geschehens [...] « (Festl 2019: 62). Beide Teile dürften, so Festl, keinesfalls als voneinander getrennt betrachtet werden. Die beiden Teile - soziologische Analyse und geschichtsphilosophische Prämissen - kulminieren gewissermaßen im Ausweg, den Lukács aus der verhängnisvollen Situation gesellschaftlicher Verdinglichung vorschlägt: im Aufstand der Arbeiterklasse. Diese Lösung ist gleichzeitig der - auch von Lukács selbst ${ }^{151}$ - am vehementesten kritisierte Aspekt seiner Theorie. »Ist die endgültige Wirtschaftskrise des Kapitalismus eingetreten, so hängt das Schicksal der Revolution (und damit der Menschheit) von der ideologischen Reife des Proletariats, von seinem Klassenbewußtsein

$15^{1}$ Im Vorwort zur Neuauflage von Geschichte und Klassenbewußtsein (1967) nimmt Lukács diese »letzte philosophische Grundlage« eines im »Geschichtsprozess sich realisierenden identischen Subjekt-Objekt[s] « zurück (Lukács 1967: 24-25). In Bezug auf die Wirkungsgeschichte seines Buches sagt er: »Leider weiß ich, daß aus Gründen der gesellschaftlichen Entwicklung und der von ihr produzierten theoretischen Einstellungen, das, was ich heute als theoretisch falsch ansehe, oft zu den wirksamsten und einflussreichsten Momenten der Wirkung gehört« (ebd.: 29). 
ab« (Lukács 2013 [1923]: 245). Das Bewusstsein der Arbeiterklasse über ihre gesellschaftliche Lage sei also die Bedingung sowohl für eine gesellschaftliche Revolution als auch für eine Veränderung der Philosophie. Bei Lukács ist, wie Willem van Reijen schreibt, das gesellschaftliche Bewusstsein des Proletariats mit der materialistischen Theorie der Gesellschaft tendenziell identisch. »Idealistisch überhöht bedeutet das, daß die Identität von Klassenbewusstsein und Theorie die notwendige und hinreichende Bedingung ist für die Änderung der gesellschaftlichen Ordnung « (van Reijen 1984: 30). In Bezugnahme auf Hegel konzipiert Lukács eine Theorie, in der das Proletariat ein Klassenbewusstsein entwickelt und so eine Stufe des historischen Prozesses das Identisch-Werden von Subjekt und Objekt - verwirklicht. ${ }^{152}$

Die Philosophie nimmt innerhalb dieser geschichtsteleologischen Konzeption eine doppelseitige Rolle ein: Auf der einen Seite bedeutet die Engführung von Philosophie und Klassenrevolution, die Philosophie als einen Bereich vorzustellen, an und in dem gesellschaftliche Veränderung stattfindet. ${ }^{153}$ Ideologien und insbesondere die Philosophie werden nicht lediglich als ein Reflex sozialer Verhältnisse vorgestellt, sondern als »konstitutive[] Momente der menschlichen Welt « (Vranicki 1974 [1961/1971]: 515). ${ }^{154}$ Gerade weil die Philosophie (bzw. Theorie) beides ist, sowohl Produzentin als auch Produkt gesellschaftlicher Prozesse, wird sie als eine Praxis begriffen. Die Philosophie bilde also keine sewigen Korsch die bürgerliche Philosophie suggeriere -, sondern vielmehr sei sie ein aktives und konstituierendes Element gesellschaftlicher Verhältnisse. Auf der anderen Seite wird die Philosophie als ein Hemmnis für die Klassenrevolution dargestellt: Als ideologischer Überbau der bürgerlichen Ordnung erschwert oder verhindert sie sogar die Entwicklung des proletarischen Bewusstseins.

Besonders deutlich wird dieser Aspekt in einer Textpassage aus Korschs Text Kernpunkte der materialistischen Geschichtsauffassung: Die bürgerliche Philosophie sei von der Vorstellung »besessen «, dass es »irgendwelche >ewigen<, unvergänglichen und unwandelbare Wahrheiten >an sichく [gäbe], nach denen

$15^{2}$ Wie weiter unten deutlich wird, ist die Kritik an jeglichem Totalitätsdenken eine zentrale Argumentationspraktik der Kritischen Theorie.

153 »Der Klassenkampf kann sich also nicht auf die ökonomische und politische Aktion beschränken, sondern muss als notwendigen Bestandteil des revolutionären Gesamtprozesses auch die >geistige Aktion< umfassen, die Korsch als revolutionäre wissenschaftliche Kritik und agitatorische Arbeit versteht« (Buckmiller 1973: 47).

154 Wie Predrag Vranicki betont, liegt in diesem Aspekt eine Gemeinsamkeit von Korsch und Lukács. Sie kritisieren die in der Periode der Zweiten Internationale sehr verbreiteten »vulgär-marxistischen Konzeptionen, nach denen die Ideologie und insbesondere die Philosophie nur ein Reflex der sozialen Verhältnisse, ja Schein oder gar bloße gedankliche, gegenstandslose Spekulation seien (Vranicki 1974 [1961/1971]: 515). 
die Wissenschaft und die Philosophie zu suchen hätten, bis sie sie endlich fänden und nun in hinfort nicht mehr veränderlicher Weise besäßen« (Korsch 1922: 20). Eine solche Vorstellung sei »ein Traum, und nicht einmal ein schöner, denn eine unwandelbare, unveränderliche Idee wäre natürlich zugleich eine nicht mehr entwicklungsfähige Idee« (ebd.). Für dergleichen könne sich »natürlich nur eine saturierte Klasse begeistern, die sich in dem gegenwärtigen Zustande wohl und bestätigt fühlt« (ebd.). Niemals aber tauge es »für eine vorwärtstreibende und drängend, in dem gegenwärtig erreichten Zustand also notwendig unbefriedigte Klasse« (ebd.). Nur verwöhnte Wohlstandsbürger, so Korsch, seien daran interessiert, die Idee ewiger Wahrheiten aufrechtzuerhalten. Ohne gesellschaftlichen Umbruch, so die Implikation, könne sich die Philosophie ihrer »Besessenheit « von dieser Idee nicht bewusst werden. Kritik an der (bürgerlichen) Philosophie lässt sich also lediglich ausgehend vom Standpunkt der Arbeiterklasse üben. Dafür wiederum sei eine Veränderung der materiellen Bedingungen in Form einer Revolution zwingend: »Diese gesellschaftlichen Bewußtseinsformen können vielmehr auch im Denken, auch im Bewußtsein nur aufgehoben werden unter gleichzeitiger praktisch-gegenständlicher Umwälzung der in diesen Formen bisher begriffenen materiellen Produktionsverhältnisse selbst « (Korsch 1966 [1923]: 132). In der gesellschaftlichen Revolution besteht gleichzeitig die Möglichkeit einer Veränderung der Philosophie. Das heißt, dem >Verhängnis des Bewusstseins< lässt sich in Lukács' und Korschs Perspektive im Gegensatz zu Seidels Perspektivlosigkeit durchaus entgehen: durch die Veränderung der Gesellschaft. Mit Argumenten aus der marxistischen Tradition, so folgt daraus, formulieren Lukács und Korsch Möglichkeiten, wie der in Seidels Darstellung verhängnisvollen Soziologisierung des Geistes philosophisch zu entkommen ist. Die Lösung, die aus Lukács' und Korschs Überlegungen folgt, kulminiert in der gesellschaftlichen Revolution und damit zusammenhängend in der Figur der Aufhebung der Philosophie.

\section{Aufhebung der Philosophie: Durchdringung von Theorie und Praxis}

In seiner historischen Analyse des Marxismus stellt Korsch fest, dass in der Folge von Marx und Engels - also in der zweiten Hälfte des 19. Jahrhunderts - sowohl die bürgerliche als auch die marxistische Wissenschaft eine Abkoppelung des Marxismus von der Philosophie betrieben habe: »Die bürgerlichen Philosophieprofessoren versicherten sich gegenseitig, daß der Marxismus einen eigenen philosophischen Gehalt nicht besäße - und glaubten damit etwas Großes gegen ihn gesagt zu haben. Die orthodoxen Marxisten ihrerseits versicherten sich ebenfalls gegenseitig, daß ihr Marxismus seinem Wesen nach mit der Philosophie nichts zu tun habe - und glaubten damit etwas Großes für 
ihn zu sagen« (ebd.: 76). Diese Entkoppelung von Marxismus und Philosophie ist in Korschs Perspektive falsch. ${ }^{155}$ Falsch wäre es aber auch, an die Stelle der alten Philosophie schlicht eine neue - marxistische - setzen zu wollen. Marx und Engels, so Korsch mit seinem üblichen Rückbezug auf die >Gründerväter des Marxismus, seien »weit davon entfernt gewesen [...], eine neue Philosophie aufstellen zu wollen« (ebd.: 89). In Kernpunkte der materialistischen Geschichtsauffassung schreibt er: »Ganz falsch sind alle jene Vorstellungen der bürgerlichen und halbsozialistischen Gelehrsamkeit, die davon ausgehen, dass der Marxismus an die Stelle der bisherigen (bürgerlichen) Philosophie eine neue $>$ Philosophie< [...] setzen wollte. Karl Marx setzt sich stattdessen als Ziel die $>$ Kritikく der bürgerlichen Philosophie [...] (Korsch 1922: 8). Die Schwierigkeit, die aus diesem gleichsam negativen Verhältnis resultiert, beschreibt Korsch wie folgt:

Die eigentümliche und das richtige Verständnis des Problems Marxismus und Philosophie außerordentlich erschwerende Situation besteht nun aber darin, daß es so scheint, als ob gerade durch dieses Überschreiten der Grenzen des bürgerlichen Standpunktes, durch welches der wesentlich neue Inhalt der Philosophie des Marxismus grundsätzlich überhaupt erst ein begreiflicher Gegenstand wird, dieser Gegenstand als ein philosophischer zugleich aufgehoben und vernichtet würde. (Korsch 1966 [1923]: 89)

Aus der Überschreitung des bürgerlichen Standpunkts folge also zwingend die Auflösung und Vernichtung der Philosophie - auch derjenigen des Marxismus. Diese Gedankenfigur, so argumentiert Korsch weiter, sei ein Kernpunkt von Marx' und Engels Schriften und - entgegen der Ansicht vieler zeitgenössischer Interpreten - ernst zu nehmen. »Wir müssen [...] unbedingt davon ausgehen, daß nach den unmißverständlichen eigenen Worten von Marx und Engels nicht nur die Aufhebung der bürgerlichen Idealphilosophie, sondern damit zugleich auch die Aufhebung der Philosophie, d.h. aller Philosophie, als eine notwendige Konsequenz ihres neuen materialistisch-dialektischen Standpunkts erscheint« (ebd.: 91).

Völlig verkehrt wäre es nun aber gemäß Korsch, sich diese Aufhebung als eine Ersetzung der Philosophie durch die positiven Wissenschaften vorzustellen: Man bewundere »den Scharfsinn derjenigen neueren Marxisten, die [...] sich unter der Marx-Engelsschen Aufhebung der Philosophie eine Ersetzung dieser Philosophie durch ein System abstrakter und undialektischer positiver

155 Die Ursache dieser laut Korsch »oberflächlichen und unvollständigen Erfassung des [...] Sachverhalts« liege darin, dass in der zweiten Hälfte des 19. Jahrhunderts »jene >dialektische< Betrachtung des Verhältnisses von Philosophie und Wirklichkeit, Theorie und Praxis gänzlich verlorengegangen sei« (Korsch 1966 [1923]: 77-78). 
Wissenschaften vorgestellt haben« (ebd.: 109). Vermutlich zielt Korsch mit dieser Aussage auf Autoren und Autorinnen, die später u.a. als Wiener Kreis bzw. Berliner Gruppe bekannt werden sollten. Mit der Aufhebung der Philosophie meint er also etwas gänzlich anderes, als dass die Philosophie in naturwissenschaftliche oder ökonomische Modelle aufgehoben werden müsse, wie er es positivistischen Ansätzen unterstellt.. ${ }^{156}$ Er denkt ausgehend von der Praxis: Da die Philosophie und die Wissenschaften der Ausdruck der materiellen Verhältnisse sind, lösen sie sich zwingend auf, wenn sich die gesellschaftlichen Verhältnisse verändern:

Der wirkliche Gegensatz zwischen dem wissenschaftlichen Sozialismus Marxens und allen bürgerlichen Philosophien und Wissenschaften beruht vielmehr allein darauf, daß dieser wissenschaftliche Sozialismus der theoretische Ausdruck eines revolutionären Prozesses ist, der mit der völligen Aufhebung dieser bürgerlichen Philosophen und Wissenschaften, zugleich mit der Aufhebung derjenigen materiellen Verhältnisse, die in diesen Philosophien und Wissenschaften ihren ideologischen Ausdruck gefunden hatten, endigen wird. (Korsch 1923: 109)

Korsch wendet sich also vehement gegen die Vorstellung, wonach im Marxismus eine neue Philosophie enthalten sei. Im Gegenteil verteidigt und aktualisiert er die marxistisch-philosophische Gedankenfigur der Aufhebung der Philosophie durch die Praxis. Dem von Seidel konstatierten >Verhängnis des Bewusstseins< lasse sich - so die Implikation - entkommen, weil sich Praxis und Theorie gegenseitig durchdrängen. Die Praxis berge das Potenzial, Philosophie verändern zu können. Durch die Hintertüre der Praxis unterminieren Lukács und Korsch also gewissermaßen die für die Philosophie potenzielle Bedrohung, nämlich dass der menschliche Geist lediglich ein Ausdruck gesellschaftlicher Strukturen sei. Durch und in der Praxis lässt sich das Bewusstsein verändern. Der Philosophie wird dadurch ex negativo Handlungsfähigkeit zugesprochen.

Lukács und Korsch verstehen und analysieren die Philosophie, so kann zusammenfassend festgehalten werden, ausgehend von den materiellgesellschaftlichen Verhältnissen. Philosophie und Gesellschaft durchdringen einander wechselseitig, wobei der Praxis (Gesellschaft) ein klarer Vorrang vor

${ }_{156}$ Korschs Kritik zielt somit implizit auf die Idee der »Einheitswissenschaft«, die im Kapitel zum Wiener Kreis thematisiert worden ist. Auch hier spielte die Figur der Auflösung der Philosophie eine Rolle: Vor allem Otto Neurath sei Zeit seines Lebens von der Auflösung der Philosophie als einer autonomen Disziplin in ein umfassendes empiristisches Konzept des Enzyklopädismus überzeugt gewesen (Stadler 1997: 584). Gegen diese Weise der Auflösung der Philosophie schreibt Korsch an. 
der Theorie (Philosophie) eingeräumt wird. Diese zentrale Gedankenfigur wird von Adorno und Horkheimer - so soll im Folgenden gezeigt werden - aufgenommen und neu arrangiert: Die Erfahrung, dass die reale Verwirklichung der Philosophie in der Praxis gescheitert ist, ist für Horkheimer und Adorno die Basis, von der ausgehend sie das Verhältnis zwischen Theorie und Praxis, wie es von Lukács und Korsch gedacht wird, argumentativ letztlich umkehren. Wo die Philosophie in Lukács' und Korschs Perspektive ein Problem der bürgerlich-kapitalistischen Gesellschaft ist, wird die bürgerlich-kapitalistische Gesellschaft in Adornos und Horkheimers Perspektive zum Problem für die Philosophie.

\subsection{Die Gesellschaft als Problem der Philosophie (Adorno und Horkheimer)}

Horkheimer und Adorno gelten nebst Herbert Marcuse als Begründer der Kritischen Theorie. ${ }^{157}$ Mit ihnen wird im Folgenden ähnlich verfahren wie mit Lukács und Korsch: Die Unterschiede beider Autoren werden zwar an einzelnen Stellen angesprochen, sie stehen aber nicht im Zentrum der Analysen. Fokussiert werden vielmehr ihnen gemeinsame Argumentationsstrategien. Als Textgrundlagen ausgewählt wurden Texte, in denen Horkheimer und Adorno ihr philosophisches Programm explizit präsentieren: Horkheimers Antrittsrede als neuer Direktor des Instituts für Sozialforschung, die er $193^{1}$ unter dem Titel »Die gegenwärtige Lage der Sozialphilosophie und die Aufgaben des Instituts für Sozialforschung « an der Universität Frankfurt am Main gehalten hat, Adornos Antrittsvorlesung »Die Aktualität der Philosophie«, die er im selben Jahr an derselben Universität gehalten hat, Horkheimers 1940 veröffentlichter Aufsatz »Die gesellschaftliche Funktion der Philosophie« und schließlich Adornos 1962 veröffentlichter Aufsatz »Wozu noch Philosophie?«. Beide, Adorno und Horkheimer, haben im Verlaufe ihrer Karrieren unzählige Arbeiten veröffentlicht, die Auswahl der untersuchten Texte ist folglich auch hier notwendig auf für das Thema besonders repräsentative beschränkt. Mehr noch als in den anderen Kapiteln ließen sich die Zusammenhänge, die hier

157 Mit Clemens Albrecht, Günter C. Behrmann, Michael Bock und Harald Homann - den Autoren von Die intellektuelle Gründung der Bundesrepublik. Eine Wirkungsgeschichte der Frankfurter Schule (1999) - wird hier davon ausgegangen, dass die Kritische Theorie sich in den 196oer-Jahren mit Rückbezug auf die Texte der 193oer-Jahre konstituiert hat. »Was als Kritische Theorie in den 6oer Jahren verbreitet wurde, waren nicht die jüngsten Veröffentlichungen, sondern die kritische Theorie aus den zoer Jahren« (Albrecht et al. 1999: 560). 
interessieren, auch an anderen Texten, Büchern und Projekten aufzeigen, allen voran an den groß angelegten Studien über Autorität und Familie, die im Auftrag des Instituts für Sozialforschung 1936 publiziert worden sind, sowie am Forschungsprojekt The Authoritarian Personality, das an der University of California durchgeführt worden ist und 1950 publiziert wurde. Sie sollen an dieser Stelle zumindest kurz erwähnt werden: »Wenn wir die psychologischen Determinanten der Ideologien kennen «, so steht im Vorwort von The Authoritarian Personality, „wissen wir immer noch nicht, welches die wahre Ideologie ist; wir können nur ein paar Hindernisse aus dem Weg räumen, auf dem wir sie suchen « (Adorno 1995 [1950]: 15). Die Studie war »an der Hypothese orientiert, daß die politischen, wirtschaftlichen und gesellschaftlichen Überzeugungen eines Individuums häufig ein umfassendes und kohärentes, gleichsam durch eine >Mentalität oder einen >Geist` zusammengehaltenes Denkmuster bilden, und daß dieses Denkmuster Ausdruck verborgener Züge der individuellen Charakterstruktur ist « (ebd.: 1). Worum Seidel gerungen hat, nämlich das Bewusstsein zu objektivieren, wird hier gewissermaßen zum wissenschaftlichen Programm: Der Geist bzw. das Bewusstsein wird insofern zum Untersuchungsgegenstand, als dass er bzw. es als ein »Ausdruck « der politischen, wirtschaftlichen und gesellschaftlichen Überzeugungen verstanden und verhandelt wird. Im Vorwort zu Studien über Autorität und Familie schreibt Horkheimer:

Nicht bloß erfährt der Einzelne in ihrem Kreis [dem der Familie, MD] zuerst den Einfluss der kulturellen Lebensmächte, so dass seine Auffassung der geistigen Inhalte und ihre Rolle in seinem seelischen Leben wesentlich durch dieses Medium bestimmt ist, sondern die patriarchalische Struktur der Familie in der neueren Zeit wirkt selbst als entscheidende Vorbereitung auf die Autorität in der Gesellschaft, die der Einzelne im späteren Leben anerkennen soll. (Horkheimer 1936: VIII)

Die patriarchale Familie wird als Ort beschrieben, wo die »geistigen Inhalte « allererst bestimmt werden. Es gehöre, schreibt Horkheimer, schon seit mehreren Jahren »zu den Aufgaben des Instituts [für Sozialforschung, MD], den Zusammenhang zwischen den verschiedenen Bereichen der materiellen und geistigen Kultur zu erforschen " (Horkheimer 1936: VII-VIII). Dass diese Aufgaben politisch motiviert sind, wird vor allem im Vorwort von The Authoritarian Personality deutlich. »Im Mittelpunkt des Interesses stand das potentiell faschistische Individuum, ein Individuum, dessen Struktur es besonders empfänglich für antidemokratische Propaganda macht « (Adorno 1995 [1950]:1). Die Autoren der Studie sind der Meinung, »dass keine politischsoziale Strömung unsere traditionellen Werte und Institutionen so gravierend 
bedroht wie der Faschismus, und dass er, wenn die psychologischen Kräfte erkannt sind, die ihn begünstigen, schließlich besser zu bekämpfen ist« (ebd.). In diesen Sätzen ist die weiter oben erwähnte Diskrepanz angesprochen, die zwischen den Erneuerungsstrategien des Wiener Kreises und denjenigen der Kritischen Theorie liegt: Wissenschaftliche Forschung - und wie weiter unten deutlich wird: auch die Philosophie - wird hier explizit in den Dienst der Gesellschaft gestellt. In den vom Institut für Sozialforschung lancierten Studien wird mit psychologischen und soziologischen Mitteln die Bildung von Ideologien untersucht und dies mit dem Anspruch verbunden, diese Ideologien verändern und überwinden zu können.

Diese Programmatik wird in der Kritischen Theorie durch eine Kooperation mit den empirischen Sozialwissenschaften einerseits und durch eine Abgrenzung gegenüber der Wissenssoziologie andererseits verfolgt. Horkheimer und Adorno nehmen die an Lukács und Korsch aufgezeigte Gedankenfigur der gegenseitigen Durchdringung von Theorie und Praxis auf, um davon ausgehend ein traditionelles Philosophieverständnis zu aktualisieren: die Philosophie als Instanz der Kritik an der Gesellschaft.

\section{Positionierung in der philosophischen Tradition}

Als Horkheimer $193^{1}$ die Leitung des Instituts für Sozialforschung in Frankfurt am Main übernahm, trat er gleichzeitig den von der Philosophischen Fakultät neu geschaffenen Lehrstuhl für Sozialphilosophie an. ${ }^{158}$ Nach dem Gründungsdirektor des Instituts - dem Austromarxisten und Nationalökonomen Carl Grünberg - übernimmt also erstmals ein Lehrstuhlinhaber der Philosophie die Leitung des Instituts. Dass sich das Institut für Sozialforschung in der Folge zunehmend als eine philosophische Einrichtung verstehen wird, wird an Horkheimers programmatischer Antrittsrede deutlich. »Horkheimer als Philosoph (während Grünberg Historiker [sic!] gewesen war) setzte in seiner Antrittsrede neue Akzente im Sinne einer Verlagerung der Institutsarbeit von der Beschäftigung mit dem historischen Materialismus als >Wissenschaft< hin zur Entwicklung einer durch empirische Untersuchungen ergänzten >Sozialphilosophie« (Anderson 1978 [1976]:55). Wie der Titel besagt, stellt Horkheimer in dieser Rede - gemäß Rolf Wiggershaus ein »Meisterwerk bedächtiger Stilisierung« (Wiggershaus 1986:51) - die Aufgaben,

${ }_{15} 8$ Es handelte sich dabei in Deutschland um den einzigen Lehrstuhl für Sozialphilosophie (Wirkus 1996: 148). »Alle anderen Ordinariate wurden für Philosophie, Soziologie, Politische Soziologie, Nationalökonomie, Staatswissenschaften usw. ausgeschrieben« (ebd.). 
die das Institut für Sozialforschung zukünftig zu bewältigen habe, in einen unmittelbaren Zusammenhang mit der Sozialphilosophie.

Dass der Philosoph Horkheimer in den für das Institut bisher bestimmenden Disziplinen - Nationalökonomie und Soziologie - nicht ausgebildet war, brachte ihn, wie Michael Bock es ausdrückt und entlang einiger Passagen aus Horkheimers Antrittsvorlesung aufzeigt, »in nicht geringe Verlegenheit« (Bock 1999: 45). Bocks Beobachtung, »dass bei Horkheimer so gut wie keine Rezeption oder Auseinandersetzung mit der fachwissenschaftlichen Nationalökonomie und Soziologie der letzten hundert Jahre stattfindet« (ebd.: 43), wird auch von Helmut Dubiel bestätigt: »Mit der fachwissenschaftlichen Soziologie der Weimarer Republik im engeren Sinne waren offenbar weder Horkheimer noch andere Mitarbeiter seines Kreises besonders vertraut« (Dubiel 1978: 156). Dass die Soziologie von Horkheimer (und anderen Vertretern der Kritischen Theorie) kaum rezipiert worden ist, ${ }^{159}$ ist in der hier eingenommenen Perspektive bezeichnend: Es verweist darauf, dass Horkheimer zwar argumentativ auf die Soziologie zurückgreift, seine eigene Position aber nicht innerhalb der Soziologie verortet, sondern diese auf der Grundlage seiner eigenen Disziplin, d.h. auf der Grundlage philosophischer Prämissen, konzipiert. ${ }^{160}$

In Horkheimers Antrittsrede, so soll im Folgenden gezeigt werden, wird eine ambivalente Bewegung sichtbar: Auf der einen Seite positioniert er die Gesellschaftstheorie als neue Form der Philosophie, auf der anderen Seite wiederum

159 Insbesondere Bocks Ausführungen münden diesbezüglich in einer scharfen Kritik an Horkheimer: Es wirke befremdlich, so moniert Bock, »wenn Horkheimer sämtliche soziologische Richtungen ohne Skrupel der >traditionellen Theorie einordnet, indem er die bestehenden Unterschiede schlicht für irrelevant erklärt« (Bock 1999: 47). Horkheimers Gesellschaftstheorie »lebt mindestens teilweise von einer an die Grenze der Seriosität reichenden Missachtung der nationalökonomischen und soziologischen Diskussionslage« (ebd.: 55). Bock veranschaulicht an zwei Beispielen aus der zeitgenössischen Soziologie (Siegfried Landshut mit Kritik der Soziologie und Hans Freyer mit Soziologie als Wirklichkeitswissenschaft), inwiefern Horkheimers »eigenmächtiger Umgang mit der soziologischen Tradition« sich wirkungsgeschichtlich als vorteilhaft erweist: So gebe es »keine womöglich kompromittierenden Stellungnahmen zu den kongenialen MarxInterpreten Freyer und Landshut mit ihrer auf die Überwindung der Klassengesellschaft zielenden Soziologie« (ebd.: 54). Horkheimer, so könnte gefolgert werden, verortet sich also gerade aufgrund seiner Missachtung der soziologischen Literatur in der Philosophie.

16o In diesem Aspekt liegt für Bock »einer der Gründe für den geistigen Bruch mit der Gründungsära des Instituts für Sozialforschung« (Bock 1999: 44). 
grenzt er sich dezidiert von einer möglichen Aufhebung der Philosophie in die empirischen Sozialwissenschaften ab. ${ }^{161}$

\section{Zusammenschluss der Philosophie mit den empirischen Sozialwissenschaften}

An der zeitgenössischen Sozialphilosophie kritisiert Horkheimer, dass diese sich »polemisch zum Positivismus« verhalte. Die Philosophie - an dieser Stelle verwendet er bezeichnenderweise den allgemeineren Begriff Philosophie statt Sozialphilosophie - setze den »feststellbaren Tatsächlichkeiten [...] Ideen, Wesenheiten, Totalitäten, selbstständige Sphären des objektiven Geistes, Sinneinheiten, Volksgeister als ebenso ursprüngliche, ja als >echtere< Seinsbestände gegenüber« (Horkheimer 1931: 27). Die Sozialphilosophie bzw. die Philosophie setze sich also von empirischen Tatsachen ab, indem sie einen davon gesonderten Bereich behaupte. Genau darin liege deren »Mangel «- und dieser Mangel müsse überwunden werden (ebd.: 27). Es geht Horkheimer also um die Einbeziehung empirischer Forschung in die Philosophie. Dadurch, so die Implikation, könne die philosophische Tradition erweitert und >verbessert< werden. Dem möglichen Einwand, dass doch die einzelwissenschaftliche Soziologie und nicht die Philosophie mit der »Untersuchung der bestimmten Formen der Vergesellschaftung zu tun habe« (ebd.: 28), begegnet Horkheimer mit dem Argument, dass dieser Ansicht »ein nicht mehr haltbarer Begriff der Philosophie« (ebd.) zugrunde liege:

Wie man auch die Grenzen zwischen einzelwissenschaftlicher Fachsoziologie und Sozialphilosophie ziehen mag, ich glaube, ein großes Maß an Willkür wäre dabei unvermeidlich, eines ist gewiss: wenn das sozialphilosophische Denken über das Verhältnis von Individuum und Gesellschaft, über den Sinn von Kultur, über den Grund der Gemeinschaftsbildung, über die Gesamtstruktur des gesellschaftlichen Lebens, kurz über die großen und prinzipiellen Fragen gleichsam als Bodensatz in dem Reservoir der gesellschaftlichen Probleme zurückgeblieben sein sollte, nachdem diejenigen Fragen ausgeschüttet worden sind, die man in konkreten Untersuchungen vorwärtsbringen kann, z.B. eben die der Verklärung, um ihre intellektuelle Fruchtbarkeit aber wäre es geschehen. (ebd.: 28, Herv. MD)

Horkheimers Argumentation ist bezüglich der darin angewandten Aktualisierungsstrategien äußerst aufschlussreich: Mit dem Argument, die Philosophie würde ihre »intellektuelle Fruchtbarkeit« verlieren, wenn sie lediglich

161 In der hier eingenommenen Perspektive ist es also keineswegs so, dass es Horkheimer schlicht um die »Aufhebung der Philosophie in die Gesellschaftstheorie« ging, wie Jürgen Habermas schreibt (Habermas 1986: 164). 
als »Bodensatz« der empirischen Forschung fungieren würde, plädiert er für eine konstitutive Verbindung zwischen den empirischen Sozialwissenschaften und der Philosophie. Die unhaltbare Trennung zwischen »Einzelforscher« und »Philosoph« werde gegenwärtig »durch den Gedanken einer fortwährenden Durchdringung und Entwicklung von philosophischer Theorie und einzelwissenschaftlicher Praxis überwunden «. ${ }^{162}$ In der Folge stellt Horkheimer die Interdisziplinarität als jene neue Form dar, mit der der Mangel der Philosophie zu beheben sei:

Vielmehr kommt es heute darauf an, und ich stehe mit dieser Ansicht gewiß nicht allein, auf Grund aktueller philosophischer Fragestellungen Untersuchungen zu organisieren, zu denen Philosophen, Soziologien, Nationalökonomen, Historiker, Psychologen in dauernder Arbeitsgemeinschaft sich vereinigen und das gemeinsam tun, was auf anderen Gebieten im Laboratorium einer allein tun kann, was alle echten Forscher immer getan haben: nämlich ihre aufs Große zielenden philosophischen Fragen an Hand der feinsten wissenschaftlichen Methoden zu verfolgen, die Fragen im Verlauf der Arbeit am Gegenstand umzuformen, zu präzisieren, neue Methoden zu ersinnen und doch das Allgemeine nicht aus den Augen zu verlieren. (ebd.: 29-30)

Ähnlich wie es am Beispiel des Wiener Kreises deutlich geworden ist, verlagert Horkheimer die >Fruchtbarkeit $\triangleleft$ der Philosophie in die empirischen Wissenschaften. Im Unterschied zu den Erneuerungsstrategien des Wiener Kreises aber, in denen die Philosophie mit den empirischen Wissenschaften identifiziert wird, argumentiert er für eine Kooperation zwischen Philosophie und empirischen Sozialwissenschaften und hält damit an der Unabhängigkeit der Philosophie fest.

Horkheimer betont, dass er dem Ruf, dieses Forschungsinstitut zu leiten, gefolgt sei im Hinblick »auf diese für Philosophie und Empirie gleich wichtige Möglichkeit und nicht, um die Tatsachenforschung zur ancilla philosophiae zu machen $[. .$.$] « (ebd.: 31). Dass es sich beim interdisziplinär angelegten$ Forschungsprogramm des Instituts aber letztlich um ein philosophisches Programm handelt, begründet und legitimiert er mit dem Verweis auf die

162 Ein gutes Beispiel für diese gegenseitige Durchdringung sei die »Beziehung zwischen Naturphilosophie und Naturwissenschaft« (Horkheimer 1931: 29). Horkheimer nimmt hier in affirmativer Weise jene zeitgenössischen Bestrebungen auf, die u.a. von den Vertretern des Wiener Kreises vorangetrieben wurden. Dass sowohl der Wiener Kreis als auch die Kritische Theorie >Interdisziplinarität $<$ zum neuen Schlagwort philosophischer Forschung stilisieren, ist mit Blick auf ihre Argumentationsstrategien bezeichnend: Im Unterschied zu Husserls Abgrenzungspraktik ist sowohl in der Fundierungsstrategie des Wiener Kreises als auch in der Kooperationsstrategie der Kritischen Theorie der Zusammenschluss mit den Wissenschaften ein antreibendes Element. 
philosophische Tradition selbst: So sei der am Institut zu erforschende »Zusammenhang zwischen dem wirtschaftlichen Leben der Gesellschaft, der psychischen Entwicklung der Individuen und den Veränderungen auf den Kulturgebieten« eine »aktuelle Fassung ältester und wichtigster philosophischer Probleme [...] « (ebd.: 32). Bei diesen Fragen handele es sich letztlich um die »alten Fragen nach dem Zusammenhang von besonderer Existenz und allgemeiner Vernunft, von Realität und Idee, von Leben und Geist, nur eben auf die neue Problemkonstellation bezogen« (ebd.). Letztlich, so legt Horkheimer nahe, betreibe das Forschungsinstitut nichts anders als Philosophie im ursprünglichen Sinn. ${ }^{163}$

Er begründet und legitimiert diesen Befund wiederum mit der philosophischen Tradition. Er argumentiert dafür, dass das Motiv der Gesellschaft immer schon ein entscheidendes Element der Philosophie und ihrer Geschichte gewesen sei. Besonders prägnant ist diese Argumentationsstrategie in seinem zehn Jahre später verfassten Aufsatz »Die gesellschaftliche Funktion der Philosophie« formuliert: »Wer die neuere Philosophie studiert, nicht bloß in durchschnittlichen Kompendien, sondern indem er selbst ihrer Geschichte nachgeht, wird das gesellschaftliche Problem als ein sehr entscheidendes Motiv in ihr erkennen « (Horkheimer 1941:346). Bereits Aristoteles habe gesagt, so erhärtet er sein Argument, dass das höchste Glück - die Selbstbetrachtung der Seele - »nur auf einer spezifischen materiellen Basis, also unter bestimmten gesellschaftlichen und ökonomischen Bedingungen, möglich ist « (ebd.). Werde die Philosophie und deren Geschichte unter materiellen Aspekten interpretiert, so sehe man - dies Horkheimers Folgerung -, dass die Gesellschaft schon immer ein entscheidendes und fundierendes Element der Philosophie gewesen sei. Die Gesellschaft wird von ihm zu einem vorrangigen philosophischen Problem erklärt. Das »gesellschaftliche Thema« (ebd.) wird also nicht nur als eines unter anderen philosophischen Problemen dargestellt, sondern - weit radikaler - als das für die Philosophie vorherrschende Problem. Umgekehrt wird dadurch die Philosophie im Medium der Sozialwissenschaften verstanden. »Die Philosophie muss «, so fasst Jürgen Habermas diesen Aspekt, »solange sie nicht verwirklicht werden kann, in ein anderes Medium übertreten, um nicht zur Ideologie zu verkommen - und für Horkheimer sollten

163 Dass dieser Aussage eine »philosophische Überzeugung« zugrunde liegt, die keineswegs von allen Institutsmitgliedern (auch nicht von Adorno, wie weiter unten deutlich werden wird) geteilt wurde, betont z.B. Jürgen Habermas: »Daß Horkheimers Philosophie in dieser Zusammenarbeit mit Ökonomen, Psychologen, Juristen, Historikern und Soziologen, Musik- und Literatursoziologen vor allem, aufgehen sollte, hatte seinen Grund in einer philosophischen Überzeugung, die andere Institutsmitarbeiter keineswegs teilten die jedenfalls für deren Arbeit nicht das primum movens war« (Habermas 1986: 163). 
die im Brennspiegel der kritischen Gesellschaftstheorie gebündelten, eingeschmolzenen und zugleich erneuerten Sozialwissenschaften dieses Medium sein « (Habermas 1986: 164).

Diese Kooperation wird nicht nur mit den empirischen Sozialwissenschaften generell, sondern auch mit der Soziologie hergeleitet. Konzis bringt dies Adorno in seiner Vorlesung Philosophie und Soziologie von 196o auf den Punkt. In der ersten Stunde sagt er:

Ich möchte $[. .$.$] versuchen, diejenigen von Ihnen, die von der einen oder der$ anderen Seite herkommen, ein wenig über die Problematik dessen aufzuklären, daß nun also hier an dieser Universität in einer gewissen Personalunion sowohl bei Herrn Horkheimer wie bei mir zwei Fächer sich vereinigt finden, die im Sinn eines jedenfalls nach beiden Seiten sehr weit verbreiteten Vorurteils eigentlich inkompatibel sind und nichts miteinander zu tun haben. (Adorno 2011: 9-10)

Adorno stößt durch dieses Vorgehen dann aber auf ein Problem, und zwar eines, »das sowohl soziologisch wie philosophisch von erheblicher Relevanz ist und dem beide Disziplinen sich nicht entziehen können: nämlich auf das Problem der Idee der Wahrheit auf der einen Seite und auf der anderen Seite auf [das] der gesellschaftlichen Determination von Erkenntnis überhaupt« (Adorno 2011: 10).

Zusammenfassend kann festgehalten werden, dass Horkheimer und Adorno die zentrale marxistische Einsicht der gegenseitigen Durchdringung von Philosophie und Gesellschaft mit dem Ziel aufnehmen, die Gesellschaft zum privilegierten philosophischen Bereich zu erklären. Indem das interdisziplinär angelegte Forschungsprogramm des Instituts jedoch als ein philosophisches Programm präsentiert wird, ordnen sie die neu zu entwickelnde Gesellschaftstheorie explizit in die Tradition der Philosophie ein. ${ }^{164}$

\section{Abgrenzung gegenüber der Wissenssoziologie}

Mannheims Wissenssoziologie spielt - so wurde zu Beginn des Kapitels im Zusammenhang mit Seidel angedeutet - für die philosophische Positionierung der Kritischen Theorie eine zentrale Rolle. ${ }^{165}$ In der Auseinandersetzung von

\footnotetext{
164 Der Anspruch nach der Überwindung der Metaphysik ist in allen drei Beispielen sichtbar. Aktualisierungsstrategisch erweist sich dies als zentral (siehe dazu insbesondere S. 193-194).

165 Wie Adorno und Horkheimer das komplizierte und komplexe Verhältnis zwischen Soziologie, Sozialwissenschaften und Philosophie in ihren zahlreichen Schriften bestimmen und definieren, ist weder einheitlich, noch bleibt es im Verlaufe ihres Schaffens gleich. Vielmehr ist diese Verhältnisbestimmung sowohl auf institutioneller als auch auf ideeller Ebene selbst Teil der Entstehung der Kritischen Theorie (siehe Demirović 1999).
} 
Horkheimer und Adorno mit Mannheim wird eine Strategie der Abgrenzung ähnlich wie bei Husserl deutlich. ${ }^{166}$ Indem Horkheimer und Adorno der Wissenssoziologie Mannheims Lücken und Fehler nachweisen, argumentieren sie für die Wichtigkeit einer genuin philosophischen Perspektive. ${ }^{167}$

1929 erscheint Mannheims Buch Ideologie und Utopie. »Die Philosophen «, so sagt Mannheim zu Beginn des Buches, »haben sich allzulange bloß mit ihrem eigenen Denken befasst« (Mannheim 1978 [1929]: 3). Diese gewissermaßen idiosynkratische Ausrichtung philosophischen Denkens lehnt Mannheim ab. Sein Buch befasse sich »mit dem Problem, wie Menschen wirklich denken« (ebd.). Er stellt klar, dass das Denken der Philosophen lediglich ein »Typus des Denkens« und »nur unter ganz bestimmten Umständen anwendbar« ist (ebd.). Er nimmt also eine soziologische Perspektive auf das Denken - und somit auch auf das philosophische Denken - ein. Wie Martin Jay betont, sah sich die Kritische Theorie, jeden Anspruch auf absolute Wahrheit zurückweisend, häufig mit denselben Problemen konfrontiert, nach deren Lösung auch die Wissenssoziologie suchte (Jay 1973: 87-88). Weder Horkheimer noch andere Vertreter der Kritischen Theorie seien jedoch je bereit gewesen, Mannheim »darin zu folgen, den Marxismus nur als eine unter anderen Ideologien zu >entlarven « (Jay 1973: 88). Mannheim, so Jay weiter, schien mit seiner Behauptung, alles Wissen sei sseinsgebunden<, die fundamentale marxistische Unterscheidung zwischen richtigem und falschem Bewusstsein zu untergraben - »eine Unterscheidung, an der die Kritische Theorie ausdrücklich festhielt« (ebd.). Demnach ist einer der wesentlichen Vorwürfe aus Sicht der Kritischen Theorie an Mannheim, dieser würde eine Abkehr von einer marxistisch geprägten Ideologiekritik praktizieren (Huke-Didier 1985: 39).

Dubiel geht in seinem Aufsatz Ideologiekritik versus Wissenssoziologie (1975) den »immanent theoretischen Gründe[n] « für die »übergroße und anhaltende Aufmerksamkeit« nach, die die Vertreter der Kritischen Theorie der Wissenssoziologie Mannheims widmeten, und stellt fest: »Mannheims Wissenssoziologie diente den Vertretern der kritischen Theorie gerade in den

166 Nebst Horkheimer haben auch Marcuse und Adorno ihre Position dezidiert von der Wissenssoziologie abzugrenzen versucht. Zum Beispiel Marcuse 1982 [1929]; Adorno 1977 [1955].

167 Sabine Maasen formuliert die Kritik der Kritischen Theorie an Mannheim wie folgt: »Die Kritik der Frankfurter Schulde am Mannheim'schen Ansatz zielt auf dessen PseudoRadikalität: Das Konzept der gesellschaftlichen Totalität sei erstens idealistische Metaphysik, zweitens bleibe der Zusammenhang zwischen Bewusstsein und sozialer Existenz vage und drittens sei der totale Ideologiebegriff ohne kritisches Potential, da er auf einem inhaltsleeren Kriterium, der bloßen Perspektivität von Ideen beruhe« (Maasen 2009: 27). 
Kernpunkten ihres Selbstverständnisses als Kontrastfolie ihrer positionellen Selbstdefinition « (Dubiel 1975: 223). ${ }^{168}$ Im gemeinsam verfassten Aufsatz Philosophie und Kritische Theorie schreiben Marcuse und Horheimer: »Die Soziologie, welche sich nur mit den Bedingtheiten beschäftigt, hat es nicht mit der Wahrheit zu tun; ihr in manchem nützliches Geschäft verfälscht das Interesse und das Ziel der kritischen Theorie (Horkheimer/Marcuse 1970 [1937]: 643). Die »Sorge« der Kritischen Theorie hingegen sei, »daß die Wahrheiten nicht verloren gehen, auf die das vergangene Wissen schon hingearbeitet hatte« (ebd.). Im Zusammenhang mit einer Abgrenzung gegenüber der Wissenssoziologie bringen Marcuse und Horkheimer hier das Selbstverständnis der Philosophie als jener Wissenschaft hervor, die mit Wahrheit verbunden ist. Die Kritische Theorie, so die Implikation, kümmere sich im Gegensatz zur Wissenssoziologie um diesen Aspekt. »Die Auseinandersetzung der kritischen Theorie mit der Philosophie ist an dem Wahrheitsgehalt der philosophischen Begriffe und Probleme interessiert: sie setzt voraus, daß Wahrheit wirklich in ihnen enthalten ist. Das Geschäft der Wissenssoziologie dagegen betrifft immer nur die Unwahrheiten, nicht die Wahrheiten der Philosophie« (ebd.: 640). Hier wird offensiv für den philosophischen Gehalt der Kritischen Theorie argumentiert und dieser Gehalt mit dem Begriff der Wahrheit verbunden. ${ }^{169}$

Eine ähnliche argumentative Bewegung ist auch bei Horkheimer in dessen Aufsatz »Ein neuer Ideologiebegriff?« zu beobachten. Mannheim falle - so die Stoßrichtung der Argumentation - letztlich in genau jene metaphysischen Strukturen zurück, die er mit »einigen Stücken aus der Rüstkammer des Marxismus « zu kritisieren beabsichtigt hatte: »Diese grundstürzende, alles >dynamisch auflösende Soziologie kommt [...] ohne den Halt einer dogmatischen Metaphysik nicht aus, vielmehr hebt sie die Zerstörung aller absoluten philosophischen Sinnforschungen damit wieder auf, dass

168 In Anlehnung an diese Feststellung Dubiels möchte Tae-Kook Jeon in seiner Dissertation Karl Mannheims Ideologietheorie und ihr Verhältnis zur Kritischen Theorie der Frankfurter Schule zeigen, dass »die `Kontrastfolie`, mit der die Frankfurter Schule ihre Kritische Theorie von der Lehre Mannheims abzugrenzen versuchte, nicht begründet ist, weil die Kritische Theorie in ihrem Kernpunkt die Mannheimsche Lehre aufnahm« (Jeon 1984: 4). Jeon kehrt somit die Hauptkritik, die Horkheimer, Marcuse und Adorno an Mannheim übten - dessen Abweichung vom Marxismus -, in ihr Gegenteil: Demnach sei nicht die Kritische Theorie, sondern die »Lehre Mannheims im Wesentlichen die Weiterentwicklung der Marxschen Lehre« (ebd.).

169 Auch Dubiel stellt im betreffenden Aufsatz fest, dass die Vertreter der Kritischen Theorie in ihrer Kritik an der Wissenssoziologie auf den Begriff der Wahrheit zurückgreifen: »Es wird [in vielen Äußerungen der >Frankfurter< über die Mannheim'sche Wissenssoziologie, MD] dabei in der Regel die Formulierung verwendet, dass in jeder ideologischen Aussage immer auch Wahrheit enthalten sei« (Dubiel 1975: 232). 
sie sich selbst als ihre fortgeschrittenste Form empfiehlt« (Horkheimer 1987 [1930]: 281).

Horkheimer entwickelt sein eigenes Philosophieverständnis entlang einer Abgrenzung zur Wissenssoziologie. Zehn Jahre nach besagtem Aufsatz nimmt er die Kritik an Mannheim in seinem Aufsatz »Die gesellschaftliche Funktion der Philosophie« (1940) nämlich erneut auf. Mit dem Verweis auf Mannheims Ideologie und Utopie wendet er sich hier gegen jene Auffassungen, die die Philosophie mit Ideologie gleichsetzen. Diese Auffassungen behaupten gemäß Horkheimer »philosophisches Denken, oder richtiger: Denken als solches sei bloßer Ausdruck einer spezifischen gesellschaftlichen Situation « (Horkheimer 1940: 342). Horkheimer betont zwar, dass diese marxistische Perspektive bis zu einem gewissen Grade richtig sei, denn »viele der heute verbreiteten Ideen enthüllen sich als bloße Illusionen, wenn man sie von ihrer gesellschaftlichen Basis her betrachtet« (ebd.), dennoch setzt er sich von einer wissenssoziologischen Perspektive ab. »Man muß tiefer gehen«, sagt er, »und sie [die heute verbreiteten Illusionen, MD] aus dem historischen Prozeß entwickeln, aus dem die sozialen Gruppen selbst zu erklären sind « (ebd.: 342-343). Die Soziologie, so sagt Horkheimer dezidiert, »bleibt unzureichend. Wir brauchen eine umfassende Theorie der Geschichte« (ebd.: 343). Der Verlust des geschichtlichen Aspekts, der in der Wissenssoziologie sichtbar werde, berge die Gefahr, »bedeutsame Philosopheme mit unbedeutenden oder jedenfalls nicht entscheidenden Gruppen in Beziehung zu setzen oder auch das Gewicht einer spezifischen Gruppe im Ganzen der Gesellschaft und damit den gegebenen Kulturzusammenhang misszudeuten « (ebd.). Im Zusammenhang mit seiner Absetzung von der Wissenssoziologie betont Horkheimer also die Wichtigkeit der Geschichte für die Kritik an bestehenden Verhältnissen. ${ }^{170}$

Auch hier wird der Wahrheitsbegriff verwendet, um die Position der Kritischen Theorie von der Wissenssoziologie abzugrenzen. So liege der »wesentliche Einwand« gegen eine Soziologisierung des Denkens darin, dass

170 Es könnten vermutlich ähnliche Argumentationsstrategien in Bezug auf das Verhältnis zwischen Philosophie und Geschichte gefunden werden, wie sie hier in Bezug auf das Verhältnis zwischen Philosophie und Soziologie herausgearbeitet werden. So fordern Horkheimer und Adorno zwar in dezidierter Weise eine Geschichtsphilosophie, ohne jedoch die Geschichtswissenschaften konstruktiv in ihre Theorie aufzunehmen bzw. ihren Standpunkt in der Geschichtswissenschaft zu verorten. Herbert Schnädelbach, dessen Habilitation erst von Adorno und nach dessen Tod von Habermas begutachtet wurde, benennt Adornos Überlegungen zur Geschichte als »Geschichtsphilosophie ohne Geschichte« (Schnädelbach 2008: 131). Die Geschichte komme bei Adorno überhaupt nicht vor. Wo in der Dialektik der Aufklärung noch eine Geschichte erzählt werde - nämlich »die Geschichte hinter der Geschichte, die wahre Geschichte« (ebd.: 132) -, komme die Geschichte in der Negativen Dialektik gar nicht mehr vor (ebd.: 133). 
diese Denkrichtung philosophische Wahrheit und damit Wahrheit überhaupt verleugne: »Die stereotype Anwendung des Ideologiebegriffs auf jedes Denkgebilde beruht letztlich auf der Vorstellung, daß es keine philosophische und damit überhaupt keine Wahrheit für die Menschheit gebe, daß alles Denken sseinsgebunden< sei« (ebd.: 343). Hier wird exakt das Dilemma aufgenommen, aus dem Seidel analytisch keinen Ausweg weiß: Wird jedes Denken als Ideologie aufgefasst, fehlt, so lässt sich Bewußtsein als Verhängnis verstehen, jegliche Grundlage, von der aus gedacht werden kann. Mannheim löst das Problem insofern, dass er sich auf einen soziologischen Standpunkt stellt und davon ausgehend den >Geist bzw. das Bewusstsein soziologisiert. Analog dazu lösen Horkheimer und Adorno das Problem so, dass sie sich - mit dem Argument, dass an der Wahrheit festgehalten werden müsse - zu einem philosophischen Standpunkt bekennen. Horkheimer bringt gegen die Relativierung von Wahrheit das Argument vor, dass eine solche Perspektive im »philosophischen Skeptizismus und Nihilismus « münde (ebd.: 341). Gleichzeitig parallelisiert er den philosophischen Skeptizismus und Nihilismus mit der Auflösung der Philosophie in die Soziologie: »Wir erkennen mühelos«, sagt er, »daß diese Schule [die Mannheim-Schule, MD], die schließlich darauf hinausläuft, die Philosophie in eine Spezialwissenschaft, in Soziologie aufzulösen, nur die skeptizistische Position wiederholt, die wir bereits kritisiert haben« (ebd.: 344). Eine Verleugnung philosophischer Wahrheit, d.h. die Auflösung der Philosophie in die Soziologie, darf laut Horkheimer jedoch nicht propagiert werden. Die Wissenssoziologie sei keineswegs darauf angelegt, so moniert er, die "gesellschaftliche Funktion der Philosophie zu erklären, sondern hat vielmehr ihrerseits eine solche: dem in die Zukunft weisenden Denken die Courage abzukaufen, seine praktische Tendenz zu unterbinden« (ebd.: 344 ).

Horkheimer bringt mit seiner Kritik - ex negativo - ein bestimmtes philosophisches Selbstbild hervor: Wenn er erstens schreibt, dass viele neuere (wissenssoziologisch orientierte) Autoren die Philosophie als »Dienerin « und nicht mehr als »Kritikerin« der Wissenschaft und der Gesellschaft allgemein verstehen würden, erzeugt er ein Selbstbild der Philosophie als Kritikerin der Wissenschaften. Wenn er zweitens schreibt, dass diese Autoren die These vertreten würden, dass »ein Denken, das die herrschenden Formen wissenschaftlicher Betätigung und damit den Horizont der gegenwärtigen Gesellschaft transzendiert«, unmöglich sei, entwirft er ein Selbstbild, das der Philosophie ein Vermögen zur Transzendierung zuschreibt. Und wenn er drittens moniert, dass wissenssoziologische Positionen kaum das spezifisch Philosophische »enthüllen«, also dasjenige, was die Philosophie von den Einzelwissenschaften unterscheide, behauptet er etwas genuin und spezifisch Philosophisches, 
etwas, das sich von den anderen Disziplinen per se unterscheidet (Horkheimer 1941: 341).

Indem Horkheimer sich von wissenssoziologischen Perspektiven abgrenzt, verteidigt er eine `wirkliche Philosophie bzw. die philosophische Wahrheit. Wie Bernd Wirkus betont, hält Horkheimer »an einem traditionellen, d.h. absoluten Wahrheitsbegriff fest, der über jeder Kontingenz der geschichtlichen Veränderungen und Faktizitäten zu stehen scheint. In dieser unterschiedlichen Konzeption des Wahrheitsbegriffs entsteht einer der wesentlichen Unterschiede zwischen der Kritischen Theorie und der Position der Wissenssoziologie« (Wirkus 1996: 150). Dass Horkheimer sein eigenes Philosophieverständnis durch die Abgrenzung zu wissenssoziologischen Perspektiven entwickelt, wird auch auf der Ebene seiner Textkonzeption deutlich: er spricht unmittelbar nach seiner Kritik an der Wissenssoziologie seine berühmt gewordene Definition der Philosophie aus: »Die wahre gesellschaftliche Funktion der Philosophie liegt in der Kritik des Bestehenden« (ebd.: 344). Durch die Kritik an der Wissenssoziologie wird in Abhebung von dieser die Philosophie als jene Wissenschaft aktualisiert, die sich um die Wahrheit kümmert. Philosophie, Wahrheit und Kritik werden von Horkheimer intrinsisch miteinander verbunden.

\section{Neubestimmung: Die Philosophie als Instrument der Kritik}

Lukács und Korsch konzeptualisieren, so ist deutlich geworden, Philosophiekritik im Dienste des Marxismus: Ziel und Zweck philosophischer Selbstkritik lägen in der gesellschaftlichen Veränderung. Lukács und Korsch >re-philosophieren< den Marxismus, indem sie ihn als Instrument konzeptualisieren, mit dem die (bürgerliche) Philosophie kritisiert werden kann. Diesen Aspekt nehmen Horkheimer und Adorno auf, um ausgehend vom Marxismus eine neue Bestimmung für die Philosophie im Allgemeinen zu konfigurieren. Das marxistische Ziel einer Umwälzung der Gesellschaft wird in der Kritischen Theorie zugunsten einer Neubestimmung der Philosophie zurückgestellt. ${ }^{171}$ »Das Selbstverständnis von Theorieproduktion«, so sagt Michael Buckmiller lakonisch, »nahm für die neue Generation von Mitarbeitern des Instituts [Horkheimer, Adorno etc., MD] in zunehmenden

171 Die Schwerpunktverlagerung eines politisch verstandenen Marxismus hin zur philosophischen Akademisierung kann auch an der Umbenennung der Zeitschrift des Instituts für Sozialforschung beobachtet werden: So stellt das Institut $193^{2}$ die Zeitschrift Archiv für die Geschichte des Sozialismus und der Arbeiterbewegung ein und ersetzte sie durch die Zeitschrift für Sozialforschung - ein laut Perry Anderson »unschuldiger« Name (Anderson 1978 [1976]: 55). 
Maße wieder die Züge der Philosophie an, weil es den aktiven Adressaten, die Arbeiterklasse, verloren hatte «(Buckmiller 1988: 173). Vor allem in den Jahren 1968-1973 wurde diese Entwicklung ausgehend von der marxistischen Studentenbewegung intensiv thematisiert und auch kritisiert. ${ }^{172}$ Die Kritische Theorie, die sich der Kritik jeglichen Systemdenkens verschrieben hat, habe sich - so der Vorwurf - selbst zu einem System, d.h. zur (bürgerlichen) Erkenntnistheorie mit universalem Anspruch, gewandelt. Die kritischen Theoretiker (allen voran Adorno) würden sich im Elfenbeinturm der Theorie verschanzen, statt ihre Theorie in der Praxis zu verwirklichen. ${ }^{173}$ »Aber der praktische Klassenstandpunkt«, so schreibt etwa Hans-Jürgen Krahl, einer der exponiertesten Studentenaktivisten und Schüler von Adorno, »[...] ist nicht theoretisch konstitutiv in die Theorie eingegangen « (Krahl 1971: 289). Mit welchen argumentativen Strategien - so die Frage, die sich in der hier eingenommenen Perspektive stellt - begründen Adorno und Horkheimer die Denkfigur der Durchdringung von Praxis und Theorie selbst als Philosophie?

Die Neubestimmung der Philosophie im Allgemeinen wird u.a. an der von Horkheimer und Adorno gemeinsam verfassten Schrift Dialektik der Aufklärung ${ }^{174}$ von 1944 deutlich. Es handelt sich dabei um eine breit angelegte Zeitdiagnose, die, so Alfons Söllner, »die Weltgeschichte als ganze zum Thema macht « (Söllner 1979: 190). Horkheimer und Adorno stellen dabei das Ziel gesellschaftlicher Veränderung zugunsten einer umfassenden Interpretation der Gegenwart zurück. Sie verwandeln die »materialistische Gesellschaftstheorie zurück in Geschichtsphilosophie« (ebd.). Die Vernunft, so eine Kernaussage der Dialektik der Aufklärung, äußere sich seit der Aufklärung nicht nur als Emanzipations-, sondern auch als Herrschaftsmittel. Die Durchsetzung der Vernunftprinzipien der Aufklärung hätte folglich keinen Befreiungsprozess in Gang gesetzt, sondern vielmehr einen Prozess der universellen Selbstzerstörung. Die Aufklärung falle in Mythologie zurück. Die Ursache für diesen Rückfall, so schreiben die Autoren im Vorwort, liege »bei der in Furcht vor der Wahrheit erstarrenden Aufklärung selbst« (Horkheimer/Adorno 2008

172 Siehe z.B. Habermas et al. 1968; Holz 1968; Heiseler/Steigerwald/Schleifstein (Hrsg.) 1970; Beyer 1971; Krahl 1971; Klüver/Wolf (Hrsg.) 1972.

173 Indem das Institut für Sozialforschung - so Martin Jay - »die faktische, ja sogar die mögliche Existenz eines historischen Subjekts bezweifelte, welches in der Lage war, eine vernünftige Gesellschaft herbeizuführen, warf das Institut die zentrale Prämisse in Marx' Werk von der Einheit von Theorie und Praxis endgültig über Bord. Die Konflikte seiner Mitglieder mit der deutschen Neuen Linken in den sechziger Jahren waren nur die Auswirkung dieser bereits eingetretenen Wandlung « (Jay 1981 [1973]: 343).

174 Die Dialektik der Aufklärung wurde als Rückzug der kritischen Gesellschaftstheorie von Horkheimer und Adorno in eine universalistische Geschichtsphilosophie interpretiert (z.B. Söllner 1979: 191). 
[1944]: 3-4). Aus diesen Thesen leiten sie eine neue Aufgabe für die nun nicht mehr »traditionelle«, sondern »kritische« Philosophie ab: Der Philosophie als kritischer Theorie komme die Rolle zu, diesem Prozess der Selbstzerstörung Einhalt zu gebieten, und zwar vermittels Selbstkritik, einer »negativen Dialektik«, wie Adorno diese Methode später auf den Begriff bringt. ${ }^{175}$ Der bedingungslose Glaube an die Vernunft, so Horkheimer und Adorno, birgt gesellschaftliches, politisches und soziales Zerstörungspotenzial. Sie machen um den Bezug zu Seidel aufzunehmen - das >Bewusstsein als Verhängnis $<$ zum Dreh- und Angelpunkt ihres Erneuerungsanspruchs, d.h., sie konzipieren ihre Einsicht in die prinzipielle Selbstzerstörung von Vernunft - paradoxerweise als neues philosophisches Programm. Die »geschichtsphilosophische Globalkonstruktion «, so Söllner, sei die »konsequente wissenschaftliche Realisierung dessen, was sich seit Anfang der 4oer Jahre als neue Funktionsbestimmung der Philosophie herausgebildet hatte« (Söllner 1979: 190).

Diese paradoxe Strategie wird im Folgenden an zwei Dokumenten nachvollzogen: erstens an Adornos Antrittsvorlesung, die er unter dem Titel »Die Aktualität der Philosophie « 1931 an der Universität Frankfurt am Main gehalten hat, und zweitens an seinem Artikel »Wozu noch Philosophie?«, der 1962 in der Zeitschrift »Merkur« veröffentlicht wurde.

\section{Ein Paradox produktiv machen: Philosophie trotz ihrer Unmöglichkeit!}

»Wer heute philosophische Arbeit als Beruf wählt«, so Adorno, »muß von Anbeginn auf die Illusion verzichten, mit der früher die philosophischen Entwürfe einsetzten: daß es möglich sei, in Kraft des Denkens die Totalität des Wirklichen zu ergreifen « (Adorno 1973b: 325). Adorno erteilt in seiner Antrittsvorlesung ${ }^{176}$ allen philosophischen Totalitätsentwürfen - allen voran Heideggers Fundamentalontologie - eine Absage (Kertesz 1999: 30). Seine Kritik richtet sich somit auch an Lukács' Verwendung des Totalitätsbegriffs. Indem Adorno den von Lukács in Geschichte und Klassenbewußtsein vertretenen Ansatz, Wahrheit durch Klassenherkunft zu begründen, zurückweist (Jay 1982: 74), formuliert er eine Kritik an den Prämissen des philosophischen Marxismus der 1920er-Jahre. Im Verlauf seiner Vorlesung wird zudem eine Kritik an Horkheimers Arbeitsprogramm des Instituts deutlich: Adorno

175 In diesem Zusammenhang ist Adornos berühmte Forderung zu verstehen, Auschwitz dürfe sich nie wieder wiederholen.

${ }_{17}$ Die Vorlesung wurde zu Lebzeiten Adornos nicht publiziert. Möglicherweise weil sie, wie Jay aus Briefen rekonstruiert, auf Vorbehalte gestoßen sei. Seine Zuhörer, so zitiert Jay Adorno, hätten nichts begriffen, und Mannheims Mutmaßung, er, Adorno, sei zum Wiener Kreis übergegangen, sei die dümmste aller dummen Reaktionen (Jay 1981 [1973]: 72). 
kritisiere, so Jay, »implizit die Behauptung aus Horkheimers Antrittsvorlesung, Sozialphilosophie und wissenschaftliche Forschung könnten sich vereinigen, um Erkenntnis vom gesellschaftlichen Ganzen zu gewähren« (ebd.: 73). Im Gegensatz dazu versteht Adorno die Philosophie und die Einzelwissenschaften als zwei grundsätzlich verschiedene Erkenntnisweisen. »Schlicht gesagt: Die Idee der Wissenschaft ist Forschung, die der Philosophie Deutung « (Adorno 1973b: 334). Ähnlich wie es am Beispiel von Husserl deutlich geworden ist, argumentiert also auch Adorno für einen prinzipiellen Unterschied zwischen Philosophie und Einzelwissenschaften.

In Auseinandersetzung mit den prominenten Philosophien seiner Zeit (Idealismus, Neukantianismus, Lebensphilosophie, Positivismus und vorrangig: Phänomenologie) stellt Adorno seine zentrale Frage, nämlich »ob nach dem Scheitern der letzten großen Anstrengungen überhaupt noch eine Angemessenheit zwischen den philosophischen Fragen und der Möglichkeit ihrer Beantwortung besteht: ob nicht vielmehr das eigentliche Ergebnis der jüngsten Problemgeschichte die prinzipielle Unbeantwortbarkeit der philosophischen Kardinalfragen sei« (ebd.). Er gibt weder eine positive noch eine negative Antwort auf diese Frage. Seine Strategie ist es vielmehr, diese Frage selbst zu einem relevanten Thema der Philosophie zu erheben. Philosophiekritik sei die wesentliche Aufgabe der Philosophie. Für ihn besteht diese Aufgabe vorrangig darin, den Totalitätsbegriff der Philosophie zu kritisieren. Die Philosophie müsse lernen, »auf die Totalitätsfrage zu verzichten « (ebd.: 336). ${ }^{177}$ Adorno transponiert den marxistisch-geschichtsphilosophischen Gedankengang, wonach sich die Philosophie im Namen gesellschaftlicher Veränderungen aufzulösen habe, also in den Bereich der Philosophie: Er konfiguriert die Denkfigur der gegenseitigen Durchdringung von Praxis und Theorie als ein zentrales und neues Problem für die Philosophie selbst und nicht, wie Lukács und Korsch, als ein affirmativ verstandenes Ziel, um gesellschaftliche Veränderung zu erreichen.

Die Frage nach der Auflösung der Philosophie, so bekräftigt Adorno, sei keineswegs »rhetorisch« gemeint, sondern »buchstäblich« zu nehmen, denn

177 In diesem Aspekt decken sich die Bemühungen von Adorno mit jenen von Michel Foucault: »Was bedeutet heute eigentlich >philosophieren<? Es bedeutet nicht die Konstituierung eines Diskurses über die Totalität, eines Diskurses, in dem die Totalität der Welt eingefangen ist, sondern eher die Ausübung einer bestimmten Tätigkeit« (Foucault 1974: 18). Die salte Philosophie`, so sagt Foucault in ähnlicher Weise wie Horkheimer und Adorno, habe darin bestanden, die Totalität der Welt einzufangen. Die >neue $\triangleleft$ die gegenwärtige Philosophie jedoch bestehe in einer Tätigkeit. »Wenn die Philosophie also nicht mehr so sehr ein bestimmter Diskurs, als vielmehr eine einem objektiven Feld immanente Tätigkeit ist, kann sie nicht mehr eine totalisierende Perspektive beanspruchen« (ebd.). 
»jede Philosophie, der es heute nicht auf Sicherheit des bestehenden geistigen und gesellschaftlichen Zustandes, sondern auf Wahrheit ankommt, sieht sich dem Problem einer Liquidation der Philosophie selber gegenüber « (ebd.). Diese Aussage erinnert an Korschs Vehemenz, mit der er die Auflösung der Philosophie als ein zentrales Moment marxistischer Theorie artikuliert. ${ }^{178}$ Sie ist hier in mehrfacher Hinsicht bedeutungsvoll: Eine Philosophie, der es auf Wahrheit ankomme, so mahnt Adorno, weiß um deren potenzielle Auflösung. Die Wahrheit der Philosophie liegt für ihn also darin, dass die Wahrheit nie gefunden werden kann. Er macht ein Paradox produktiv, das seine gesamte Philosophie durchzieht: dass Wahrheit zwar nie gefunden, aber dennoch immerwährend angestrebt werden muss. Es bleibe »das große, vielleicht das immerwährende Paradoxon: daß Philosophie stets und stets und mit dem Anspruch auf Wahrheit deutend verfahren muß, ohne jemals einen gewissen Schlüssel der Deutung zu besitzen; daß ihr mehr nicht gegeben sind als flüchtige, verschwindende Hinweise in den Rätselfiguren des Seienden und ihren wunderlichen Verschlingungen« (ebd.: 334). Adorno formuliert also in aller Deutlichkeit einen finalen Wahrheitsanspruch der Philosophie: dieser liegt darin, dass es philosophische Wahrheit in einer absoluten Version nicht gibt.

Seine Ambivalenz in Bezug auf die Frage, ob es philosophische Wahrheit gibt oder nicht, wurde in Bezug auf seinen berühmten Satz »Das Ganze ist das Unwahre « mehrfach kritisiert. ${ }^{179}$ Diese Ambivalenz ist in der hier eingenommenen Perspektive nun aber ein produktives Element innerhalb seines Erneuerungsanspruchs:

So genau ich mir der Unmöglichkeit bewußt bin, das Programm auszuführen, das ich Ihnen gab - einer Unmöglichkeit, die nicht bloß von der Enge der Stunde

${ }_{178}$ Siehe das Unterkapitel »Aufhebung der Philosophie: Durchdringung von Theorie und Praxis« (S. 152-155).

179 Es sei unverkennbar, betont etwa Demirović, »dass Adornos Argumentation tendenziell eine privilegierte Erkenntnisposition ausweist. [...]. >Das Ganze ist das Unwahre $<$ - und gegen diese über den vorfindlichen Bewusstseinsstand hinausreichende Erkenntnis gibt es kein Vetorecht. [...] Denn jede andere Theorie, die weder das Ganze umfängt noch in ähnlicher Weise verurteilt, ist lediglich ein Bestandteil des Unwahren und verhält sich nur apologetisch-affirmativ zu diesem Ganzen« (Demirović 1999: 533). Wie Demirović in der Folge ausführt, warnt Adorno jedoch vor genau dieser privilegierten Erkenntnisposition: »Er [Adorno, MD] spricht als Dialektiker über das System spätkapitalistischer Gesellschaft; doch gleichzeitig warnt er davor, diese Rede als Ausgangspunkt der Besserwisserei zu stilisieren « (ebd.: 535). In der hier eingenommenen Perspektive ist es genau diese Ambivalenz zwischen der Behauptung eines absoluten Wahrheitsanspruchs und der gleichzeitigen Ablehnung desselben, die für die Aktualisierung der Kritischen Theorie als Philosophie konstitutiv ist. 
herrührt, sondern generell besteht, weil gerade als Programm, in Vollständigkeit und Allgemeinheit dies Programm sich nicht ausführen läßt - : so deutlich sehe ich die Verpflichtung, Ihnen einige Hinweise zu geben. (ebd.: 339)

Adorno betont das Paradox, dass ein in sich geschlossenes philosophisches Programm zwar unmöglich ist, dass er aber als antretender Professor der Philosophie verpflichtet ist, ein solches anzustreben. Gerade indem er die Unmöglichkeit eines in sich geschlossenen philosophischen Systems reflektiert, legitimiert er sein eigenes neues philosophisches Programm als $»$ Deutung ${ }^{180}$ Er argumentiert hier doppelgleisig: Auf der einen Seite tritt er mit dem expliziten Anspruch auf, die Philosophie und mit ihr abschließende philosophische Systeme in ihren Grundfesten zu kritisieren. Auf der anderen Seite jedoch argumentiert er, dass in genau diesem Anspruch die neue und zukunftsweisende Philosophie liegt.

Nach diesem Auftakt, in dem Adorno sein Unbehagen ausdrückt, ein eigenes Programm überhaupt vorzustellen, stellt er es in seiner Antrittsrede dennoch vor: Erstens, so formuliert er, kämen seine eigenen Postulate einer »Liquidation« der Philosophie äußerst ähnlich. Die »Idee philosophischer Deutung weicht nicht vor jener Liquidation der Philosophie zurück, die mir durch den Zusammenbruch der letzten philosophischen Totalitätsansprüche signalisiert scheint (ebd.: 339). Sein eigenes Programm bestehe folglich in der Kritik an der Philosophie selbst: »Da das philosophische Denken der Gegenwart, jedenfalls das offizielle, bislang diese Forderungen von sich fernhält oder allenfalls einzelne gemildert sich zu assimilieren trachtet, so scheint eine der ersten und aktuellsten Aufgaben die radikale Kritik des herrschenden philosophischen Denkens« (ebd.: 339). Sein Programm zielt also erstens auf die Auflösung des Totalitätsbegriffs in der Philosophie. Es zielt zweitens auf eine Kooperation mit den Sozialwissenschaften und der Soziologie. Eine wirkliche Veränderung des philosophischen Bewusstseins, so Adorno, setze sich nur in »strengster dialektischer Kommunikation mit den jüngsten Lösungsversuchen der Philosophie« durch. Diese Kommunikation wiederum werde »ihr einzelwissenschaftliches Material vorwiegend der Soziologie zu entnehmen haben [...] « (ebd.: 340). Werden beide von Adorno fokussierten Punkte zusammengezogen, ergibt sich folgendes Bild: Um den Totalitätsbegriff in der Philosophie und damit >die Philosophie< kritisieren zu können, ist diese >neue< Philosophie auf »einzelwissenschaftliches Material« aus der Soziologie angewiesen.

180 Adorno betont an anderer Stelle, dass sein Ansatz der Hermeneutik dem von Dilthey zwar nahekommt, um aber sogleich klarzustellen, dass er mit diesem inkommensurabel sei (Adorno 2001: 182-184). 
Mithilfe der Soziologie - so die Implikation - wird Philosophie ihrer Unmöglichkeit zum Trotz wieder möglich.

Adorno rekurriert in seiner Antrittsvorlesung, genau wie Lukács und Korsch, auf die Methode von Marx. Er bezieht sein eigenes philosophisches Programm der »Deutung « sowohl auf den »Materialismus « als auch auf die »Dialektik« (ebd.: 336-339). Seine Formulierungen jedoch sind zurückhaltend: »Ich möchte hier keine materialen Behauptungen aufstellen, sondern allein die Richtung anzeigen, in welcher ich die Aufgaben philosophischer Deutung erblicke« (ebd.: 337). Im Unterschied zu Lukács und Korsch, die wie gezeigt - die Philosophie für die marxistische Theorie produktiv machen, macht Adorno marxistische Theorieelemente für die Philosophie produktiv. Eine Stelle, in der er sich ausdrücklich auf Lukács beruft, illustriert diesen Vorgang in prägnanter Weise: »Würde Philosophie heute [...] nach dem Sinn von Sein schlechtweg [fragen] - sie bliebe entweder in formaler Unverbindlichkeit stehen oder spaltete sich in eine Vielheit möglicher und beliebiger weltanschaulicher Standpunkte« (ebd.: 337). Er grenzt sich hier von der philosophischen Frage nach dem »Sein schlechtweg« ab - ein Seitenhieb gegen Heidegger -, um sogleich eine mögliche Lösung zu präsentieren, wie die Frage dennoch gestellt werden könnte: »ich gebe gedankenexperimentell ein Beispiel, ohne dessen tatsächliche Durchführbarkeit zu behaupten« (ebd.). Die Lösung liege im Rückbezug auf die Figur der »Warenform «. Damit wäre zwar nicht das Ding-an-sich-Problem gelöst, »auch nicht in der Weise, dass etwa die gesellschaftlichen Bedingungen aufgewiesen wären, unter denen das Ding an sich-Problem zustande kommt, wie noch Lukács die Lösung dachte; denn der Wahrheitsgehalt eines Problems ist von den historischen und psychologischen Bedingungen, aus welchen es erwächst, prinzipiell verschieden« (ebd.: 337). Es bestehe dadurch jedoch die Möglichkeit, dass das Ding-an-sich-Problem verschwinden würde: »dass die geschichtliche Figur der Ware und des Tauschwertes gleich einer Lichtquelle die Gestalt einer Wirklichkeit freilegte, um deren Hintersinn die Erforschung des Ding an sich-Problems vergebens sich mühte, weil sie keinen Hintersinn hat, der von ihrem einmaligen und erstmaligen geschichtlichen Erscheinen ablösbar wäre« (ebd.: 337). Adornos Andeutung, mit dem Rückbezug auf die »Figur der Warenform « das Ding-ansich-Problem zum Verschwinden zu bringen, ist bezeichnend: Ein Interesse und Anliegen von ihm liegt, so wird deutlich, im Fortschritt der Philosophie, und zwar im Sinne der Lösung traditioneller philosophischer Probleme. Die Theorieelemente des Marxismus - vorrangig der Aspekt der Auflösung der Philosophie - dienen hierfür als argumentative Instrumente.

Die Paradoxie, die Adorno und auch Horkheimer für ihr eigenes Programm produktiv machen, wird deutlich: Auf der einen Seite wird die Kritik an 
der Philosophie als eine der zentralsten Aufgaben der sneuen< Philosophie definiert. Auf der anderen Seite jedoch wird - mit Zuhilfenahme der Sozialwissenschaften und der Soziologie - dieses neue Programm dezidiert mit der philosophischen Tradition gerechtfertigt und argumentativ in diese eingefügt.

\section{Die Genese der Kritik aus der Philosophie selbst}

In seinem 1962 publiziertem Aufsatz »Wozu noch Philosophie?« macht Adorno besonders deutlich, dass der Erneuerungsanspruch der Philosophie als Kritische Theorie mit einem Rückbezug auf die Tradition der Philosophie selbst begründet wird. Er extrahiert hier Theorieelemente aus der traditionellen Philosophie, um seine Definition der Philosophie als Kritik herzuleiten: »Kants berühmtes Diktum, der kritische Weg sei allein noch offen, gehört zu jenen Sätzen, an denen die Philosophie, aus der sie stammen, sich bewährt, indem sie, als Bruchstücke, das System überdauern« (Adorno 1977 [1962]: 461). Dass die Kritik ein wesentliches Element der Philosophie ist, begründet Adorno aber nicht nur mit Kant, sondern mit den Anfängen der Philosophie selbst: »Die überlieferten Philosophen dagegen waren, seit den gepriesenen Vorsokratikern, Kritiker « (ebd.: 462). Die Philosophien von Xenophanes, Platon, Descartes, Kant, Hegel oder Marx resultierten je aus Kritik und nicht aus der Übernahme von Thesen. »Jene Denker hatten in Kritik die eigene Wahrheit. Sie allein, als Einheit des Problems und der Argumente, nicht die Übernahme von Thesen, hat gestiftet, was als produktive Einheit der Geschichte der Philosophie gelten mag « (ebd.).

Adorno begründet seine Aktualisierung der Philosophie als Kritik folglich mit dem philosophischen Kanon. ${ }^{181}$ Auffällig in diesem Zusammenhang ist, dass er zwar die abendländische philosophische Tradition in affirmativer Weise als eine Reihe von Kritiken darstellt, zwei seiner Zeitgenossen - Carnap und Heidegger - jedoch nicht in diese Reihe aufnimmt. Er bezeichnet sowohl den Positivismus von Carnap als auch die Ontologie von Heidegger als »Heteronomien «, die es zu kritisieren gelte. »Ist Philosophie noch nötig«, schreibt er, »dann wie von je als Kritik, als Widerstand gegen die sich ausbreitende Heteronomie $[. .$.$] 《 (ebd.: 464). Adorno spricht dadurch sowohl der Philosophie$ Heideggers als auch der Carnaps die Möglichkeit von Kritik ab.

181 Dieser Aspekt ist bei Adorno besonders ausgeprägt: Sein Werk, so der hier gewonnene Eindruck, ist eine einzige Beschäftigung mit der Philosophie. Zu seiner Beschäftigung mit Husserl siehe z.B. Adorno 1972a; Adorno 2002. Insbesondere mit Heidegger hat sich Adorno intensiv auseinandergesetzt, z.B. Adorno 1972c; Adorno 2002. 
In der Passage hingegen, in der Adorno entgegen seiner vorherigen positiv gefärbten Darstellung die abendländische Philosophie in negativer Weise als eine »trostlose Kette« beschreibt, fügt er Carnap und Heidegger indirekt hinzu.

\begin{abstract}
Sind aber die beiden Heteronomien [Positivismus und Ontologie] die Unwahrheit und läßt diese zwingend sich demonstrieren, dann fügt das nicht nur der trostlosen Kette der Philosophien eine neue hinzu, sondern meldet auch eine Spur von Hoffnung an, Unfreiheit und Unterdrückung, das Übel, das so wenig eines philosophischen Beweises bedarf, daß es das Übel sei, wie daß es existiert, möchte doch nicht das letzte Wort behalten. (ebd.: 465)
\end{abstract}

Adorno kritisiert zwei wirkmächtige zeitgenössische philosophische Positionen als unfrei und unterdrückend, indem er seine eigene Methode auf sie anwendet. Dadurch stützt er den Wahrheitsgehalt seiner eigenen Methodik: Wenn durch ein kritisches Verfahren deutlich gemacht werden könne, dass Ontologie und Positivismus unwahr sind, gebe es die Hoffnung auf die Möglichkeit, Wahrheit von Unwahrheit trennen zu können.

Der erste Absatz aus dem Aufsatz »Wozu noch Philosophie?« ist in Bezug auf Adornos eigene Positionierung als Philosoph aufschlussreich. Er stellt im ersten Satz klar, dass er den »amateurhaften Klang « der Frage »Wozu noch Philosophie? « nicht überhöre, obwohl er selbst für diese Formulierung verantwortlich sei. Der allvertraute Ablauf, der meistens auf diese Frage folge-»ein[] Gedankengang, der alle möglichenSchwierigkeiten und Bedenken anhäuft, um schließlich mehr oder minder vorsichtig, in ein Jedennoch zu münden und das rhetorisch Bezweifelte zu bejahen « -, entspreche einer »konformistischen und apologetischen Haltung « (Adorno 1977 [1962]: 459). Diese Haltung wiederum hängt für Adorno mit der »bürgerlichen Existenz« desjenigen zusammen, der von »Amts wegen Philosophie lehrt« und der die »eigenen handgreiflichen Interessen verletzt, sobald er sich dagegen äußert« (ebd.). Adorno legt - es zeigt sich auch an vielen anderen Textstellen - einen zentralen Aspekt von Seidels Circulus vitiosus analytisch klar. Er macht Paradoxien und Widersprüche sichtbar und lässt Fragen offen. Die Frage, wie die eigene Denk- und Sprechposition legitimiert werden kann, wenn diese Position lediglich ein Ausdruck einer privilegierten sozialen und historischen Situation (hier der bürgerlichen Existenz) ist, wird von Adorno zwar nicht abschließend beantwortet, aber als philosophisch relevant ausgewiesen. Ähnlich wie es bei Schlick und seinem Aufsatz »Die Wende der Philosophie« deutlich geworden ist, ${ }^{182}$ nimmt Adorno gleich zu Beginn den möglichen Einwand vorweg, dass die Frage, die er stellt, im Grunde eine traditionelle philosophische Frage sei,

182 Siehe das Unterkapitel »Eine grundsätzliche Wende der Philosophie« (S. 92-95). 
mit deren Beantwortung sich bürgerliche Philosophen ihre eigene Existenzberechtigung sichern wollten. Dass er - Adorno - dennoch ein Recht habe, diese Frage zu stellen, begründet er damit, dass er sich der Antwort auf die Frage nicht sicher sei. »Einiges Recht, trotzdem die Frage aufzuwerfen, habe ich bloß deshalb, weil ich der Antwort keineswegs gewiss bin« (ebd.). Er begründet sein Sprechen hier also gewissermaßen mit der sokratischen Figur des Nichtwissens: Er erklärt sein »Recht«, sich in den traditionellen philosophischen (bürgerlichen) Diskurs einzuschreiben, mit der Bemerkung, dass ihm bewusst sei, dass dieser Vorgang paradox ist. Er legitimiert seine eigene Position mit einer Reflexion auf die eigene Aussage.

Adorno verfolgt also eine ähnliche Strategie, wie sie weiter oben in Bezug auf das ausgestellte Unbehagen bezüglich der eigenen Programmatik deutlich geworden ist: Die Reflexion der eigenen Sprechposition und eine ausgestellte Unsicherheit werden als Begründung eingesetzt, sich dennoch mit traditionellen Fragen auseinanderzusetzen. Adorno stellt sich selbst in die Reihe all jener traditionellen Philosophen, die sich mit dem Sinn und Zweck von Philosophie auseinandersetzen, um sich gleichzeitig von ihnen zu distanzieren: Der Gegensatz, den Adorno zwischen seiner eigenen Position und denjenigen anderer Philosophen eröffnet, liegt im Argument, dass er sich - im Unterschied zu anderen Philosophen - bewusst sei, dass er seiner Antwort nicht gewiss ist.

In der Folge argumentiert er - auch hier gleichen seine Strategien denjenigen im Wiener Kreis -, dass Philosophie, wenn sie sich als System versteht, immer widersprüchlich ist. »Philosophie, die sich noch als total, als System aufwürfe, würde zum Wahnsystem « (ebd.: 461). Er diskutiert diesen Aspekt im Zusammenhang mit dem Positivismus Carnap'scher Prägung, der Ontologie Heideggers und der Dialektik in Anlehnung an Marx. Er formuliert ein der Philosophie inhärentes Problem: »Gibt sie [die Philosophie, MD] jedoch den Anspruch der Totalität auf; beansprucht sie nicht länger mehr, aus sich heraus das Ganze zu entfalten, das die Wahrheit sein soll, so gerät sie in Konflikt mit ihrer ganzen Überlieferung« (ebd.). Hier wird ein signifikanter Unterschied zum Wiener Kreis deutlich: Wo die Vertreter des Wiener Kreises aus der Einsicht, dass der Philosophie ein Totalitätsdenken inhärent ist, die philosophische Tradition toto genere ablehnen, beleuchtet Adorno diesen Aspekt genauer: Er macht die Kritik am Absolutheitsanspruch, welcher der Philosophie inhärent ist, zur Grundlage seines eigenen Erneuerungsanspruchs: Philosophie, wie sie angesichts des Unsäglichen, was geschah und weiter geschehen kann, allein zu verantworten wäre, dürfte nicht länger des Absoluten sich mächtig dünken, ja müsste den Gedanken daran sich verbieten, um ihn nicht zu verraten, und doch vom emphatischen Begriff der Wahrheit nichts sich abmarkten lassen. 
Dieser Widerspruch ist ihr Element. Es bestimmt sie als negative« (ebd.). Die einzig noch mögliche Philosophie, so lässt sich Adorno verstehen, müsse den Anspruch nach dem Absoluten aufgeben, gerade weil ihr dieses Absolute inhärent ist - und inhärent sein soll. Genau dieser Widerspruch wiederum definiere die Philosophie, wie sie einzig noch legitim ist: als Kritik.

In diesem Verfahren eingeschlossen ist zugleich eine bestimmte Form der Selbstkritik: »Zum Begriff der Philosophie gehört auch die Reflexion auf die Stellung der Philosophie in der Wirklichkeit ihrer geschichtlichen Stunde« (Sommer 2016: 24). Wie Marc Sommer schreibt, sei darin auch eine »Absetzung von der philosophischen Tradition impliziert, insofern diese es gewöhnlich verschmäht hat [...] auf ihre Stellung in und zur gesellschaftlich-geschichtlichen Wirklichkeit zu reflektieren«(ebd.). Adorno, so wird deutlich, reaktualisiert ein Philosophieverständnis, in dem die Philosophie auf sich selbst reflektiert. »Die von Adorno anvisierte Selbstreflexion impliziert damit auch eine Reflexion auf das Maß, in dem die Philosophie bis in ihr Innerstes von ihrer geschichtlichen Wirklichkeit affiziert wird « (ebd.). Wie bereits deutlich geworden ist, wendet er diesen Begriff von Philosophie auf zwei zeitgenössisch wirkmächtige philosophische Traditionen an: auf die Ontologie einerseits, auf den Positivismus andererseits.

\section{"Kein dritter Standpunkt" - eine Methode}

»Philosophische Kritik heute«, sagt Adorno in »Wozu noch Philosophie?«, sei »mit zwei Schulen konfrontiert, die als Geist der Zeit, gewollt oder ungewollt, übers akademische Gehege hinaus wirken « (Adorno 1977 [1962]: 462). Die eine sei der vom »Wiener Kreis inaugurierte logische Positivismus«, die andere bestehe in den »ontologischen Richtungen « (ebd.). Beide Schulen, so Adorno ausdrücklich, »divergieren und sind gleichwohl komplementär« (ebd.). »Positivismus und Ontologie sind einander anathema; jener hat durch einen seiner Hauptexponenten, Rudolf Carnap, die Theorie Heideggers, und zwar zu Unrecht, als sinnleer attackiert. Umgekehrt heißt das positivistische Denken den Ontologen Heideggerscher Provenienz seinsvergessen; es profaniere die eigentliche Frage « (ebd.: 463). ${ }^{183}$ Sowohl der Ontologe Heidegger als auch der Positivist Carnap verfehlen laut Adorno das primäre Ziel von Philosophie: »Sie haben Metaphysik als gemeinsamen Feind erkoren « (ebd.). Eine Folge dieser »gemeinsamen Aversion gegen Metaphysik« sei der Verlust des Denkens:

183 Adorno spielt hier vermutlich auf die Debatte zwischen Carnap und Heidegger an, die Heideggers 1929 erschienener Aufsatz »Was ist Metaphysik?« lanciert hatte. Siehe dazu das Kapitel »Philosophische Altlasten aus dem Weg räumen: Metaphysikkritik« (S. 100-105). 
»Denken wird beiden Richtungen zum notwendigen Übel, tendenziell diskreditiert. Es verliert das Moment von Selbstständigkeit. Die Autonomie der Vernunft entschwindet [...]« (ebd.: 464).

Adorno wirft Heidegger und Carnap also gewissermaßen in einen gemeinsamen Topf. Deren Kampf gegen die Metaphysik sei der falsche Weg. Es gehe um Wichtigeres: um die Unabhängigkeit des Denkens. ${ }^{184}$ Hier begegnet die Argumentationsstrategie, die vor allem bei Husserl, aber auch im Wiener Kreis sichtbar geworden ist, erneut: Indem Adorno zwei Denkströmungen seiner Zeit als in sich verfahren darstellt, bringt er seinen eigenen Zugang als jene Philosophie hervor, die einen Ausweg aus dieser verfahrenen Situation weisen kann. »Dialektik ist kein dritter Standpunkt[,] sondern der Versuch, durch immanente Kritik philosophische Standpunkte über sich und über die Willkür des Standpunktdenkens hinauszubringen « (ebd.: 467). Dass seine eigene Methode sich auf keinen Standpunkt bezieht, schreibt er auch zu Beginn der Negativen Dialektik: »Dialektik ist das konsequente Bewußtsein von Nichtidentität. Sie bezieht sich auf keinen Standpunkt« (Adorno 1966: 15). Den möglichen Vorwurf, dass der Dialektik »ihrerseits alles, was in ihre Mühle gerät, auf die bloß logische Form des Widerspruchs « hinauslaufe, weist er mit dem Argument zurück, dass man dadurch »die Schuld der Sache auf die Methoden« schiebe (ebd.).

Adorno formuliert explizit, worauf es in der hier eingenommenen Perspektive ankommt: Die Privilegierung der eigenen Zugangsweise wird dadurch begründet, dass die eigene Methode als standpunktlos vorgestellt und verteidigt wird. Mit dem Verfahren der immanenten Kritik könnten, so Adorno, die Unwahrheit von Ontologie und Positivismus aufgezeigt werden. Umgekehrt wiederum bestärkt dies den Wahrheitsgehalt der immanenten Kritik. Dass es sich dabei um eine Methode - und nicht etwa um ein philosophisches System - handelt, ist zentral: Wie es auch die Beispiele Husserl und Wiener Kreis nahelegen, werden philosophische Erneuerungen im 20. Jahrhundert durch die Entwicklung und Erhärtung von neuen Methoden und deren Anwendung auf andere Philosophien legitimiert. Gerade indem Adorno dezidiert betont und argumentiert, dass Dialektik sich - im Gegensatz zu den anderen Philosophien - auf keinen Standpunkt bezieht und so zumindest potenziell der Verdinglichung entkommen kann, bringt er sein eigenes Philosophieverständnis als einzige legitime Form von Philosophie hervor.

184 Diese Argumentationsstrategie ließe sich auch an Horkheimers Aufsatz »Der neueste Angriff auf die Metaphysik« (1937) zeigen. Horkheimer schließt seine scharfe Kritik am Wiener Kreis mit dem ironischen Satz: »Auf den neuesten Angriff darf die Metaphysik stolz sein; sie wird mit dem Denken verwechselt« (Horkheimer 1988 [1937]: 161). 


\section{Wahrheit statt Opferung des Geistes}

Die Wahrheit und damit letztlich auch die Philosophie, die Adorno verteidigt, ist - wie er 1965 in seiner Vorlesung »Zur Lehre von der Geschichte und von der Freiheit« formuliert - im Einzelnen lokalisiert: »Und das eben verweist die Erkenntnis des Einzelnen als eine philosophische Erkenntnis auf das einzige, was einem solchen Einzelnen und Zerstreuten gegenüber bleibt, - nämlich auf seine Interpretation, auf die Kunst seiner Deutung (Adorno 20o1: 184). Die im Einzelnen und Singulären überdauerte Wahrheit wiederum werde durch Kritik überliefert: »Im Fortgang solcher Kritik haben auch diejenigen Philosophien ihren Zeitkern, ihren geschichtlichen Stellenwert gewonnen, deren Lehrgehalt auf dem Ewigen und Zeitlosen beharrte « (Adorno 1977 [1962]: 459). Die Idee der Zeitlosigkeit der Wahrheit wird dadurch umgedeutet in die Idee der Wahrheit als Zeitkern. Adorno übernimmt diesen Begriff von Walter Benjamin. Dieser schreibt: »Entschiedene Abkehr vom Begriffe der >zeitlosen Wahrheit< ist am Platz. Doch die Wahrheit ist nicht - wie der Marxismus behauptet - nur eine zeitliche Funktion des Erkennens, sondern an einen Zeitkern, welcher im Erkannten und Erkennenden zugleich steckt, gebunden. Das ist so wahr, daß das Ewige jedenfalls eher eine Rüsche am Kleid ist als eine Idee (Benjamin 1982: 578$).{ }^{185}$

Adornos argumentative Reaktivierung einer traditionellen Vorstellung von Philosophie - die Philosophie als unabhängige Instanz des Denkens, die Wahrheit von Unwahrheit scheiden kann - scheint ein bewusster Akt gewesen zu sein. Er benennt sein eigenes Verhältnis zur Philosophie zu Beginn des Textes »Wozu noch Philosophie?« als »ungünstig «, »anachronistisch« und als »fatalistisch «. »Wer eine Sache verteidigt, die der Geist des Zeitalters als veraltet und überflüssig abtut, begibt sich in die ungünstigste Position. Seine Argumente klingen schwächlich beflissen. [...] Diese Fatalität muss einbeziehen, wer von der Philosophie nicht sich abbringen lässt« (ebd.: 459). Adorno positioniert, so ist deutlich geworden, seinen Anspruch auf eine selbstkritische Philosophie als eine neue Form von Philosophie und reiht diese in die philosophische Tradition ein. »Weil Philosophie zu nichts gut ist, ist sie noch nicht verjährt; und selbst darauf dürfte sie sich nicht berufen, wenn sie nicht ihre Schuld, die Selbstsetzung, verblendet wiederholen will« (ebd.: 471). Gerade

185 »Was die Bilder von den >Wesenheiten< der Phänomenologie unterscheidet, das ist ihr historischer Index. (Heidegger versucht vergeblich die Geschichte für die Phänomenologie abstrakt, durch die >Geschichtlichkeit< zu retten.) Diese Bilder sind durchaus abzugrenzen von den >geisteswissenschaftlichen $<$ Kategorien, dem sogenannten Habitus, dem Stil etc. Der historische Index der Bilder sagt nämlich nicht nur, daß sie einer bestimmten Zeit angehören, er sagt vor allem, daß sie erst in einer bestimmten Zeit zur Lesbarkeit kommen« (Benjamin 1982: 577). 
weil Adorno betont, dass diese »Schuld «, die der philosophiae perennis, d.h. der Idee ewiger Wahrheit, überliefert werde, nicht wiederholt werden dürfe (ebd.), aktualisiert er die Philosophie als ein Gebiet, das verteidigt werden muss. Er schlägt letztlich »die Treue zur Philosophie, das Festhalten des philosophischen Impulses trotz des Endes des Systems « vor (Adorno 2001: 183-184), denn dass die Philosophie als System nicht mehr möglich sei, bedeute nicht, dass sie »den Geist opfern soll« (ebd.: 184).

\subsection{Selbstreflexion als philosophisches Programm}

Die neue und zugleich alte, sich selbst reflektierende Philosophie wird von Adorno als eine Art Rettung beschrieben: Ohne die Unabhängigkeit des Denkens, also ohne eine sich selbst reflektierende Philosophie, würde die Menschheit den unberechenbaren Sachzwängen gesellschaftlicher Entwicklung überlassen werden. Das Moment der Krise, das vor allem am Beispiel von Husserl deutlich geworden ist, tritt auch hier hervor: Die Philosophie - in Form der Unabhängigkeit des Denkens - wird als eine Form des Widerstandes in einer in der Krise steckenden Welt dargestellt. Gerade indem Horkheimer und Adorno den Verblendungszusammenhang der Philosophie dezidiert offenlegen, evozieren sie Möglichkeiten, wie Philosophie - ihrer Unmöglichkeit zum Trotz - dennoch praktiziert werden kann: nämlich als sozialwissenschaftlich informierte Kritik. ${ }^{186}$ Gleichzeitig aktualisieren die Autoren die Relevanz der Philosophie als Gesellschaftskritik. ${ }^{187}$

Die philosophische Erneuerung durch die Kritische Theorie ist konstitutiv mit der philosophischen Erneuerung des Marxismus in den 1920er-Jahren verknüpft. Sie erzielt ihre Wirkung wesentlich durch einen spezifischen Umgang

186 Dass Horkheimer und Adorno die Kritische Theorie als eine neue, sozialwissenschaftlich ausgerichtete Philosophie institutionalisierten und dass dies in einem Spannungsverhältnis zu ihrem marxistisch geprägten philosophiekritischen Anspruch stand, beschreibt Friederich O. Wolf 1972: »Das >Absterben der Philosophie< und ihre >Aufhebung ¿ durch die >kritische Theorie der Gesellschaft< erschienen zunächst als ebenso sinnfällige wie theoretisch wohlbegründete Tatsachen, daß es sich die Mühe nur unter besonderen Umständen lohnt, die Philosophie als faktisch noch existierende akademische Disziplin zu kritisieren« (Wolf 1972: 31).

187 In ihrer Studie Zum Verhältnis von Gesellschaftstheorie und Erkenntnistheorie. Untersuchungen zum Totalitätsbegriff in der kritischen Theorie Adornos argumentiert Christel Beier, dass Adornos Intention, Gesellschaftstheorie philosophisch zu begründen, die Ebene einer wissenschaftlichen Thematisierung von Gesellschaft systematisch verfehle (Beier 1977). 
mit dem Totalitätsbegriff: ${ }^{188}$ Die Gesellschaft wird von Adorno in Anlehnung an Lukács als ein »totales Gefüge« bestimmt, das potenziell erfasst werden könne. ${ }^{189}$ Obwohl Adorno dazu aufruft, die Philosophie müsse lernen, auf die Totalitätsfrage zu verzichten, verzichten er und Horkheimer selbst nicht auf das Konzept der Totalität. Der Verzicht besteht vielmehr im Anspruch, diese Totalität vermittels der Philosophie (wie es der idealistisch-metaphysischen Philosophie unterstellt wird) oder vermittels eines Klassenstandpunktes (wie es dem Marxismus unterstellt wird) erfassen zu können. Dadurch wird eine Umkehrung der Funktion der traditionellen Philosophie möglich. Die >traditionelle< Aufgabe der Philosophie, nämlich die »Totalität der Wirklichkeit« erkennen zu können, wird umgedeutet in die `kritischeく Aufgabe der Philosophie, nämlich die »Totalität der Wirklichkeit« kritisieren zu können.

Auf der Basis des Scheiterns einer Verwirklichung der Philosophie in der Praxis rekonzeptualisieren dieVertreter der Kritischen Theorie die marxistische Philosophie durch eine Kooperation mit den empirischen Sozialwissenschaften als abstraktes Deutungsinstrument gesellschaftlicher Verhältnisse: »Dass die philosophische Arbeit eine abstrakte war und ist, gründet in den gesellschaftlichen Daseinsverhältnissen. Das Festhalten an der Abstraktheit in der Philosophie ist der Sachlage entsprechender und kommt der Wahrheit näher als jene pseudo-philosophische Konkretheit, die sich von oben zu den gesellschaftlichen Kämpfen herablässt« (Horkheimer/Marcuse 1970 [1937]: 640). Mit Rüdiger Dannemanns Einschätzung, dass Adornos Konzeption »sich in unüberbietbarer Weise [...] gegen eine Praxisorientierung « sperre (Dannemann 1987:146), wird ein zentraler Aspekt formuliert: In der Kritischen Theorie werden marxistische Theorieelemente aus den 192oer-Jahren adaptiert, um diese im Wissenschaftskontext der Bundesrepublik der 195oerbis 1970er-Jahre explizit in die Akademie zu implementieren.

Am Beispiel von Horkheimer und Adorno wird eine Selbstpositionierungsstrategie greifbar, die ihre Stärke wesentlich durch das Argument erhält, es handele sich bei der Philosophie um eine Methode und nicht um die

188 Insofern auch Heidegger in der Folge von Husserl als `Erneuerer der Philosophie gilt, ist in diesem Zusammenhang Lucien Goldmanns These, wonach sich Lukács' Totalitätsbegriff und Heideggers Seinsbegriff in vielen Aspekten überschneiden würden, bezeichnend: »Was Heidegger uns von der Kategorie des Seins sagt, stand bereits bei Lukács anläßlisch der Totalität« (Goldmann 1975: 127).

189 Adornos berühmte Definition lautet: »Mit Gesellschaft im prägnanten Sinn meint man eine Art Gefüge zwischen Menschen, in dem alles und alle von allen abhängen: in dem das Ganze sich erhält nur durch die Einheit der von sämtlichen Mitgliedern erfüllten Funktionen und in dem jedem Einzelnen grundsätzlich eine solche Funktion zufällt, während zugleich jeder Einzelne durch seine Zugehörigkeit zu dem totalen Gefüge in weitem Maße bestimmt wird« (Adorno 1956: 22). 
Verteidigung wissenschaftlicher Standpunkte. Es ist eine Strategie, die auch bei Husserl und den Vertretern des Wiener Kreises sichtbar geworden ist: Die eigene Positionierung wird durch die Anwendung einer neuen Methode auf andere Wissenschaften und Theorien erwirkt. Die Anwendungen in der Kritischen Theorie zielen weit expliziter als in den anderen Beispielen auf die Philosophie selbst. Wo Husserl und der Wiener Kreis ihre Neupositionierung wesentlich durch die Auseinandersetzungen mit anderen Wissenschaften entwickeln, wird die Neupositionierung der Kritischen Theorie vorrangig durch die kritische Auseinandersetzung mit der Philosophie, deren Tradition und vor allem mit zeitgenössischen Philosophien entwickelt. »Die Entwicklung der negativen Dialektik [...] vollzieht sich in Adornos Werk über eine Auseinandersetzung mit der Phänomenologie von Husserl und Heidegger« (Römer 2012: 67).

Durch Adornos und Horkheimers Aktualisierungsstrategien wird die Möglichkeit einer sich selbst reflektierenden Philosophie erneuert. »Kritische Theorie heißt demnach auch, dass die Theorie zur Selbstkritik in diesem grundsätzlichen Sinne fähig ist « (Thomä 20o6: 44). Wie gezeigt ist diese Forderung nach philosophischer Selbstkritik gleichzeitig eine Begründungsstrategie. An dieser Stelle wird der Unterschied zwischen Seidel (als einem in der Philosophie nicht kanonisierten Autor) und Adorno (als einem Erneuerer des philosophischen Kanons) signifikant: Wo Seidel seinen Standpunkt - wie oben gezeigt - im Zusammenhang mit anderen Disziplinen beständig selbst reflektiert, fordert Adorno eine sich selbst reflektierende Philosophie. Die Reflexion seines eigenen Standpunkts verbleibt dadurch einer philosophieinternen Logik verhaftet: Er schreibt sich selbst das Recht, als Philosoph zu sprechen, mit dem Argument zu, dass er seinen Standpunkt als Philosoph selbst reflektiere. Ungesagt bleibt, was eine solche Reflexion, würde sie disziplinenübergreifend betrieben, für Fragen aufwerfen würde. Etwa: Wer spricht von welcher Position über wen und warum? Wie W. Meier, der Verfasser des Vorworts der Neuauflage von Bewußtsein als Verhängnis in den 197oer-Jahren formuliert, könne dieses Problem »auf den so Fragenden zurückschlagen « (Meier 1979: o.S.). Wo dieses »Zurückschlagen« bei Seidel in aller Vehemenz zum Vorschein kommt, wird es von Horkheimer und Adorno philosophisch operationalisiert: Selbstreflexion und Philosophie werden miteinander verknüpft. Die Reflexion des eigenen Standpunkts erscheint bei Adorno somit als argumentative Strategie, Philosophie und philosophische Selbstkritik zu legitimieren, nicht aber als Möglichkeit, die Philosophie und deren Standpunkte selbst spiegeln zu können. (Dieser Aspekt wird im nachfolgenden Fazit noch detaillierter ausgeführt.) 
Die zu Beginn des Kapitels an Seidels Bewußtsein als Verhängnis nachgezeichnete Krise, nämlich der Verlust der Legitimität des philosophischen Standpunkts, wird von Horkheimer und Adorno also aufgenommen und produktiv gewendet. Indem sie, wie Thomä schreibt, die Fähigkeit der Selbstkritik für die Philosophie aktualisieren, reagieren sie auf die durch andere Wissenschaften (vorrangig Soziologie, Psychologie und Psychoanalyse) ausgelöste Bedrohung, die Philosophie könnte ihre Legitimität in gesellschaftlicher, aber auch wissenschaftlicher Hinsicht verlieren. Indem Horkheimer und Adorno die Kritik als jene einzige Funktion behaupten, in der Philosophie noch legitim sein kann, klammern sie die Möglichkeit aus, dass diese Setzung gespiegelt werden kann. Die Ausklammerung der Möglichkeit, ihren Standpunkt selbst infrage zu stellen, eröffnet paradoxerweise die Möglichkeit einer sich selbst reflektierenden Philosophie. In gänzlich unterschiedlicher Weise als Husserl und die Vertreter des Wiener Kreises aktualisieren dadurch auch Adorno und Horkheimer einen Machtanspruch der Philosophie: Der Philosophie kommt im Verhältnis zu den anderen Wissenschaften das Primat zu, auf sich selbst reflektieren zu können.

Mit der Kritischen Theorie, so kann abschließend festgehalten werden, wird Seidels Schlussfolgerung, nämlich dass das analytische Bewusstsein an seinem eigenen Geist - der Wahrheit - zugrunde geht (Seidel 1927: 205), für die Philosophie produktiv umgewendet:

Philosophie insistiert darauf, daß die Handlungen und Ziele der Menschen nicht das Produkt blinder Notwendigkeit sein müssen. Weder wissenschaftliche Begriffe noch die Form des gesellschaftlichen Lebens, weder die herrschende Denkweise noch herrschende Sitten sollten gewohnheitsmäßig übernommen und unkritisch praktiziert werden. Der Impuls der Philosophie richtet sich gegen bloße Tradition und Resignation in den entscheidenden Fragen der Existenz; sie hat die undankbare Aufgabe übernommen, das Licht des Bewußtseins selbst auf jene menschlichen Beziehungen und Reaktionsweisen fallen zu lassen, die so tief eingewurzelt sind, daß sie natürlich, unveränderlich und ewig scheinen. (Horkheimer 1988 [1940]: 336-337)

Wo für Seidel das Bewusstsein an der Wahrheit - sprich Philosophie - zugrunde geht, fordern es Horkheimer und Adorno als Licht zurück, das den Trug ewiger Wahrheiten - sprich Philosophien - erhellen kann.

\section{Exkurs: Wahrheit und Macht}

Der philosophische Erneuerungsanspruch, der in der Kritischen Theorie sichtbar wird, ist mit der Perspektive des vorliegenden Buches enger verbunden als die anderen beiden Beispiele. Wie die geschilderte Nähe von Seidel mit 
der Kritischen Theorie nahelegt, beschäftigen sich Horkheimer und Adorno weit intensiver als Husserl oder die Vertreter des Wiener Kreises mit der Legitimation der Philosophie und der Wissenschaft im Allgemeinen. Die Denkrichtung, die Adorno und Horkheimer einschlagen, nimmt ihren Anfang in einer Problematik, die von Seidel mit Verzweiflung artikuliert und in der Dialektik der Aufklärung ihre akademische Entsprechung gefunden hat: im Prozess der Aufklärung und in der Entwicklung der modernen Rationalität als Prozess eines fortschreitenden Verhängnisses. Wissenschaft und Philosophie stehen mit der Wahrheit nicht mehr in einer Reihe, sondern im Widerstreit.

Im Rückblick betrachtet ist die wissenschaftliche Disziplinierung, aus der das vorliegende Buch entstanden ist, als eine Reaktion darauf zu verstehen, dass der Vernunft, Rationalität, Wissenschaft, Theorie und Philosophie keine Garantie auf Wahrheit zugrunde liegen. Wahrheit - so wurde in Fächern wie Wissenschaftsforschung, Geschlechterforschung, Soziologie und allgemein in den Kulturwissenschaften gelehrt und gelernt - sei immer nur in Relationen, immer nur historisierend und nie unabhängig von Machtverhältnissen denkbar. Daraus folgt, dass auch der eigene Forschungsblick immer situiert, beschränkt, verkörpert und folglich perspektivisch ist. Dass der Seidel'sche Teufelskreis in diesem Buch eine so zentrale Rolle einnimmt, ist der Problematik geschuldet, die daraus folgt: Von welcher Position aus kann die Gegenwart erfasst werden, wenn das eigene Denken selbst nicht außerhalb dieser Gegenwart steht? Wie können Wahrheitsansprüche kritisiert werden, ohne dass dadurch der eigene Standpunkt zum Maßstab aller anderen Standpunkte erklärt wird?

Eine Möglichkeit, mit dieser Problematik umzugehen, ist, die Art und Weise, wie Wahrheiten produziert werden, selbst zum wissenschaftlichen Gegenstand zu erklären. Insbesondere Michel Foucault hat diese Aufgabe gewissermaßen zu einem neuen philosophischen Programm erhoben. ${ }^{190}$ Unabgeschlossen und im Sinne eines Ausblicks soll an dieser Stelle kurz darauf eingegangen werden. Erstens, weil Foucaults Perspektive für die in diesem Buch eingenommene Zugangsweise prägend ist, und zweitens, weil seine tentativen Analysen über die antike parrhesia es ermöglichen, aus einem weiteren Blickwinkel zu erfassen, dass die Philosophie engen disziplinären Grenzen unterliegt.

Seit Friedrich Nietzsche liege die Aufgabe der Philosophie, so konstatiert Foucault in ähnlicher Weise wie Horkheimer und Adorno, nicht mehr darin,

190 Analog zu den untersuchten Philosophen verficht auch Foucault eine Definition, was Philosophie heute ist und sein sollte. Sie sei »eine Askese, eine Übung seiner selber, im Denken« (Foucault 1989 [1984]). Es gehe darum, zu »wissen, in welchem Maße die Arbeit, seine eigene Geschichte zu denken, das Denken von dem lösen kann, was es im Stillen denkt, und inwieweit sie es ihm ermöglichen kann, anders zu denken« (ebd.). 
eine Wahrheit zu suchen, die für alle zu allen Zeiten gültig ist, sondern sie liege darin, die Gegenwart zu diagnostizieren (Foucault 1974: 12). Mit Immanuel Kants Definition der Aufklärung sieht Foucault den Beginn einer ganz spezifischen philosophischen Reflexion entstehen, nämlich das aktuelle Geschehen in eine Beziehung zur Geschichte zu setzen. ${ }^{191}$ Diese philosophische Reflexiondieses ethos, wie Foucault schreibt - sei eine »Grenzhaltung « (Foucault 2007 [1994]: 185), d.h. auch und vor allem: Wahrheit, Subjekt und Macht seien einander durchkreuzende und bedingende Aspekte, deren Beziehungen es zu untersuchen gelte. ${ }^{192}$ „Was sind denn zuletzt die Wahrheiten des Menschen?«, fragt Nietzsche, auf den sich Foucault bezieht, und antwortet: »Es sind die unwiderlegbaren Irrthümer des Menschen« (Nietzsche 2003 [1882/87]: 518). Die Wahrheit sei deshalb ein unwiderlegbarer Irrtum, sagt wiederum Foucault, »weil die Geschichte ihn so hartgesotten hat, dass er sich nicht mehr verändern lässt« (Foucault 2002 [1971]: 170). Um die Gegenwart - oder zumindest Teile davon - zu erfassen, gelte es, Wahrheiten im Kontext von Macht- und Herrschaftsverhältnissen zu verstehen und zu untersuchen. Dies wiederum sei eine Form von Kritik: »Kritik heißt herausfinden, auf welchen Erkenntnissen, Gewohnheiten und erworbenen, aber nicht reflektierten Denkweisen die akzeptierte Praxis beruht (Foucault 2005 [1981]:221). Foucault aktualisiert und rehabilitiert, ähnlich wie es an den anderen drei Beispielen dieser Arbeit deutlich geworden ist, mit dem Rückbezug auf die philosophische Tradition ein neues Philosophieverständnis. Auch an ihm könnte ein philosophischer Erneuerungsanspruch abgelesen werden, der in den hier vorgestellten Mustern bearbeitbar wäre. ${ }^{193}$ In diesem Erneuerungsanspruch werden philosophische

191 »Ich finde ihn [Kants Text Beantwortung der Frage: Was ist Aufklärung?, MD] [...] erstaunlich und interessant, weil sich dort ein Philosoph zum ersten Mal als Philosoph die Aufgabe stellt, nicht nur das System oder die metaphysischen Grundlagen wissenschaftlicher Erkenntnis, sondern ein historisches Geschehen zu analysieren, und noch dazu ein ganz aktuelles« (Foucault 2005 [1982]: 280). Mit Kant tauche also die Frage nach der Gegenwart als einem historischen Ereignis in der philosophischen Diskussion erstmals auf. »Die Philosophie als Erscheinungsort einer Gegenwart, die Philosophie als Fragen nach dem philosophischen Sinn der Gegenwart, zu der sie selbst gehört, die Philosophie als Befragung dieses swir<, dem der Philosoph zugehört und gegenüber welchem er sich verorten muss, das, scheint mir, zeichnet die Philosophie als Diskurs der Moderne, als Diskurs über die Moderne aus« (Foucault 2009 [2008]: 29).

192 Vladimir Gradev stellt hierzu fest, dass Foucaults Spätwerk darauf konzentriert sei, zu zeigen, dass es weder eine ursprüngliche noch eine universelle Wahrheit gebe, die in versteckter Weise in der okzidentalen Metaphysik zu finden wären, sondern dass die Wahrheit im Gegenteil ganz und gar eine die Machtverhältnisse durchquerende Kraft sei (Gradev 1994: 44).

193 Gemäß Andrea Hemminger gehe es Foucault um »die in die Krise geratene Subjektphilosophie« (Hemminger 2004: 137). Dieser Kommentar legt nahe, dass Foucault die Krise 
Erkenntnisse radikal historisiert, um genau dadurch Aussagen über die Gegenwart machen zu können. Wahrheit tritt hier, ähnlich wie in der Kritischen Theorie, nur kontextabhängig zutage. ${ }^{194}$

In seinen letzten Vorlesungen (Foucault 1996; 2009 [2008]; 2010 [2009]) thematisiert Foucault diesen Erneuerungsanspruch weit expliziter als in seinen früheren Schriften, indem er die antike Figur der parrhesia ${ }^{195}$ und damit zusammenhängend die antiken Kyniker untersucht. Die parrhesiastische Rede sei der Elite, also den freien und erwachsenen Männern, vorbehalten. »La position du parrésiaste ne peut être occupée que par l'homme adulte libre, membre de la Cité. En principe, les étrangers, les femmes et les esclaves ne peuvent pas dire la vérité« (Gradev 1994: 45). Wahrheitsproduktionen, so folgt daraus, sind an die soziale Situation von Personen gebunden, also kontextbezogen. »Fremde«, »Frauen« und »Sklaven« sind in der antiken Philosophie nicht in den Bereich eingeschlossen, in dem Wahrheit gesprochen wird.

Foucault entwickelt in seinen Vorlesungen ausgehend von dieser konstitutiv freien und männlichen Figur des parrhesiastes und ausgehend von den Kynikern ein spezifisches, affirmativ verstandenes Verständnis der Philosophie als Mut zur Wahrheit. ${ }^{196}$ In seiner Darstellung dramatisieren und inszenieren Kyniker - für Foucault verkörpern sie die Grenze des philosophischen Diskurses - philosophische Prinzipien durch das Leben selbst.

des Subjekts konstruktiv aufnimmt, um davon ausgehend ein neues philosophisches Programm zu entwickeln.

194 Die Figur des »Mutes zur Wahrheit« wird von Foucault mit jener Form von Kritik kurzgeschlossen, die er mit der Aufklärung hervortreten sieht: Es handle sich dabei um ein ethos. Dieses ethos beinhalte eine Art philosophischen Fragens, die »zugleich die Beziehung zur Gegenwart, die geschichtliche Seinsweise und die Konstitution seiner selbst als autonomes Subjekt problematisiert« (Foucault 2007 [1994]: 182). Diese Beziehung verbinde uns mit der Aufklärung nicht mittels der »Treue zu den Elementen einer Lehre«, sondern vielmehr durch »die permanente Reaktivierung einer Haltung « (ebd.). Dieses philosophische ethos könne als eine »permanente Kritik unseres geschichtlichen Seins« (ebd.: 182) bestimmt werden. Zur Kritik als einer verkörperten Haltung siehe Dätwyler/Weibel 2015 .

195 Etymologisch bedeutet parrhesia »alles zu sagen« (von griech. pan (alles) und rhema (das Gesagte)).

196 Auf der einen Seite schafft Foucault also Argumentationsinstrumente und eröffnet Perspektiven, die es ermöglichen, den philosophischen Diskurs unter anderen, neuen Vorzeichen zu denken, nämlich im Zusammenhang mit Machtverhältnissen. Auf der anderen Seite reproduziert Foucault ein Denken, das auf Ausschlüssen basiert: Die zentrale und wichtige Bemerkung nämlich, dass das Wahrsprechen ganz bestimmten Personen vorbehalten ist, hat für Foucaults Verständnis der parrhesia und seinen Philosophiebegriff letztlich keine Konsequenzen. Beide Aspekte - die Generierung neuer Denkmöglichkeiten und die Reproduktion alter »hartgesottene[r]« Wahrheiten - laufen auch in aktuellen philosophischen Erneuerungen parallel. 
Der Kynismus, der sich in der konkreten Lebensweise einer Person äußert, sei also jene »Fratze, die die Philosophie sich selbst schneidet, jener gebrochene Spiegel, in dem der Philosoph sich zugleich sehen, aber nicht erkennen soll« (Foucault 2010 [2009]: 350). Mit seinem Rückbezug auf die griechische Philosophie begründet und legitimiert Foucault hier ein Verständnis der Philosophie, das die Lebensweise einer Person ins Zentrum des philosophischen Interesses rückt. Es hat zugleich die Funktion, die vorherrschende Philosophie zu spiegeln. »Die Kyniker stellen nämlich in ihrer ganzen Aggressivität den Moment dar, in dem die Selbstaskese nur noch den Wert hat, als Provokation an die anderen gerichtet zu werden, weil es darum geht, aus sich selbst ein Schauspiel zu machen, das jeden mit seinen eigenen Widersprüchen konfrontiert (Gros 2010 [2009]: 458). Die Figur des »Mutes zur Wahrheit« stelle eine von zwei historischen Gründungslinien von Kritik dar: In der einen Form, der »kynischen Modalität«, trete die Wahrheit durch die Lebensweise einer Person in Erscheinung und sei somit an den bios gebunden. Die andere Form, die "platonische Modalität«, sei nicht primär an das Leben, sondern vielmehr an den logos und somit an metaphysische Voraussetzungen gebunden. In der ersten Modalität werde Wahrheit durch ein »anderes Leben « (durch die Lebensweise einer Person) manifest, wohingegen in der zweiten Modalität Wahrheit gewissermaßen abstrakt-metaphysisch durch die Vorstellung einer »anderen Welt« hervorgebracht und somit entkörpert werde. Beide Bereiche treten gemäß Foucault in der konkreten Lebenswelt nicht getrennt voneinander auf, vielmehr seien sie konstitutiv miteinander verschränkt. Allerdings habe die platonische und in diesem Sinne metaphysische Modalität die sich an der Lebensweise orientierende Modalität im Laufe der Geschichte überlagert und verdeckt (ebd.: 320-323).

Diese von Foucault in seinen Vorlesungen lediglich skizzierten Überlegungen korrespondieren mit Seidels Zwangslage, dass nämlich Wahrheit, Geist und Bewusstsein einander bedingende Aspekte seien. Seidel denkt gegen die zweite, d.h. metaphysische Modalität an, ohne sie affirmativ zu überschreiten. Besonders eindrücklich wird dies im bereits zitierten Ende von Bewußtsein als Verhängnis: »Mögen die Waffen gegen das allein herrliche analytische Bewusstsein immer schärfer gespitzt werden und es an seinem eigenen Geiste zugrunde gehen - und wäre dieser sogar: die Wahrheit selbst « (Seidel 1927: 205). In der Rezeptionsgeschichte hingegen wird Seidel zu einer Figur, die in der ersten, in der »kynischen Modalität« zu verorten ist: Er wird - insbesondere im Zusammenhang mit seinem Suizid - zu einer tragischen Figur stilisiert, in der Leben und Werk deckungsgleich sind. Dadurch wird eine Form von Wahrheit hervorgebracht und verteidigt, die ihre Wirkung aus der Suggestion eines authentisch gelebten Lebens zieht. Wie im Kapitel zu Seidel 
ausgeführt wurde, wird in dessen Rezeptionsgeschichte deutlich, dass diese Form von Wahrheit allgemeinere Aussagen beansprucht: Seidel und sein Text werden - zeitdiagnostisch - als Exempel für eine spezifisch historische Situation rezipiert und interpretiert.

Inwiefern sich Foucaults kynische Kritik tatsächlich an der Figur Seidel festmachen lässt und ob dessen philosophische Selbstzerfleischung tatsächlich Foucaults platonischer Modalität entspricht, ist nicht entscheidbar. Unbestritten aber bleibt, dass die Figur Seidel in der diffizilen Mischung aus Person und Werk einen Kynismus verkörpert, der den Philosophen des frühen 2o. Jahrhunderts einen Zerrspiegel vorhält. 


\section{Philosophische Selbstpositionierungen - Fazit}

An drei Beispielen aus dem philosophischen Kanon des 20. Jahrhunderts wurden in diesem Buch Selbstpositionierungsstrategien von Philosophen oder philosophischen Gruppen im Hinblick auf ihre Umgangsweisen mit anderen Disziplinen analysiert. Als Kontrastfolie fungierte der Text Bewußtsein als Verhängnis von Alfred Seidel. Von welcher Position aus, so eine von Seidels unterschwellig traktierten Problematiken, lassen sich andere philosophische Positionen analysieren und möglicherweise kritisieren? Seidels Gedankengänge haben innerphilosophische Dynamiken greifbar gemacht, die von kanonisierten Philosophen nicht erfasst werden: Sie zeigen, dass Philosophen insbesondere dort blinde Flecken generieren, wo sie sich mit der Selbstbegründung der Philosophie im Verhältnis zu anderen wissenschaftlichen Methoden oder Fragestellungen beschäftigen. Seidels Denken ereignet sich sozusagen dort, wo Philosophen aus sicherer Distanz zu denken anfangen und ihren Gegenstand als ein vermeintlich objektiv beobachtbares Gegenüber bestimmen: innerhalb von Krisen, d.h. an den Grenzen, die den philosophischen Diskurs von anderen Diskursen trennen. Wo Seidel die von anderen Wissenschaften ausgelösten philosophieinternen Krisen durchdenkt und - so macht es den Anschein - gleichzeitig existenziell erfährt, werden sie von den untersuchten Philosophen kritisch aufgenommen, objektiviert und mit gezielten Strategien für die Philosophie und Wissenschaft produktiv gemacht. Die Analysen dieses Buches haben gezeigt, dass Philosophen in unterschiedlichen Nuancierungen auf Krisen reagieren, um davon ausgehend philosophische Neupositionierungen und Neubegründungen dessen, was Philosophie sein kann und soll, argumentativ zu erhärten. Husserl nimmt die Gefahr eines Verlustes der Unabhängigkeit des philosophischen Denkens durch die Psychologisierung des Geistes auf, um die Philosophie als Phänomenologie zu erneuern. Der Wiener Kreis geht von der Bedrohung aus, die Philosophie verliere ihren Objektivitätsanspruch aufgrund naturwissenschaftlicher Wahrheitsansprüche, und aktualisiert die Philosophie als Logik und Sprachanalyse. Die Kritische Theorie nimmt die Angriffe, die Philosophie könne ihre Standpunkte grundsätzlich nicht mehr legitimieren, da das Bewusstsein durch gesellschaftliche Strukturen bestimmt werde, zum Anlass, die Philosophie als Kritik zu erneuern. 
Die Analysen der jeweiligen Selbstpositionierung haben sichtbar gemacht, dass die Setzung von bestimmten Prämissen in all diesen Argumentationen konstitutiv ist. Die behandelten Philosophen behaupten ihre eigene Position als richtig und bauen ihre Argumente auf diesen Setzungen auf. Die Singularitätsansprüche, die aus den jeweils neuen analytischen und methodischen Grundlagen resultieren, sind so der Selbstkritik entzogen, und dadurch soll eine erneute Destabilisierung vermieden werden. - Diese Schlussfolgerungen sollen hier noch genauer ausgeführt werden. In einem ersten Schritt werde ich einzelne der herausgearbeiteten Strategien nochmals zusammenfassend darstellen, in einem zweiten Schritt - ausgehend von meiner eigenen Positionierung - ein kurzes Fazit ziehen.

Singularitätsansprüche verteidigen: Selbstbegründungen und singuläre Selbstbehauptungen bedingen sich gegenseitig: So ist die Begründung der Phänomenologie untrennbar mit dem Anspruch verknüpft, diese Philosophie sei der richtige Weg. Die Begründung der Logik als Fundament aller Wissenschaften wiederum ist untrennbar mit dem Anspruch verknüpft, diese Philosophie sei die einzig gültige Philosophie. Und die Begründung der Philosophie als Kritik schließlich ist untrennbar mit dem Anspruch verknüpft, diese Philosophie sei die einzig noch zulässige Form von Philosophie. Kurz: Die Bestimmung davon, was Philosophie ist, und die Begründung einer neuen philosophischen Position bedingen sich gegenseitig. Sowohl Husserl als auch Carnap sowie Horkheimer und Adorno bringen in je unterschiedlicher Weise Argumente dafür an, weshalb ihre eigene Neudefinition die einzig (noch) mögliche Art und Weise wäre, Philosophie zu betreiben. ${ }^{197}$ Dieser Singularitätsanspruch des eigenen Standpunkts wird jeweils durch Strategien der Delegitimierung anderer philosophischer Positionen hergeleitet.

197 Husserl argumentiert mit der aus seiner Sicht unzulässigen Trennung der Wissenschaften in einen natur- und einen geisteswissenschaftlichen Bereich - die einzig mögliche Instanz, die in dieser verfahrenen Situation als Vermittlung fungieren könne, sei die Philosophie in Form der Phänomenologie. Er impliziert, dass jede andere Philosophie überflüssig werden wird, wenn seine Forderung >Zurück zu den Sachen selbst! $<$ methodisch korrekt durchgeführt würde. Und die Vertreter des Wiener Kreises argumentieren mit den naturwissenschaftlich-technischen Entwicklungen, die von einer traditionellmetaphysischen Philosophie nicht mehr eingeholt werden könnten - deswegen benötige es einer auf naturwissenschaftlichen Modellen streng aufbauenden Philosophie. Die logische Analyse ersetze jede andere Weise des Philosophierens. Horkheimer und Adorno schließlich argumentieren mit dem Selbstzerstörungspotenzial der Vernunft: denn ebendieses hätten die historischen Katastrophen des 20. Jahrhunderts sichtbar gemacht, und unter dieser Voraussetzung sei Philosophie nur noch in negativer Weise, d.h. als Kritik, zulässig. Das Verfahren der >immanenten Kritik«mache genau dies deutlich. 
Zeitgenössische Philosophien kritisieren: Der in der Philosophie ausgeprägte (und sich auch in der vorliegenden Arbeit widerspiegelnde) »Parteienstreit«, der sich in der Nennung von Eigennamen äußert (Schnädelbach 1983: 120), ist für die Etablierung neuer Philosophien entscheidend: Philosophen positionieren dadurch ihre Erneuerungen im philosophischen Diskurs, wobei der eigentliche Auslöser dieser philosophieinternen Krisen hier in allen Fällen in anderen Wissensgebieten liegt. Durch diese diskursive (Über-) Setzung wird der hegemoniale Wissensanspruch der Philosophie etabliert und zugleich eskamotiert, dass die angesprochenen Gefährdungen der Philosophie als Wissenschaft auch ihre neuen Denkmöglichkeiten bedingen. Die unterschiedlichen Personifizierungen von Philosophien bzw. philosophischen Traditionen zeigen die Einschreibung der Autoren in den philosophischen Diskurs ihrer Zeit auf einer allgemeinen Ebene. In diskurstheoretischer Hinsicht werden hier Ähnlichkeiten des Wiener Kreises mit der Kritischen Theorie auffällig: In beiden Traditionen spielt die Kritik an der herkömmlichen und zeitgenössischen Philosophie eine zentrale Rolle, was in den dargestellten Querelen besonders prägnant zutage tritt. ${ }^{198}$ Dass Adorno - wie auch Carnap - seine Position gerade von der Ontologie Heideggers, dessen Philosophie in der Tradition der Phänomenologie steht, dezidiert abgrenzt, ist in diesem Zusammenhang zentral. Dieter Thomä stellt dazu fest: »Adornos Verhältnis zu Heidegger ist von radikaler Konkurrenz geprägt. Bekanntlich ist jede Konkurrenz dadurch gekennzeichnet, dass es den Beteiligten um das Selbe geht, damit aber eigene Absichten verfolgt werden « (Thomä 20o6: 46). ${ }^{199}$ Wo die Erneuerungsansprüche des Wiener Kreises und der Kritischen Theorie wesentlich auf der Grundlage einer Kritik an der zeitgenössischen, als verfehlt betrachteten Philosophie begründet werden, begründet Husserl seinen Erneuerungsanspruch auf der Grundlage einer Kritik an der zeitgenössischen Wissenschaftslandschaft im Allgemeinen: Seiner Auslegung der Wissenschaften als einer in zwei Sphären getrennten Landschaft, in der die Philosophie als Bindeglied zu fungieren habe, liegt weniger eine Kritik an

198 Zum Verhältnis zwischen Adorno und Heidegger vgl. Thomä 2005. Es gebe nicht viele symmetrische Bezugnahmen auf beide Denker; eine unter ihnen stammt von Schnädelbach. Aufschlussreich ist der Hinweis Thomäs, dass Adornos Kritik an Heidegger bei diesem auf keinerlei Echo gestoßen sei. Überliefert sei nur Heideggers lakonische Bemerkung, dass er nichts von ihm (Adorno) gelesen habe. Thomä stellt fest, dass es »eher kurios« sei, einen Philosophen, zu dem man in Differenz steht, überhaupt gar nicht zu erwähnen (ebd.: 32). Bei Heidegger, so eine Folge daraus, könnte möglicherweise eine hier nicht herausgearbeitete Argumentationsstrategie sichtbar werden: die Strategie des Ignorierens.

199 Diese Absichten wurden im Zusammenhang mit den politischen Implikationen des Wiener Kreises angesprochen. Siehe das Unterkapitel »Eine politisch und wissenschaftlich neutrale Instanz« (S. 118-126). 
der Philosophie - seine Disziplinenkritik richtet sich auf die Psychologie als eine Kritik an zeitgenössischen wissenschaftlichen und philosophischen Strömungen zugrunde. Im Wiener Kreis und in der Kritischen Theorie hingegen wird gegen die Philosophie und deren Tradition polemisiert, um genau dadurch, d.h. ex negativo, eine Position innerhalb dieser Tradition zu besetzen.

Neue Methoden entwickeln und anwenden: Der jeweilige Erneuerungsanspruch wird in jedem der drei Beispiele mit der Entwicklung einer neuen Methode vorgebracht. So ist die Wesensanalyse des Bewusstseins in Husserls Phänomenologie der einzig mögliche Weg, die Welt- und Lebensrätsel in ihrem Grund zu verstehen. Für die Vertreter des Wiener Kreises bildet die logische Analyse das Fundament, auf das jedes andere wissenschaftliche Wissen zurückgeführt werden kann. Und für Horkheimer und Adorno schließlich ist das kritische Verfahren (bei Adorno: die immanente Kritik) die einzig mögliche Weise, wie - angesichts der Katastrophen des 20. Jahrhunderts überhaupt noch Philosophie betrieben werden kann und darf. ${ }^{200}$ Erst indem die Anwendungen dieser Methoden auf die Philosophie generell und auf zeitgenössische Philosophien im Besonderen plausibilisiert werden, kommt es zu einer Begründung neuer Positionen. Husserl möchte die aus seiner Sicht unhaltbare Trennung zwischen Natur- und Geisteswissenschaften überwinden und sieht dafür die phänomenologische Methode vor. Die Vertreter des Wiener Kreises streben die grundsätzliche Überwindung der Metaphysik an und finden in der Logik die geeignete Methode. Adorno schließlich wendet für seine Kritik am Positivismus und an der Ontologie die dialektische Methode auf diese beiden Positionen an. Erst durch die praktische Anwendung neuer Methoden auf andere Philosophien kann sich ein neues philosophisches Lehrgebäude im philosophischen Diskurs etablieren. Das heißt, alle untersuchten Philosophen begründen ihre Positionen prospektiv: Erst indem sie ihre neuen philosophischen Methoden (Phänomenologie, logische Analyse, immanente Kritik) auf andere zeitgenössische Positionen beziehen, werden neue philosophische Positionen erzeugt. Die Appelle in allen drei Beispielen lauten: Wenn mit der jeweiligen Methode bewiesen würde, dass streng wissenschaftliche Erkenntnisse möglich sind (Husserl), Metaphysik falsch ist (Wiener Kreis) oder

200 Die Bestimmung der Philosophie als einer Tätigkeit scheint auch in aktuelleren Erneuerungen konstitutiv zu sein. Philosophie, so mutmaßt z.B. Foucault, werde verschwinden, »nicht aber die Art von »philosophische[n] Tätigkeiten, die in gewissen Bereichen ausgeübt werden können und die im allgemeinen darin bestehen, daß man die Gegenwart einer Kultur diagnostiziert« (Foucault 1974: 31). Die Diskursanalyse scheint sich inzwischen auch als philosophische Methode etabliert zu haben. Siehe dazu den Exkurs »Wahrheit und Macht« (S. 183-188). 
dass Wahrheit zeitgebunden ist (Kritische Theorie), dann erst werde deutlich werden, dass die jeweils neue Philosophie den richtigen Weg weise.

Andere Wissenschaften miteinbeziehen: Die wissenschaftliche Gültigkeit der jeweiligen Erneuerung wird durch die gezielte Einbettung in den zeitgenössischen Wissenschaftskontext hergestellt. Erst durch die Aufnahme philosophieexternen Wissens werden Argumente generiert, mit denen neue philosophische Positionen wiederum philosophieintern begründet werden. Bei Husserl ist vorwiegend die Abgrenzung zur Psychologie, beim Wiener Kreis die Identifikation mit den Naturwissenschaften und bei der Kritischen Theorie die Kooperation mit den Sozialwissenschaften signifikant. Das `Außen< (hier: andere Disziplinen) ist für die Herstellung des >Innen< (der Philosophie) konstitutiv. Der Kontrast zu Seidel hat genau dies erkennbar gemacht: Seidel konstruiert kein `Innen< der Philosophie, sondern breitet aus, was Philosophen für ihre Neupositionierungen aufgreifen, im Zuge ihrer Argumentationsstrategien aber gleichzeitig unsichtbar machen, nämlich die Durchlässigkeit der Grenzen, die ihre eigene Disziplin von anderen Disziplinen trennen: Die Philosophie generiert sich selbst aus Krisen, die von anderen Wissenschaften ausgelöst werden. ${ }^{201}$

Metaphysik überwinden: Das Thema einer Überwindung der Metaphysik ist in allen drei Erneuerungsansprüchen ein konstitutives Element. »Der revolutionäre Bruch mit der metaphysischen Denkweise beherrscht nahezu alle einflussreichen philosophischen Richtungen - Formen affirmativer Metaphysik spielen in der internationalen philosophischen Diskussion kaum eine Rolle mehr« (Braun 1992: 1). Während die Metaphysik von den Vertretern des Wiener Kreises als historisches und unwissenschaftliches Überbleibsel gewissermaßen ad acta gelegt wird, wird die Überwindung der traditionellen Metaphysik von Adorno als ein falsches Ziel dargestellt. Er wendet sich, wie gezeigt worden ist, sowohl gegen Carnap als auch gegen Heidegger, um ihnen ihren Kampf gegen die Metaphysik als ein falsches Bestreben vorzuwerfen. Dies verweist darauf, dass die Metaphysik in der Philosophie des 20. Jahrhunderts eine Art Scharnierbegriff ist, über den und mit dem Positionierungskämpfe

201 Diese Einsicht markiert eine entscheidende Ergänzung zu der in der Einleitung zitierten Studie Kampfplatz endloser Streitigkeiten. Philosophierende, so schreibt Berthold, seien gezwungen, sich »auf dem >Kampfplatz endloser Streitigkeiten zu behaupten - und zwar mit Behauptungen, die die Pluralität und damit das Agonale des Philosophischen bezeugen, auch wo sie alles daran setzen, sie zu widerlegen « (Berthold 2011: 48). Dieser Befund wurde in den Analysen dieser Arbeit auf der Ebene von Argumentationsstrategien zwar bestätigt, allerdings ist deutlich geworden, dass der »Kampfplatz«, auf dem sich Philosophen und Philosophinnen bewegen, die Wissenschaftslandschaft im Allgemeinen ist. 
ausgefochten werden: Mit den je neu entwickelten philosophischen Methoden - Phänomenologie, Logik und immanente Kritik - soll das überkommene metaphysische Denken überwunden oder neu beurteilt werden. ${ }^{202}$ Wie das Beispiel des Wiener Kreises anschaulich gezeigt hat, fungiert die Metaphysik dort als Chiffre für die Unwissenschaftlichkeit der Philosophie per se. Der Begriff der Metaphysik nimmt in allen drei Beispielen die Funktion ein, die Überwindungsbedürftigkeit zeitgenössischer Philosophien herauszustellen.

Wissenschaftlichkeit garantieren: Dass die Philosophie ihren Anspruch auf Wissenschaftlichkeit keinesfalls aufgeben darf, ist in allen drei Beispielen, aber insbesondere bei Husserl, ein zentrales Motiv. Während Husserl die Philosophie mit dem Prinzip der Wissenschaftlichkeit gleichsetzt, möchten die Vertreter des Wiener Kreises diese Wissenschaftlichkeit dadurch garantiert wissen, dass sie die aus ihrer Sicht neuen philosophischen Grundlagen - die Logik mit den Methoden der exakten Wissenschaften gleichsetzen. Horkheimer und Adorno wiederum sehen die Wissenschaftlichkeit der Philosophie dadurch gegeben, dass sie diese ausgehend von einer marxistischen Tradition mit sozialwissenschaftlichen Methoden verbinden.

Die Rolle der Philosophie insgesamt bestimmen: Husserl, die Vertreter des Wiener Kreises sowie Horkheimer und Adorno leiten ihre Neubestimmung der Philosophie von der Klärung von deren Rolle, Aufgaben und Funktionen her. Die Begründung des je neuen philosophischen Programms verläuft in allen Beispielen parallel zu einer Neudefinition der Philosophie im Allgemeinen. Die prinzipielle Unbestimmtheit und Vagheit des Begriffs Philosophie, die sich im Topos äußert, dass letztlich jeder Mensch ein Philosoph bzw. eine Philosophin sei, ist für Versuche der Neupositionierung konstitutiv. Der Begriff der Philosophie kann in diesem Zusammenhang als ein Signifikant verstanden werden, dem viele unterschiedliche Signifikate entsprechen. Während bei Husserl und im Wiener Kreis in je unterschiedlicher Weise die Rolle der Philosophie als erkenntnistheoretisches Fundament der Wissenschaften argumentativ rehabilitiert wird, erneuert die Kritische Theorie die Rolle der Philosophie

202 Lucien Goldmann, der Lukács' und Heideggers Denken in seinem Buch Lukács und Heidegger miteinander in Beziehung setzt, schreibt: »Wie Heidegger kündigt Lukács in diesem Vorwort [von Geschichte und Klassenbewußtsein] den totalen Bruch mit der traditionellen Wissenschaft und Metaphysik an. Er bezeichnet aber selbstverständlich die richtige Methode nicht als ontologisch und metaphysisch, sondern als dialektisch « (Goldmann 1975 [1973]: 99). In diesem Sinne geht es Adorno (hier verstanden als Lukács' Nachfolger) und Heidegger (hier verstanden als Husserls Nachfolger) um das Gleiche wie den Vertretern des Wiener Kreises und Husserl, wenn auch - wie Thomä schreibt mit anderen Absichten: um eine Überwindung der traditionellen Metaphysik. 
als Korrektiv für die Wissenschaften und die einzelwissenschaftlichen Wahrheitsansprüche im Allgemeinen. Alle Autoren bestimmen ihr jeweiliges Philosophieverständnis zwar explizit und emphatisch als neu und originär, rekurrieren jedoch in je unterschiedlicher Weise auf die philosophische Tradition, damit dieses Verständnis plausibilisiert und legitimiert wird.

Die Philosophie als Leitwissenschaft rehabilitieren:Sowohl Husserl als auch die Vertreter des Wiener Kreises sowie Horkheimer und Adorno transferieren das traditionelle Selbstverständnis der Philosophie als Leitwissenschaft in aktuelle Kontexte. Während bei Husserl und dem Wiener Kreis die Rehabilitierung der Philosophie als Fundament aller Wissenschaften fokussiert wird, ist bei der Kritischen Theorie eine Rehabilitierung der Philosophie als Korrektiv für die Wissenschaften maßgeblich. Husserl identifiziert seine Position explizit mit der tradierten Vorstellung, wonach die Philosophie »tiefer blicken « könne als andere Wissenschaften. Die Philosophie sei die Wissenschaft, die »uns die Welt- und Lebensrätsel enthüllen soll« (Husserl 1910/11: 336). Er sieht gewissermaßen kein Problem darin, der Philosophie diese Sonderrolle zuzusprechen. Die Vertreter des Wiener Kreises hingegen problematisieren dieses Selbstverständnis. Sie nehmen es zwar zum Ausgangspunkt ihres Erneuerungsanspruches, aber nur, um es als einen Anspruch, den die Philosophie erheben könnte, zurückzuweisen. Da sie jedoch eine neue, aus den exakten Wissenschaften extrahierte Methode als Grundlage aller Wissenschaften konzipieren und in die Philosophie hineintragen, wird hier - in noch viel stärkerem Ausmaß als in den anderen zwei Beispielen - die Philosophie als »Alpha und Omega aller wissenschaftlichen Erkenntnis « (Schlick 1930/31: 8) rehabilitiert. Am Beispiel des Wiener Kreises wird besonders deutlich, dass die >Re-Definierung des Begriffes Philosophie für philosophische Erneuerungen grundlegend ist: Die Vertreter des Wiener Kreises lehnen den herkömmlichen Begriff der Philosophie mit der Begründung ab, er enthalte gänzlich falsche Implikationen, um ihn unter den Vorzeichen der Logik dann doch wieder neu zu besetzen. In Horkheimers und Adornos Erneuerungsanspruch wiederum ist die Sachlage komplizierter: Auf der einen Seite formuliert Adorno eine klare Absage an die Philosophie als eine Wissenschaft, die >über< oder >unter den anderen Wissenschaften stünde. Diese Absage ist gewissermaßen Teil seines eigenen Programms: Da Philosophie gemäß Adorno nur noch als Kritik, d.h. negativ fungieren kann, wird ihr Selbstbild als Königin der Wissenschaften abgelehnt. Auf der anderen Seite spricht er der neuen, nun kritischen Philosophie das spezifische Vermögen zu, »eben jener Gestalt geistiger Freiheit« zu helfen, »die in den herrschenden philosophischen Richtungen keine Stelle hat" (Adorno 1977 [1962]: 468). Ähnlich wie im Wiener Kreis und bei Husserl wird 
auch hier - über den Umweg der Negation - das Selbstbild der Philosophie als jener Wissenschaft verteidigt, die als Korrektiv für die anderen Wissenschaften fungieren darf und soll.

Die Philosophie mit Kritikgleichsetzen: In allen drei Beispielen wird der Philosophie nicht nur die Aufgabe zugewiesen, Kritik zu betreiben, sondern sie wird in je unterschiedlicher Weise mit Kritik gleichgesetzt. In der Argumentation der Kritischen Theorie ist dies erklärtermaßen Bestandteil: Der Philosophie könne nur noch eine kritische Funktion zukommen. In der Argumentation des Wiener Kreises erfolgt diese Gleichsetzung über die Bestimmung der Philosophie als logischer Analyse, der wiederum das Vermögen zukomme, alle wissenschaftlichen Unwahrheiten auszuräumen. Bei Husserl ist die definitorische Gleichsetzung der Philosophie mit Kritik - ähnlich wie in der Kritischen Theorie - ebenfalls programmatisch: Ohne Philosophie verliere die Wissenschaft ihr eigentliches und kritisches Prinzip.

Die Philosophie als Heilmittel bestimmen: Im Zusammenhang mit den Bestimmungen der Philosophie als Kritik wird ihr in allen drei Beispielen das Vermögen zugesprochen, auf Krisen inner- und außerhalb der Wissenschaften reagieren zu können: Sie wird jeweils als »Heilmittel« (Husserl) für die Misere in den Wissenschaften, für die Unwissenschaftlichkeit der traditionellen Philosophie oder für eine desolat bis unerträglich gewordene gesellschaftliche Gegenwart insgesamt in Stellung gebracht.

Den philosophischen Geltungsbereich stabilisieren: Es können Aktualisierungen des tradierten Topos, dass die Philosophie im Unterschied zu den Einzelwissenschaften das »Ganze« zu ihrem Gegenstand habe, beobachtet werden: Zunächst aktualisieren alle Autoren in ihren Rückgriffen auf die philosophische Tradition je spezifische Aspekte des philosophischen Selbstverständnisses: Husserl fokussiert die Wissenschaftlichkeit, die Vertreter des Wiener Kreises den Anspruch auf Letztgültigkeit von Erkenntnissen sowie Horkheimer und Adorno schließlich das kritische Potenzial von Philosophie. In jedem der drei Erneuerungsansprüche ist folglich eine spezifische Eingrenzung des philosophisch Relevanten sichtbar geworden: Wo Husserl das Bewusstsein als den philosophisch entscheidenden Bereich konturiert, definieren dieVertreter des Wiener Kreises die Sprache und die Wissenschaft als die für die Philosophie zentralen Gebiete. Horkheimer und Adorno wiederum konfigurieren die Gesellschaft als denjenigen Bereich, in dem sich die Philosophie zu bewegen habe. Paradoxerweise erzeugen diese Eingrenzungen argumentativ zugleich eine schier unendliche Ausdehnung philosophischer Anwendungsbereiche. Das »Sein«, die »Sprache« und die »Gesellschaft« (Schnädelbach 1992: 309) sind Themen, die - pointiert gesagt - beinahe das gesamte Spektrum der Wissenschaft abdecken. Keine andere Wissenschaft, so 
kann geschlussfolgert werden, dehnt den Raum ihrer Expertise so weit aus wie die Philosophie: Sie kann, soll und darf über alles sprechen.

An der Wahrheit festhalten: Die Wahrheit wird in allen drei Beispielen nicht im Rahmen eines abgeschlossenen philosophischen `Systems`, sondern innerhalb des Rahmens der Wissenschaften beansprucht. Dass an der Wahrheit festgehalten werden muss, wenn Philosophie und Wissenschaft weiterhin Gültigkeit beanspruchen wollen, wird von jedem der untersuchten Philosophen durch ihre je unterschiedlichen Argumentationsstrategien verteidigt. Während Husserl und Adorno explizit betonen, dass an der wissenschaftlichen Wahrheit als einer überzeitlichen Idee festgehalten werden muss (Husserl), auch wenn man sie möglicherweise nie finden wird (Adorno), liegt die wissenschaftliche Wahrheit für den Wiener Kreis in logischen Prämissen. Die hier durchgeführten Untersuchungen legen nahe, dieses Festhalten an der Möglichkeit von Wahrheit als zwingendes Kriterium philosophisch-wissenschaftlicher Tätigkeit zu verstehen. Die Analysen verweisen jedoch darauf, dass es gänzlich unterschiedliche Weisen gibt, an der Wahrheit festzuhalten: Während die Möglichkeit philosophischer Wahrheit im Wiener Kreis und bei Husserl eher implizit, d.h. als Voraussetzung, eine Rolle spielt, wird sie von der Kritischen Theorie explizit aufgenommen und zu einem zentralen Thema für die Philosophie selbst konfiguriert.

Setzungenvornehmen-PhilosophieverständnisalsAusgangspunkt:Eswerden spezifische, nicht weiter begründete Setzungen sichtbar. Dass das Prinzip der Wissenschaftlichkeit der Philosophie immanent ist, ist für Husserl klar. Dass Wissenschaft - und damit auch die Philosophie - objektiv und universal ist, ist für die Mitglieder des Wiener Kreises gesetzt. Und dass Philosophie nur noch negativ, d.h. als Kritik, möglich und sinnvoll ist, ist für Horkheimer und Adorno unbestritten. Die Philosophen beanspruchen für sich innerhalb ihrer eigenen Bezugsrahmen letztgültige Wahrheiten, die sie an anderen Positionen kritisieren. Diese Wahrheiten wiederum sind mit der Bestimmung dessen, was Philosophie ist, eng verbunden. Die Analysen zeigen, dass Setzungen, die in der Philosophie vorgenommen werden und vorgenommen werden müssen, über das jeweilige Philosophieverständnis verlaufen. Letztlich wird in allen Beispielen der Anspruch sichtbar, mit der nun neuen Position die wahre, zeitgemäße Philosophie gefunden zu haben. Die argumentative Entwicklung einer neuen philosophischen Position, so legen es die Analysen in diesem Buch nahe, geht damit einher, das jeweils eigene Philosophieverständnis als einzig richtiges zu behaupten und es vermittels gezielter, trag- und anschlussfähiger Strategien im Wissenschaftskontext zu positionieren. Um philosophische Positionen im Wissenschaftskontext verteidigen und legitimieren zu können, so folgt daraus, gelangen Denkbewegungen dort an eine Grenze, wo es um 
die Reflexion der eigenen Setzungen geht. Dessen ungeachtet, wie reflektiert philosophische Positionen auch anmuten, blinde Flecken bleiben immer. Denn wie der nächste Abschnitt deutlich macht, folgen aus den Singularitätsansprüchen Positionen, die reflexiv nicht erfasst werden können.

\section{Sich am eigenen Schopf aus dem Sumpf ziehen}

Die untersuchten Philosophen treten alle mit einem klaren Verständnis dessen auf, was Philosophie ist und vor allem: was sie in der Gegenwart und zukünftig sein soll. Durch gezielte Argumente begründen sie, warum ihr Verständnis das richtige ist. Seidel hingegen, so ist deutlich geworden, legt offen, wie sehr er mit der Frage ringt, was Philosophie (oder auch: Denken, Wahrheit, Wissenschaft, Objektivität, Metaphysik etc.) überhaupt ist oder sein soll. Sein »Wahrheitssadismus « (Seidel 1927: 212) hindert ihn daran, vor seinen eigenen Überzeugungen Halt zu machen. Aus dem Anspruch, seine eigenen Setzungen analytisch zu durchdenken, folgt der endlose Regress, an dem ex negativo deutlich wird, wo und wie Philosophen - ihrer disziplininternen Logik folgend - blinde Flecken produzieren: Sie schließen die Reflexion der eigenen Setzungen aus und perpetuieren dadurch Dynamiken, die die Spiegelung der Philosophie auf sich selbst unmöglich machen. Gleichzeitig wiederum - auch dies macht die Kontrastfolie Seidel deutlich - erneuern sie diese Dynamiken gerade aufgrund der Spiegelungen aus anderen Disziplinen. Die Spiegelung der Philosophie auf sich selbst durch andere Disziplinen evoziert Positionen, die sich reflexiv nicht erfassen oder einholen lassen. ${ }^{203}$

Diese Gedankenfigur wurde von der Philosophin und Wissenschaftsforscherin Donna Haraway in den 198oer-Jahren als "god trick « bezeichnet. Es handele sich dabei um eine Perspektive, die vorgibt, gleichzeitig alles von nirgendwo und überall aus sehen zu können. »The god trick is self-identical, and we have mistaken that for creativity and knowledge, omniscience even « (Haraway 1988: 587). Der selbstidentische Blick, so impliziert Haraway, erzeugt die Vorstellung von Objektivität bzw. die Vorstellung eines allgemeingültigen und universalen Blicks. ${ }^{204}$ Das Pendant zu dieser Totalisierung des Blicks

203 Das Selbstverständnis der Philosophie als einer Wissenschaft, die sich selbst reflektiert, ist persistent. Michael Hampe z.B. beendet seine Buchbesprechung von Bertholds Kampfplatz endloser Streitigkeiten 2012 mit den Worten: »Weil sie [die Philosophie, MD] sich der historischen Bedrohtheit ihrer Gewissheiten bewusst ist, gibt es wohl keine >behauptende< Tätigkeit, die der Philosophie an Reflektiertheit das Wasser reichen könnte« (Hampe 2012: 62).

204 Lorraine Daston und Peter Galison verorten die Entstehung des wissenschaftlichen Konzepts 〉Objektivität< in der Mitte des 19. Jahrhunderts. »Objectivity the thing was as new as objectivity the word in the mid-nineteenth century« (Daston/Galison 2007: 34). 
sei der Relativismus. »Relativism is the perfect mirror twin of totalization in the ideologies of objectivity; both deny the stakes in location, embodiment, and partial perspective, both make it impossible to see well. Relativism and totalization are both >god tricks< promising vision from everywhere and nowhere equally and fully, common myths in rhetorics surrounding science « (ebd.: 584).

Die Kontrastierung von Seidel mit Husserl, den Vertretern des Wiener Kreises sowie Horkheimer und Adorno hat es ermöglicht, die Prozesse nachzuzeichnen, mit denen Philosophen diesen Dualismus zwischen totaler Objektivität auf der einen und totalem Relativismus auf der anderen Seite reaktivieren. Die besprochenen Philosophen erklären zunächst alle Erkenntnis für fallibel, für relativ, für standortgebunden, für kontingent und vergänglich. Indem sie das Relative so totalisieren, schaffen sie zugleich die Grundlage für den einen und einzigen Punkt, an dem sich doch noch letzte Gewissheiten einstellen: das intentionale Bewusstsein bei Husserl, die logische Methode beim Wiener Kreis und die unausweichliche Kritik bei Adorno.

Indem sie ihre eigenen Setzungen von der Reflexion ausnehmen, machen sie - mit Haraway gesprochen - einen »leap out of the marked body [...] into a conquering gaze from nowhere (ebd.: 581). Dieser erobernde Blick der Allwissenheit sei »the gaze that mythically inscribes all the marked bodies, that makes the unmarked category claim the power to see and not be seen, to represent while escaping representation. This gaze signifies the unmarked positions of Man and White [...] « (ebd.). Haraway transferiert mit ihrer Gedankenfigur des unsichtbar Allsehenden also die Tatsache, dass die kanonisierte Wissenschaft und Philosophie eine von europäischen Männern repräsentierte Geschichte ist, auf eine erkenntnistheoretische Ebene: Die Vorstellung von totaler Objektivität oder Relativität sei intrinsisch mit einer in der traditionellen Philosophie und Wissenschaft unmarkierten Position verknüpft. »The Western eye has fundamentally been a wandering eye, a traveling lens. These peregrinations have often been violent and insistent on having mirrors for a conquering self but not always « (ebd.: 586). In gewissem Sinne dreht Haraway einen Topos der abendländischen Philosophie argumentativ um: »Knowledge from the point of view of the unmarked is truly fantastic, distorted, and irrational. The only position from which objectivity could not possibly be practiced and honored is the standpoint of the master, the Man, the One God, whose Eye produces and

Objektivität sei »the suppression of some aspects of the self, the countering of subjectivity« (ebd.: 36). Eine Kontrastierung der Objektivitätsverständnisse von Philosophen und Philosophinnen ab Mitte des 19. Jahrhunderts mit Dastons und Galisons wissenschaftshistorischen Analysen wäre ein lohnenswertes Unterfangen. 
appropriates, and orders all difference (ebd.: 587). Objektivität, so Haraway, entstehe aus einer verorteten, situierten und partialen Perspektive und nicht aus einem selbstidentischen Standpunkt: $»$ The moral is simple: only partial perspective promises objective vision « (ebd.: 583). Demgegenüber wird in allen drei Neupositionierungen - Phänomenologie, Positivismus und Kritische Theorie - in je unterschiedlicher Weise ein >schwebender Thron< konstruiert, von dem aus sich das Geschehen überblicken oder bewerten lässt. Haraway verweist auf die Problematik, die damit einhergeht: Der Anspruch, einen Überblick zu gewinnen, ist mit dem Verlust von Perspektiven verbunden. Wer alles sieht, sieht nichts Bestimmtes.

Die Konfrontation der Selbstpositionierungsstrategien von Husserl, den Vertretern des Wiener Kreises sowie von Horkheimer und Adorno mit Haraways Perspektive legt also nahe, dass philosophische Erneuerungen im 20. Jahrhundert Denkweisen reproduzieren, die - im feministisch-postkolonialen Jargon gesprochen - mit kolonialen und patriarchalen Dynamiken zusammenspielen. Es werden vorgeblich frei schwebende, nicht situierte Wissensstandpunkte erzeugt, die jedoch keineswegs frei und schwebend sind, sondern auf spezifische Positionen und >Blickrichtungen`zurückgebunden werden können. Wie genau diese Vorgänge funktionieren und wirken, müsste in weiteren Untersuchungen an konkreten Materialien erforscht werden. Die hier durchgeführten Analysen zeigen jedoch einen möglichen Weg auf, der mit nachfolgenden Studien gegangen werden könnte: Es wäre interessant, zu untersuchen, welche Wissensaspekte Philosophinnen und Philosophen mit welchen Argumenten im Namen ihrer eigenen Position ausklammern. Das heißt, dass zusätzlich zu den in dieser Arbeit untersuchten Strategien der Verbindungen, Identifikationen und Kooperationen solche der Ignoranz oder Invisibilisierung in den Blick kommen müssten. Wo hier anhand eines heuristischen Modells die Frage fokussiert wurde, wie Philosophen ihre Disziplin durch die Aufnahme der Herausforderungen aus anderen Wissenschaften aktualisieren, müsste die daran anschließende Frage lauten:Welches Wissen wird aus welchen Gründen aus der Philosophie ausgelagert, verdrängt oder verkannt? Eine solche Untersuchung müsste - so legen es die Analysen nahe - dort lokalisiert werden, wo Philosophen und Philosophinnen zu denken beginnen: in der Verbalisierung ihres Philosophieverständnisses. ${ }^{205}$

Im Unterschied zu den hier betrachteten philosophischen Positionen hat Seidel nicht die Frage umgetrieben, was Philosophie ist und was sie sein soll,

205 Diese weiterführenden Fragen wären als Ergänzung zu Studien zu verstehen, die die Konstruktionsprozesse des männlichen und europäischen Subjekts in und an der Philosophie aufzeigen. Siehe Fn. 209. 
sondern die Frage, durch welche »Ideologien« seine Gegenwart und seine eigenen Analysen bestimmt sind. Es macht den Anschein, dass er dadurch mit der Begründung seines Denkens und seiner Position ringt. »Wie kann man an dem eigenen Schopfe sich selbst aus dem Sumpfe ziehen, ohne dabei, immer natürlich nach physikalischen Gesetzen, auch wieder hinein zu rutschen[?] « (Seidel 1927: 212). Diese Metapher ist vermutlich an eine der Lügengeschichten angelehnt, die dem Baron Hieronymus Carl Friedrich von Münchhausen zugeschrieben werden und vielfach literarisch ausformuliert worden sind. Im philosophischen Zusammenhang wirft die Anekdote, wonach der Baron samt seinem Pferd im Sumpf umgekommen wäre, wenn er sich nicht selbst am eigenen Haarschopf aus dem Morast gezogen hätte, die Frage nach Letztbegründungen auf. ${ }^{206}$ Sie wird auch von Adorno aufgenommen: »Vom Denkenden heute wird nicht weniger verlangt, als daß er in jedem Augenblick in den Sachen und außer den Sachen sein soll - der Gestus Münchhausens, der sich an dem Zopf aus dem Sumpf zieht, wird zum Schema einer jeden Erkenntnis, die mehr sein will als entweder Feststellung oder Entwurf« (Adorno 2001 [1951]: 130). ${ }^{207}$ Adorno, so kann gefolgert werden, geht mit dem Problem der Begründung der eigenen Position insofern um, dass er es affirmativ auflöst: Die eigene Position müsse - durchaus paradox - letztlich mit der eigenen Position begründet werden. Erst dadurch entstünden Erkenntnisse, die weder lediglich deskriptiv noch tentativ sind. »Und dann kommen noch die angestellten Philosophen und machen uns zum Vorwurf, daß wir keinen festen Standpunkt hätten« (ebd.). ${ }^{208}$ Während Adorno eine standpunktlose Philosophie zumindest für möglich hält, scheint es Seidel nicht möglich zu sein, dieses erkenntnistheoretische Paradox als Ausgangspunkt seines Denkens gelten und stehen zu lassen. Indem er seine eigenen Wahrheitsansprüche gnadenlos seziert, rutscht er - so jedenfalls impliziert es der Duktus seines Textes - immer wieder in den Sumpf unendlicher Wissensperspektiven, d.h. angestrebter, aber nicht zu erfüllender Letztbegründungen, ab. Sein Text verdeutlicht dadurch die Aporie des Dualismus zwischen totaler Objektivität und totalem Relativismus

206 Hans Albert hat in Bezug auf das Begründungsproblem das »Münchhausen-Trilemma« formuliert: Wenn man nach einem archimedischen Punkt der Erkenntnis sucht, d.h. für alles eine Begründung verlangt ist, habe man letztlich die Wahl zwischen drei Möglichkeiten: einem infiniten Regress, einem logischen Zirkel oder einem Abbruch des Verfahrens (Albert 1991: 15).

207 Ich danke Flurin Dummermuth für den Hinweis auf diese Textstelle.

208 Der Abschnitt ist mit »Zur Moral des Denkens« betitelt. »Die Moral des Denkens besteht darin, weder stur noch souverän, weder blind noch leer, weder atomistisch noch konsequent zu verfahren« (Adorno 2001 [1951]: 130). Insofern es Adorno hier um den Schutz des Besonderen vor der totalitären Gewalt des abstrakten Allgemeinen zu gehen scheint, führt die Textstelle in das Zentrum von Adornos Philosophie. 
in aller Vehemenz. Husserl, die Vertreter des Wiener Kreises sowie Horkheimer und Adorno hingegen ziehen sich selbst insofern aus dem Sumpf, als dass sie die Frage nach der Legitimität ihrer eigenen Wahrheitsansprüche zugunsten einer Erneuerung ihrer Disziplin gar nicht erst aufkommen lassen. Sie verteidigen je im Auftrag einer Wahrheit ihre Disziplin.

Seidel hat die Philosophie nicht explizit verteidigt. Er erzeugt jedoch vielleicht gerade deswegen und vielleicht in noch stärkerem Ausmaß als die hier erwähnten Philosophen - eine spezifische Form der Wahrheit, die, wie im zweiten Kapitel ausgeführt, mit einem Anspruch nach Wahrhaftigkeit einhergeht. In der Rezeptionsgeschichte Seidels wird von diesem das Bild eines Menschen erzeugt, der explizit für die Wahrheit gelebt hat und gestorben ist. Diese Form der Wahrheit hat in der >westlichen< Philosophie- und Kulturgeschichte eine lange Tradition. Wie weiter oben angesprochen, hat Foucault diese Form der Wahrheit in Abgrenzung zur »platonischen« als »kynische« Form der Wahrheit bezeichnet. Sie wird auch auf der Ebene von Seidels Analysen in aller Vehemenz sichtbar: Alle Lösungen konsequent ablehnend, selbst den Nihilismus nihilisierend, denkt Seidel Krisen gleichwohl als Wirklichkeiten, denen sich aber kein Konstrukt mehr entgegensetzen lässt. Insofern wird in Bewußtsein als Verhängnis die totale Affirmation des menschlichen Geistes als konsequente Absage sichtbar: Indem Seidel das Leiden und Scheitern an der akademischen Philosophie und an der Wissenschaft im Allgemeinen ausdrückt, drückt er gleichzeitig die Unzulänglichkeit, Unvollständigkeit und Brüchigkeit wissenschaftlicher und auch philosophischer Ansprüche aus.

\section{Ein Dilemma, das bleibt}

Wird die Anlage des vorliegenden Buches konsequent zu Ende gedacht, könnte die so unbefriedigende wie unrealistische Schlussfolgerung gezogen werden, dass Philosophinnen und Philosophen sich entweder für den "god's trick« oder für die Selbsttötung zu entscheiden haben. Eine solche apodiktische und gleichzeitig traditionelle Schlussfolgerung wäre jedoch in genau jener Logik verortet, die in diesem Buch nun gerade hinterfragt worden ist: letztgültige Definitionen der Philosophie zu suchen. Das Ziel war, punktuell philosophieinterne Dynamiken offenzulegen und die Deutungsmacht, die der Philosophie inner- und außerhalb der Wissenschaften zukommt, kritisch zu untersuchen: einerseits, um besser zu verstehen, mit welchen Mechanismen philosophische und geisteswissenschaftliche Argumentationen Wirkungsmacht entfalten und bewahren, und andererseits, um innerhalb dieser Mechanismen Momente einzufangen, die darauf verweisen, dass nicht nur die Philosophie und ihre Geschichte, sondern alle, die sich damit auseinandersetzen, ganz spezifischen 
Denk- und Wahrheitstraditionen und damit auch Machtansprüchen verpflichtet sind.

Der Wahrheitsanspruch, der das vorliegende Buch angeleitet hat und der durch die Figur Seidel gewissermaßen manifest wird, ist einer Disziplinierung geschuldet, die ihrerseits als eine philosophische Neupositionierung verstanden werden kann: Ab Mitte des 20. Jahrhunderts wurden vermehrt - eng verbunden mit den in dieser Arbeit behandelten Traditionen und insbesondere mit der Kritischen Theorie - Theorien und Denkweisen Bestandteil der akademischen Diskussion, die die Kritik an den Macht- und Wahrheitsansprüchen der kanonisierten Philosophie und in diesem Zusammenhang an einer anthropo- und androzentrischen Perspektive in den Fokus rückten. ${ }^{209}$ Philosophische Wahrheiten - so die These bzw. die bewusst vorgenommene Setzung - werden immer aus einem bestimmten Blickwinkel mit bestimmten Machtinteressen postuliert. Der Blick, der beansprucht, von nirgendwo und überall alles sehen zu können, wird durch die Forderung nach einem situierten und verorteten Blick verabschiedet. Gemäß dieser philosophischen Haltung gilt es, Widersprüche, Brüche und Unvollständigkeiten auszuhalten, statt sie in Ausrichtung auf eine übergeordnete Wahrheit auflösen zu wollen. Daraus folgt - Seidels bzw. Münchhausens Metapher aufnehmend -, dass der eigene Schopf gar nicht aus dem Sumpf gezogen werden muss bzw. soll.

Exemplarisch für diese Traditionslinie kann erneut Haraway zitiert werden: »We are humus, not Homo, not anthropos; we are compost, not posthuman" (Haraway 2016: 55). In ihrem kürzlich erschienenen Buch Staying with the Trouble schlägt sie konsequenterweise vor, sich in den Sumpf zu begeben, denn wir seien »beings of the mud more than the sky« (ebd.: 11). Analog dazu seien gute Darstellungen der Welt immer verortet und partial - das Ziel, so könnte Haraway paraphrasiert werden, ist nicht, sich selbst aus dem Sumpf zu ziehen, sondern den Sumpf, in dem man steckt, sichtbar zu machen, um ihn mit anderen teilen zu können (Haraway 1988: 586). ${ }^{210}$ Haraway verwendet dafür den Begriff der Positionierung:»Positioning is, therefore, the key practice

209 Luce Irigaray hat mit Speculum de l'autre femme (1974) in Bezug auf Geschlechteraspekte die wahrscheinlich einflussreichste Arbeit vorgelegt. Ihr falle »keine Feministin ein«, sagt Judith Butler - eine weitere prominente Autorin dieser Richtung -, »die die Philosophiegeschichte ähnlich aufmerksam, akribisch und kritisch gelesen und neu gelesen hat wie sie [Irigaray, MD] « (Butler 1997: 63). Weitere Beispiele: Beauvoir 1951 [1949]; Butler 1997 [1993]/2009 [2004]; Cavarero 1997 [199o]; Deuber-Mankowsky 2012; Fox Keller 1985; Fraser 1994; Harding 1986/1996; Hartsock 1983; Haslinger 20o8; Hooks 2004; Lloyd 1984; Maihofer 1995; McClintock 1995; Purtschert 2006; Said 1979; Spivak 2008 [1988].

210 Zum Beispiel Haraway 1988: 579-580. 
in grounding knowledge organized around the imagery of vision, and much Western scientific and philosophic discourse is organized this way. Positioning implies responsibility for our enabling practices« (ebd.: ${ }_{587}^{8}$ ). Dezidierte und offengelegte Selbstpositionierung ist für Haraway eine Möglichkeit, die Machtstrukturen, die der akademisch-philosophischen Wissensproduktion inhärent sind, zu konfrontieren, statt sie zu reproduzieren: Durch die Offenlegung und Situierung der eigenen wissenschaftlich-philosophischen Tätigkeit bekommt, so Haraway, der »conquering gaze from nowhere (Haraway 1988: 581) eine konkrete und erfassbare Gestalt. Die Offenlegung jener Macht- und Wahrheitsverhältnisse, die den eigenen Blick formen und lenken, bedeutet für Haraway folglich einen gangbaren Weg, an den Instrumenten der Wissenschaft und Philosophie für eine weniger machtvoll organisierte Welt festzuhalten, obwohl und weil Wissenschaft und Philosophie an solchen Macht- und Herrschaftsstrukturen maßgeblich beteiligt sind. ${ }^{211}$ Haraway - sie wird hier stellvertretend auch für andere Autoren und Autorinnen zitiert - zeigt, ähnlich wie es am Beispiel der Kritischen Theorie deutlich geworden ist, einen Ausweg aus Seidels Problematik, wie der eigene Forschungsstandpunkt angesichts der Einsicht in die Machtstrukturen von Wissenschaft und Philosophie noch legitimierbar ist. Analog zu den in diesem Buch untersuchten Philosophen wird also auch bei Haraway eine Operationalisierung von Seidels Teufelskreis sichtbar. Objektiviert wird Seidels Hadern mit dem Gedanken, dass auch die eigenen Wahrheitsansprüche lediglich zeitgebundene Ideologien sind und somit an Gültigkeit verlieren. Wenn die eigene Positionierung transparent gemacht, wenn also die Situiertheit und Verortung des eigenen Wissensstandpunkts explizit offengelegt und die Alterität anderer Positionen anerkannt wird, ist - gemäß dieser Traditionslinie - wissenschaftliche Wahrheitsbehauptung legitim.

Das sich selbst reflektierende Bewusstsein jedoch ist in Bezug auf die eigene Positionierung begrenzt. Haraway begegnet dem Problem, indem sie diesen Gedanken offenlegt und als Teil einer neuen Programmatik versteht. Sie moniert, dass es mehr benötige als Selbstreflexion. »We are also bound to seek perspektive from those points of view, which can never be known in advance, that promise something quite extraordinary, that is, knowledge potent for

211 Es wäre ein lohnenswertes Unterfangen, auch Haraways Philosophie mit den in dieser Arbeit entwickelten Instrumenten zu untersuchen. Sie schreibt ihre Position explizit in aktuelle wissenschaftliche, politische, ökologische und gesellschaftliche Diskussionen ein, und es liegt nahe, zu vermuten, dass sie ihre Position ebenfalls in den hier vorgeschlagenen Mustern argumentativ begründet und legitimiert. 
constructing worlds less organized by axes of domination « (Haraway 1988: 585). Aus diesem Blickwinkel gesehen würde »the unmarked category [...] really disappear - quite a difference from simply repeating a disappearing act« (ebd.). Visionen selbst sind in dieser Perspektive alles andere als frei von Macht. »Vision is always a question of the power to see - and perhaps of the violence implicit in our visualizing practices « (ebd.). Haraway legt offen, was Husserl, die Vertreter des Wiener Kreises und - in gänzlich anderer Weise - auch Horkheimer und Adorno unterschlagen, nämlich, dass der philosophische Forschungsblick immer an die jeweilige Person und dadurch an deren Stellung in der Wissenschaft, Gesellschaft und Welt generell gebunden ist. Das Stillschweigen ist kein Lapsus, sondern Teil einer philosophieinternen Logik, Positionen zu erzeugen, die sich selbst reflexiv nicht einholen lassen.

Es gilt, auch in und von der Philosophie anzuerkennen, dass Forschungsperspektiven interessegeleitet sind und mit Machtverhältnissen korrespondieren. Dem Wahrheits- und Objektivitätsgehalt von Philosophie und Wissenschaft tut dies keinen Abbruch. Im Gegenteil: Erst wenn deutlich gemacht wird, dass philosophische als auch wissenschaftliche Wahrheit ganz spezifische Formen von Wahrheiten (im Plural) enthalten, kann der Status von Philosophie und Wissenschaft geschützt werden.

Das vorliegende Buch ist somit mit einem Wahrheitsanspruch verbunden, der seit Mitte des letzten Jahrhunderts begonnen hat, die geistes- und sozialwissenschaftliche Wissensproduktion und vor allem die Kulturwissenschaften zu prägen:212 Transparenz in Bezug auf Wissensstandpunkte, so die Setzung, ist angesichts der Einsicht, dass Wissenschaft und Philosophie euro- und androzentristischen Strukturen unterworfen sind, notwendig geworden. Jedoch zu glauben, dass die Einlösung dieser Forderung Seidels Teufelskreis auflösen würde, wäre falsch. Eigene Setzungen können reflexiv nicht erfasst werden, da der oder die Forschende zwingend an sein bzw. ihr Bewusstsein gebunden ist. Wahrheitsansprüche können immer auch zum Verhängnis werden. Die Verluste der Außenperspektiven, die von Seidel so konsequent aufgezeigt werden, gilt es ernst zu nehmen und auszuhalten. »Gewöhnlich wird das, was ein Denker über seine philosophischen Voraussetzungen, seine Methode und vor allem sein Verhältnis zu andern Denkern urteilt, von ihm selbst am wenigsten richtig eingeschätzt« (Seidel 2008: 187-188). Es ist eine so simple wie folgenreiche Wahrheit: Ich bin bereits im Sumpf, wenn ich mich selbst herausziehen will. Mit anderen Worten, im Bewusstsein und in der Philosophie befinden wir

212 Dieser Erneuerungsanspruch ist vor allem feministischen, poststrukturalistischen, postkolonialen und wissenssoziologischen Perspektiven zuzurechnen. 
uns immer schon in einer morastigen Umgebung. Und weil wir uns selbst nicht herausheben und die Topografie von oben betrachten können, ist die Strategie, dieses Dilemma nicht aufzulösen, die aktuell bedeutsamste. Sie bietet uns die existenzielle und politische - und damit auch philosophische - Möglichkeit, die Beschaffenheit des Sumpfes, in dem wir stecken, mit den Händen zu greifen. 


\section{Dank}

Die Unterstützung zahlreicher Personen und einzelner Institutionen hat wesentlich zur Realisierung der Dissertation, auf deren Grundlage das vorliegende Buch entstanden ist, beigetragen. Für die vielfältig erfahrene Hilfe bedanke ich mich an dieser Stelle herzlich:

Mein Dank gilt meinen Betreuungspersonen Dieter Thomä und Patricia Purtschert, die das Projekt vertrauensvoll und mit großer Fachkundigkeit begleitet haben. Danken möchte ich außerdem Sabine Maasen und Mario Kaiser, durch deren Begleitung die Grundsteine des Projekts gelegt wurden, sowie Philip Kitcher, der mich während meines Auslandsjahres als Visiting Scholar an der Columbia University in New York kompetent beraten hat. Mein Dank gilt zudem dem Fachbereich Philosophie an der Universität St. Gallen: Die Kolloquien, in denen meine Arbeit kritisch diskutiert worden ist, waren von unschätzbarem Wert. Ein weiterer Dank geht an das Graduiertenkolleg Gender Studies der Universität Basel, dessen Kollegiatin ich in der zweiten Hälfte der Projektzeit war.

Beim Schweizerischen Nationalfonds SNF bedanke ich mich für die finanzielle Unterstützung und damit die Schaffung der Rahmenbedingungen, die die Durchführung der Dissertation und die Publikation des Buches überhaupt erst ermöglicht haben. Ein großer Dank geht selbstverständlich auch an den mentis Verlag und Michael Kienecker für die Betreuung dieser Publikation und die Aufnahme in das Verlagsprogramm. Ein ganz besonderer Dank gilt Thorsten Tynior: Sein sorgfältiges Lektorat des Manuskripts hat wesentlich zur Realisierung des Buches beigetragen. Ebenfalls danke ich Marco Baumgartner für die Idee zum Buchcover.

Der größte Dank gilt den Freunden und Freundinnen, die zum Teil kontinuierlich, zum Teil in einzelnen Phasen intensiv an meinem Denkund Schreibprozess teilgenommen und in Inhalt und Form wesentlich zur Realisierung dieses Buches beigetragen haben. Besonders danke ich Mario Schulze, Simon Morgenthaler, Jane Haller, Sabina Giger und Franco Bezzola. Weiter danke ich Eliane Albisser, Eva Brugger, Philipp Casula, Anna Dätwyler, Katharina Dräger, Flurin Dummermuth, Jonas Gillmann, Gassan Gradwohl, Karin Hostettler, Barbara Hauenstein, Ana Keilson, Kathrin Klohs, Esther Kobel, Anna-Kaisa Meklin, Deborah Mühlebach, Michael Mülli, Michael Räber, Beatrix Rubin, David Rinderknecht, Nathan Schocher, Barbara Sutter, Blanka Šiška, Corinna Virchow und Christian Vogel. Meinen Eltern Barbara und Hans Dätwyler danke ich herzlich für ihre vielfältige Unterstützung. 


\section{Literatur}

Adorno, Theodor W. 1956: »Soziologische Exkurse«, in: Frankfurter Beiträge zur Soziologie, Band 4, Frankfurt: Europäische Verlagsanstalt.

Adorno, Theodor W. 1973a: »Die Transzendenz des Dinglichen und Noematischen in Husserls Phännomenologie«, in: ders.: Gesammelte Schriften 1, Frankfurt a.M.: Suhrkamp, S. 7-77.

Adorno, Theodor W. 1973b: »Die Aktualität der Philosophie«, in: ders.: Gesammelte Schriften 1, Frankfurt a.M., S. 325-344.

Adorno, Theodor W. 1973c: »Die Idee der Naturgeschichte«, in: ders.: Gesammelte Schriften 1, Frankfurt a.M.: Suhrkamp, S. 345-365.

Adorno, Theodor W. 1977 [1955]: »Das Bewusstsein der Wissenssoziologie«, in: ders.: Gesammelte Schriften 10.1, Suhrkamp: Frankfurt a.M., S. 31-46.

Adorno, Theodor W. 1977 [1962]: »Wozu noch Philosophie? (1962)«, in: ders.: Gesammelte Schriften 10.2, Suhrkamp: Frankfurt a.M., S. 459-473.

Adorno, Theodor W. 1966: Negative Dialektik, Frankfurt a.M.: Suhrkamp.

Adorno, Theodor W. 1995 [1950]: Studien zum autoritären Charakter, Frankfurt a.M.: Suhrkamp.

Adorno, Theodor W. 2001: »Zur Lehre von der Geschichte und von der Freiheit« (1964/65), Nachgelassene Schriften, Abteilung IV: Vorlesungen, Band 13, herausgegeben von Rolf Tiedemann, Frankfurt a.M.: Suhrkamp.

Adorno, Theodor W. 2001 [1951]: Minima Moralia, Frankfurt a.M.: Suhrkamp.

Adorno, Theodor W. 2002: Ontologie und Dialektik, Frankfurt a.M.: Suhrkamp.

Adorno, Theodor W. 2011 [196o]: Philosophie und Soziologie (196o), herausgegeben von Dirk Braunstein, Berlin: Suhrkamp.

Albert, Hans 1991 [1968]: Traktat über kritische Vernunft, Tübingen: Mohr.

Albrecht, Clemens/Behrmann, Günter C./Bock, Michael 1999: Die intellektuelle Gründung der Bundesrepublik. Eine Wirkungsgeschichte der Frankfurter Schule, Frankfurt a.M.: Campus.

Amslinger, Julia 2017: Eine neue Form von Akademie. Poetik und Hermeneutik - die Anfänge, Paderborn: Wilhelm Fink.

Anderson, Perry 1978 [1976]: Über den westlichen Marxismus, Frankfurt a.M.: Syndikat. Ayer, Alfred Jules 1936: Language Truth and Logic, London: Victor Gollancz.

Baker, Gordon 2003 (Hrsg.): The Voices of Wittgenstein. The Vienna Circle. Ludwig Wittgenstein and Friedrich Waismann, transcribed, edited and with an introduction by Gordon Baker, London/New York: Routledge.

Barker Gillian/Kitcher Philip 2014: Philosophy of Science. A new Introduction, New York/ Oxford: Oxford University Press. 
Beauvoir, Simone de 1951 [1049]: Das andere Geschlecht. Sitte und Sexus der Frau, Hamburg: Rowohlt.

Behrens, Roger 2005: »Konkrete Totalität«, in: Plass, Hanno (Hrsg.): Klasse Geschichte - Bewusstsein: Was bleibt von Georg Lukács' Theorie? Berlin: Verbrecher Verlag, S. $185^{-206 .}$

Beier, Christel 1977: Zum Verhältnis von Gesellschaftstheorie und Erkenntnistheorie. Untersuchungen zum Totalitätsbegriff in der kritischen Theorie Adornos, Frankfurt a.M.: Suhrkamp.

Beiersdörfer, Kurt 1986: Max Weber und Georg Lukács. Über die Beziehung von Verstehender Soziologie und Westlichem Marxismus, Frankfurt a.M./New York: Campus Verlag.

Benjamin, Walter 1982: Gesammelte Schriften V. Das Passagen Werk, herausgegeben von Rolf Tiedemann, Frankfurt a.M.: Suhrkamp.

Berthold, Jürg 2011: Kampfplatz endloser Streitigkeiten. Studien zur Geschichtlichkeit der Philosophie, Basel: Schwabe.

Beyer, Wilhelm Raimund 1971: Die Sünden der Frankfurter Schule. Ein Beitrag zur Kritik der >Kritischen Theorie`, Berlin: Akademie-Verlag.

Bloch, Ernst 1965: »Bewusstsein als Verhängnis« (1938), in: Literarische Aufsätze, Frankfurt a.M.: Suhrkamp, S. 66-71.

Blum, Harald 2015: »Zur Analytik von Krisenrhetoriken. Metaframes, Narrative und Topoi«, in: Über Krise und Kritik, Studia Philosophica, Vol. 74, herausgegeben von Michael Festl, Florian Grosser und Dieter Thomä, Basel: Schwabe, S. 39-54.

Bollenbeck, Georg/Knobloch, Clemens (Hrsg.) 2004: Resonanzkonstellationen. Die illusionäre Autonomie der Kulturwissenschaften, Heidelberg: Synchron.

Bourdieu, Pierre 2001 [1997]: Meditationen. Zur Kritik der scholastischen Vernunft, Frankfurt a.M.: Suhrkamp.

Breidbach, Olaf 1997: Die Materialisierung des Ichs. Zur Geschichte der Hirnforschung im 19. und 20. Jahrhundert, Frankfurt a.M.: Suhrkamp.

Braun, Eberhard 1992: »Aufhebung der Philosophie«. Karl Marx und die Folgen, Stuttgart/ Weimar: Metzler.

Bredtmann, Bastian 2015: »Westlicher Marxismus und Kritische Theorie«, in: Plass, Hanno (Hrsg.): Klasse - Geschichte - Bewusstsein: Was bleibt von Georg Lukács' Theorie? Berlin: Verbrecher Verlag, S. 257-301.

Bruns, Claudia 2008: Politik des Eros. Der Männerbund in Wissenschaft, Politik und Jugendkultur (1880-1934), Köln/Weimar/Wien: Böhlau Verlag.

Buckmiller, Michael 1973: »Marxismus als Realität. Zur Rekonstruktion der theoretischen und politischen Entwicklung Karl Korschs«, in: Über Karl Korsch, herausgegeben von Claudio Pozzoli, Frankfurt a.M.: Fischer, S. 15-85. 
Buckmiller, Michael 1988: »Die >Marxistische Arbeitswoche 1923 und die Gründung des >Instituts für Sozialforschung««, in: Reijen, Willem van/Schmid Noerr, Gunzelin (Hrsg.): Grand Hotel Abgrund. Eine Photobiographie der Frankfurter Schule, Hamburg: Junius, S. 141-173.

Butler, Judith 1997 [1993]: Körper von Gewicht. Die diskursiven Grenzen des Geschlechts, Frankfurt a.M.: Suhrkamp.

Butler, Judith 2009 [2004]: »Kann das >Andere der Philosophie sprechen?«, in: Die Macht der Geschlechternormen, Frankfurt a.M.: Suhrkamp, 367-393.

Carnap, Rudolf 1930/1931: »Die alte und die neue Logik«, in: Erkenntnis 1, S. 12-26.

Carnap, Rudolf 1931: »Überwindung der Metaphysik durch logische Analyse der Sprache«, in: Erkenntnis 2, S. 219-241.

Carnap, Rudolf 1928: Der logische Aufbau der Welt, Berlin-Schlachtensee: Weltkreis-Verlag.

Carnap 1993 [1963]: Mein Weg in die Philosophie, übersetzt und mit einem Nachwort sowie einem Interview herausgegeben von Willy Hochkeppel, Stuttgart: Reclam.

Cavarero, Adriana 1997 [199o]: Platons Töchter. Frauengestalten der antiken Philosophie, Hamburg: Rotbuch Verlag.

Churchland, Patricia 1986: Neurophilosophy, Cambridge, Massachusetts: The MIT Press.

Claussen, Detlev 2015: »Geschichte ohne Klassenbewusstsein. Georg Lukács' kurzes 20. Jahrhundert. Vortrag in Hamburg am 11. Juni 2013", in: Plass, Hanno (Hrsg.): Klasse - Geschichte - Bewusstsein: Was bleibt von Georg Lukács' Theorie? Berlin: Verbrecher Verlag, S. $155^{-183}$.

Dahms, Hans-Joachim 1994: Positivismusstreit. Die Auseinandersetzungen der Frankfurter Schule mit dem logischen Positivismus, dem amerikanischen Pragmatismus und dem kritischen Rationalismus, Frankfurt a.M.: Suhrkamp.

Dale, Jacquette 2003 (Hrsg.): Philosophy, Psychology, and Psychologism. Critical and Historical Readings on the Psychological Turn in Philosophy, Dordrecht: Kluwer.

Dannemann, Rüdiger 1987: Das Prinzip Verdinglichung. Studie zur Philosophie Georg Lukács', Sendler: Frankfurt a.M.

Daston, Lorraine/Galison, Peter 2007: Objectivity, New York: Zone Books.

Dätwyler, Maria/Weibel Fleur 2015: »Eine kritisch-feministische Haltung in paradoxen Verhältnissen«, in: Bargetz, Brigitte/Fleschenberg, Andrea/Kerner, Ina/Kreide, Regina/Ludwig, Gundula (Hrsg.): Kritik und Widerstand. Feministische Praktiken in androzentrischen Zeiten, Berlin und Toronto: Barbara Budrich, S. 187-202.

Dätwyler, Maria 2018: »Philosoph werden. Selbstheroisierung am Beispiel von Bruno Latour «, in: helden, heroes, héros, special issue 4: Heroes and heroization in science, scholarship, and knowledge-production, herausgegeben von Monika Mommertz, S. $75^{-87}$. 
Demirović, Alex 1999: Der nonkonformistische Intellektuelle. Die Entwicklung der Kritischen Theorie zur Frankfurter Schule, Frankfurt a.M.: Suhrkamp.

Derrida, Jacques 2004: Die différance. Ausgewählte Texte, herausgegeben und eingeleitet von Peter Engelmann, Stuttgart: Reclam.

Deuber-Mankowsky, Astrid 2012: »Philosophie außer sich! Gender Geschlecht, Queer, Kritik und Sexualität«, in: Philosophie und die Potenziale der Gender Studies. Peripherie und Zentrum im Feld der Theorie, Bielefeld: transcript, S. 211-23o.

Deuticke, Franz 1933 (Hrsg.): Krise und Neuaufbau in den exakten Wissenschaften. Fünf Wiener Vorträge, Leipzig und Wien: Deuticke.

Dilthey, Wilhelm 1931 [1911]: Die Typen der Weltanschauung und ihre Ausbildung in den metaphysischen Systemen « (1911), in: ders.: Gesammelte Schriften, Bd. VIII: Weltanschauungslehre. Abhandlungen zur Philosophie der Philosophie, Leipzig/Berlin: Teubner, S. $75^{-118 .}$

Dubiel, Helmut 1975: »Ideologiekritik versus Wissenssoziologie. Die Kritik der Mannheimschen Wissenssoziologie in der Kritischen Theorie«, in: Archiv für Rechts- und Sozialphilosophie 2, S. 223-236.

Dubiel, Helmut 1976: Wissenschaftsorganisation und politische Erfahrung. Studien zur frühen Kritischen Theorie, Frankfurt a.M: Suhrkamp.

Dvořák Johann 1985: »Wissenschaftliche Weltauffassung, Volkshochschule und Arbeiterbildung im Wien der Zwischenkriegszeit. Am Beispiel von Otto Neurath und Edgar Zilsel, in: Philosophie, Wissenschaft, Aufklärung, herausgegeben von Joachim Dahms, Berlin: Walter de Gruyter, S. 12-143.

Dvořák, Johann 1993: «Wissenschaft als gesellschaftliche Auseinandersetzung und als kollektiver Arbeitsprozess. Edgar Zilsel und sein Werk«, in: Wien, Berlin, Prag. Der Aufstieg der wissenschaftlichen Philosophie, Wien: Höder, Pichler, Tempsky, S. 424-446.

Fechner, Robert: 2012: »Mit Weber zu Marx - und hinter beide zurück«, in: Lukács, Georg u.a.: Verdinglichung, Marxismus, Geschichte. Von der Niederlage der Novemberrevolution zur kritischen Theorie, herausgegeben und eingeleitet von Markus Bitterolf und Denis Maier, Freiburg: ça ira-Verlag, S. 225-241.

Festl, Michael G. 2018: »Logischer Empirismus«, in: Handbuch Pragmatismus, herausgegeben von Michael G. Festl, Stuttgart: Metzler, S. 271-28o.

Festl, Michael G. 2019: Scheitern an Kontingenz. Politisches Denken in der Weimarer Republik, Frankfurt/New York: Campus.

Fetscher, Iring 1973: »Zum Begriff der >Objektiven Möglichkeit< bei Max Weber und Georg Lukács«, in: Revue Internationale de Philosophie, Vol. 27, No. 106 (4), Lukács (1973), S. 501-525.

Fleck, Ludwig 1983 [1929]: »Zur Krise der >Wirklichkeit««, in: ders.: Erfahrung und Tatsache. Gesammelte Aufsätze, herausgegeben von Lothar Schäfer und Thomas Schnelle, Frankfurt a.M.: Suhrkamp, S. 46-58. 
Fleck, Ludwik 2011 [1935]: Denkstile und Tatsachen. Gesammelte Schriften und Zeugnisse, herausgegeben von Werner, Sylwia/Zittel, Claus, Berlin: Suhrkamp.

Fleck, Ludwik 1980 [1935]: Entstehung und Entwicklung einer wissenschaftlichen Tatsache. Einführung in die Lehre vom Denkstil und Denkkollektiv, mit einer Einleitung herausgegeben von Lothar Schäfer und Thomas Schnelle, Frankfurt a.M.: Suhrkamp.

Fodor, Jerry 1987: Psychosemantics: The Problem of Meaning in the Philosophy of Mind, Cambridge, Massachusetts: MIT Press.

Foucault, Michel 1974: Von der Subversion des Wissens, übersetzt und herausgegeben von Walter Seitter, Frankfurt a.M.: Fischer.

Foucault, Michel 1976 [1975]: Überwachen und Strafen. Die Geburt des Gefängnisses, Frankfurt a.M.: Suhrkamp.

Foucault, Michel 1977 [1976]: Der Wille zum Wissen. Sexualität und Wahrheit 1, Frankfurt a.M.: Suhrkamp.

Foucault, Michel 1989 [1984]: Der Gebrauch der Lüste. Sexualität und Wahrheit 2, Frankfurt a.M: Suhrkamp.

Foucault, Michel 1996: Diskurs und Wahrheit. Berkeley-Vorlesungen 1983, Berlin: Merve.

Foucault, Michel 2002 [1971]: »Nietzsche, die Genealogie, die Historie«, in: Schriften in vier Bänden, herausgegeben von Daniel Defert und François Ewald unter Mitarbeit von Jacques Lagrange, Band 2, Frankfurt a.M.: Suhrkamp, S. 116-191.

Foucault, Michel 2005 [1981]: »Ist es also wichtig, zu denken? Gespräch 1981«, in: Schriften in vier Bänden, herausgegeben von Daniel Defert und François Ewald unter Mitarbeit von Jacques Lagrange, Band 4, Frankfurt a.M.: Suhrkamp, S. 219-223.

Foucault, Michel 2005 [1982]: »Subjekt und Macht«, in: Schriften in vier Bänden. Dits et Ecrits, herausgegeben von Daniel Defert und François Ewald unter Mitarbeit von Jacques Lagrange, Bd. 4, Frankfurt a.M.: Suhrkamp, S. 269-294.

Foucault, Michel 2005 [1984]: »Polemik, Politik und Problematisierungen (Gespräch 1984)«, in: Schriften in vier Bänden. Dits et Ecrits, herausgegeben von Daniel Defert und François Ewald unter Mitarbeit von Jacques Lagrange, Band 4, Frankfurt a.M.: Suhrkamp, S. 724-734.

Foucault, Michel 2007 [1994]: »Was ist Aufklärung?«, in: Ästhetik der Existenz. Schriften zur Lebenskunst, Frankfurt a.M.: Suhrkamp, S. 171-19o.

Foucault, Michel 2009 [2008]: Die Regierung des Selbst und der anderen. Vorlesungen am Collège de France 1982/83, Frankfurt a.M.: Suhrkamp.

Foucault, Michel 2010 [2009]: Der Mut zur Wahrheit. Vorlesungen am Collège de France 1983/84, Berlin: Suhrkamp.

Fox Keller, Evelyne 1985: Reflection on Gender and Science, New Haven: Yale University Press.

Fracchia, Joseph, G. 1987: Die Marxsche Aufhebung der Philosophie und der philosophische Marxismus, New York: Peter Lang. 
Frank, Philipp 1930/1931: »Eröffnungsansprache« in: Erkenntnis 1, S. 93-95.

Frank, Philipp 1949: Modern science and its philosophy, Cambridge: Harvard University Press.

Fraser, Nancy 1989: Unruly practices: pwer, discourse, and gender in contemporary social theory, Minneaposis: University of Minnesota Press.

Frese, Jürgen 2002: »>Bewußtsein als Verhängnis<. Alfred Seidels Bedeutung für fortwirkende Soziologische Theoriebildung der 2oer Jahre«, in: Etappe. Zeitschrift für Politik, Kultur und Wissenschaft, Heft 16, 47-63.

Friedman, Michael 2000: A Parting of the Ways. Carnap, Cassirer, and Heidegger, Chicago: Open Court.

Gamm, Gerhard 2009: Philosophie im Zeitalter der Extreme. Eine Geschichte philosophischen Denkens im 20. Jahrhundert, Darmstadt: Primus Verlag.

Gerlach, Erich 1966: »Die Entwicklung des Marxismus von der revolutionären Philosophie zur wissenschaftlichen Theorie proletarischen Handelns bei Karl Korsch«, in: Korsch, Karl 1966: Marxismus und Philosophie, herausgegeben von Erich Gerlach, Frankfurt a.M.: Europäische Verlagsanstalt, S. 9-3o.

Goettle, Gabriele 2005: Hand- und Kopfarbeit. Besuch bei der Buchhändlerin Bettina Wassmann, in: taz Nr. 7807, S. 15-16.

Goeze, Annika/Strobl, Korinna 2011: »Krisenrhetorik«, in: Ueding, Gert (Hrsg.): Historisches Wörterbuch der Rhetorik, Band 10, Darmstadt: WBG, S. 511-530.

Goldmann, Lucien 1975 [1973]: Lukacs und Heidegger. Nachgelassene Fragmente, Texteinrichtung und Einleitung von Youssef Ishaghpour, Darmstadt/Neuwied: Luchterhand.

Gradev, Vladimir 1994: »Foucault et les jeux de la vérité«, in: Brossat, Alain (Hrsg.): Michel Foucault. Les jeux de la vérité et du pouvoir, Nancy: Presses Universitaires, S. 41-49.

Grunwald, Henning/Pfister, Manfred (Hrsg.) 2007: Krisis! Krisenszenarian, Diagnosen und Diskursstrategien, München: Fink.

Habermas, Jürgen et. al. 1968: Die Linke antwortet Jürgen Habermas, Frankfurt a.M.: Europäische Verlagsanstalt.

Habermas, Jürgen 1986: »Bemerkungen zur Entwicklungsgeschichte des Horkheimerschen Werkes«, in: Schmidt, Alfred/Altwicker, Norbert: Max Horkheimer heute: Werk und Wirkung, Frankfurt a.M.: Fischer, S. 163-179.

Hagner, Michael 2001: »Ansichten der Wissenschaftsgeschichte«, in: Ansichten der Wissenschaftsgeschichte, herausgegeben von Michael Hagner, Frankfurt a.M.: Fischer, S. 7-39.

Hahn, Hans 1930/31: »Die Bedeutung der wissenschaftlichen Weltauffassung, insbesondere für Mathematik und Physik«, in: Erkenntnis 1, 96-105.

Haller, Rudolf 1993: Neopositivismus. Eine historische Einführung in die Philosophie des Wiener Kreises, Darmstadt: Wissenschaftliche Buchgesellschaft. 
Hamann, Julian 2014: Die Bildung der Geisteswissenschaften. Zur Genese einer sozialen Konstruktion zwischen Diskurs und Feld, München: UVK Verlagsgesellschaft mbH.

Hampe, Michael 2012: Neutralität ausgeschlossen, in: NZZ 233 (11), S. 62.

Haraway, Donna 1988: »Situated Knowledges: The Science Question in Feminism and the Privilege of Partial Perspective«, in: Feminist Studies, Vol. 14, No. 3, S. 575-599.

Haraway, Donna 2016: Staying with the Trouble. Making Kin in the Chthulucene, Durham/ London: Duke University Press.

Harding, Sandra 1986: The science Question in Feminism, Milton Keynes: Open University Press.

Harding, Sandra 1998: Is Science multicultural? Postcolonialism, Feminism, and Epistemologies, Bloomington: Indiana University Press.

Haslinger, Sally 2008: »Changing the Ideology and Culture of Philosophy: Not by Reason (Alone) «, in: Hypatia, Volume 23, Issue 2, S. 210-223.

Hartsock, Nancy 1983: »The Feminist Standpoint: Developing The Ground For A Specifically Feminist Historical Materialism« in: Harding/Hintikka (Hrsg.): Discovering Reality. Feminist Perspektives on Epistemology, Metaphysics, Methodology and Philosophy of Sience, Dordrecht/Boston/London: Reidel, 283-310.

Hegselmann Rainer/Siegwart, Geo 1991: »Zur Geschichte der >Erkenntnis««, in: Erkenntnis 35, S. 461-471.

Heidegger, Martin 2008 [1927]: Sein und Zeit, Tübingen: Max Niemeyer.

Heiseler von, Johannes Henrich/Steigerwald, Robert/ Schleifstein, Josef (Hrsg.) 1970: Die >Frankfurter Schule im Lichte des Marxismus. Zur Kritik der Philosophie und Soziologie von Horkheimer, Adorno, Marcuse, Habermas, Frankfurt a.M.: Verlag Marxistische Blätter GmbH.

Heller, Agnes 2015: Vorwort, in: Plass, Hanno (Hrsg.): Klasse - Geschichte - Bewusstsein: Was bleibt von Georg Lukács' Theorie? Berlin: Verbrecher Verlag, S. 7-31.

Hemminger, Andrea 2004: Kritik und Geschichte. Foucault - ein Erbe Kants? Berlin/ Wien: Philo.

Hofmann Peter/Hirschauer Stefan 2012: »Die konstruktivistische Wende«, in: Maasen, Sabine/Kaiser, Mario/Reinhard, Martin/Sutter, Barbara (Hrsg.): Handbuch Wissenschaftssoziologie, Wiesbaden: Springer Verlag, S. 85-99.

Holz, Hans Heinz 1968: Utopie und Anarchismus. Zur Kritik der kritischen Theorie Herbert Marcuses, Köln: Pahl-Rugenstein Verlag.

hook bell 2004: The Will to Change. Men, Masculinity and Love, New York et al., Washington Square Press.

Horkheimer, Max 1936: »Vorwort«, in: Studien über Autorität und Familie, Paris: Librairie Félix Alcan, S. VII-XII.

Horkheimer, Max/Adorno Theodor W. 2008 [1944]: Dialektik der Aufklärung. Philosophische Fragmente, Frankfurt a.M.: Fischer. 
Horkheimer, Max 1982 [1929]: »Zur Wahrheitsproblematik der soziologischen Methode«, in: Meja, Volker/Stehr, Nico (Hrsg.) 1982: Der Streit um die Wissenssoziologie. Rezeption und Kritik der Wissenssoziologie 2, Frankfurt a.M.: Suhrkamp, S. $459-473$.

Horkheimer, Max 1988 [1931]: »Die gegenwärtige Lage der Sozialphilosophie und die Aufgaben eines Instituts für Sozialforschung, in: ders.: Gesammelte Schriften 3, Frankfurt a.M.: Fischer, S. 20-35.

Horkheimer, Max 1988 [1937]: »Der neueste Angriff auf die Metaphysik«, in: ders.: Gesammelte Schriften 4, Frankfurt a.M.: Fischer, S. 108-161.

Horkheimer, Max 1988 [1937]: »Traditionelle und kritische Theorie «/«Nachtrag«, in: ders.: Gesammelte Schriften 4, Frankfurt a.M.: Fischer, S. 162-225.

Horkheimer, Max 1988 [1940]: »Die gesellschaftliche Funktion der Philosophie (1940)«, in: ders.: Gesammelte Schriften 4, Frankfurt a.M.: Fischer, S. 332-351.

Horkheimer, Adorno/Marcuse, Herbert 1970 [1937]: »Philosophische und Kritische Theorie«, in: Zeitschrift für Sozialforschung VI/3, München: Kösel Verlag, S. 625-647.

Huke-Didier, Eckart 1985: Die Wissenssoziologie Karl Mannheims in der Interpretation durch die Kritische Theorie - Kritik einer Kritik, Frankfurt a.M.: Peter Lang.

Husserl, Edmund 2009 [1910/11]: Philosophie als strenge Wissenschaft, Hamburg: Meiner.

Husserl, Edmund 1910/11: »Philosophie als strenge Wissenschaft«, in: LOGOS. Internationale Zeitschrift für Philosophie der Kultur, Bd. I, Heft 3, S. 289-341.

Husserl Edmund 1913: »Ideen zu einer reinen Phänomenologie und phänomenologischen Philosophie. Erstes Buch: Allgemeine Einführung in die reine Phänomenologie«, in: Jahrbuch für Philosophie und phänomenologische Forschung, Halle: Max Niemeyer Verlag, S. 1-323.

Irigaray, Luce 1974: Speculum de l'autre femme, Paris: Les éditions de minuit.

Jahnke et. al. 1998 (Hrsg.): Psychologiegeschichte. Beziehung zu Philosophie und Grenzgebieten, München/Wien: Profil Verlag.

Janik, Allan/Toulmin, Stephen 1974: Wittgenstein's Vienna, New York: Simon and Schuster.

Jay, Martin 1981 [1973]: Dialektische Phantasie. Die Geschichte der Frankfurter Schule und des Instituts für Sozialforschung 1923-1950, Frankfurt a.M.: Fischer.

Jay, Martin 1982: »Positive und negative Totalität. Adornos Alternativentwurf zur interdisziplinären Forschung«, in: Sozialforschung als Kritik, Frankfurt a.M.: Suhrkamp, S. 67-86.

Jeon, Tae-Kook (1984): Karl Mannheims Ideologietheorie und ihr Verhältnis zur Kritischen Theorie der Frankfurter Schule, unveröffentlichte Dissertation, Frankfurt a.M.

Kaiser-el-Safti, Margret/Loh, Werner 2011: Die Psychologismus-Kontroverse, Göttingen: Vandenhock\&Ruprecht. 
Kertesz, Gerald 1999: »Adorno und Heidegger«, in: Mitteilungen für Wissenschaft und Kunst, Jg. 54, S. 27-32.

Koselleck, Reinhart 2004: »Krise«, in: Brunner, Otto/Conze, Werner/Koselleck, Reinhard: Geschichtliche Grundbegriffe, Bd. 3. Stuttgart: Klett-Cotta, S. 617-65o.

Koselleck, Reinhart 2006: Begriffsgeschichten, Frankfurt a.M.: Suhrkamp.

Koselleck, Reinhart 1979 [1954]: Kritik und Krise, Frankfurt a.M.: Suhrkamp.

Kautsky, Karl 1924: »Marxismus und Philosophie«, in: Die Gesellschaft. Internationale Revue für Sozialismus und Politik, Erster Band, herausgegeben von Rudolph Hilferding, Dietz Verlag: Berlin, S. 306-314.

Kettner, Fabian 2012: »Die Verdinglichung der Theorie in der Kritik der Verdinglichung «, in: Verdinglichung, Marxismus, Geschichte. Von der Niederlage der Novemberrevolution zur kritischen Theorie, Freiburg: ça ira-Verlag, S. 375-413.

Klages, Ludwig 1928: »A. Seidel (†), Bewußtsein und Verhängnis« [sic!], in: Deutsche Medizinische Wochenzeitschrift, Jg. 1928, Nummer 15, S. 629.

Kleeberg, Bernhard/Suter, Robert 2014: »>Doing Truth $<$ Bausteine einer Praxeologie der Wahrheit«, in: Zeitschrift für Kulturphilosophie, 2, 211-226.

Klüver, Jürgen/Wolf, Friedrich O. (Hrsg.) 1972: Wissenschaftskritik und sozialistische Praxis. Konsequenzen aus der Studentenbewegung, Frommann-Holzboog Verlag: Stuttgart-Bad Cannstatt.

Köhler, Eckehart 1995: »Die Metaphysik beim Wiener Kreis«, in: Philosophie, Wissenschaft, Aufklärung, herausgegeben von Joachim Dahms, Berlin: Walter de Gruyter, S. 190-204.

Kolakowski, Leszek 1979 [1978]: Die Hauptströmungen des Marxismus. Entstehung Entwicklung - Zerfall, Bd. 3., München: Piper \& Co.

Korsch, Karl 1966 [1923]: Marxismus und Philosophie, herausgegeben und eingeleitet von Erich Gerlach, Frankfurt a.M: Europäische Verlagsanstalt.

Korsch, Karl 1971 [1929]: »Die materialistische Geschichtsauffassung«, in: Die materialistische Geschichtsauffassung und andere Schriften, herausgegeben und eingeleitet von Erich Gerlach, Frankfurt a.M./Köln: Europäische Verlagsanstalt, S. 31-130.

Korsch, Karl 1922: Kernpunkte der materialistischen Geschichtsauffassung. Eine quellenmäßige Darstellung, Berlin/Leipzig: Vereinigung Internationaler Verlagsanstalten (Frankes Verlag).

Kracauer, Siegfried 2011 [1927]: »Ein Dokument der Zeit«, in: Frankfurter Zeitung vom 9. Jan. 1927, Werke Bd. 5.2, S. 521-524.

Krahl, Hans-Jürgen 1971: Konstitution und Klassenkampf. Zur historischen Dialektik von bürgerlicher Emanzipation und proletarischer Revolution, Frankfurt a.M.: Verlag Neue Kritik.

Kramme, Rüdiger 1995: »Philosophische Kultur als Programm. Die Konstituierungsphase des LOGOS«, in: Hubert Treiber, Karól Sauerland (Hrsg.): Heidelberg im 
Schnittpunkt intellektueller Kreise. Zur Topographie der >geistigen Geselligkeit< eines >Weltdorfes«: 1850-1950, Opladen, S. 119-147.

Kramme Rüdiger 1996: »LOGOS 1933/34. Das Ende der >Internationalen Zeitschrift für Philosophie der Kultur««, in: Rechtstheorie 27, S. 92-116.

Kramme Rüdiger 1997: »>Kulturphilosophie < und >Internationalität $<$ des >LOGOS $<$ im Spiegel seiner Selbstbeschreibungen«, in: Gangolf Hübinger, Rüdiger vom Bruch, Friedrich Wilhelm Graf (Hrsg.), Kultur und Kulturwissenschaften um 1900, Bd. 2: Idealismus und Positivismus, Stuttgart, S. 122-134.

Kuhn, Thomas, S. 1976 [1962]: Die Struktur wissenschaftlicher Revolutionen, Frankfurt a.M.: Suhrkamp.

Kusch, Martin 1995: Psychologism. A Case Study in the Sociology of Philosophical Knowledge, London/New York: Routledge.

Kusch, Martin 2000: »The Sociology of Philosophical Knowledge: A Case Study and a Defense«, in: ders.: Sociology of Philosophical Knowledge, Dordrecht/Boston/ London: Kluwer Academic Publishers, S. 15-38.

Latour, Bruno/Woolgar Steve 1979: Laboratory life, Beverly Hills: Sage.

Laube, Reinhard 2004: Karl Mannheim und die Krise des Historismus. Historismus als wissenssoziologischer Perspektivismus, Göttingen: Vandenhoeck \& Ruprecht.

Lembeck, Karl-Heinz 2010: Philosophie als Zumutung? Ihre Rolle im Kanon der Wissenschaften, Würzburg: Königshausen \& Neumann.

Lepenies, Wolf 1979: »Vorbemerkungen des Herausgebers«, in: Canguilhem Georges: Wissenschaftsgeschichte und Epistemologie. Gesammelte Aufsätze, herausgegeben von Wolf Lepenies, Frankfurt a.M., Suhrkamp.

Lewin, Kurt 1930/31: »Der Übergang von der aristotelischen zur galileischen Denkweise in Biologie und Psychologie«, in: Erkenntnis 1, S. 421-466.

Lloyd, Genevieve 1985: The man of reason. »Male« and »Female« in Western Philosophy, London: Methuen.

Lukács, Georg 2013 [1923]: Geschichte und Klassenbewusstsein, Bielefeld: Aisthesis Verlag.

Lukács, Georg 1967: »Vorwort«, in: Geschichte und Klassenbewusstsein, Hermann Luchterhand, Neuwied/Berlin, S. 11-41.

Liptow, Jasper 2013: Philosophie des Geistes zur Einführung, Hamburg: Junius.

Maasen, Sabine 20o9: Wissenssoziologie, Bielefeld: transkript.

Mannheim, Karl 1929: »Die Bedeutung der Konkurrenz im Gebiete des Geistigen«. Verhandlungen des 6. Deutschen Soziologentages vom 17. bis 19. September 1928 in Zürich, Tübingen: Mohr Siebeck, S. 35-83.

Mannheim, Karl 1978 [1929]: Ideologie und Utopie, Frankfurt a.M.: Verlag G. Schulte-Bulmke.

McClintock Anne 1995: Imperial Leather. Race, Gender and Sexuality in the Colonial Context, New York: Routledge. 
McDowell, John 1994: Mind and World, Cambridge: Harvard University Press.

Meier, W. 1979: »Vorwort«, in: Seidel, Alfred 1927: Bewusstsein als Verhängnis, Bremen: Edition Subversion-Verlag Impuls.

Merleau-Ponty, Maurice 1968 [1955|: Die Abenteuer der Dialektik, Frankfurt a.M.: Suhrkamp.

Milkòv, Nikolay 2011: »Hans Reichenbachs wissenschaftliche Philosophie«, in: ders. (Hrsg.): Ziele und Wege der heutigen Naturphilosophie. Fünf Aufsätze zur Wissenschaftstheorie, Hamburg: Felix Meiner Verlag, S. VII-XLIV.

Milkòv, Nikolay 2015: »Einleitung. Die Berliner Gruppe des Logischen Empirismus «, in: Ders. (Hrsg.): Die Berliner Gruppe. Texte zum Logischen Empirismus, Hamburg: Felix Meiner Verlag, S. IX-LXI.

Morgenthaler, Simon 2020: Formationen einer Kunstwissenschaft. Text- und Archivstudien zu Hans Sedlmayr, Berlin/Boston: De Gruyter.

Müller-Doohm Stefan 2006: »Die Aktualität der Philosophie«, in: Honneth, Axel (Hrsg.): Schlüsseltexte der Kritischen Theorie, Wiesbaden: VS Verlag für Sozialwissenschaften, S. 99-92.

Müller, Stefan/Rhein, Johannes 2015: »Totalität, Vermittlung und Unmittelbarkeit. Kategorien materialistischer Dialektik bei Georg Lukács und Theodor W. Adorno «, in: Plass, Hanno (Hrsg.): Klasse - Geschichte - Bewusstsein: Was bleibt von Georg Lukács' Theorie? Berlin: Verbrecher Verlag, S. 215-255.

Nagel, Ernest 1936: »Impressions and Appraisals of Analytic Philosophy in Europe«, in: The Journal of Philosophy, Volume 33, No.1, S. 5-25.

Neurath, Otto/Hahn, Hans/Carnap, Rudolf 1929: Wissenschaftliche Weltauffassung. Der Wiener Kreis, Wien: Arthur Wolf Verlag.

Neurath, Otto 1930/1931: »Wege der wissenschaftlichen Weltauffassung «, in: Erkenntnis 1, S. 106-125.

Neurath, Paul 1993: »Zur gesellschaftlichen Funktion des Wiener Kreises«, in: Wien, Berlin, Prag: Der Aufstieg der wissenschaftlichen Philosophie: Zentenarien Rudolf Carnap, Hans Reichenbach, Edgar Zilsel, herausgegeben von Rudolf Haller und Friedrich Stadler, Hölder Pichler Tempsky: Wien, S. 634-641.

Nietzsche, Friedrich 2003 [1882/87]: Die Fröhliche Wissenschaft, § 265, in: Colli/ Montinari (Hrsg.): KSA, Bd. 3, München: dtv, S. 343-651.

Northoff, Georg 2008: »Mit Kant ins Labor«, in: Gehirn und Geist, Heidelberg: Spektrum der Wissenschaft Verlag, S. 68-72.

Northoff, Georg 2000: Das Gehirn. Eine neurophilosophische Bestandsaufnahme, Paderborn: mentis.

Oeser, Erhard 2003: Popper, der Wiener Kreis und die Folgen. Die Grundlagendebatte der Wissenschaftstheorie, Wien: WUV.

Oexle, Otto Gerhard (Hrsg.) 2007: Krise des Historismus - Krise der Wirklichkeit. Wissenschaft, Kunst und Literatur 1880-1932, Göttingen: Vandenhoeck\&Ruprecht. 
Paulitz, Tanja 2012: Mann und Maschine, Bielefeld: transcript.

Peters, Tobias 2016: Ein vergessener Forschungsstand. Friedrich Adolf Trendelenburg, Hermann Rudolf Lotze, Carl Stumpf und Kurt Lewin, Essen: Books on Demand.

Plass, Hanno 2015: »Nachwort«, in: ders. (Hrsg.): Klasse - Geschichte - Bewusstsein: Was bleibt von Georg Lukács' Theorie? Berlin: Verbrecher Verlag, S. 303-312.

Plümacher, Martina 1996: Philosophie nach 1945 in der Bundesrepublik Deutschland, Reinbek b. Hamburg: Rowohlt.

Prinzhorn, Hans: 1927: Persönlichkeit und Werk, in: Seidel, Alfred 1927: Bewußtsein als Verhängnis. Fragmente über die Beziehungen von Weltanschauung und Charakter oder über Wesen und Wandel der Ideologien, aus dem Nachlass herausgegeben und mit einem Vorwort versehen von Hans Prinzhorn, Bonn: Verlag Friedrich Cohen, S. 46-68.

Purtschert, Patricia 2006: Grenzfiguren. Kultur, Geschlecht und Subjekt bei Hegel und Nietzsche, Frankfurt a.M.: Campus Verlag.

Ranchio, Filippo 2016: Dimensionen der zweiten Natur. Hegels praktische Philosophie, Hamburg: Felix Meiner Verlag.

Rath, Matthias 1994: Der Psychologismusstreit in der deutschen Philosophie, Freiburg im Breisgau: Alber.

Reichenbach, Hans 1911 [1931]: »Ziele und Wege der heutigen Naturphilosophie«, in: Ziele und Wege der heutigen Naturphilosophie. Fünf Aufsätze zur Wissenschaftstheorie, herausgegeben und eingeleitet von Milkòv Nikolay, Hamburg: Felix Meiner Verlag, S. 47-94.

Reichenbach, Hans 1930/31: »Zur Einführung«, in: Erkenntnis 1, S. 1-3.

Reijen van, Willem 1984: Philosophie als Kritik. Einführung in die Kritische Theorie, Königstein/Ts: Anton Hain.

Reijen van, Willem/Schmid Noerr, Gunzelin (Hrsg.) 1988: Grand Hotel Abgrund. Eine Photobiographie der Frankfurter Schule, Hamburg: Junius.

Rentsch, Thomas 2014: Philosophie des 20. Jahrhunderts. Von Husserl bis Derrida, München: C.H. Beck.

Rheinberger Hans-Jört 2007: Historische Epistemologie zur Einführung, Hamburg: Junius.

Rickert, Heinrich 1910/1911: »Vom Begriff der Philosophie«. In: Logos 1, S. 1-34.

Ringer, Fritz K. 1983 [1969]: Die Gelehrten. Der Niedergang der deutschen Mandarine 1890-1933, Stuttgart: Deutscher Taschenbuch Verlag.

Römer, Inga 2012: »Gibt es eine >geistige Erfahrung` in der Phänomenologie? Zu Adornos Kritik an Husserl und Heidegger«, in: Phänomenologische Forschungen, Heft 1, S. $67-85$.

Romizi, Donata 2013: «War die >Wissenschaftliche Weltauffassung des Wiener Kreises nicht doch auch eine Weltanschauung?« in: Nemeth, Elisabet/Stadler, Friedrich: Die europäische Wissenschaftsphilosophie und das Wiener Erbe, Wien: Springer. 
Said, Edward 1994: Orientalism, New York: Vintage Books.

Sauerland, Karol 2017: »Der Begriff des Denkstils bei Ludwik Fleck«, in: Diskurse über $>$ Form<, >Gestalt< und >Stil< in den 2oer und 3oer Jahren des 20. Jahrhunderts, herausgegeben von August H. Leugers-Scherzberg und Lucia Scherzberg, Saarbrücken: Universaar, S. $37-58$.

Schlick, Moritz 1939/31: »Die Wende der Philosophie«, in: Erkenntnis 1, S. 4-11.

Schmidt, Nicole D. 1995: Philosophie und Psychologie. Trennungsgeschichte, Dogmen und Perspektiven, Reinbeck b. Hamburg: Rowohlt.

Schnädelbach, Herbert 1982: »Philosophieren nach Heidegger und Adorno«, in: ders.: Zur Rehabilitierung des animal rationale. Vorträge und Abhandlungen 2, Frankfurt a.M.: Suhrkamp, S. 307-328.

Schnädelbach, Herbert 1983: Philosophie in Deutschland 1831-1933, Frankfurt a.M.: Suhrkamp.

Schnädelbach, Herbert 1992: Zur Rehabilitierung des animal rationale. Vorträge und Abhandlungen 2. Frankfurt a.M.: Suhrkamp.

Schnädelbach, Herbert 2008: »Adorno und die Geschichte«, in: Kohler, Georg/MüllerDoohm, Stefan (Hrsg.): Wozu Adorno? Beiträge zur Kritik und zum Fortbestand einer Schlüsseltheorie des 20. Jahrhunderts, Weilerswist:Velbrück Wissenschaft, S. 130-154.

Schneiders, Werner 1998: Deutsche Philosophie im 20. Jahrhundert, München: Beck.

Scholten, Helga (Hrsg.) 2007: Die Wahrnehmung von Krisenphänomenen. Fallbeistpiele von der Antike bis in die Neuzeit, Köln/Weimar/Wien: Böhlau Verlag.

Seidel, Alfred 1927: Bewußtsein als Verhängnis. Fragmente über die Beziehungen von Weltanschauung und Charakter oder über Wesen und Wandel der Ideologien, aus dem Nachlass herausgegeben und mit einem Vorwort versehen von Hans Prinzhorn, Bonn: Verlag Friedrich Cohen.

Seidel, Alfred (1927 [1979]): Bewusstsein als Verhängnis, herausgegeben und mit einem Vorwort versehen von >W. Meier< (d.i. Helmut Höge), Bremen: Impuls Verlag.

Seidel, Alfred (2008): »Produktivität und Klassenkampf. Ein Beitrag zur Interpretation des historischen Materialismus von Karl Marx und Freidrich Engels«, Inauguraldissertation zur Erlangung der philosophischen Doktorwürde einer hohen philosophischen Fakultät der Universität Heidelberg, in: Archiv für die Geschichte des Widerstandes und der Arbeit 18, Bochum: Germinal Verlag, S. 185-234.

Siegmund, George 1970: Sein oder Nichtsein. Die Frage des Selbstmordes, Trier: Paulinus-Verlag.

Sigmund, Karl 2015: Sie nannten sich der Wiener Kreis. Exaktes Denken am Rand des Untergangs, Wiesbaden: Springer Spektrum.

Söllner, Alfons 1979: Geschichte und Herrschaft. Studien zur materialistischen Sozialforschung 1919-1942, Frankfurt a.M.: Suhrkamp. 
Sommer, Nicolas M. 2016: Das Konzept einer negativen Dialektik, 2016, Tübingen: Mohr Siebeck.

Spivak, Gayatri Chakravorty 2008 [1988]: Can the Subaltern Speak? Postkolonialität und subalterne Artikulation, Wien: Turia + Kant.

Stadler, Friedrich 1993: »Wien - Berlin - Prag. Zum Aufstieg der wissenschaftlichen Philosophie«, in: Stadler, Friedrich/Haller Rudolf 1993 (Hrsg.): Wien - Berlin - Prag. Zum Aufstieg der wissenschaftlichen Philosophie; Zentenarien Rudolf Carnap - Hans Reichenbach - Edgar Zilsel, Wien: Hölder-Pichler-Tempsky, S. 11-37.

Stadler, Friedrich 1997: Studien zum Wiener Kreis. Ursprung, Entwicklung und Wirkung des logischen Empirismus im Kontext, Frankfurt a.M.: Suhrkamp.

Susman, Margarete 1927: »Alfred Seidel: >Bewußtsein als Verhängnis««, in: Der Morgen. Monatsschrift der Juden in Deutschland, Heft 3 (August 1927), S. 338-341.

Thomä, Dieter 2006: »Verhältnis zur Ontologie. Adornos Denken des Unbegrifflichen«, in: Honneth, Axel/Menke Christoph (Hrsg.): Theodor W. Adorno, Negative Dialektik. Klassiker Auslegen, Berlin: Akademie, S. 29-48.

Thomä, Dieter 2018: »Aufbruch an den Rand der Philosophie. Kommentar zur Urfassung von Heideggers Sein und Zeit«, in: Deutsche Zeitschrift für Philosophie, 66 Bd. 1, S. S. 98-111.

Vaihinger, Hans/Schmidt, Raymund 1919: »Programm der Zeitschrift«, in: Annalen der Philosophie 1, III-VI.

Voller, Christian 2012: »Radikales Denken. Über Alfred Seidels fragmentarische Schrift Bewusstsein als Verhängnis von 1927«, in: Zeitschrift für Kulturphilosophie, Bd. 6, Heft 2, Felix Meiner Verlag: S. 313-325.

Voller, Christian 2017: »Alfred Seidel und die Nihilisierung des Nihilismus. Ein Beitrag zur Vorgeschichte der Kritischen Theorie«, in: Zeitschrift für Kritische Theorie, Heft 44/45, zu Klampen: S. 6o-88.

Voller, Christian/Braunstein, Dirk (Hrsg.): 2017: »Ein Brief von Seidel an Theodor W. Adorno«, in: Zeitschrift für Kritische Theorie, Heft 44/55, S. 89-95.

Vranicki, Predrag 1974 [1961/1971]: Geschichte des Marxismus, Bd. 2, Frankfurt a.M.: Suhrkamp.

Weiss, Andreas 2012: »Theoretische Zugänge zur Krise. Einführung«, in: Mergel (Hrsg.): Krisen verstehen. Historische und kulturwissenschaftliche Annäherungen, Frankfurt/ New York: Campus.

Wiggershaus, Rolf 1986: Die Frankfurter Schule. Geschichte, theoretische Entwicklung, politische Bedeutung, München: Deutscher Taschenbuch Verlag.

Wirkus, Bernd 1996: Deutsche Sozialphilosophie in der ersten Hälfte des 20.Jahrhunderts, Darmstadt: Wissenschaftliche Buchgesellschaft.

Wittgenstein, Ludwig 1984: Tractatus logico-philosophicus, Frankfurt a.M.: Suhrkamp. 
Wolf, Friedrich O. 1972: »Philosophie, Wissenschaftsorganisation, Gesellschaftsform. Zum Problem der konkreten Aufhebung der Philosophie als institutionalisierter Wissenschaft«, in: Klüver, Jürgen/Wolf, Friedrich O. (Hrsg.): Wissenschaftskritik und sozialistische Praxis. Konsequenzen aus der Studentenbewegung, FrommannHolzboog Verlag: Stuttgart-Bad Cannstatt, S. 31-55.

Wundt, Wilhelm 1913: Die Psychologie im Kampf ums Dasein, Leipzig: Alfred Kröner.

Wrana, Daniel et.al. (Hrsg.): DiskursNetz. Wörterbuch der interdisziplinären Diskursforschung, Berlin: Suhrkamp.

Ziche, Paul 2008: Wissenschaftslandschaften um 1900. Philosophie, die Wissenschaften und der nichtreduktive Szientismus, Zürich: Chronos. 